NISTIR 8182

\title{
US Army ARDEC Joint Fuze Technology Program (JFTP) Task 2 Report: Quasi-Static Tensile Tests of Microfabricated Electrodeposited (LIGA) Ni Alloys
}

\author{
Li-Anne Liew \\ David T. Read \\ Ryan White \\ Nicholas Barbosa III
}

This publication is available free of charge from:

https://doi.org/10.6028/NIST.IR.8182

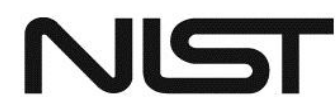

National Institute of

Standards and Technology

U.S. Department of Commerce 


\title{
US Army ARDEC Joint Fuze Technology Program (JFTP) Task 2 Report: Quasi-Static Tensile Tests of Microfabricated Electrodeposited (LIGA) Ni Alloys
}

\author{
Li-Anne Liew \\ David T. Read \\ Ryan White \\ Nicholas Barbosa III \\ Applied Chemicals and Materials Division \\ Material Measurement Laboratory
}

This publication is available free of charge from:

https://doi.org/10.6028/NIST.IR.8182

May 2018

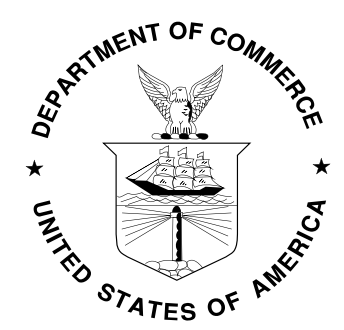

U.S. Department of Commerce

Wilbur L. Ross, Jr., Secretary

National Institute of Standards and Technology

Walter Copan, NIST Director and Undersecretary of Commerce for Standards and Technology 
Certain commercial equipment, instruments, or materials are identified in this paper to foster understanding. Such identification does not imply recommendation or endorsement by the National Institute of Standards and Technology, nor does it imply that the materials or equipment identified are necessarily the best available for the purpose 


\begin{abstract}
The LIGA process (Lithographie, Galvanoformung, Abformung, or lithography, electrodeposition, shaping) offers the possibility of mass producing strong mesoscale (order of a few mm or less) metal components of nearly any planar shape. Multilayer deposition has been developed to create three-dimensional shapes. The overall objective of this multi-year project is to enable the use of the Johnson-Cook flow and fracture models for evaluation of structural elements made from two LIGA alloys of interest, by providing the material property data at the microscale needed to carry out structural analyses utilizing these models. This report documents the first milestone in the project, which is the measurement of the room-temperature tensile properties of two LIGA alloys of one commercial vendor's proprietary materials - one optimized for strength and the other for ductility, with nominal thicknesses $190 \mu \mathrm{m}$ and 170 $\mu \mathrm{m}$ respectively - at strain rates $0.001 / \mathrm{s}$ and $1 / \mathrm{s}$, utilizing four specimen geometries with gauge widths ranging from $75 \mu \mathrm{m}$ to $700 \mu \mathrm{m}$. Test methods adapted to the scale of these materials were applied. Results, measurement uncertainties, and statistical variations for the ultimate tensile strength and apparent Young's modulus are quantified for all combinations of these material/geometry/rate variations. In addition, preliminary studies were conducted into the effects of low-temperature annealing on the materials' strength, and use of electron back scatter diffraction to observe the microstructure.
\end{abstract}

\title{
Keywords
}

Structural materials, micro scale, tensile tests, LIGA, MEMS, metal alloys, materials characterization

\section{Acknowledgments}

We acknowledge the University of Colorado at Boulder's Department of Mechanical Engineering for use of their ovens for specimen annealing, and Zen Machine and Scientific Instruments in Lyons, $\mathrm{CO}$ for machining the new adapters for the $1 / \mathrm{s}$ test apparatus. The cooperation of Todd Christenson at HT Micro Analytical Inc, of Albuquerque, NM, in supplying the specimens is appreciated.

This project is funded by the U.S. Army Armament Research Development and Engineering Center (ARDEC) under the Joint Fuze Technology Program (JFTP). The JFTP project number is 14-G-006, Micro Scale Materials and Energetic Effects Characterization, the ARDEC principal investigator is John Geaney. The content of this report has been approved for public release by ARDEC under Distribution Statement A (unclassified). 


\section{Executive Summary}

This report presents the results of room-temperature tensile tests on microfabricated specimens of two LIGA Ni alloys of interest to the project sponsor and supplied by a commercial vendor. Microtensile specimens of the vendor's proprietary materials - "Alpha" and "C" - were supplied with nominal thicknesses of $190 \mu \mathrm{m}$ and $170 \mu \mathrm{m}$, respectively, and of four different sizes with gauge widths ranging from $0.075 \mathrm{~mm}$ to $0.7 \mathrm{~mm}$. The Alpha material is very strong, with consistent strength around $1900 \mathrm{MPa}$ over several fabrication runs of the material. The $\mathrm{C}$ material has lower strength - around $600 \mathrm{MPa}$ - and is more ductile. Both materials were tested at strain rates $0.001 / \mathrm{s}$ and $1 / \mathrm{s}$; Figure 1 shows typical engineering stress-strain curves. Small size- and rate effects were found in both materials in the ranges tested. Pin-loaded tensile specimens were used with general purpose tensile test apparatus consistent with the scale of the specimens. This approach succeeded in measurements of the strength and ductility. However, attempts to measure the Young's modulus were not fully successful because of large experimental uncertainties and a microplasticity phenomenon similar to that reported as material instability in the previous literature on LIGA Ni materials. Figure 1. shows stressstrain curves for 2 nominal specimens, one of each material, tested at the two strain rates. The Alpha material clearly exhibits much higher strength and lower ductility than the $\mathrm{C}$ material.

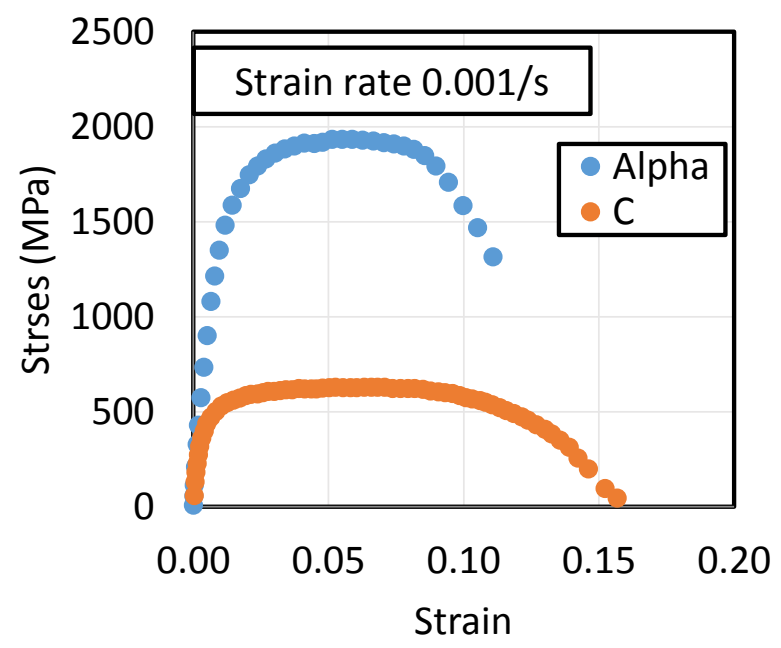

(a)

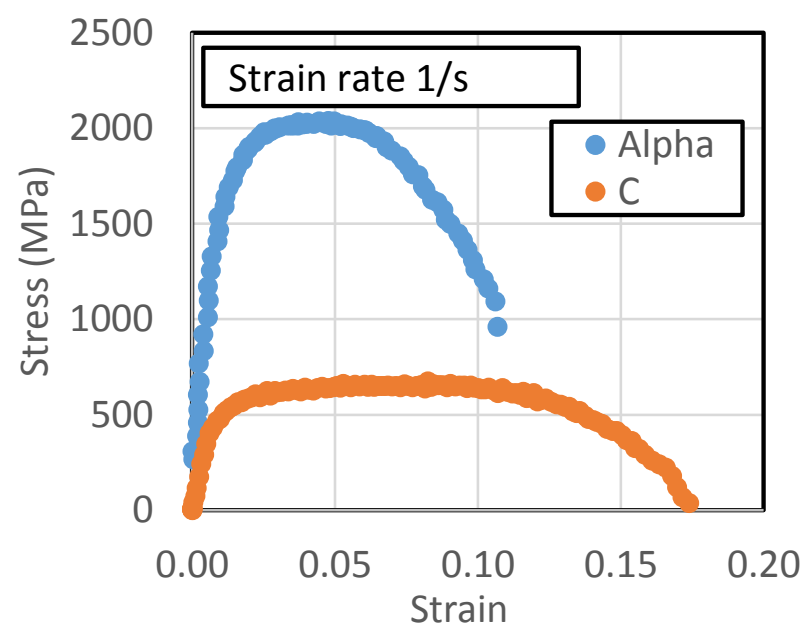

(b)

Figure 1. Engineering stress-strain curves of an S1 specimen of Alpha and C material, tested at strain rate of (a) $0.001 / \mathrm{s}$, and (b) $1 / \mathrm{s}$. 


\section{Table of Contents}

Executive summary

1. Introduction

2. Final micro tensile specimens fabricated by commercial vendor

3. Tensile test results for Alpha material

3.1. Size and rate effects on UTS

3.2. High- vs low-strain analysis for apparent Young's modulus

3.3. Strain concentrations

4. Tensile test results for $\mathbf{C}$ material

4.1. Size and rate effects on UTS

4.2. High- vs low-strain analysis for apparent Young's modulus

5. Comparison of Alpha and $\mathrm{C}$ materials

6. Uncertainties in UTS and apparent Young's modulus

6.1. Error analysis for UTS

6.2. Error analysis for apparent Young's modulus

6.3. Synchronization issue in $1 / \mathrm{s}$ tests of $\mathrm{C}$ material

7. Discussion of difficulty in measuring Young's modulus from tensile tests

8. Effects of low-temperature annealing on tensile properties

9. SEM/EBSD imaging of microstructure

10. Conclusion

References

Appendices

Appendix A. Improvements to microtensile test set-up

A-1. Improvements to strain rate $0.001 / \mathrm{s}$ test

A-2. Improvements to strain rate $1 / \mathrm{s}$ test

A-3. Custom specimen carriers

Appendix B. Summary of tensile specimens tested 
Appendix C: Stress-strain curves for Alpha material, at strain rate 0.001/s

Appendix D: Stress-strain curves for Alpha material, at strain rate 1/s

Appendix E: Stress-strain curves for C material, at strain rate 0.001/s

Appendix F: Stress-strain curves for C material, at strain rate 1/s

Appendix G: Contributions to measurement error for UTS

Appendix H: Contributions to measurement error for apparent Young's modulus

Contribution of the U.S. National Institute of Standards and Technology (NIST), an agency of the United States government. Not subject to copyright in the U.S.

Brand names are used to identify certain items of experimental equipment and materials sources in order to clearly describe the work carried out. No endorsement is intended or implied. 


\section{Introduction}

This report summarizes NIST's measurements of the tensile properties of two commercially fabricated LIGA (Lithographie, Galvanoformung, Abformung) materials used by the U.S. Army Armament Research Development and Engineering Center (ARDEC). Micro tensile test procedures developed during this project's Task 1 performance period as described in the Task 1 report to ARDEC [1] were used. The specimens were fabricated by the same commercial vendor as in Task 1 (HT Micro Analytical Inc., in Albuquerque, NM.) We performed tensile tests on two of the vendor's proprietary LIGA materials ("Alpha" and "C" alloys), over four different specimen sizes, at room temperature and at two rates (strain rates $0.001 / \mathrm{s}$ and $1 / \mathrm{s}$ ), both of which are considered to be quasi-static. We investigated rate and size effects on the ultimate tensile strength (UTS), and found them to be either nonexistent or small, depending on the specimen type and size. We report the measurement errors (accuracy) as well as the statistical variations due to material variability, for UTS and the apparent Young's modulus. We measured the UTS to well within 15 percent variation for all specimens (combined accuracy of the measurement and statistical scatter in the material properties).

We were unable to reliably measure the Young's modulus, E, because of large measurement uncertainties in most of the material/geometry/testing-rate categories as well as microplasticity in the materials; we report analysis procedures, measured values and experimental uncertainties of an apparent Young's modulus (apparent E). We quantified the uncertainty in the apparent $\mathrm{E}$ due to both measurement error and material variability, and found both categories of uncertainties to be significant. This is in agreement with the literature on conventional macro-scale tensile tests, where the Young's modulus is the most variable property; both the National Physical Laboratory in the UK [2] and ASM International [3] advise dynamic methods for measuring the Young's modulus. This supports the decision to utilize the Young's modulus values obtained by the fabricator through dynamic methods where such values are needed.

In addition, outside the scope of this project's statement of work, we present data on the effects of low-temperature annealing (up to $280{ }^{\circ} \mathrm{C}$ ) on the tensile properties, and on the grain structure of a "B" material from the first dummy fabrication run obtained by use of SEM/EBSD.

\section{Final Micro Tensile Specimens Fabricated by Commercial Vendor}

The design of the specimens is unchanged since the Task 1 report; an example is shown in Figure 2. The vendor improved the fabrication quality compared to the "dummy" specimens used in Task 1, which had quicker fabrication turnaround to aid the development of our test methods. These are indicated below. The present specimens were designated as "real" specimens for reporting material properties. 


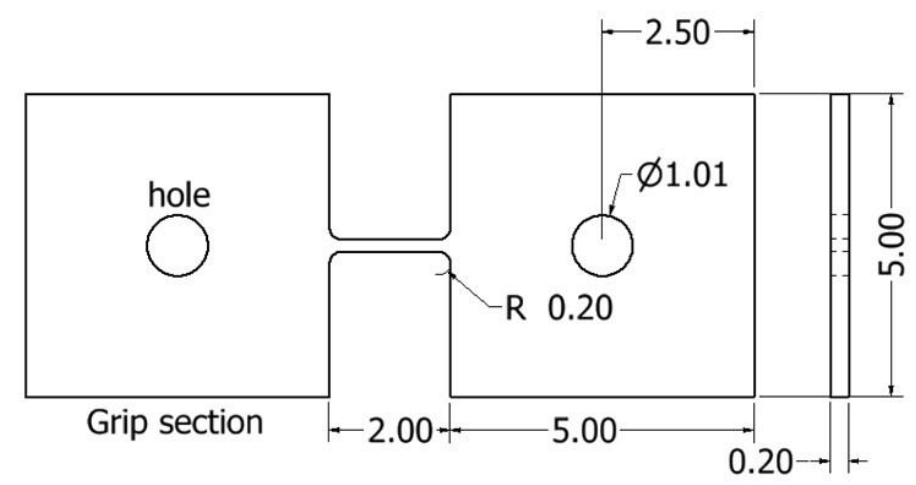

Dimensions in $\mathrm{mm}$.

Figure 2. Design of nominal micro tensile specimen (this figure is from our Task 1 report to ARDEC [1]).

The specimens tested here represent the lower limit of the size range that can be tested by use of generally conventional specimen designs and test techniques, including extensometry by digital imaging, which has become conventional in recent years for micro scale specimens. Smaller specimens cannot be handled manually for gripping, and would require more elaborate specimen designs and test procedures, such as the silicon-framed tensile specimen [4] or use of other rigid support substrates [5].

The size of these ARDEC tensile specimens is similar to those used in several studies in the literature for studying tensile properties of LIGA Ni alloys [6 - 10].

Tensile specimens of four different sizes, of the designs described in the Task 1 report, were fabricated from two proprietary LIGA materials, "Alpha" and "C", with the following nominal gauge section geometries;

S1 design: gauge length $=2 \mathrm{~mm}$, gauge width $=0.2 \mathrm{~mm}$ (the "nominal" specimen)

S2 design: gauge length $=3 \mathrm{~mm}$, gauge width $=0.5 \mathrm{~mm}$

S3 design: gauge length $=3 \mathrm{~mm}$, gauge width $=0.7 \mathrm{~mm}$ (the "Sandia" specimen)

S4 design: gauge length $=1.2 \mathrm{~mm}$, gauge width $=0.075 \mathrm{~mm}$ (the "small" specimen)

All specimens had the same size grip sections $(5 \mathrm{~mm}$ x $5 \mathrm{~mm}$ ) with $1 \mathrm{~mm}$ diameter pin holes. The target thickness for the specimens was approximately $200 \mu \mathrm{m}$ (micrometers). The dimensions for all the specimens tested are listed in Appendix B. While the actual thicknesses turned out to be $190 \mu \mathrm{m}$ for the Alpha specimens and $170 \mu \mathrm{m}$ for the $\mathrm{C}$ specimens, the thicknesses were very uniform across all specimens of each material, as shown in Table 1. 
Table 1. Average values and standard deviations for the specimen thicknesses and gauge widths. There were typically 6 specimens within each material-geometry category: 3 for low-rate testing and 3 for medium-rate testing. (This table is from our August 2016 progress report to ARDEC.)

\begin{tabular}{|c|c|c|c|c|c|c|}
\hline \multicolumn{7}{|c|}{ Average dimensions of the specimens of Alpha material } \\
\hline $\begin{array}{c}\text { Specimen } \\
\text { design }\end{array}$ & $\begin{array}{c}\text { Thickness } \\
(\mu \mathrm{m})\end{array}$ & $\begin{array}{c}\text { Standard } \\
\text { deviation } \\
(\mu \mathrm{m})\end{array}$ & $\begin{array}{c}\text { Variation } \\
(\text { percent })\end{array}$ & $\begin{array}{c}\text { Width of } \\
\text { gauge } \\
\text { length } \\
(\mu \mathrm{m})\end{array}$ & $\begin{array}{c}\text { Standard } \\
\text { deviation } \\
(\mu \mathrm{m})\end{array}$ & $\begin{array}{c}\text { Variation } \\
(\text { percent })\end{array}$ \\
\hline S4 & 190.0 & 1.1 & 0.6 & 70 & 2.3 & 3.3 \\
\hline S1 & 189.2 & 0.8 & 0.4 & 197 & 1.9 & 0.9 \\
\hline S2 & 188.8 & 1.0 & 0.5 & 498 & 1.5 & 0.3 \\
\hline S3 & 189.5 & 1.2 & 0.6 & 696 & 2.4 & 0.3 \\
\hline
\end{tabular}

\begin{tabular}{|c|c|c|c|c|c|c|}
\hline \multicolumn{7}{|c|}{ Average dimensions of the specimens of C material } \\
\hline $\begin{array}{c}\text { Specimen } \\
\text { design }\end{array}$ & $\begin{array}{c}\text { Thickness } \\
(\mu \mathrm{m})\end{array}$ & $\begin{array}{c}\text { Standard } \\
\text { deviation } \\
(\mu \mathrm{m})\end{array}$ & $\begin{array}{c}\text { Variation } \\
(\text { percent })\end{array}$ & $\begin{array}{c}\text { Width of } \\
\text { gauge } \\
\text { length } \\
(\mu \mathrm{m})\end{array}$ & $\begin{array}{c}\text { Standard } \\
\text { deviation } \\
(\mu \mathrm{m})\end{array}$ & $\begin{array}{c}\text { Variation } \\
(\text { percent })\end{array}$ \\
\hline S4 & 171.3 & 2.8 & 1.6 & 82.3 & 1.0 & 1.3 \\
\hline S1 & 171.6 & 2.1 & 1.2 & 206 & 2.6 & 1.3 \\
\hline S2 & 172.6 & 2.3 & 1.2 & 508 & 2.5 & 0.5 \\
\hline S3 & 171.2 & 2.8 & 1.4 & 706 & 2.1 & 0.3 \\
\hline
\end{tabular}

The top surface of each specimen is coated with a thin layer of gold, with $1 \mu \mathrm{m}$-thick microfabricated dots deposited and patterned on top of the gold. The dots function as fiducial markers for digital image correlation (DIC) used in analyzing the experimental data. (See our Task 1 report [1] for more details.) Figure 3 shows a typical micro tensile specimen. The sidewalls are much straighter on these specimens than on the dummy specimens used for procedure development, as determined by the widths measured from the top and bottom surfaces (Table 1). There is also much less undercutting of the bottom surface.

As in the dummy fabrication runs, the present Alpha specimens are of slightly higher fabrication quality than the $\mathrm{C}$ specimens. The widths of the Alpha specimens had less variation, and the microfabricated dots were more distinct under optical microscopy. The 
C specimens still exhibit a slightly trapezoidal cross section, as evidenced by the gauge widths being slightly different when measured from the top surfaces versus the bottom surfaces. Also, many of the $\mathrm{C}$ specimens had minor scratches on the top surfaces, presumably from polishing, whereas none of the Alpha specimens had noticeable surface scratches. Nevertheless, both sets of specimens were overall of very high fabrication quality such that any statistical variation in measured properties would not be dominated by variation in fabricated geometry. Figure 3 shows an example of a nominal specimen, and Figure 4 shows an example of the smallest (S4) design. In particular, with our use of custom specimen carriers to prevent damage during shipping and handling (see Appendix A), none of the S4 specimens tested were bent, an improvement over the dummy S4 specimens.
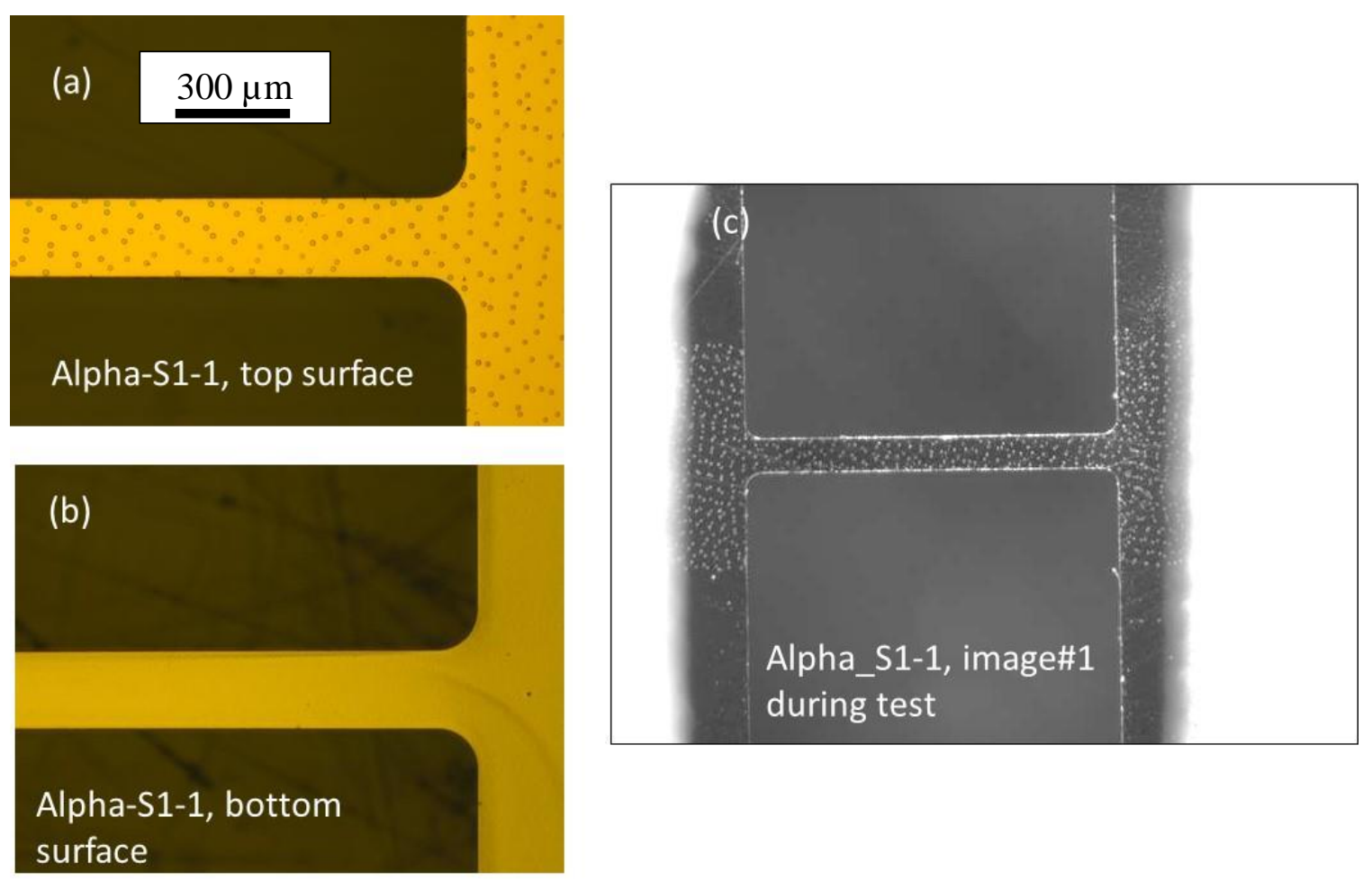

Figure 3. Optical microscope photographs of a nominal tensile specimen with microfabricated fiducial markers on the top surface. The gauge width is measured from micrographs similar to those shown in (a) and (b), which have a magnification of 5X. (c) is an optical microscope image of the same specimen from the $0.001 / \mathrm{s}$ tensile test (magnification 2X). (This figure is from our February 2016 progress report to ARDEC.) 

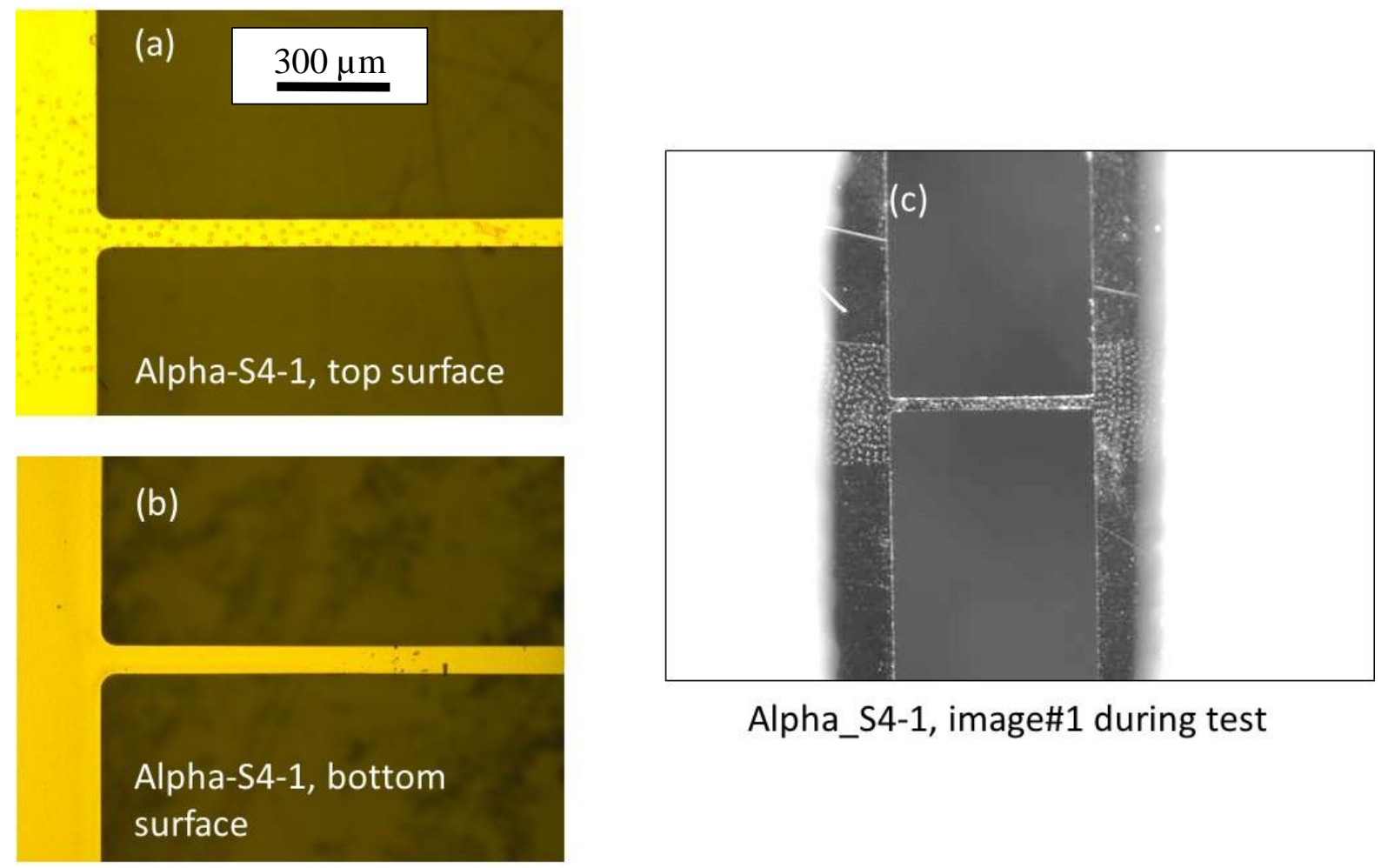

Alpha_S4-1, image\#1 during test

Figure 4. Optical micrographs of an S4 specimen. The gauge width is measured from the photos in (a) and (b), for which an objective lens with magnification of $5 \mathrm{X}$ was used. (c) is an optical microscope image of the same specimen from the 0.001/s tensile test (objective lens magnification 2X). (This figure is from our February 2016 progress report to ARDEC.)

\section{Tensile Test Results for Alpha Material}

The test procedures used here were described in detail in our Task 1 report to ARDEC [1]. A summary of additional improvements in procedures and apparatus applied to the testing of the present specimens is given in Appendix A. The effect of the changes was a reduction in the experimental uncertainties, as discussed below.

Tables 2 and 3 show the tensile test results on the Alpha material, averaged over all specimens tested for the $0.001 / \mathrm{s}$ and $1 / \mathrm{s}$ testing rates, respectively. We tabulate the extension to maximum force, listed in the table as Extension to UTS, as a substitute for the elongation to failure, which is typically reported in conventional tests. The conventional procedure for measuring this quantity, which relies on manually fitting the broken pieces of the tensile specimen back together, cannot be applied to the present specimens. The relative standard deviations for all properties, except for the apparent Young's modulus, are within 15 percent. The S1 and S4 specimens all broke in the middle of the gauge sections, whereas the S2 and S3 specimens broke about one-third from the end of the gauge section. The measured engineering stress-strain curves on which these results are based are all shown in Appendices C and D. 
Table 2. Average tensile properties for all Alpha specimens tested at strain rate 0.001/s. The apparent Young's modulus was obtained using a high-strain analysis, discussed below. (This table is from our April 2016 progress report to ARDEC.)

\section{Summary of results for Alpha material tested at a strain rate of $0.001 / \mathrm{s}$}

\begin{tabular}{|c|c|c|c|c|}
\hline Quantity & $\begin{array}{c}\text { UTS } \\
\text { (MPa) }\end{array}$ & $\begin{array}{c}\text { Apparent E } \\
(\mathrm{GPa})\end{array}$ & $\begin{array}{c}\text { YS } \\
(\mathrm{MPa})\end{array}$ & $\begin{array}{c}\text { Extension to } \\
\text { UTS } \\
\text { (percent) }\end{array}$ \\
\hline Value & 1918 & 143 & 1387 & 5.5 \\
\hline $\begin{array}{c}\text { Standard } \\
\text { deviation }\end{array}$ & 52 & 13 & 75 & 0.6 \\
\hline $\begin{array}{c}\text { Variation, } \\
\text { percent }\end{array}$ & 2.7 & 9 & 5.4 & 11 \\
\hline \multicolumn{5}{|l}{ (UTS, ultimate tensile strength; E, Young's modulus; YS, yield strength) } \\
\hline
\end{tabular}

Table 3. Average tensile properties for all Alpha specimens tested at strain rate 1/s. (This table is from our April 2016 progress report)

\begin{tabular}{|c|c|c|c|c|}
\hline \multicolumn{5}{|c|}{ Summary of results for Alpha material tested at a strain rate of 1/s } \\
\hline Quantity & $\begin{array}{c}\text { UTS } \\
\text { (MPa) }\end{array}$ & $\begin{array}{c}\text { Apparent E } \\
\text { (GPa) }\end{array}$ & $\begin{array}{c}\text { YS } \\
\text { (MPa) }\end{array}$ & $\begin{array}{c}\text { Extension to } \\
\text { UTS } \\
\text { (percent) }\end{array}$ \\
\hline Value & 2041 & 150 & 1561 & 4.5 \\
\hline $\begin{array}{c}\text { Standard } \\
\text { deviation }\end{array}$ & 29 & 35 & 85 & 0.5 \\
\hline $\begin{array}{c}\text { Variation, } \\
\text { percent }\end{array}$ & 1.4 & 23 & 5.4 & 11 \\
\hline \multicolumn{5}{|l|}{ (UTS, ultimate tensile strength; E, Young's modulus; YS, yield strength) } \\
\hline \multicolumn{5}{|l}{}
\end{tabular}

\subsection{Size and Rate Effects on Alpha Material:}

Figure 5 shows a summary of the Alpha specimens' UTS, for each specimen size and testing rate. Each data point is the average of all the specimens of that type (typically 3 specimens). The error bars represent the accuracy or measurement error, and were calculated through an error propagation analysis as described in our Task 1 report. These data indicate that, with the exception of the smallest (S4) size, there is a rate effect on the Alpha material but no size effect. 


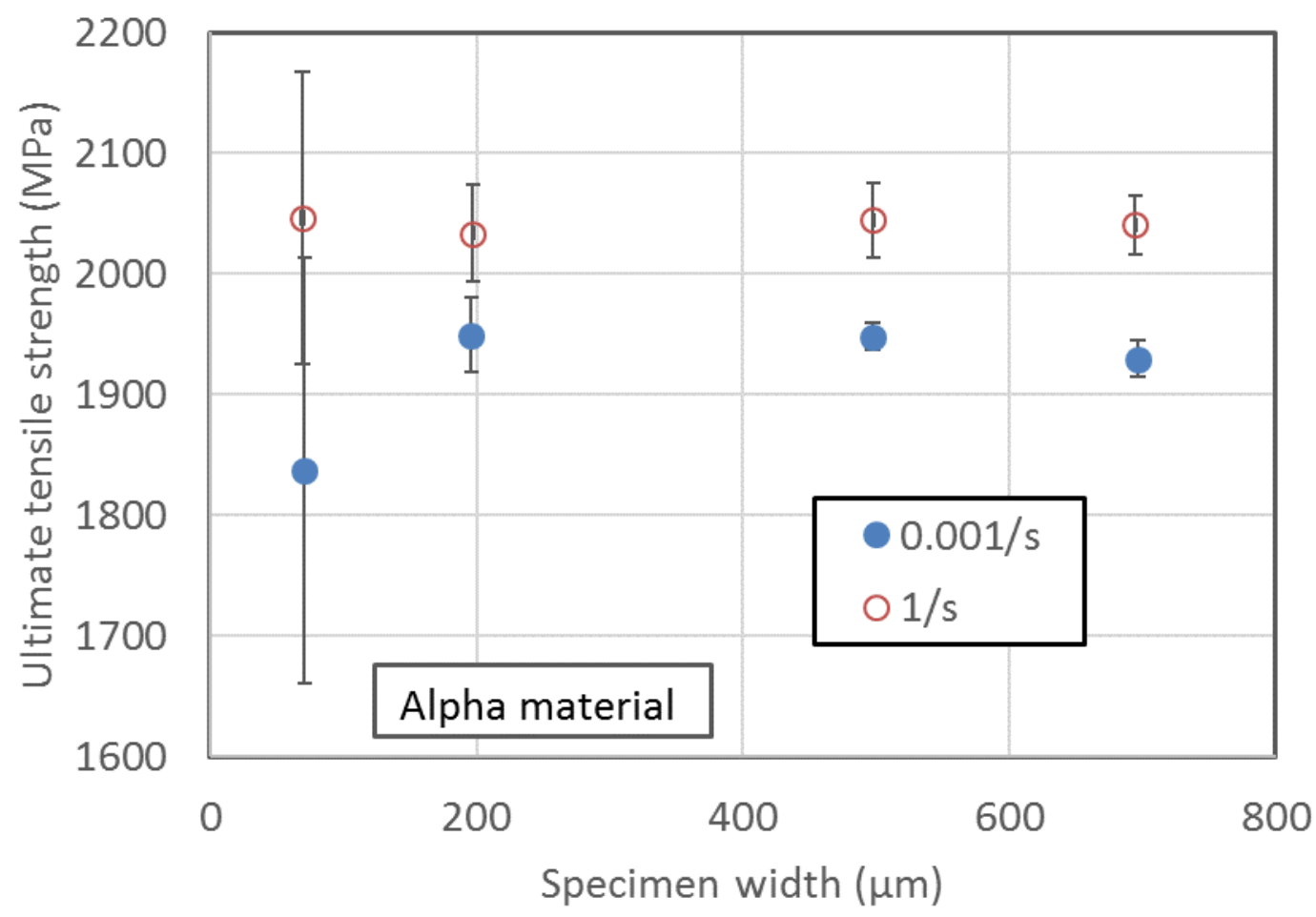

Figure 5. Plot of rate and size effects on the UTS for the Alpha material (this graph is from our August 2016 progress report). The error bars represent the measurement accuracy derived from an error analysis; their values are reported in Tables 6 and 7.

Compared to the $0.001 / \mathrm{s}$ test, the $1 / \mathrm{s}$ tests on the Alpha material show:

○ 6.5 percent higher UTS

- 4.3 percent higher apparent Young's modulus

○ 12.6 percent higher yield strength

○ 17.9 percent lower extension to UTS

This rate effect on the UTS is similar to that reported by Schwaiger et al [9], who performed micro tensile testing of LIGA Ni-Fe alloys at strain rates $10^{-4}$ to $10^{-2}$.

\subsection{High- and Low-Strain Analysis for Obtaining Apparent Young's Modulus:}

For almost all the Alpha specimens in the $0.001 / \mathrm{s}$ test there appear to be two linear regions of the stress-strain curve: an initial linear region (low-strain) with a steep slope followed by a longer linear region (high-strain) with a shallower slope. We speculate that this change in slope is due to microplasticity in the material. As the specimen is loaded past a certain point, its microstructure starts to "settle", resulting in a change in the apparent E. A similar phenomenon has been reported in the literature on other LIGA Ni alloys [10, 11]. Linear 
fits to these two ranges of strain result in significantly different values of the apparent Young's modulus and yield strength, as shown schematically in Figure 6. Therefore, for each Alpha specimen tested at a strain rate of $0.001 / \mathrm{s}$ we report two values of apparent $\mathrm{E}$ and yield strength: one corresponding to a "low-strain analysis" (strain up to approximately 0.0005 ) and another corresponding to a "high-strain analysis" (strains of approximately 0.0005 to 0.008). The low-strain analysis results in higher values of apparent $\mathrm{E}$ and lower values of yield strength, caused by the analysis procedure, as indicated in Figure 6.

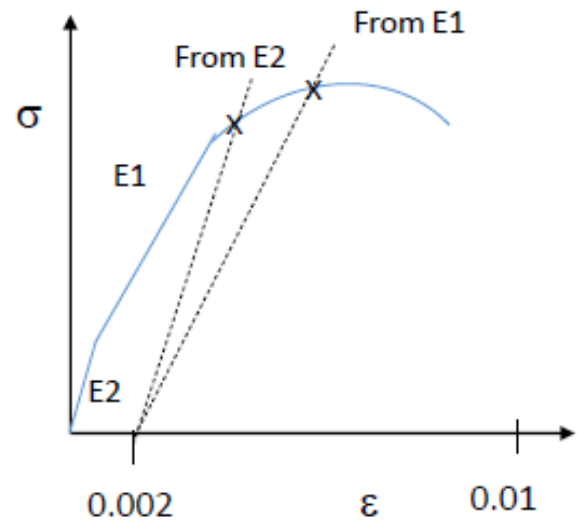

Figure 6. Sketch of a typical stress-strain $(\sigma-\varepsilon)$ curve of the Alpha specimens in the $0.001 / \mathrm{s}$ test. Most of the Alpha specimens exhibited two linear regions with different slopes. The first region - roughly corresponding to strains of under 0.0005 - has higher slope, corresponding to apparent Young's modulus E2, and is labeled as the 'low strain' region. The second region - corresponding to strains typically between 0.0008 and 0.01 - that we call the "high-strain region" corresponds to a lower slope which gives the apparent modulus $E 1$. The value of the 0.002 offset yield strength differs depending on whether $E 1$ or $E 2$ is used to compute the 0.002 offset.

It is our opinion that the apparent Young's modulus and yield strength obtained from the high-strain analysis - i.e., E1 in Figure 6 -- is more appropriate for use as input into finite element analysis of actual components. In a real-world application where large loads are applied to the microfabricated LIGA component, the strains will likely be much greater than 0.0005 and therefore the material would have undergone stabilization due to microplasticity and its elastic behavior would then correspond to the slope E1. In fact, Collins et al [10] propose that MEMS devices made from LIGA Ni materials should undergo deliberate cyclic loading to stabilize their mechanical properties before service, akin to the "burn in" of microelectronics devices.

We nonetheless present both sets of values for completeness and for comparison with values of Young's modulus from the LIGA literature. It is established in the mechanical testing community that the tensile test is not a reliable way to measure the Young's modulus [2] even for the much larger conventional specimens tested according to the current international tensile test standards, and that dynamic methods utilizing impact or resonant excitation give more accurate measures of the Young's modulus. These dynamic methods involve cyclic loading at strains typically on the order of $10^{-5}$ to $10^{-8}$ [12-14] which is 1 to 4 orders of magnitude smaller than the strains we can reliably measure in our 
tensile test set-up, particularly on micro-scale specimens such as the ones in this test program. The measurement issue for Young's modulus is discussed further in Section 7.

During the Task 1 performance period we also undertook a study, using the dummy specimens, in which we tried to obtain more consistent values of apparent $\mathrm{E}$ by performing tests where the specimen was repeatedly loaded and unloaded at low stresses and strains, see our Task 1 report [1]. However, this did not reduce the scatter in the apparent E, which we attribute to microplasticity of the material. Furthermore, when those same dummy specimens were then tensile tested to fracture and the resultant stress-strain curves analyzed, the apparent $\mathrm{E}$ from their tensile tests differed from the apparent $\mathrm{E}$ from their earlier loading/unloading tests, even on the same specimens. This mirrors the "cyclic stabilization" phenomenon reported on other LIGA Ni tensile specimens by Collins et al. They found that the repeated loading cycles tended to increase the material's stiffness, which we also observed in our dummy specimens.

For the 1/s tensile tests we did not distinguish between a low- or high-strain analysis, because the high-speed camera [1] has insufficient resolution to measure the low strains. Thus, for the 1/s tests we report only a single value of apparent $E$ and yield strength for each specimen, corresponding to a high-strain analysis.

\subsection{Strain Concentrations}

For the majority of the $0.001 / \mathrm{s}$ tests the specimens were illuminated using oblique lighting from a pair of fiber optic light sources angled from the side of the specimens, as this produced a better image contrast for the microfabricated fiducial markers. A few tests, however, were done using 'metallurgical illumination' or 'reflected light microscopy' instead; that is, the illumination passes through the objective lens of the microscope itself, such that the specimens were illuminated perpendicular to the surface, and the microscope captured the reflected light. This illumination mode revealed not only the formation of the slip bands on the specimen surfaces during the plastic deformation, but also the development of strain concentrations, see Figure 7. The strains at the strain concentrations were measured using DIC, and compared to the strains closer to the middle of the gauge section, as shown in Figure 8. The difference in strain is about 0.005. 
(a)
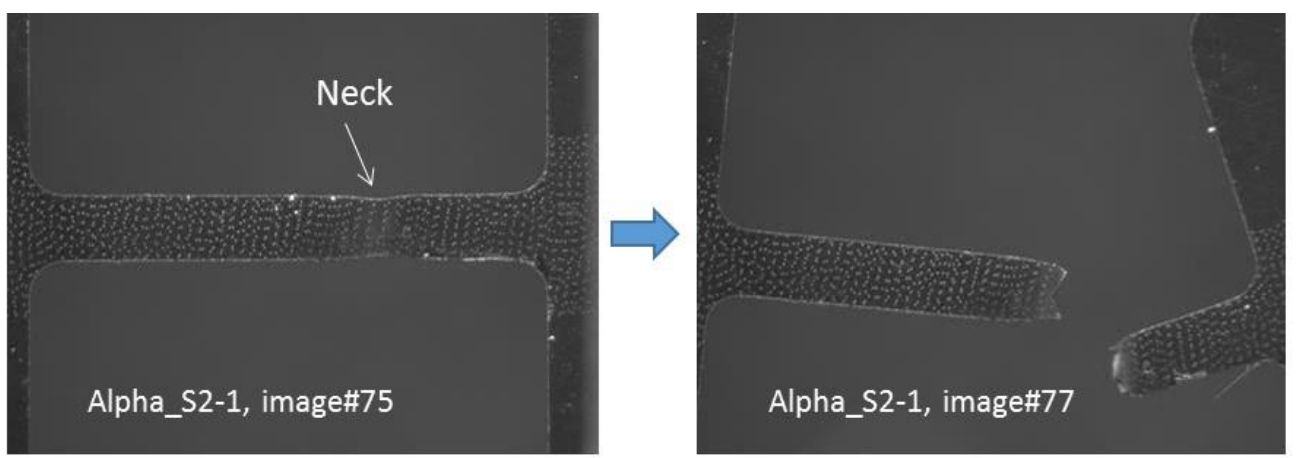

(b)
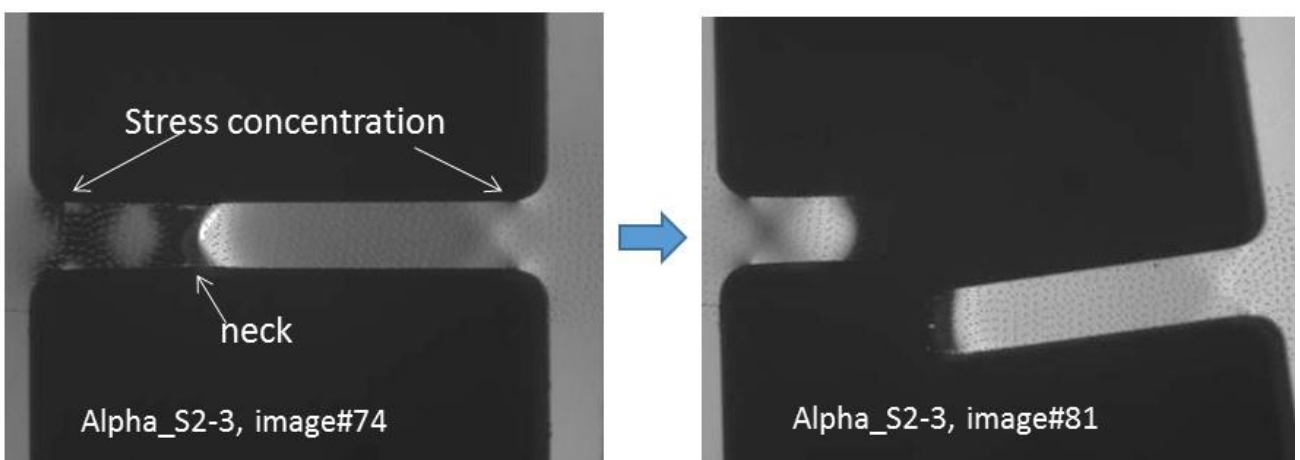

Figure 7. Oblique (a) vs vertical (b) illumination in the $0.001 / \mathrm{s}$ test, and the formation of stress concentrations revealed by vertical illumination. (This figure is from our April 2016 progress report to ARDEC.)
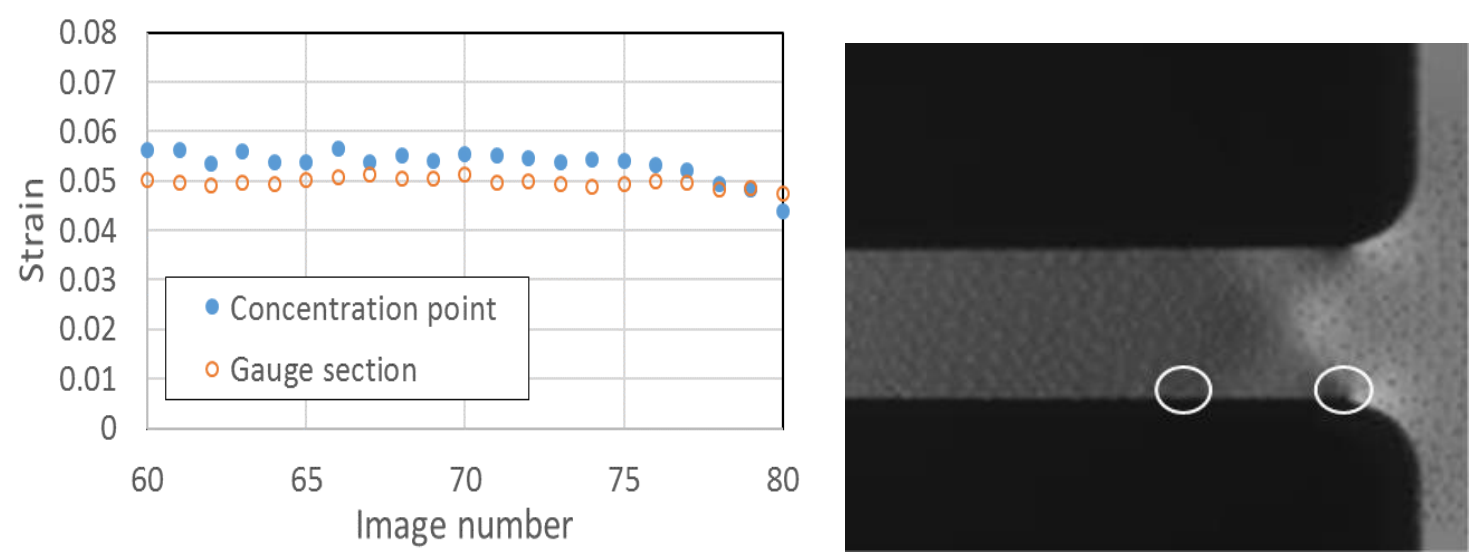

Figure 8. (a) Measured strains along the edge of the gauge section of specimen Alpha_S23 , at and away from the strain concentration. (b) The photograph shows the regions on the specimen where the strains were measured. (This figure is from our April 2016 progress report to ARDEC.)

We were able to reproduce these strain concentrations in finite element analysis (FEA), which showed that the strain concentrations are due to the specimen design. An FEA model of an Alpha-S1 specimen was constructed, and the measured tensile stress-strain curve for 
an Alpha S1 specimen was used as an input. The overall stress-strain result of the FEA agreed with the input, see Figure 9, validating the stress-strain behavior of the FEA model. The model was then examined for the presence of strain- and stress-concentrations. Figure 10 shows the predicted strain along the edge of the gauge section length. Strain concentrations are indeed present in the FEA prediction, thus confirming that it is due to the design of the specimen. The predicted strain concentrations are also minimal (more so than those measured in Figure 8 above, but the measurement was performed on an S2 geometry whereas the FEA is for an S1 geometry.). Figure 11 shows the predicted stress along the gauge length. No noticeable stress concentration is evident in the FEA. We therefore consider that these strain concentrations are inconsequential to our measurements of the tensile properties.

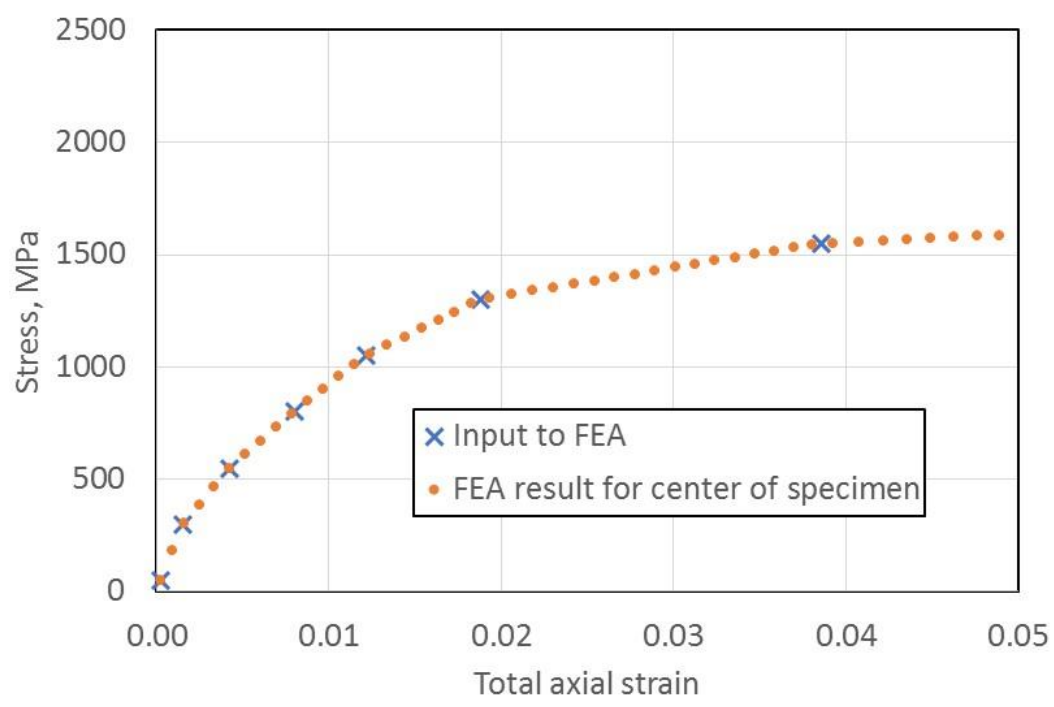

Figure 9. Predicted stress-strain curve for an Alpha_S1 specimen, using measured values of stresses and strains as inputs to the FEA (to capture both the low- and high-strain apparent Young's modulus, E1 and E2). (This figure is from our April 2016 progress report to ARDEC.) 

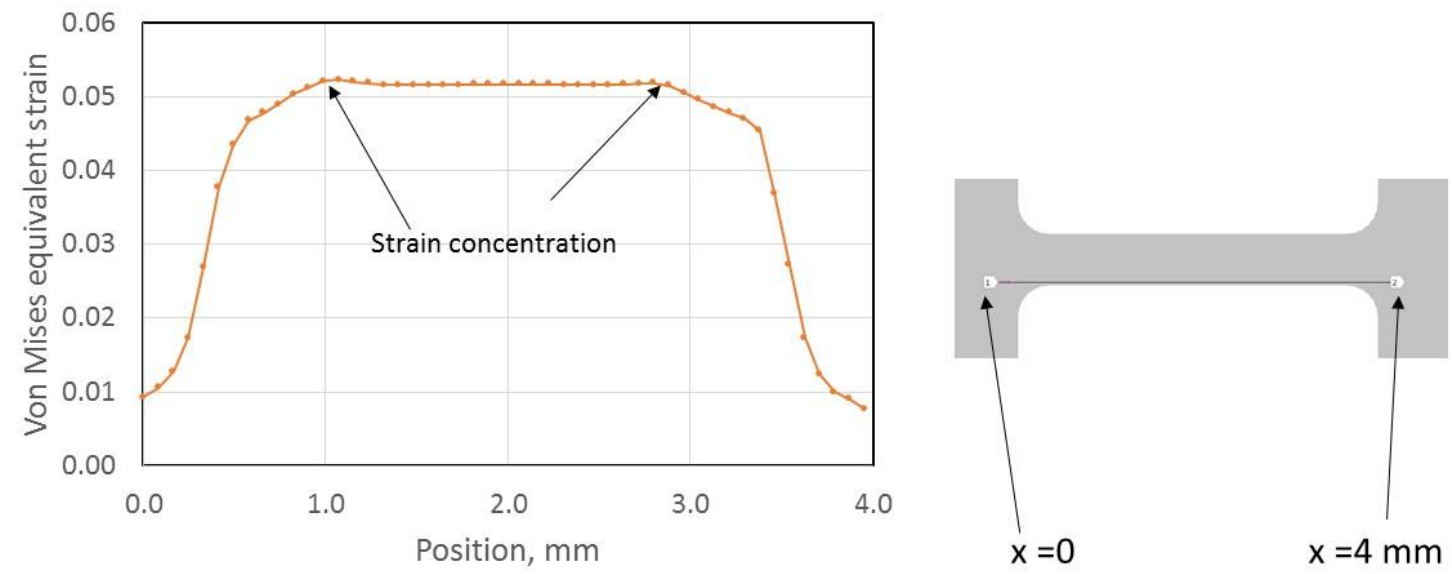

Figure 10. Strain concentration from the FEA in the previous figure, and the path along which it is plotted. (This figure is from our April 2016 progress report to ARDEC.)
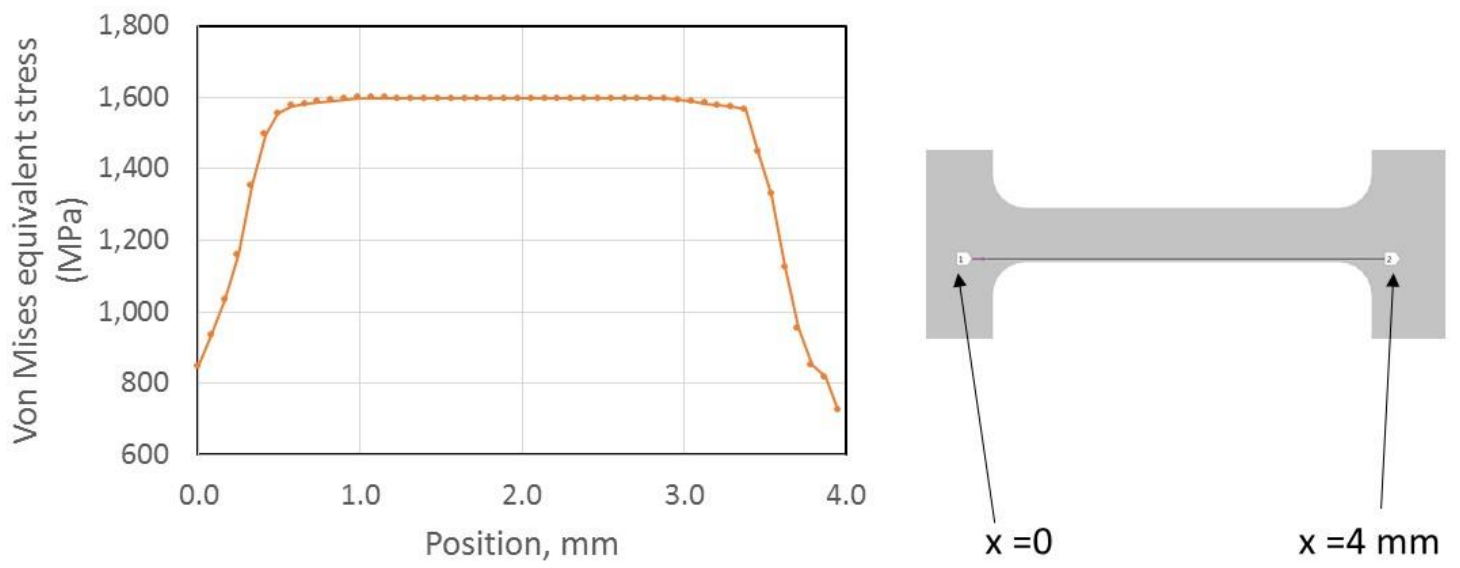

Figure 11. Stress from the FEA in the previous figure, and the path along which it is plotted. No noticeable stress concentration is predicted. (This figure is from our April 2016 progress report)

The ASTM E8 [15] specimen design calls for the ratio of the fillet radius to the gauge width to be 1 . Our specimens have slightly smaller radii relative to the widths. This could account for the observed and predicted strain concentrations. Nevertheless, the strains at the concentration are minimal, and the FEA predicts no significant stress concentration at those locations, so we ignored these strain concentrations in our analysis. 


\section{Tensile Test Results for C Material}

Tables 4 and 5 show the results of the $0.001 / \mathrm{s}$ and $1 / \mathrm{s}$ tensile tests on the $\mathrm{C}$ material. There is larger scatter (standard deviation) in all properties than for the Alpha material. The measured engineering stress-strain curves on which these results are based are all shown in Appendices $\mathrm{E}$ and $\mathrm{F}$.

Table 4. Average tensile properties for all $\mathrm{C}$ specimens tested at strain rate $0.001 / \mathrm{s}$. (This table is from our July 2016 progress report to ARDEC.)

\begin{tabular}{|c|c|c|c|c|}
\hline \multicolumn{1}{|c|}{ Summary of results for C material tested at a strain rate of $0.001 / \mathrm{s}$} \\
\hline Quantity & $\begin{array}{c}\text { UTS } \\
\text { (MPa) }\end{array}$ & $\begin{array}{c}\text { Apparent E } \\
\text { (GPa) }\end{array}$ & $\begin{array}{c}\text { YS } \\
\text { (MPa) }\end{array}$ & $\begin{array}{c}\text { Extension to } \\
\text { UTS } \\
\text { (percent) }\end{array}$ \\
\hline Value & 653 & 160 & 431 & 5.7 \\
\hline $\begin{array}{c}\text { Standard } \\
\text { deviation }\end{array}$ & 76 & 47 & 40 & 0.9 \\
\hline $\begin{array}{c}\text { Variation, } \\
\text { percent }\end{array}$ & 12 & 30 & 9 & 16 \\
\hline \begin{tabular}{l} 
(UTS, ultimate tensile strength; E, Young's modulus; YS, yield strength) \\
\hline
\end{tabular}
\end{tabular}

Table 5. Average tensile properties for all $\mathrm{C}$ specimens tested at strain rate 1/s. (This table is from our July 2016 progress report)

\begin{tabular}{|c|c|c|c|c|}
\hline \multicolumn{2}{|c|}{ Summary of results for C material tested at a strain rate of 1/s } \\
\hline Quantity & $\begin{array}{c}\text { UTS } \\
\text { (MPa) }\end{array}$ & $\begin{array}{c}\text { Apparent E } \\
\text { (GPa) }\end{array}$ & $\begin{array}{c}\text { YS } \\
\text { (MPa) }\end{array}$ & $\begin{array}{c}\text { Extension to } \\
\text { UTS } \\
\text { (percent) }\end{array}$ \\
\hline Value & 709 & 113 & 468 & 7.6 \\
\hline $\begin{array}{c}\text { Standard } \\
\text { deviation }\end{array}$ & 82 & 44 & 85 & 1.4 \\
\hline $\begin{array}{c}\text { Variation, } \\
\text { percent }\end{array}$ & 12 & 39 & 18 & 18 \\
\hline \multicolumn{2}{|l|}{ (UTS, ultimate tensile strength; E, Young's modulus; YS, yield strength) } \\
\hline
\end{tabular}

\subsection{Size and Rate Effects on C Material}

Figure 12 shows the C specimens' UTS, for each specimen size and testing rate. Each data point is the average of all the specimens of that type (typically 3 specimens). The error bars represent the accuracy or the measurement error and were calculated through an error propagation analysis as we had described in our Task 1 report [1]. With the exception of the smallest (S4) size, there are both rate and size effects, both small. 


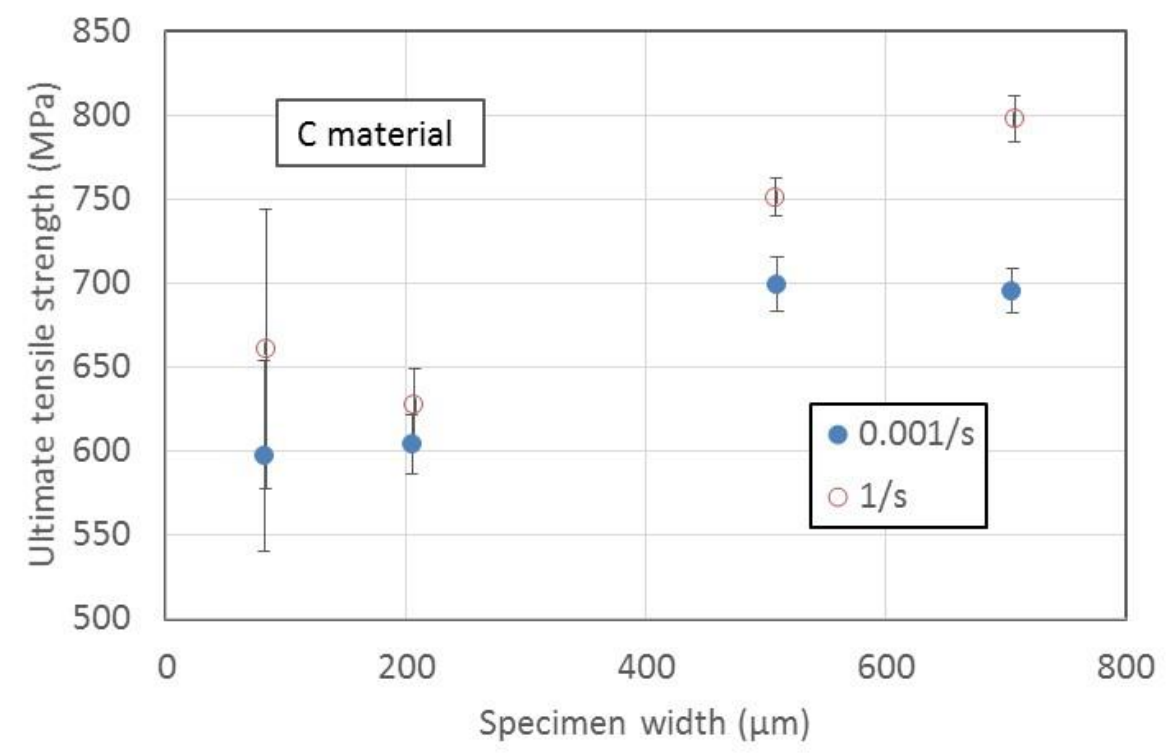

Figure 12. Rate and size effects on the UTS for the $\mathrm{C}$ material. The error bars are the accuracy derived from an error analysis, their values are reported in Tables 6 and 7. (This graph is from our August 2016 progress report to ARDEC.)

\subsection{High- vs. Low-Strain Analysis for Obtaining Apparent Young's Modulus}

Unlike the Alpha material, for the $\mathrm{C}$ material the low-strain analysis is more appropriate for determining the apparent E. Figure 13 shows detailed experimental results for one specimen as an example. For the $\mathrm{C}$ specimens, using the lower circled set of strain data points (Fig. 13 (a)) the linear regression leads to a minimal zero-strain offset correction as shown in Fig. 13 (b) and (c), whereas using the higher strains for the linear regression results in a severe zero-strain offset as shown in Fig. 13 (d) and (e). Since all the specimens in the $0.001 / \mathrm{s}$ test were preloaded there should be minimal amount of specimen shifting at the start of the test, thus a large zero-strain offset indicates an issue with the analysis procedure. Therefore, for the $\mathrm{C}$ specimens of S1, S2 and S3 design the low-strain analysis is more appropriate for obtaining the apparent E. For the C-S4 specimens the high-strain analysis was used because the forces were so low $(<10 \mathrm{~N})$ that the low-strain region could not be measured accurately.

Some $\mathrm{C}$ specimens did not show a distinct change in slopes in the region of the stress-strain curve where elastic behavior is expected (unlike the Alpha specimens for which nearly all did). Thus, for the $\mathrm{C}$ specimens only one analysis per specimen was done to obtain the apparent Young's modulus. 


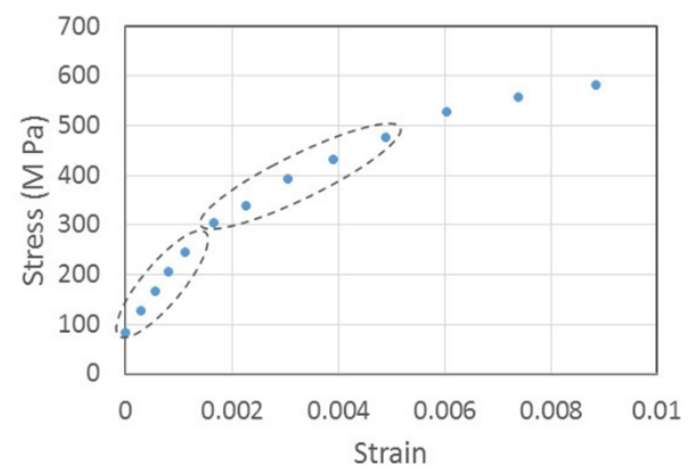

(a)

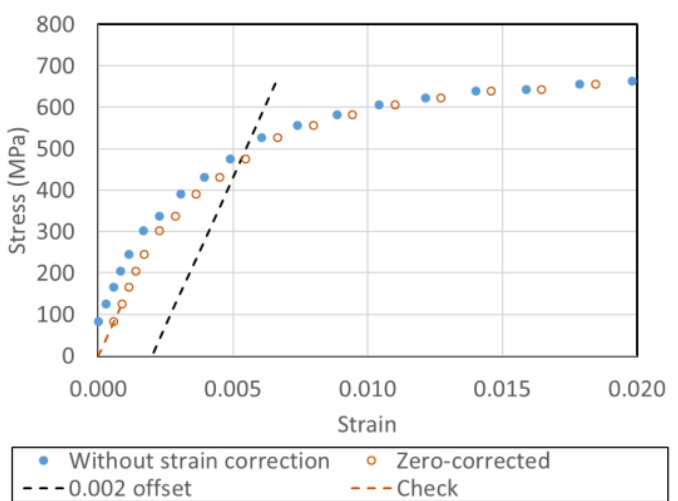

(b)

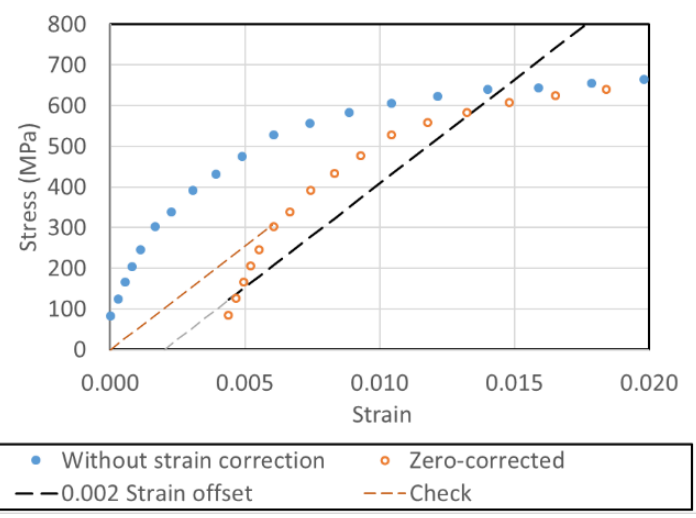

(d)

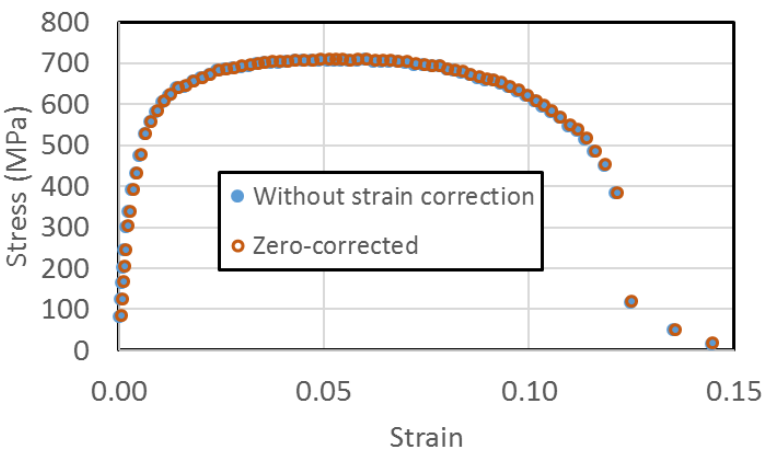

(c)

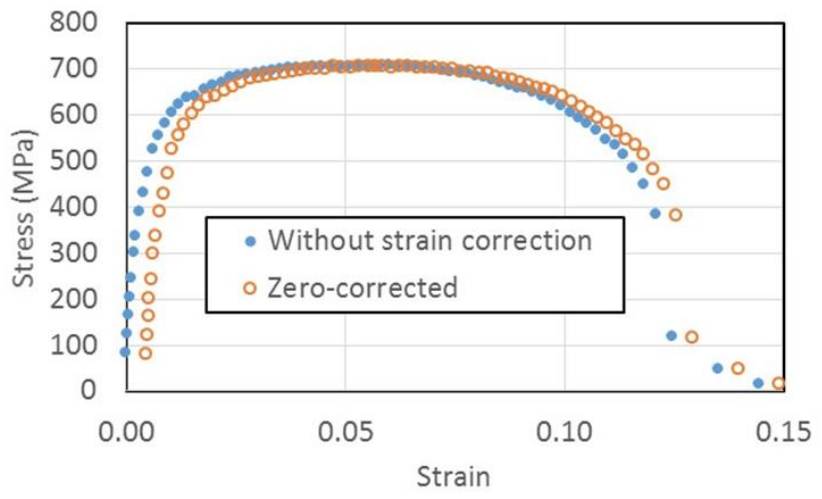

(e)

Figure 13. Plots of data from specimen C_S2-2 as an example of why the low-strain analysis is more appropriate for the $\mathrm{C}$ specimens, for fitting the linear part of the stressstrain curve to obtain the apparent Young's modulus. (a) Plot of the initial region of the stress-strain curve, showing two distinct slopes corresponding to the low- and high-strain behaviors; (b) and (c) The same data with the zero-corrected strains resulting from a lowstrain analysis, showing minimal offset from the raw strains, as expected; (d) and (e) The same data plotted with the zero-correction resulting from a high-strain analysis, showing a large offset of almost 0.005 between the corrected and uncorrected strains. (These graphs are from our July 2016 progress report to ARDEC.) 


\section{Comparison of Alpha and C Materials}

Figure 14 shows stress-strain curves for two S1 specimens, one of each material, tested at each of the testing rates. The Alpha material clearly exhibits much higher strength and lower ductility than the $\mathrm{C}$ material.

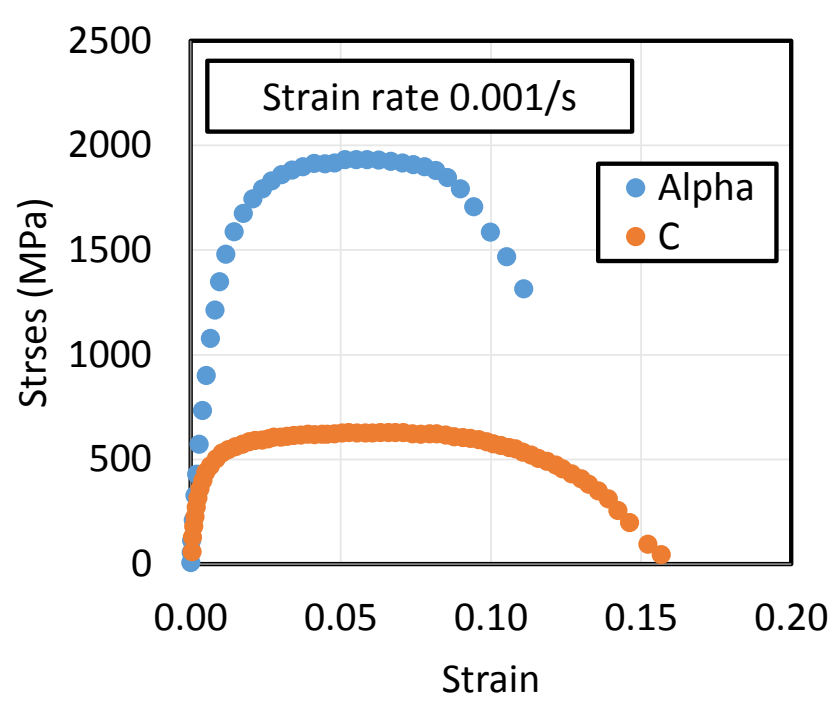

(a)

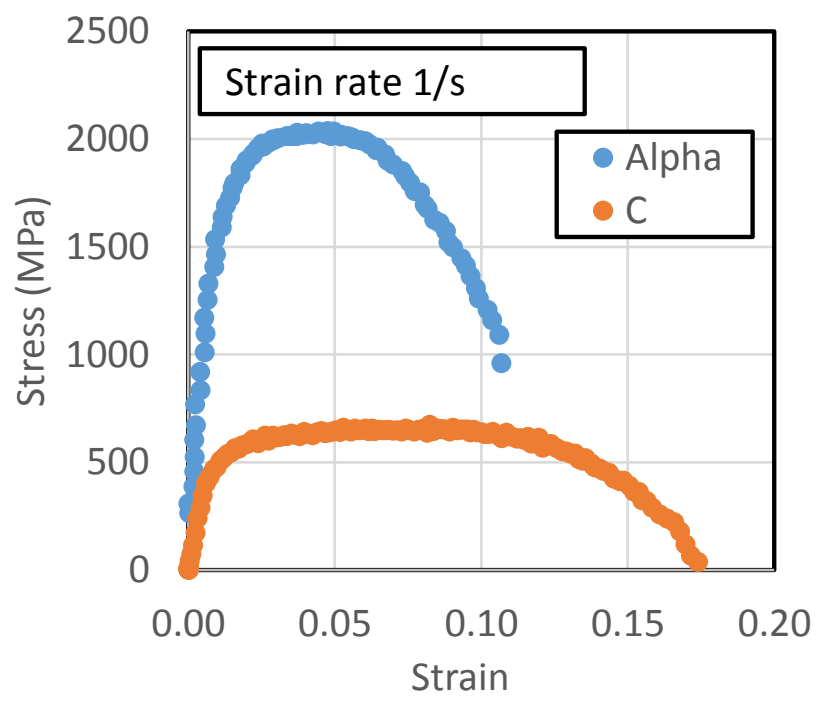

(b)

Figure 14. Stress-strain curves of an $\mathrm{S} 1$ specimen of Alpha and $\mathrm{C}$ material, tested at strain rate of (a) 0.001/s, and (b) 1/s. (This graph is from our August 2016 progress report.)

The UTS values of the Alpha and C materials are comparable to those reported in the literature where the LIGA $\mathrm{Ni}$ is electrodeposited from a Watts solution and a sulfamate solution, respectively [8]. Figures 15 and 16 compare the UTS of the Alpha and C materials for each specimen size, when tested at strain rate $0.001 / \mathrm{s}$ and $1 / \mathrm{s}$, respectively. 


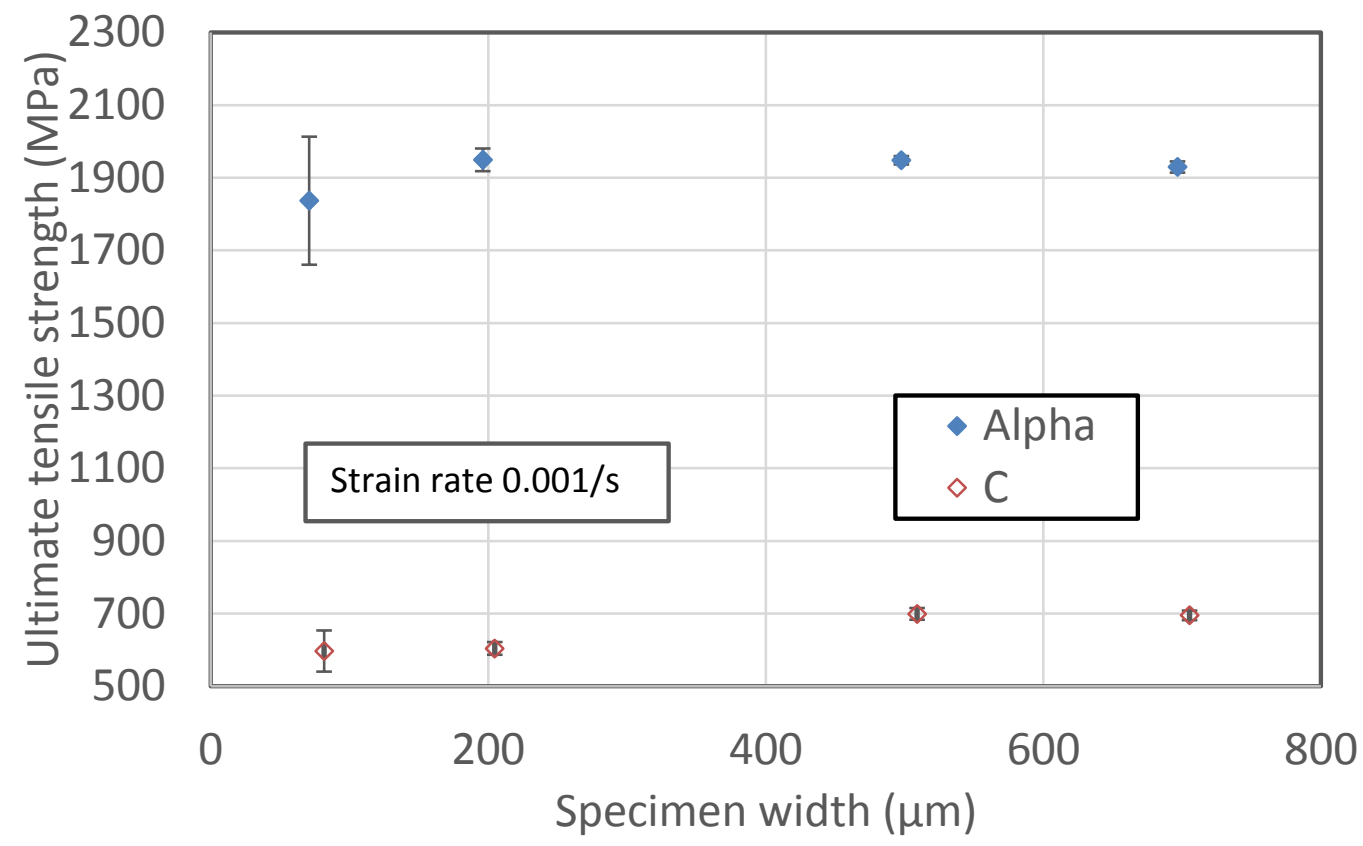

Figure 15. UTS of Alpha and C specimens tested at strain rate $0.001 / \mathrm{s}$. Each data point is the average of all the specimens of that type. The error bars are the measurement uncertainty, calculated by error analysis; the uncertainty values are reported in Tables 6 and 7. (This graph is from our August 2016 progress report to ARDEC.)

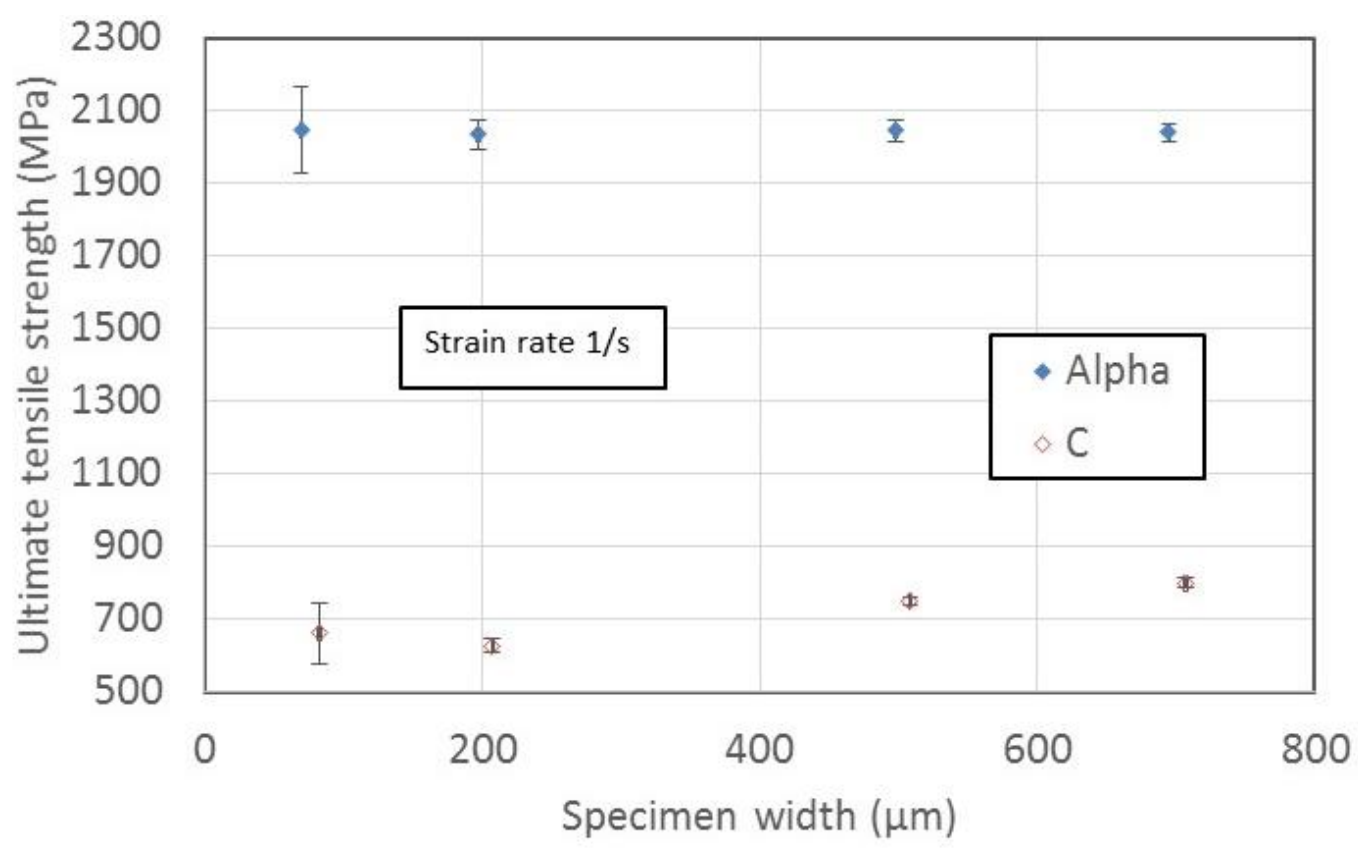

Figure 16. UTS of Alpha and C specimens tested at strain rate 1/s. Each data point is the average of all the specimens of that type. The error bars are the uncertainty in accuracy, calculated by error analysis, their values are reported in Tables 6 and 7 below. (This graph is from our August 2016 progress report to ARDEC.) 


\section{Measurement Uncertainties in UTS and Apparent Young's Modulus}

There are three major categories of uncertainty that contribute to the uncertainty in the measured properties reported here:

1. Uncertainty due to precision of the instruments

2. Uncertainty due to the accuracy of the measurement technique

3. Uncertainty due to the variability of the specimen material itself.

The uncertainty in our micro tensile tests caused by instrument precision (\#1) is small compared to all the uncertainties from accuracy and specimen repeatability. For example, the precision of our load cell readout is absorbed by the load cell calibration (see Appendix A for the calibration of the new $334 \mathrm{~N}(75 \mathrm{lb})$ load cell, resulting in a force uncertainty of $0.5 \mathrm{~N}$ which is a significant improvement from the $3.9 \mathrm{~N}$ uncertainty of our previous load cell from our Task 1 report [1]). Because our strain measurements are obtained as ratios of pixel counts, the imprecision of the cameras is negligible compared with all the other measurement uncertainties. Therefore, our measurement uncertainties are dominated by the accuracy of the individual measurements that contribute to our reported results (\#2), which we determine by error analysis, and by the specimen-to-specimen variation (\#3) which is a statistical scatter represented by the standard deviation of the results. The latter can be attributed to actual specimen-to-specimen material variation only if the measurement uncertainties are sufficiently small.

This last category (\#3) is especially significant for small-scale materials, as it is welldocumented in the literature that properties of thin and thick films are highly processdependent and can vary widely between and within fabrication runs. Also, whereas the uncertainties due to instrument precision (\#1) and specimen repeatability (\#3) are statistically-based and will vary with the number of specimens tested, the uncertainty due to the accuracy of the measurement technique (\#2) is derived from analyzing the errors in the underlying measurement methods and their propagation and is independent of the number of tests conducted.

We carried out a systematic analysis of our measurement uncertainties for the UTS and the apparent Young's modulus. Much of the literature on micro tensile testing of MEMS materials - including LIGA alloys - does not clearly report the uncertainties in the measured properties. Where uncertainties are given, they typically are solely the standard deviation across many specimens. Many papers also report properties by giving a range but also with little explanation, and it also seems common in the literature for uncertainties not to be reported altogether. Given the vast amount of literature on microscale tensile testing of various materials, spanning decades, it is very possible that there are papers that do report uncertainties in accuracy versus in precision and statistical variation, but from our survey of the literature we have not found them.

\subsection{Error analysis for the UTS}

We did an error analysis of the UTS according to the same procedure described in Appendix $\mathrm{C}$ of our Task 1 report to ARDEC [1]. The only difference is in some of the values. Our force uncertainty is now much lower than that reported in our Task 1 report 
( $0.5 \mathrm{~N}$ as opposed to $3.9 \mathrm{~N}$ ) due to our use of a new load cell with smaller range (see Appendix A). The present specimens have straighter sidewalls than the two runs of "dummy" specimens, which lowers the relative error in the cross-sectional area. Tables 6 and 7 show the calculated measurement errors for the UTS. These values are used to draw the error-bars in the graphs in Figures 5, 12, 15, 16.

Table 6. Relative uncertainty in the UTS by specimen type due to measurement accuracy as calculated by error analysis, for tensile tests at strain-rate $0.001 / \mathrm{s}$. These values are for a 1 standard deviation or 68 percent confidence level. For 2 standard deviations $(95$ percent confidence), multiply these values by 2. (This table was reported in our August 2016 progress report to ARDEC.)

\begin{tabular}{|c|c|c|c|c|}
\hline Strain rate & \multicolumn{4}{|c|}{$0.001 / \mathrm{s}$} \\
\hline Specimen type & S4 & S1 & S2 & S3 \\
\hline Material & \multicolumn{4}{|c|}{ Relative uncertainty in UTS, percent } \\
\hline Alpha & 9.6 & 1.6 & 0.6 & 0.8 \\
\hline C & 9.5 & 2.9 & 2.3 & 1.9 \\
\hline
\end{tabular}

Table 7. Relative uncertainty in the UTS by specimen type due to measurement accuracy as calculated by error analysis, for tensile tests at strain-rate $1 / \mathrm{s}$. These values are for a 1 standard deviation or 68 percent confidence level. For 2 standard deviations $(95$ percent confidence), multiply these values by 2. (This table was reported in our August 2016 progress report to ARDEC.)

\begin{tabular}{|c|c|c|c|c|}
\hline Strain rate & \multicolumn{4}{|c|}{$1 / \mathrm{s}$} \\
\hline Specimen type & S4 & S1 & S2 & S3 \\
\hline Material & \multicolumn{4}{|c|}{ Relative uncertainty in UTS, percent } \\
\hline Alpha & 5.9 & 2.0 & 1.5 & 1.2 \\
\hline C & 12.6 & 3.4 & 1.5 & 1.7 \\
\hline
\end{tabular}

Figures 17 and 18 show the relative magnitudes of the various contributions to the above tabulated UTS uncertainties. These figures below are for the largest and smallest specimens. Similar graphs for all other material-geometry combinations are in Appendix G. The error in the cross-sectional area is calculated from the errors in the width and thickness. These figures show that the largest contribution to the UTS error is the width measurement, which propagates into the error in the cross-sectional area and on to the stress. The relative error in the width is defined as the absolute uncertainty in the width, divided by the average value of the width. The absolute uncertainty in the width is, in turn, defined as the difference in the widths when measured from the top surface of the specimen 
versus the bottom surface. This captures the verticality of the sidewalls due to fabrication quality. We found that the larger the specimens, the straighter the sidewalls and thus the smaller the error in width.
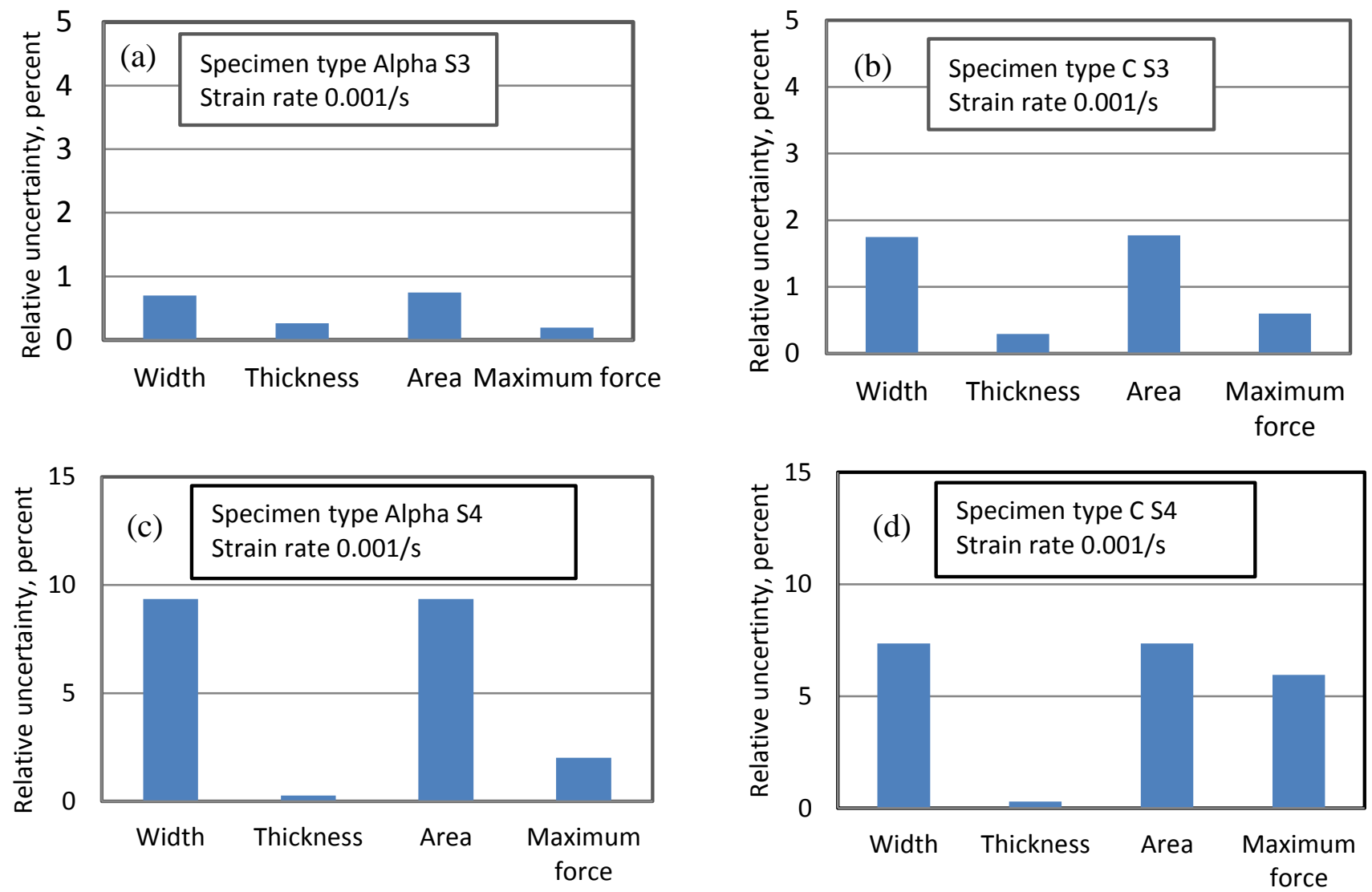

Figure 17. Contributions to the experimental uncertainty in the UTS for the low-rate tensile test, for specimen types: (a) Alpha-S3, (b) C-S3, (c) Alpha-S4, (d) C-S4. (These figures are from our August 2016 progress report to ARDEC.) 


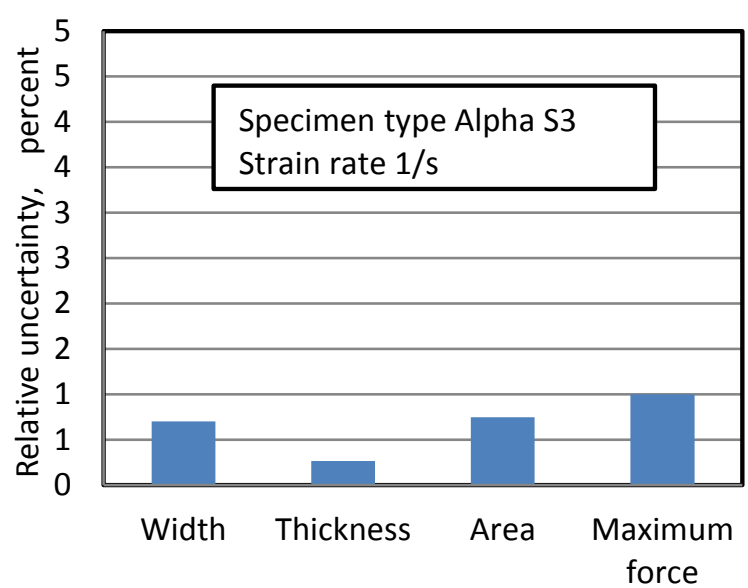

(a)

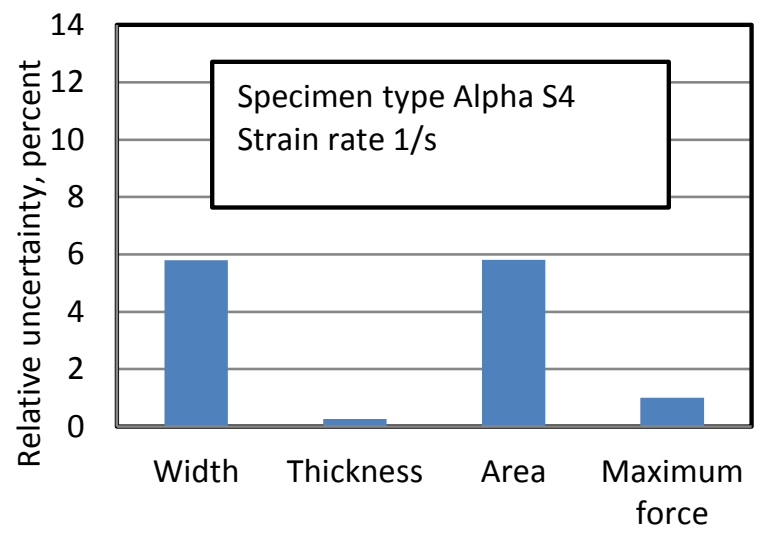

(c)

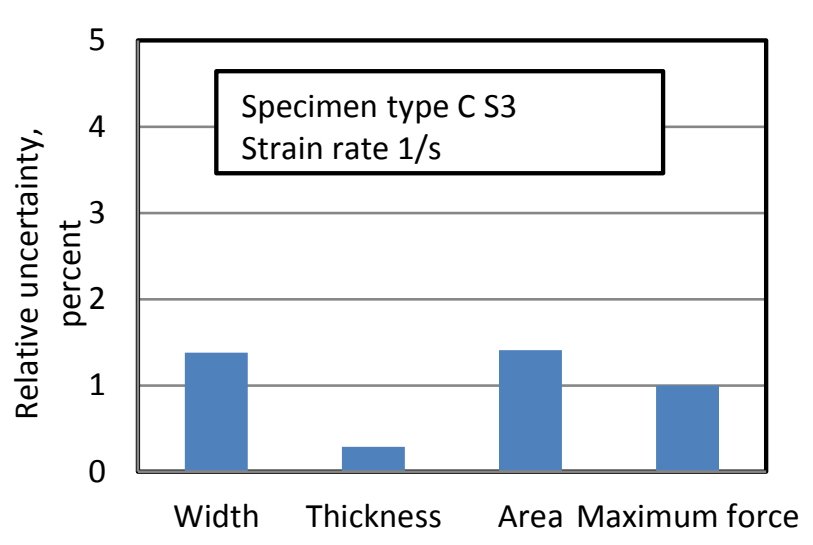

(b)

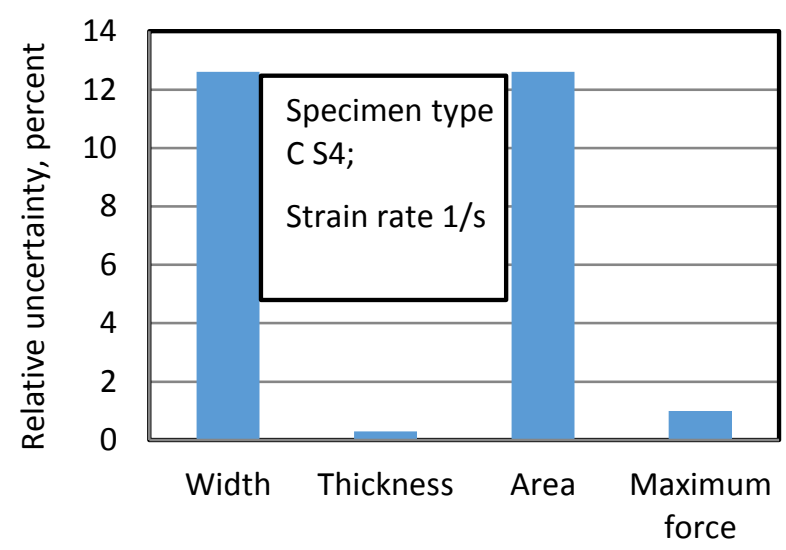

(d)

Figure 18. Contributions to the UTS error in the medium-rate tensile test, for (a) AlphaS3, (b) C-S3, (c) Alpha-S4, (d) C-S4. (These figures are from our August 2016 progress report to ARDEC.)

From the above figures, the relative error in width is less than 2 percent for all but the smallest (S4) specimens. The S4 specimens have errors in width of up to 12 percent, the error being higher for the $\mathrm{C}$ material. This trend is expected, since the Alpha specimens have straighter sidewalls than the $\mathrm{C}$ specimens in general, and the fabrication is higher quality for the larger geometries. The C-S4 specimens were expected to show the largest errors due to the fabrication quality being the lowest in this material-geometry combination, while the Alpha-S3 specimens were expected to show the smallest errors due to having the best fabrication quality. These are confirmed in the error analysis.

The UTS values in Tables 2 - 5 above were obtained by averaging over all the specimens of all geometries, and the percent variation reported in those tables is the standard deviation, which represents the statistical scatter due to specimen variability. The measurement errors calculated in this section represent the accuracy, or how "correct" each measurement of UTS on each test type (combination of material/geometry/testing rate) is. 
Comparing the final uncertainties caused by the statistical scatter (the standard deviations from Tables 2 - 5) and the uncertainties caused by measurement accuracy (the error analysis results from Tables 6 and 7), results in the following summary in Table 8:

Table 8. Summary of uncertainties in UTS, by nominal strain rate and material type, due to measurement error and specimen repeatability.

\begin{tabular}{|c|c|c|c|c|}
\hline \multirow{2}{*}{$\begin{array}{l}\text { Strain } \\
\text { rate } \\
\text { Material } \\
\text { type }\end{array}$} & \multicolumn{2}{|c|}{$0.001 / \mathrm{s}$} & \multicolumn{2}{|c|}{$1 / \mathrm{s}$} \\
\hline & Uncertainty & $\begin{array}{l}\text { Statistical variation } \\
\text { (Standard deviation) }\end{array}$ & Uncertainty & $\begin{array}{l}\text { Statistical variation } \\
\text { (Standard deviation) }\end{array}$ \\
\hline Alpha & $\begin{array}{c}<10 \% \\
\text { (If S4 is excluded, }<5 \% \text { ) }\end{array}$ & $2 \%$ & $\begin{array}{c}<10 \% \\
\text { (if S4 is excluded, }<5 \% \text { ) }\end{array}$ & $1.4 \%$ \\
\hline C & $\begin{array}{c}<<10 \% \\
\text { (if S4 is excluded, }<5 \% \text { ) }\end{array}$ & $11.7 \%$ & $\begin{array}{c}<<13 \% \\
\text { (if S4 is excluded, }<5 \% \text { ) }\end{array}$ & $11.6 \%$ \\
\hline
\end{tabular}

From Table 8 above, if the smallest (S4) specimens are discounted, the measurement uncertainties for both alloys are roughly equivalent to the statistical scatter. But if the S4 specimens are included, the measurement errors exceed the statistical scatter for Alpha material but are less than the statistical scatter for $\mathrm{C}$ material. These results indicate that specimen-to-specimen variability was too small to be detected in the Alpha material, but was present in the $\mathrm{C}$ material at a level of about 10 percent.

The error in UTS for the S4 geometry could have been reduced somewhat by using a higher-magnification on the microscope used to measure specimen gauge widths. However, for this test series the magnification was kept the same across all specimens for consistency. The lowest magnification was used so as to accommodate the largest (S3) specimens. However, even if higher magnification was used to test the S4 specimens, the fact remains that the $\mathrm{S} 4$ specimens had more-trapezoidal sidewalls (attributed to fabrication), and thus the error in their cross-sectional area is also greater than for the larger specimens.

\subsection{Error analysis for the Apparent Young's Modulus}

It is established in the mechanical-testing community that tensile testing is not a reliable method for measuring a material's Young's modulus $[2,3]$ - even for conventional specimens. This is discussed in detail in Section 7. We attempted to extract the apparent Young's modulus and yield strength from the micro tensile tests. Not surprisingly, we obtained large variations in the apparent $\mathrm{E}$ from one specimen to another. We also found the apparent $\mathrm{E}$ to vary widely with small changes to the data analysis procedures. This is in agreement with Lord and Morrell [2], except that our variabilities are significantly larger due to the micro scale of our test. We attempted to 'standardize' our test and data analysis methods as much as possible to obtain a nominal value of apparent $E$ for each specimen. In this section we report our error analysis for the apparent $\mathrm{E}$. 
Note that in much of the literature on LIGA micro tensile testing, where Young's modulus is reported there is often no mention of the uncertainties, or the uncertainties are simply reported as a range but without explanation as to how they were derived. It is assumed therefore, that those are statistical variations (standard deviations). However, our work in analyzing the error in our apparent E from LIGA tensile tests indicates that the measurement error (accuracy) is substantial. Since our micro tensile test techniques do not differ significantly from that of recent and contemporary works in the literature, we believe that our conclusions may also be applied to previous published reports and perhaps help to shed some light on discrepancies in Young's modulus reported in the literature.

Tables 2 - 5 in an earlier section listed the values of the tensile properties of our specimens, averaged over all specimens tested. The tables show that the standard deviations in the apparent Young's modulus are very high, ranging from 9 percent (for Alpha material in the $0.001 / \mathrm{s}$ test) to 39 percent (C material in the $1 / \mathrm{s}$ test).

Since the standard deviations were higher for the $\mathrm{C}$ material than for the Alpha material, at the suggestion of our project sponsor we then selected the $\mathrm{C}$ specimens that had the most well-behaved stress-strain curves, and used those to identify a range for apparent $\mathrm{E}$. The list of those specimens and their apparent E's are in Appendix H. The results averaged over those specimens are shown in Table 9 below.

Table 9. Average apparent E and statistical variation, for the "best" $\mathrm{C}$ specimens. (This table is from our Aug 2016 progress report to ARDEC).

\begin{tabular}{|c|c|c|c|}
\hline Strain rate & $\begin{array}{c}\text { Average } \\
\text { apparent E } \\
\text { (GPa) }\end{array}$ & $\begin{array}{c}\text { Standard } \\
\text { deviation } \\
\text { (GPa) }\end{array}$ & $\begin{array}{c}\text { Percent } \\
\text { variation }\end{array}$ \\
\hline $0.001 / \mathrm{s}$ & 156 & 35 & 22 \\
\hline $1 / \mathrm{s}$ & 109 & 25 & 23 \\
\hline
\end{tabular}

The error analysis procedure for the apparent $\mathrm{E}$ closely follows that for the UTS (described in detail in the Appendix of our Task 1 report to ARDEC [1]), but now with the additional factor of the error in strain measurement. Since engineering strain is "du/length", where " $d u$ " is the displacement in pixels (from the DIC analysis) and length is the specimen's gauge length in pixels, the relative error in strain is calculated from the relative errors in " $d u$ " and the relative errors in gauge length.

Calculating the relative errors in the gauge length is straightforward. The procedure is similar to calculating the relative error in width; here it is applied to the imaging apparatus used in the test. Both length and $d u$ errors are greater for the 1/s tests than for the $0.001 / \mathrm{s}$ tests because the high-speed camera used in that test set-up has lower resolution and thus fewer pixels.

The relative error in " $d u$ " is calculated as the absolute uncertainty in " $d u$ " divided by the total value of " $d u$ ". In our Task 1 report we stated that the absolute uncertainty in $d u$ is 0.2 pixels for our DIC methods. This is a conservative practical estimate, originally based on 
tensile test conditions with cameras and microscopes similar to those used in this study for the low rate tests. The total value of $d u$ is found for each specimen by choosing a strain of roughly 0.001 , representative of the strain levels where the Young's modulus must be measured, and finding the $d u$ value corresponding to that value of strain. The average value of $d u$ for each specimen type (A-S1, A-S2, C-S1, C-S2, etc.) is then found and used to compute the relative error in $d u$ for that specimen type. In this way, the relative error in strain, at a nominal strain of around 0.001 for a high-strain analysis and strain 0.0005 for low-strain analysis, is calculated for each specimen type.

The relative error in the stress is computed in a manner similar to the error in UTS, except here the stresses are those corresponding to nominal strain of 0.001 and 0.0005 for highand low-strain analyses, respectively. The error in apparent $\mathrm{E}$ is then the obtained by adding in quadrature the relative errors in the stress and strain.

Tables 10 and 11 show the calculated measurement errors in apparent $E$ for each specimen type, tested at strain rate $0.001 / \mathrm{s}$. These values correspond to 1 standard deviation or 68 percent confidence level. For 2 standard deviations (95 percent confidence), multiply the values in the tables by 2 . Note that these are measurement errors obtained from the error analysis, and do not account for the specimen material's variability such as from microplasticity or fabrication process non-uniformities.

Table 10. Error analysis of apparent Young's modulus in the $0.001 / \mathrm{s}$ test, high-strain analysis. Note that for the Alpha material the high-strain analysis is more appropriate for obtaining the apparent $\mathrm{E}$, while for the $\mathrm{C}$ material the low-strain analysis is more appropriate. (This table is from our Aug 2016 progress report to ARDEC.)

\begin{tabular}{|c|c|c|c|c|}
\hline \multicolumn{2}{|c|}{ Strain rate: $0.001 / \mathrm{s}$} & \multicolumn{4}{c|}{ High-strain analysis } \\
\hline Specimen type & S4 & S1 & S2 & S3 \\
\hline Material & Relative measurement uncertainty in apparent E, percent \\
\hline Alpha & 27 & 12 & 8 & 9 \\
\hline C & 37 & 17 & 9 & 9 \\
\hline
\end{tabular}

Table 11. Error analysis of apparent Young's modulus in the $0.001 / \mathrm{s}$ test, low-strain analysis. Note that for Alpha material the high-strain analysis is more appropriate for obtaining the apparent $\mathrm{E}$, while for the $\mathrm{C}$ material the low-strain analysis is more appropriate. (This table is from our Aug 2016 progress report.)

\begin{tabular}{|c|c|c|c|c|}
\hline \multicolumn{2}{|c|}{ Strain rate: $0.001 / \mathrm{s}$} & \multicolumn{3}{c|}{ Low-strain analysis } \\
\hline $\begin{array}{c}\text { Specimen } \\
\text { type }\end{array}$ & $\mathrm{S} 4$ & $\mathrm{~S} 1$ & $\mathrm{~S} 2$ & $\mathrm{~S} 3$ \\
\hline Material & \multicolumn{3}{|c|}{ Relative measurement uncertainty in apparent E, percent } \\
\hline Alpha & 61 & 41 & 17 & 18 \\
\hline C & 73 & 26 & 18 & 16 \\
\hline
\end{tabular}


Figure 19 summarizes the total measurement error in the apparent $\mathrm{E}$ for the low-rate test in graphical form. As with the error in UTS, the errors are highest for the smallest (S4) specimens due to higher uncertainty in measuring smaller strains, as well as less-straight sidewalls from fabrication. Also as with the UTS, the errors are lower for the Alpha material than for the $\mathrm{C}$ material.

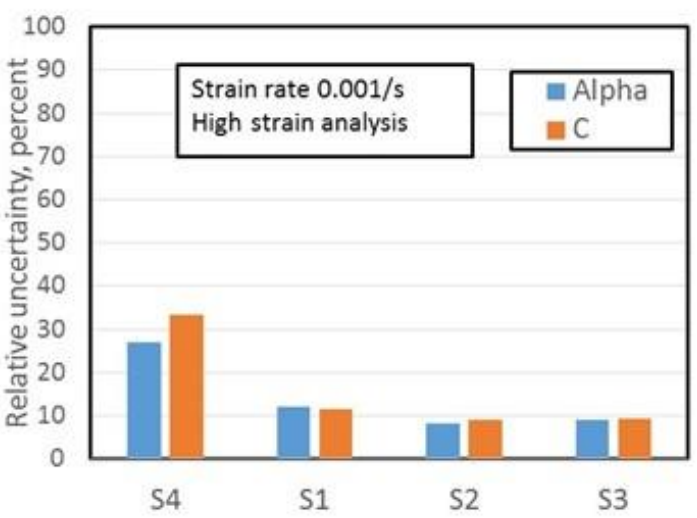

(a)

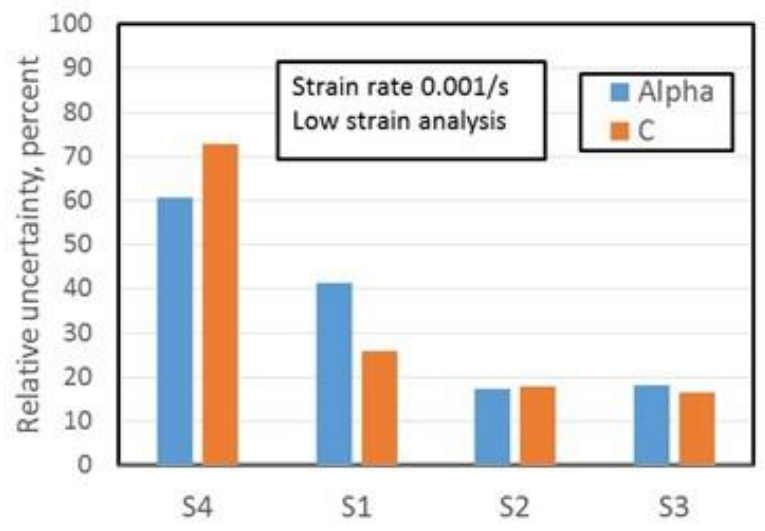

(b)

Figure 19. Graphical representation of the measurement uncertainties in apparent $E$ for each specimen type in the 0.001/s test, when analyzed using (a) the high strain analysis, and (b) the low strain analysis. Note that for Alpha-S2 and Alpha-S3, the error in apparent $\mathrm{E}$ when using the high-strain analysis is under 10 percent. (These figures are from our August 2016 progress report to ARDEC.)

Note from Figure 19 above that for the Alpha-S2 and Alpha-S3 specimens in the 0.001/s test, the measurement error in apparent $\mathrm{E}$ is $<10$ percent. If the specimen material were constant (i.e. no microplasticity) this might be sufficient to obtain the apparent $\mathrm{E}$ from the tensile test. But in reality the LIGA alloy itself is not repeatable due to microplasticity thus a measurement error under 10 percent is still insufficient to measure the apparent E. For all other specimen sizes our measurement error is so large, particularly for the S4 specimens, that even if the specimens did not have any microplasticity we would still not recommend obtaining the apparent $\mathrm{E}$ from the micro tensile test.

Figure 20 shows the contributions of individual factors to the total error, for the low-rate test. The two extremes of specimen types are shown; similar graphs for all other specimen types are in Appendix $\mathrm{H}$. These graphs show that the largest contribution to the error in Young's modulus is the error in strain measurement resulting from the error in $d u$. As expected, this error in $d u$ is higher for the smaller specimens because of fewer pixels in the gauge section, and for the 'low-strain analysis' (because the displacements are smaller in the low strain region).

Also note that the $\mathrm{C}-\mathrm{S} 4$ specimens have larger error in force than the bigger specimens, because of their very low elastic displacements and corresponding low forces $(<10 \mathrm{~N})$. The same test set-up was used for all specimen geometries, so the large errors for the S4 specimens in principle could be reduced somewhat by altering the set-up to accommodate 
the smaller specimens, such as use of a higher magnification objective on the microscope to reduce the error in $d u$, and a smaller load cell to reduce the uncertainty in the measured force.

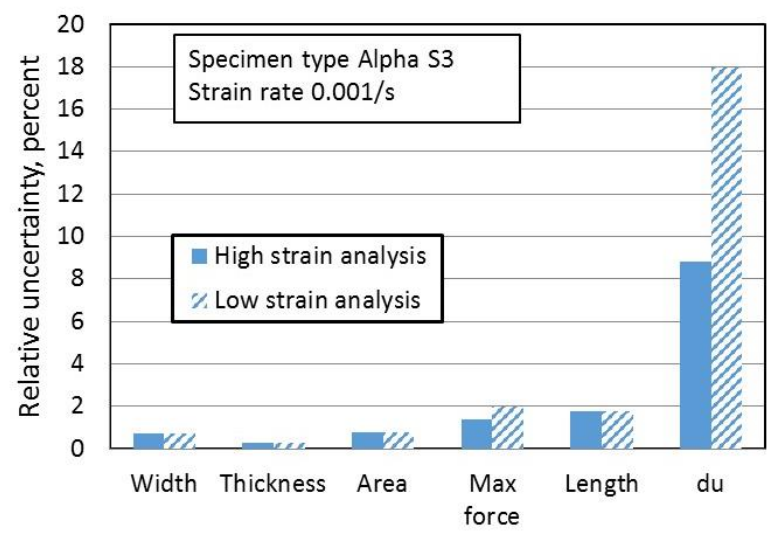

(a)

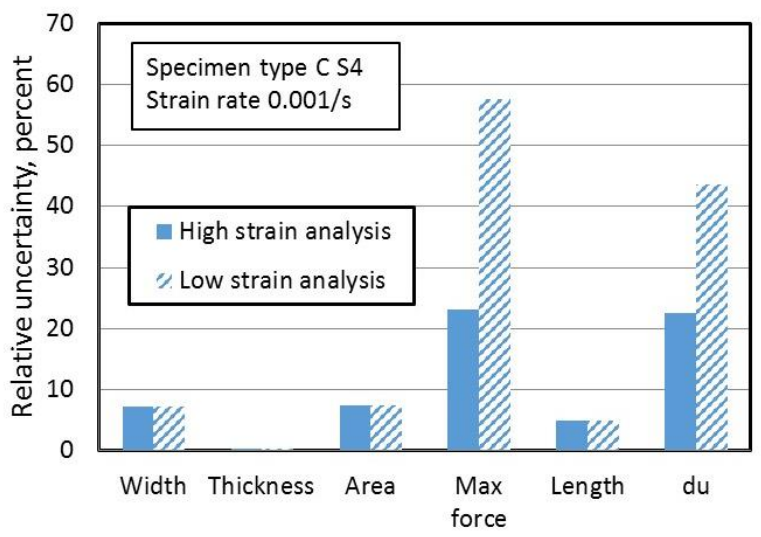

(b)

Figure 20. Contributions to the error in apparent E for (a) Alpha-S3, and (b) C-S4, for the 0.001/s test. (Graphs are from our August 2016 progress report to ARDEC.)

Table 12 and Figure 21 show the calculated errors in the apparent E for the medium-rate test. These values are for 1 standard deviation or a 68 percent confidence level. For 2 standard deviations or 95 percent confidence level, multiply these values by 2 . The errors are larger for the Alpha material because of a systematic shift in experimental procedure during the $1 / \mathrm{s}$ tests. In the $1 / \mathrm{s}$ test set-up, the high-speed camera is on a wheeled cart and the magnification can be adjusted by positioning the camera closer to the specimen, i.e., the magnification of the images is not automatically set, unlike in the 0.001/s test set-up which takes place under an optical microscope. During the period when the $\mathrm{C}$ specimens were tested, the camera was positioned closer to the specimens than during the period of Alpha testing which was 2 months earlier, thus the $\mathrm{C}$ specimen tests had consistently higher magnification images. With more pixels in the gauge lengths, the measurement errors in length and $d u$ are lower for the $\mathrm{C}$ than for the Alpha specimens.

Overall, though, the errors in apparent E for the medium-rate test are extremely high, much higher than for the low-rate test, and as such we do not recommend obtaining apparent $\mathrm{E}$ from the $1 / \mathrm{s}$ tensile test. This is a reflection primarily on the inadequate resolution of our high-speed camera for measuring the extremely small strains in the elastic region of these small specimens. Table 13 summarizes the measurement errors and statistical variations for both materials and both testing rates. 
Table 12. Error analysis of apparent Young's modulus in the $1 / \mathrm{s}$ test, not including the error contributed from the synchronization issue. (This table is from our August 2016 progress report to ARDEC.)

\begin{tabular}{|c|c|c|c|c|}
\hline Strain rate & \multicolumn{4}{|c|}{$1 / \mathrm{s}$} \\
\hline $\begin{array}{c}\text { Specimen } \\
\text { type }\end{array}$ & $\mathrm{S} 4$ & $\mathrm{~S} 1$ & $\mathrm{~S} 2$ & $\mathrm{~S} 3$ \\
\hline Material & \multicolumn{4}{|c|}{ Relative measurement uncertainty, in apparent E, percent } \\
\hline Alpha & 126 & 81 & 50 & 82 \\
\hline C & 63 & 75 & 67 & 69 \\
\hline
\end{tabular}

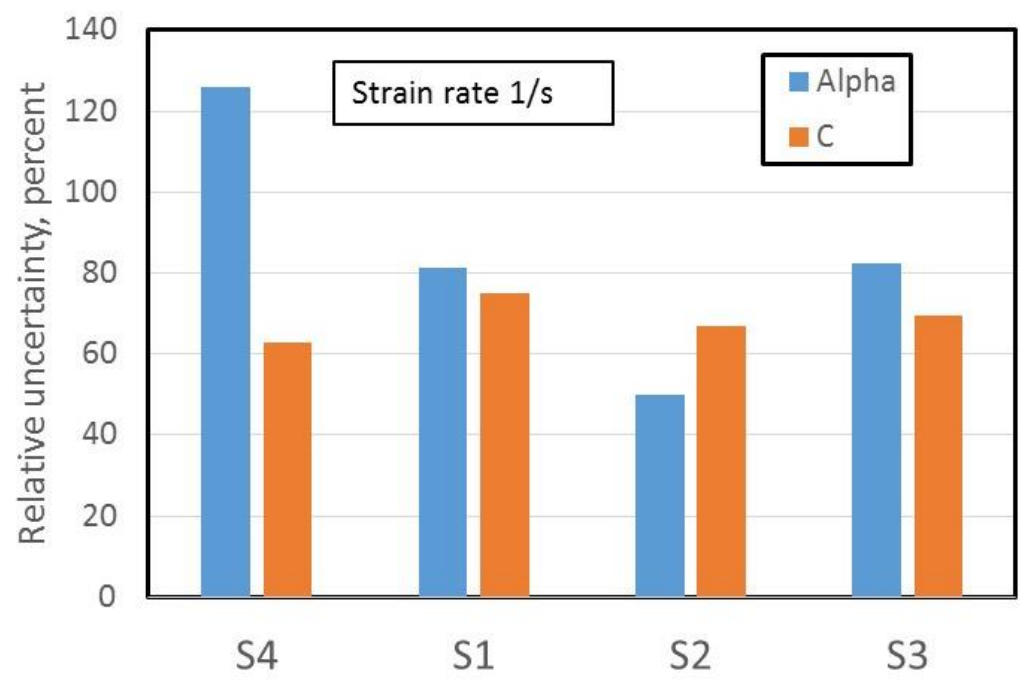

Figure 21. Graphical representation of the errors in apparent E, tested at strain rate 1/s. (This figure is from our August 2016 progress report to ARDEC.) 
Table 13. Summary of measurement uncertainties and statistical variations in the apparent Young's modulus, by specimen type and strain rate. The high strain analysis is reported for the Alpha material at rate $0.001 / \mathrm{s}$. The low strain analysis is reported for the $\mathrm{C}$ material at rate $0.001 / \mathrm{s}$.

Comparison of measurement uncertainty and statistical variation in the measured apparent Young's modulus

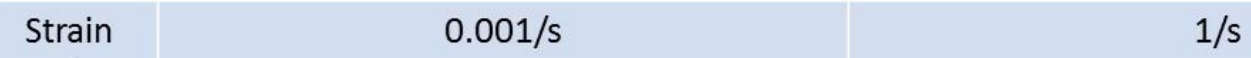

\begin{tabular}{c|c|c|c|c|}
$\begin{array}{c}\text { Material } \\
\text { type }\end{array}$ & Uncertainty & $\begin{array}{c}\text { Statistical variation } \\
\text { (Standard deviation) }\end{array}$ & Uncertainty & $\begin{array}{c}\text { Statistical variation } \\
\text { (Standard deviation) }\end{array}$ \\
\hline Alpha & $\begin{array}{c}<13 \% \text { excluding S4 } \\
\text { (S4: } 27 \%)\end{array}$ & 9.2 & $\begin{array}{c}<50-80 \% \\
\text { excluding S4 }\end{array}$ & 23.4 \\
\hline
\end{tabular}

(S4: $27 \%)$

(S4: 126\%)
C
$<16-26 \%$
22.1
$<50-80 \%$
22.7

(S4: 73\%)

We conclude that our test set-ups are not accurate enough for measuring the Young's modulus of LIGA alloys as part of a tensile test. For Alpha-S2 and Alpha-S3 specimens tested at rate $0.001 / \mathrm{s}$, the measurement errors are under 10 percent but microplasticity in the LIGA material is still a problem. For all other specimen categories, the measurement errors alone are too high. Dynamic methods as recommended in [2] are a possible alternative.

Finally, the measurement errors for the $1 / \mathrm{s}$ tests of the $\mathrm{C}$ material are actually even higher than in Table 12 and Figure 21 because of an additional source of uncertainty. This is the error associated with uncertainty in synchronizing the stresses and strains, and is discussed in the next section along with a proposed approach to quantify that error and to reduce it.

\subsection{Synchronization Issues in the $1 / \mathrm{s}$ Tests of $\mathrm{C}$ Specimens}

All the 1/s tests on the $\mathrm{C}$ material had an additional source of measurement uncertainty in the strain values used to obtain the apparent Young's modulus that is not accounted for in the total errors reported in the preceding section. This uncertainty is due to synchronization of the stresses and strains. In the 1/s test set-up, the force values and their acquisition times are recorded on the computer that controls the load frame. The images are recorded on a separate computer that controls the high speed camera. The two computers are connected by an electronic trigger which causes the camera software on the second computer to stop recording images when the load frame computer detects a significant decrease in force. However, the exact timing between the acquisition of images and forces is not consistent because each computer runs on its own internal clock and the exact time of the stop pulse is not recorded on the load frame computer. Therefore, synchronization between the forces and images had to be done manually during post-processing of the data. Our procedure is 
to use the time of specimen fracture as the point of synchronization as this is an event that should be readily identified both in the force data as the time when the force goes to zero and as the first image to show the specimen being broken.

However, while this procedure was straightforward for the Alpha material tests, with the $\mathrm{C}$ specimens there is some uncertainty in identifying exactly at which image the specimen fracture occurs. This is due to the extreme ductility of the $\mathrm{C}$ material. Figure 22 shows the data recording the failure process for a $\mathrm{C}$ specimen in the low-rate test (where the forces and images are automatically synchronized as both are recorded on the same computer). As shown in the figure, necking results in the formation of ligaments that become progressively thinner until the ligament eventually breaks while the force gradually decreases to zero. Contrast this with Figure 23 which shows an Alpha specimen of the same design. The Alpha material is much more brittle and fractures clearly and abruptly with much less necking.
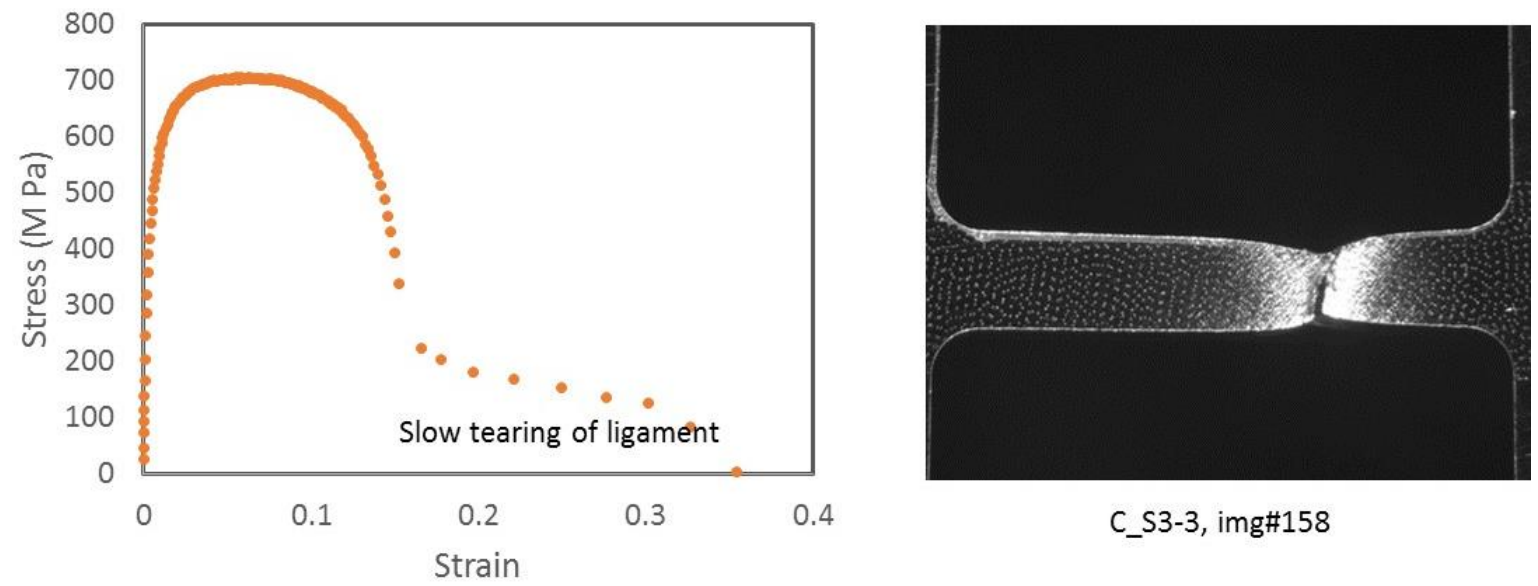

C_S3-3, img\#158

Figure 22. Engineering stress-strain curve of specimen C_S3-3 tested at strain rate 0.001/s, and photograph of the specimen just before fracture, showing the ductility of the $\mathrm{C}$ material. (This figure is from our July 2016 progress report to ARDEC) 

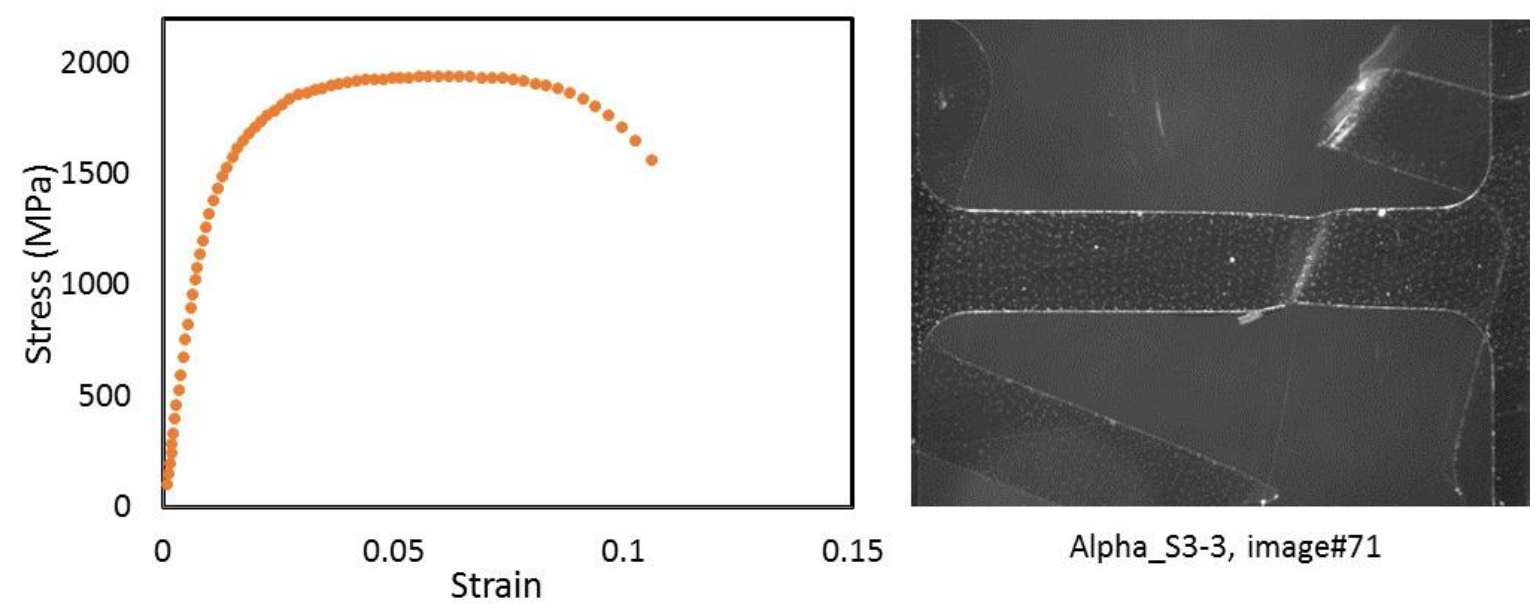

Figure 23. Engineering stress-strain curve of specimen Alpha_S3-3 tested at strain rate $0.001 / \mathrm{s}$, and photograph showing the specimen breaking. The recoil of the specimen that is seen within the exposure time of about 162 milliseconds shows the abruptness of the fracture. (These figures are from our April 2016 progress report to ARDEC.)

In Figure 22 above, the ligament formed in the $\mathrm{C}$ specimen can be clearly seen. But in the $1 /$ s test set-up with a lower-resolution camera, the images are far less clear. Figure 24 below shows a typical $\mathrm{C}$ specimen in the 1/s test, around the time of fracture. This series of images illustrates the difficulty in identifying exactly at which image (and thus which time) the fracture occurs. Since in our procedure the stresses and strains in the $1 / \mathrm{s}$ test are synchronized with respect to the time of the fracture, the uncertainty in choosing the correct image therefore leads to an uncertainty in synchronization. 

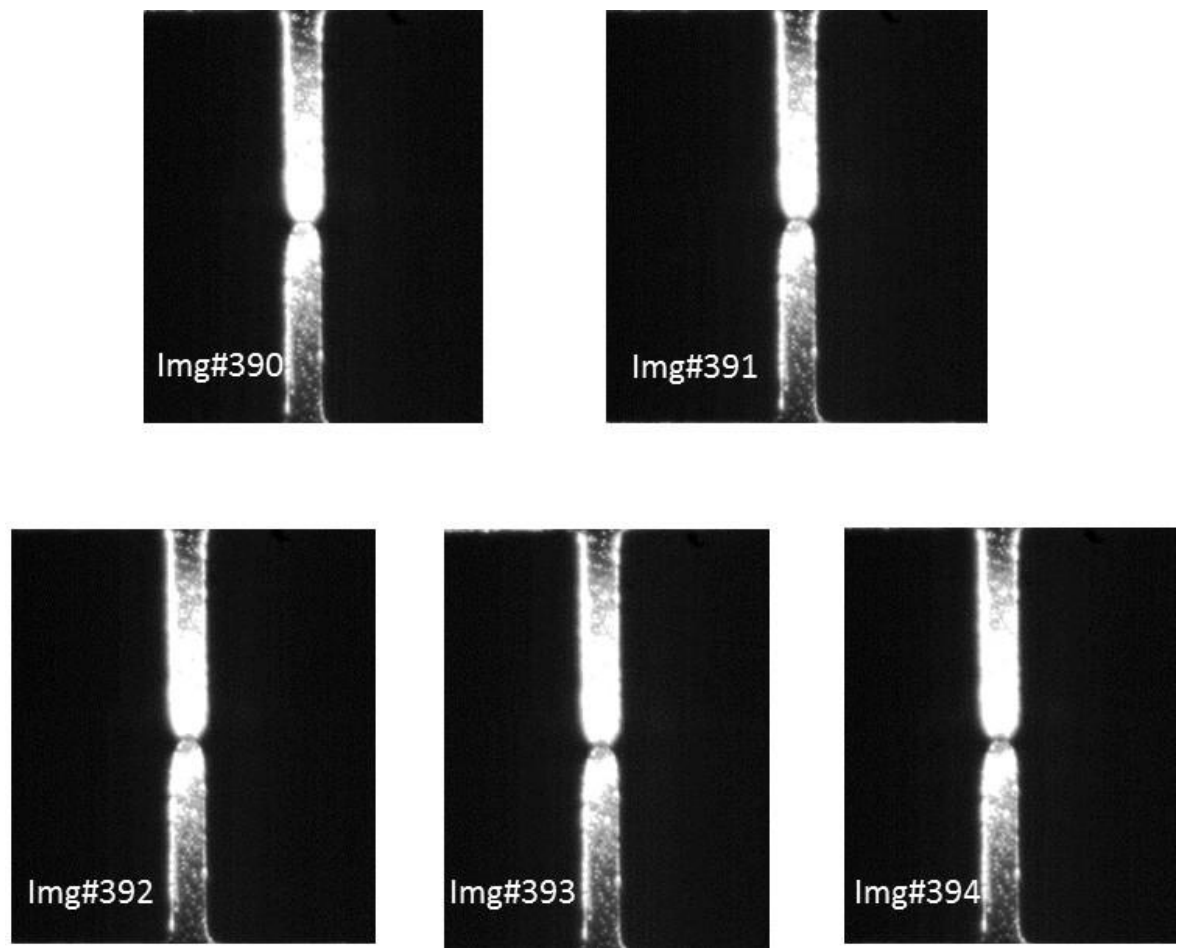

Figure 24. Sequence of images from test of specimen MTS_C_S1-4, during the time of fracture. This series of images illustrates the ambiguity in identifying exactly at which image the specimen break occurs, and thus which image should be synchronized with the force's transition to force $=0$. This range of images corresponds to an uncertainty in time of failure of 3.3 milliseconds as the time between images is 0.67 milliseconds. (This figure is from our July 2016 progress report to ARDEC.)

While the uncertainty in synchronization does not affect the measurement of the UTS, it can lead to significant differences in the linear part of the stress-strain curve if the synchronization is offset by just one image, as illustrated schematically in Figure 25. 
Example:

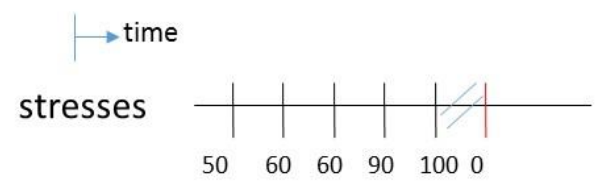

Images

(strains)
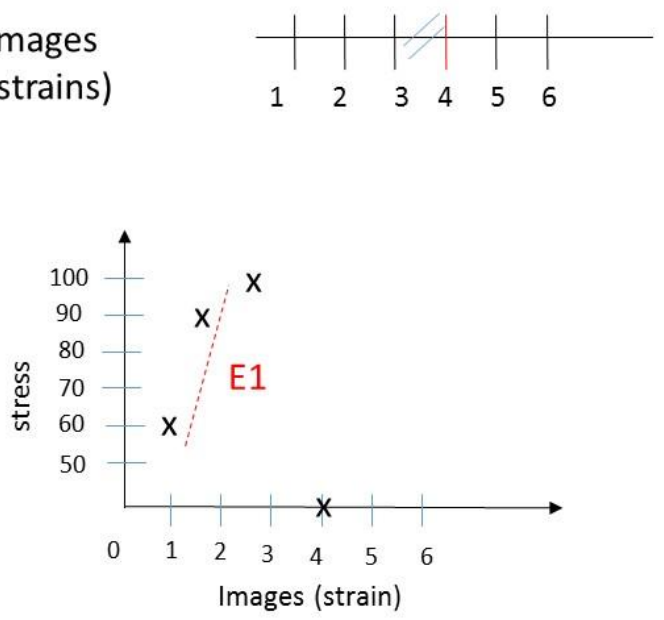

Images shifted by -2:
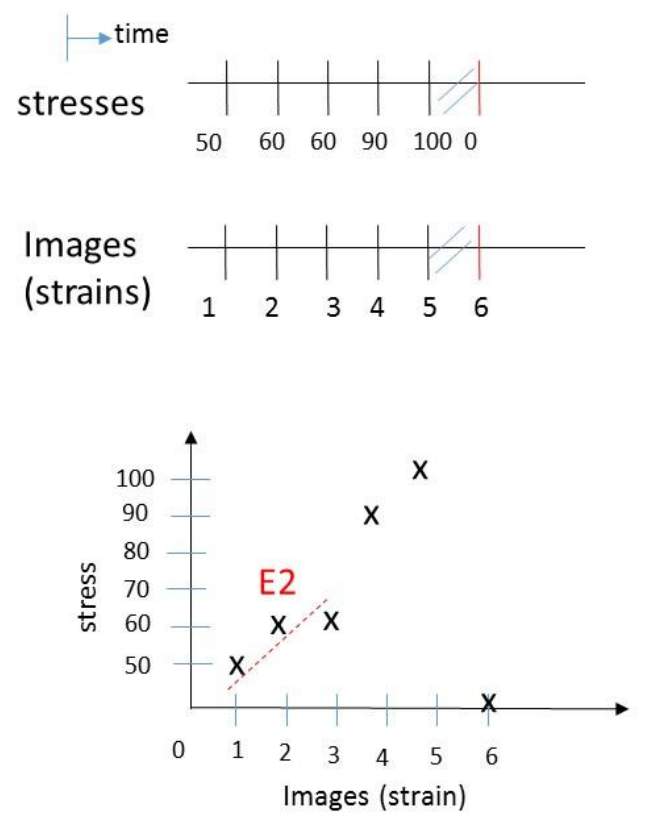

Figure 25. Schematic illustrating how synchronizing the forces to different images in the sequence will lead to different values of the apparent Young's modulus. (This figure is from our July 2016 progress report to ARDEC.)

Figure 26 shows one of our specimens with different apparent E values when the synchronization is offset by a few images in the analysis. In principle, this "image-shifting analysis" could be applied to every $1 / \mathrm{s} \mathrm{C}$ test, but it would still be questionable unless sufficiently supported by the data. 


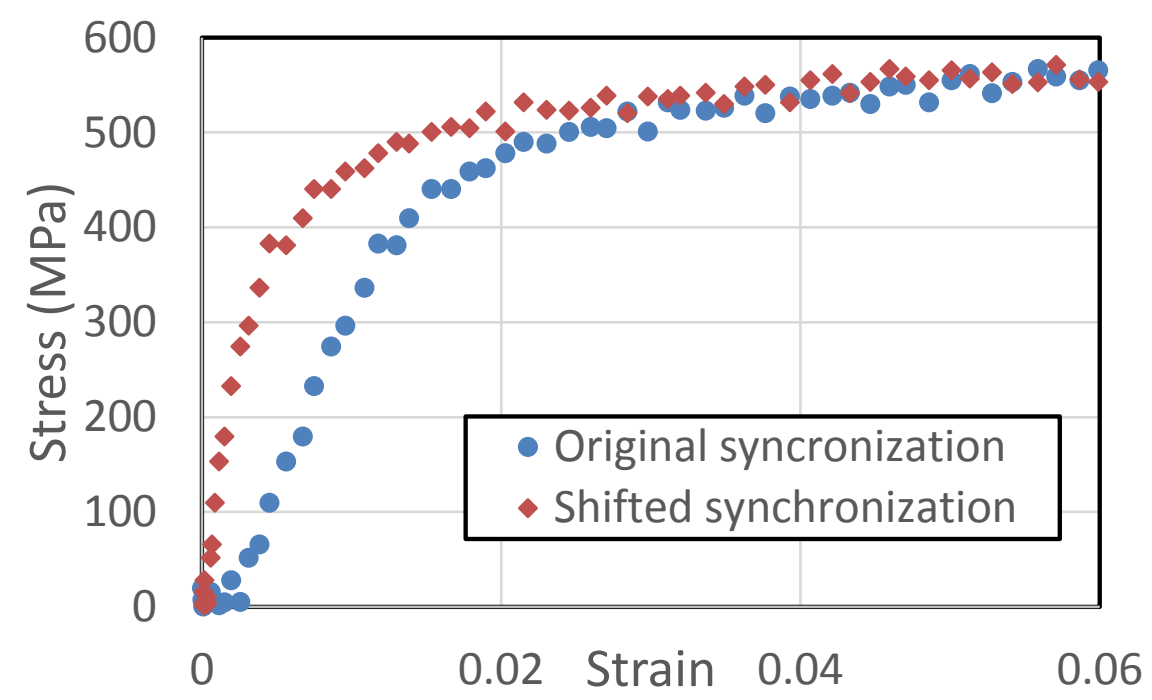

Figure 26. A specimen with image-shifting analysis. The apparent Young's modulus is about $43 \mathrm{GPa}$ for the original analysis, and about $129 \mathrm{GPa}$ when the images are shifted by -7 images. (This figure is from our July 2016 progress report to ARDEC.)

This synchronization issue does not occur in the $0.001 / \mathrm{s}$ tests because for that test set-up the images and forces are recorded on the same computer and are thus automatically synchronized. This issue also does not occur for the 1/s test of the Alpha specimens, because the Alpha material is more brittle thus there is little to no ambiguity in identifying the exact image where the specimen breaks. Therefore, the synchronization error occurs only for the $1 / \mathrm{s}$ tests of the $\mathrm{C}$ material, and the error associated with it is an additional error contributing to the total error in the apparent $\mathrm{E}$.

Below we describe an approach to quantify this error associated with synchronization for the 1/s tests of the $\mathrm{C}$ material. This error could then be added in quadrature to the errors in the stress and $d u$ and length as previously calculated, to find the synchronization contribution to the total error in apparent Young's modulus. 
Proposed Approach to Quantify Error in Synchronization for 1/s Tests of C Material

Since the error in synchronization is basically an error in identifying at which image the specimen fractures, the proposed approach to quantify this error is as follows, using specimen MTS_C_S1-4 as an example (its stress-strain curve is in Appendix F):

Step 1: the series of images that make up the DIC sequence are visually inspected, and the range of images that might correspond to the specimen break are identified. For MTS_C_S1-4, the forces were synchronized based on choosing image\#391 as the failure point, but from visual inspection it was determined that any of the images from 391 to 397 could also be where the specimen broke. There is therefore a range of -7 images that could be used for the synchronization. i.e., the uncertainty in number of images is 7 images in the negative direction. (The direction being 'negative' refers to the images after the one currently used for the synchronization. This is because synchronizing the forces to a later image has the effect of pushing the earlier images backwards with respect to the forces they are currently aligned to, as illustrated in Figure 25 above.)

Step 2: In the analysis file for that specimen, the raw strain of $\sim 0.001$ is used to determine a nominal point on the curve in the elastic region, with the corresponding stress, and used to calculate the relative uncertainties in stress, $d u$ and length as described in the earlier sections. For MTS_C_S1-4, we synchronized the break to image\#391 to construct the stress-strain curve. A raw strain of 0.001142 corresponds to image\#242.

Step 3: The number of ambiguous images is then counted back from the image corresponding to raw strain $\sim 0.001$. The raw strain corresponding to this last image is identified from the stress-strain analysis file. For MTS_C_S1-4, the number of ambiguous images is -7. Counting back 7 images from image\#242 (which corresponds to strain 0.001142 ), leads to image\#235 which corresponds to a raw strain 0.000118 . The difference between the raw strain 0.001142 and the 0.000118 , is then calculated. This is 0.001025 for this example. This is the absolute uncertainty in strain due to the uncertainty in image synchronization. In other words, while the individual stress values stay the same and likewise the strain values (from DIC) stay the same, the uncertainty is in which strains line up with which stresses. Therefore, if for MTS_C_S1-4 the images are shifted by -7 images, then such a shift corresponds to a possible change in strain by up to $(0.001142-0.000118)$ at that same stress.

Step 4: The total raw strain that comprises the specimen's linear elastic region is found, by choosing the raw strain data point on the stress-strain curve where the curve is definitely not linear anymore. This may be done by visual inspection of the curve, or by calculating the instantaneous slope at each point on the curve and selecting the strain at which the instantaneous slope drops significantly. For MTS_C_S1-4, this is a raw strain of 0.013015 . Step 5: Finally, the relative error in strain due to synchronization is then calculated as the strain in step 3 divided by the total strain in step 4. For MTS_C_S1-4, this results in a relative uncertainty of 7.9 percent. 
This relative error in strain due to synchronization should then be added in quadrature to the previously calculated error in strain due to the uncertainties in $d u$ and length, as well as the uncertainty in stress, to calculate the new total error in apparent Young's modulus.

This calculation was repeated on another specimen, MTS_C_S3-1. The range of ambiguous images was determined as -5 , not by visual inspection of the images but by inspection of the stress-strain curve and shifting the images until the stresses and strains at the beginning curve rise simultaneously. (This assumes the specimen was not physically shifting in the clevises or 'bedding in' at the start of the test.) The corresponding relative error in strain due to synchronization for this specimen is calculated at 8 percent.

\section{$\underline{\text { Proposed Method of Reducing the Stress versus Strain Synchronization Error }}$}

The synchronization error arises because the stress values come from the force data record produced by the force cell of the servo-hydraulic testing machine, while the strain values are obtained from DIC of images recorded by the high-speed camera. These two instruments are only approximately synchronized electronically, only to within several milliseconds. As described in the previous section, a different synchronization setting produces a different stress-strain curve, because the pairing between the stress and strain values is different. While the overall shape of these curves is practically the same, different synchronization settings result in significant differences in the apparent Young's modulus. Two approaches were considered to improve the synchronization. The first was to choose the synchronization setting that resulted in the highest value of $\mathrm{E}$; this was rejected because it could bias the results, particularly when it is already unclear what the true value of $\mathrm{E}$ should be due to microplasticity effects. The second is presented in detail here.

The stress and strain data are both time series. The effective sample rate is set by the frame rate of the high-speed camera (1500 frames per second). Both data records begin with a series of constant (within experimental uncertainty) values that is followed by a series of increasing values. The values are constant before the grips engage and load the specimen, and increase as the specimen is loaded in tension. In well-behaved tests, it is observed that the transition from constant to increasing values can be localized to within approximately plus or minus one data point (that is, one image). If it were assumed that the stress and strain values should simultaneously make the transition from constant to increasing values, then this simultaneity could be used to set the synchronization between the two data records to within plus or minus one data point.

Figure 27 shows experimental stress and strain data for specimen MTS_C_S3-1, plotted together, with the different synchronization settings indicated in each plot legend. For this data set the setting of -5 appears best, with -4 and -6 also being possible choices. This synchronization method does not involve choosing among $E$ values, but it does require the assumption that the stress and strain rise at the same time. Applying this method changed the apparent $\mathrm{E}$ for this specimen by approximately a factor of 2 , from about $80 \mathrm{GPa}$ (corresponding to the original analysis) to about $160 \mathrm{GPa}$ (with the shift). 

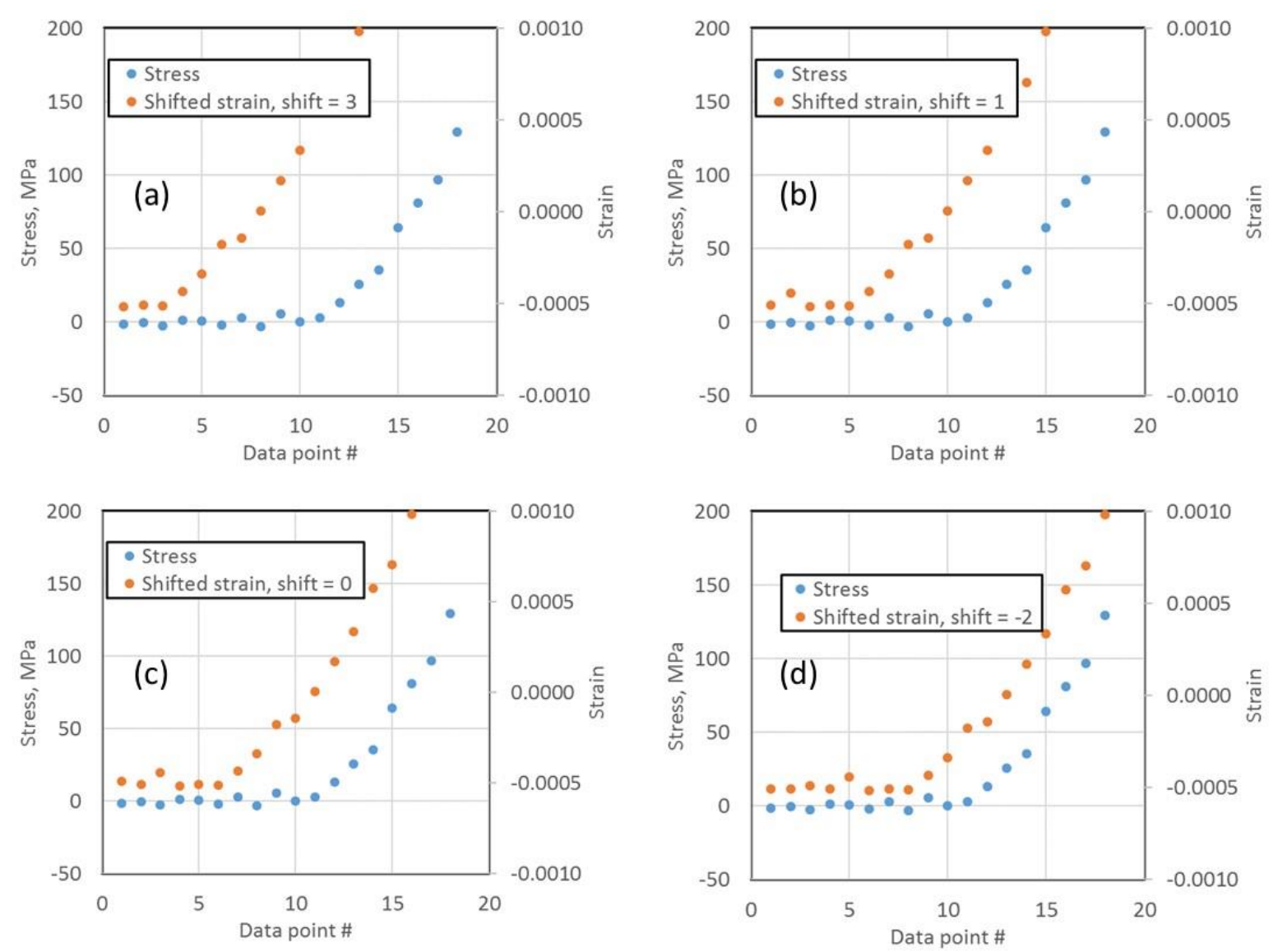

Figure 27. Beginning of stress-strain curve for MTS_C_S3-1, with images shifted by different amounts until the forces and strains rise from non-zero simultaneously. 

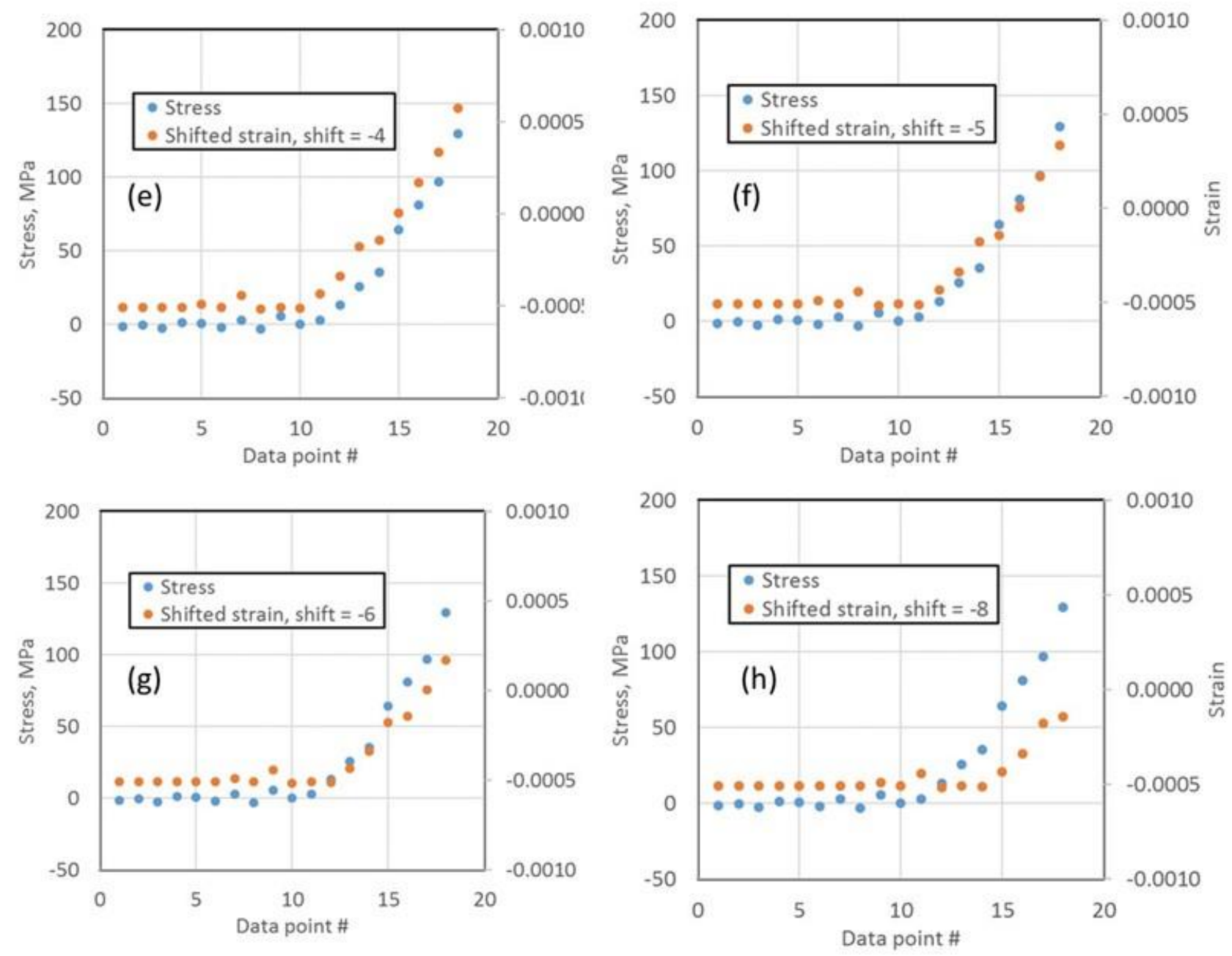

Figure 27 (continued). Beginning of stress-strain curve for MTS_C_S3-1, with images shifted by different amounts until the forces and strains rise from non-zero simultaneously. 


\section{Discussion of Difficulty in Measuring Young's Modulus from Tensile Tests}

From the preceding sections it is clear that while we have low measurement errors and statistical uncertainties in the UTS, the opposite is true for the apparent Young's modulus. We first reported the difficulty with measuring E on the dummy specimens during the Task 1 performance period in October 2015 [1], and again during July-August 2016 on the real specimens. Not only do we observe large variation in the apparent $\mathrm{E}$ across specimens, but there is the possibility for large variation in apparent $\mathrm{E}$ for each individual specimen depending on data analysis procedures, even when synchronization issues do not apply. This section explains why our difficulty in obtaining the apparent $\mathrm{E}$ from our micro tensile tests is not unique.

In the mechanical testing community, it has been established that the tensile test is not a reliable way for measuring a material's Young's modulus, even for conventional largescale tests performed according to tensile testing standards [2, 3]. This is contrary to the expectations of most design, structural and application engineers. The problems are exacerbated for micro scale tensile tests, and furthermore on materials that have microplasticity such as LIGA materials. Therefore, it is not surprising that our errors and statistical variations in apparent $\mathrm{E}$ are large.

The National Physical Laboratory in the UK has published the Measurement Good Practice Guide for measuring Young's modulus by use of different methods [2]. In this document they explain that the tensile test (according to ASTM and international tensile testing standards) is not a reliable method for measuring the Young's modulus, and that the E is the tensile property that has the most variation. They recommend using dynamic methods or modified loading/unloading methods to measure E, and on larger specimens than the standard, so that low strains can be measured more accurately.

According to the NPL Guide, the practical difficulties associated with obtaining E from a tensile test include:

1) Specimen alignment and shifting in the grips at the start of the test. These effects can be difficult to eliminate completely, and yet can distort the stress-strain curve at the small stresses and strains characteristic of the elastic region.

2) Accuracy of the force and strain measurement instruments, in particular the strain measurement. In a tensile test the specimen is loaded until failure, but the elastic region is a much smaller portion of the total strain. A strain measurement technique that measures the total strain to fracture is unlikely to have the resolution to also accurately measure the much smaller strains in the elastic region. A static test to measure Young's modulus should consist of loading and unloading the specimen at the very small stresses and strains corresponding to the elastic region, so that the load cell and strain measurement instrument (typically an extensometer for standard tensile tests) can be matched in size and resolution to the small stresses and strains. It is recommended that larger specimens be used as well, so that the displacements are larger. 
3) Data analysis methods. Even though fitting a straight line to the data seems straightforward, in reality different fitting procedures can lead to different slopes. NPL reports that in a recent European Union study where the same raw data was analyzed by different EU participants using different analysis procedures, up to 16 percent variation in Young's modulus was obtained.

The above issues become more extreme as the size of the specimen decreases. For example, for micro specimens, the small strains in the elastic region correspond to very small displacements. While we measure these displacements with DIC (other researchers working on micro tensile testing also use DIC or laser interferometry), these very small displacements can be severely affected by physical shifting of the specimen in the grips at the start of the test, and sub-pixel image correlation has a certain uncertainty level, taken here as 0.2 pixel.

For the above reasons, NPL [2] and ASM International [3] recommend that Young's modulus could be more accurately measured by dynamic methods. Alternatively, NPL also recommends using a modified static test that consists of loading and unloading a largerthan-standard specimen, at low stresses and strains, and with strain measured with an extensometer ranged for the small strains (as opposed to performing a full tensile test). Application of these improvements to our microscale tests, however, is not straightforward. For example, we could reduce our measurement uncertainty by approximately a factor of two by increasing the magnification so that the full field of view is utilized. Such use of a higher magnification objective, however, does not lead to significantly higher sensitivity in strain measurement. If, on the other hand, a specimen could be fabricated that were large enough to accommodate observation by two objective lenses, one for each end of the modified gauge length, significant reductions in uncertainty in strain - and in Young's modulus - may be possible.

Another contribution to the variability in apparent $\mathrm{E}$ in the present results is specimen repeatability. It is widely reported in the MEMS literature that the material properties of microfabricated components can vary (sometimes significantly) from one fabrication run to another, and even within the same fabrication run. Mechanical test structures are often included on a wafer as a way to monitor the material properties for each wafer in-situ. For electroplated thick films such as in the LIGA process, the plating current density can vary across the wafer depending on factors such as the composition of the plating bath, the shape and size of the electrodes, and the amount and nature of agitation of the bath. For example, Collins et al [10] found their tensile properties varied significantly across the wafer, as shown in Figure 28. They found that their LIGA Ni alloy exhibited an apparent Young's modulus of 80-110 GPa before their "cyclic stabilization" and up to $170 \mathrm{GPa}$ following cyclic stabilization. 


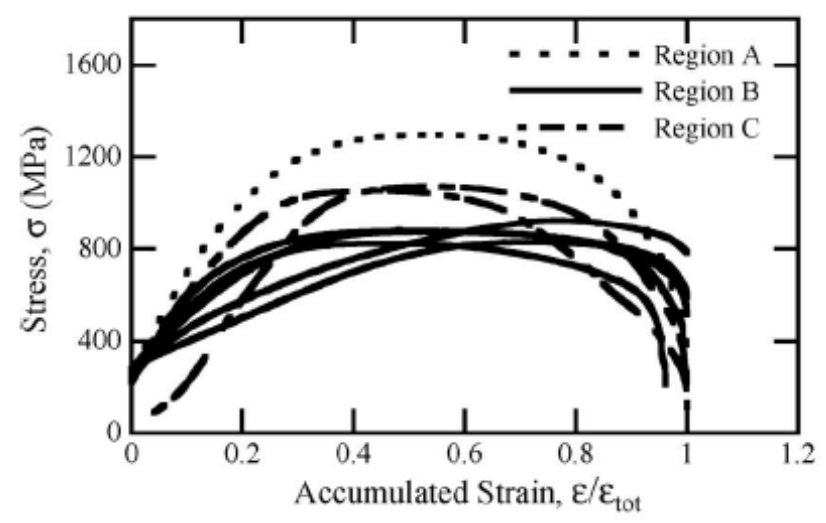

Figure 28. Figure 7 from Collins et al. [10] from micro tensile testing of a LIGA Ni alloy. Each "region" is a different location on the wafer. The specimen gauge section was 550 $\mu \mathrm{m}$ long, $120 \mu \mathrm{m}$ wide, and had thickness of 25 and $35 \mu \mathrm{m}$.

During the Task 1 performance period we attempted to measure the apparent E on the dummy specimens by loading/unloading them at low stresses, though without increasing the magnification, see our Task 1 report [1]. Those tests were not conclusive due to the large measurement uncertainties and because the LIGA Ni materials in their as-deposited state do not have stable microstructure and can exhibit microplasticity $[10,11]$ and "cyclic stabilization" [10]. The consequence of the material instability is that the measurement process changes the apparent E. In fact, Collins et al recommended that all LIGA MEMS components be cyclically loaded ahead of time to stabilize their elastic properties before being deployed, similar to the "burn in" of microelectronics devices. Sharpe et al [11] used the extreme low-stress regions from their tensile curves, 50-100 MPa, for the linear fit to obtain the E for their LIGA Ni specimens, because of the tendency of their LIGA Ni alloys to yield at stresses higher than this.

Note that while we are certainly not the only researchers to perform tensile tests on microfabricated LIGA Ni alloys (there are many papers in the literature over the last two decades on micro tensile testing of LIGA materials), from surveying the literature we found few papers which report the measurement errors in the tensile properties, and particularly the errors in the Young's modulus, along with the measured values. Most papers we found report the Young's modulus by giving a range of values, or by reporting a central value with $+/$ - range but without explanation for how this range was derived. Many papers that report Young's modulus or UTS from the tensile test do not even report any uncertainties. Given the large volume of literature on LIGA Ni tensile properties, it is possible that there are more papers such as Mazza et al [16] that quantify the measurement errors and separate them from the statistical variations, but we have not found them as it does not appear to be the norm.

We have found that our measurement error in apparent Young's modulus ranges from 9 percent to over 100 percent depending on the combination of material, specimen size, and testing rate. This is independent of the material repeatability, which has statistical 
variations comparable to or even lower than the measurement error for the various combinations of material/geometry/rate.

Considering that our test methods do not differ substantially from that of recent and contemporary works, and that we are using state of the art commercial load frames and cameras, it is doubtful that other researchers would have had significantly more accurate measurement capabilities than us. This observation may help to put into perspective other literature values of Young's modulus of LIGA materials in micro tensile tests and account for some discrepancies in the literature values.

Our study in the errors and uncertainties in apparent $E$ also support our decision to use the Young's modulus obtained from dynamic test methods by the fabrication vendor.

\section{Effects of Low-Temperature Annealing on Tensile Properties}

In preparation for possible future studies on the effect of temperature on the mechanical behavior of our LIGA alloys, we undertook an investigation of the effects of lowtemperature annealing on the Alpha and C materials' tensile properties at the low strainrate. Unlike some studies in the literature on LIGA materials in which annealing is at temperatures above $400{ }^{\circ} \mathrm{C}$, we annealed the specimens at up to $280{ }^{\circ} \mathrm{C}$. All specimens were annealed for 1 hour unless otherwise stated in the following graphs. All specimens in this study were from the second "dummy" fabrication run, and were of the S1 design.

The annealing was done in air at temperatures $160{ }^{\circ} \mathrm{C}$ and $275^{\circ} \mathrm{C}$. A separate oven was used to anneal at $280{ }^{\circ} \mathrm{C}$ in vacuum. The heating in the air oven took about 10-15 minutes, while for the vacuum oven it took about 30 minutes. After the anneal period, the air oven was cooled to about $100{ }^{\circ} \mathrm{C}$ over $10-15$ minutes and then the specimens were removed from the oven. For the vacuum oven (at $280{ }^{\circ} \mathrm{C}$ ), the oven was cooled to $150{ }^{\circ} \mathrm{C}$ over 45 minutes, then the oven was vented to air until it reached $100{ }^{\circ} \mathrm{C}$, and then the specimens were removed from the oven.

It was noted that the Alpha specimens annealed at $275{ }^{\circ} \mathrm{C}$ and $280{ }^{\circ} \mathrm{C}$ developed a reddish color on the non-gold-coated side, with the vacuum-annealed specimen $\left(280{ }^{\circ} \mathrm{C}\right)$ being less red. This leads us to speculate that the reddish color was due to oxidation. None of the $\mathrm{C}$ specimens exhibited any color change.

Following annealing, the specimens were tested at room temperature at strain rate $0.001 / \mathrm{s}$. The specimens were preloaded to about 10 percent of $F_{\max }$ before the test. Figures 29 to 32 show the stress-strain curves for the annealed specimens, compared with un-annealed specimens from the same dummy fabrication run. 


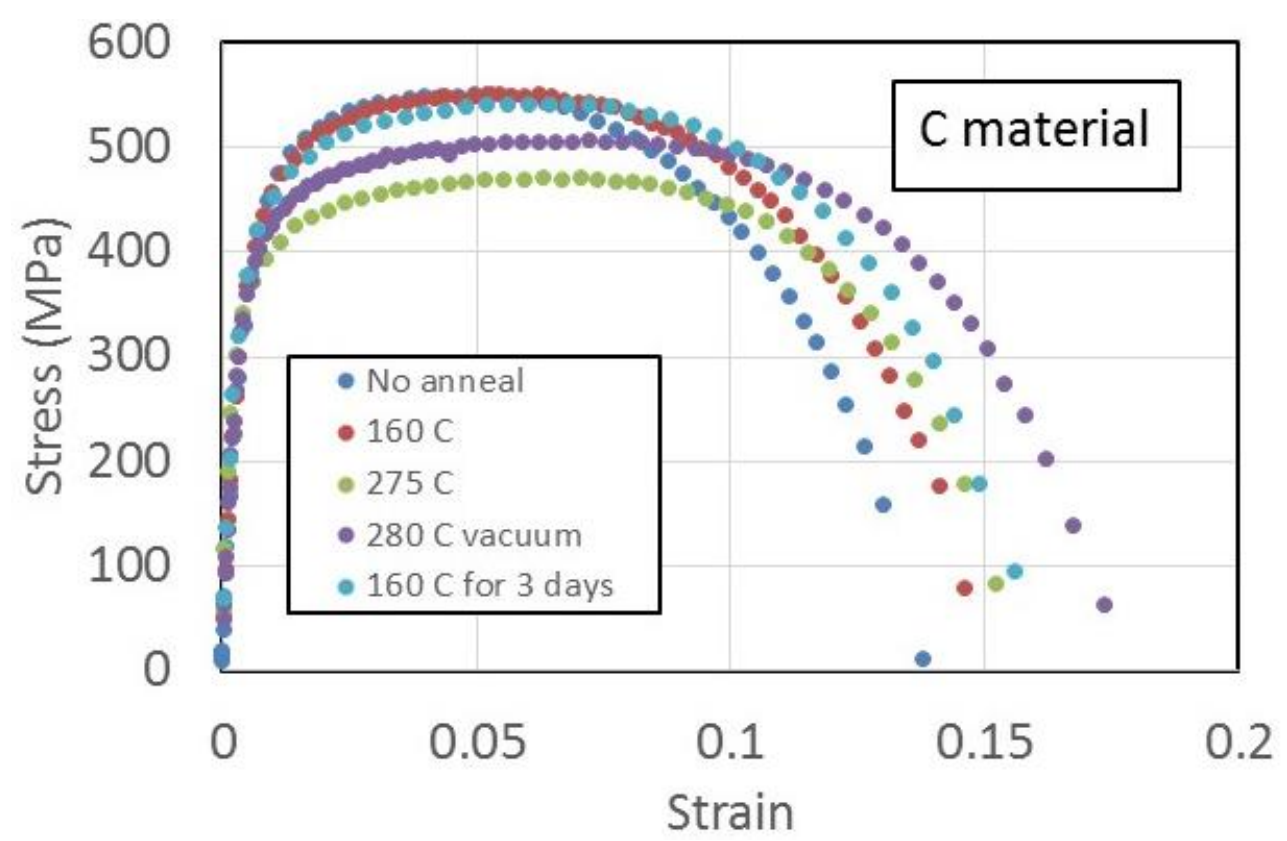

Figure 29. Engineering stress-strain curves of the annealed dummy $\mathrm{C}$ specimens. Unless otherwise stated, the annealing time was 1 hour in air. (This figure is from our May 2016 progress report to ARDEC.)

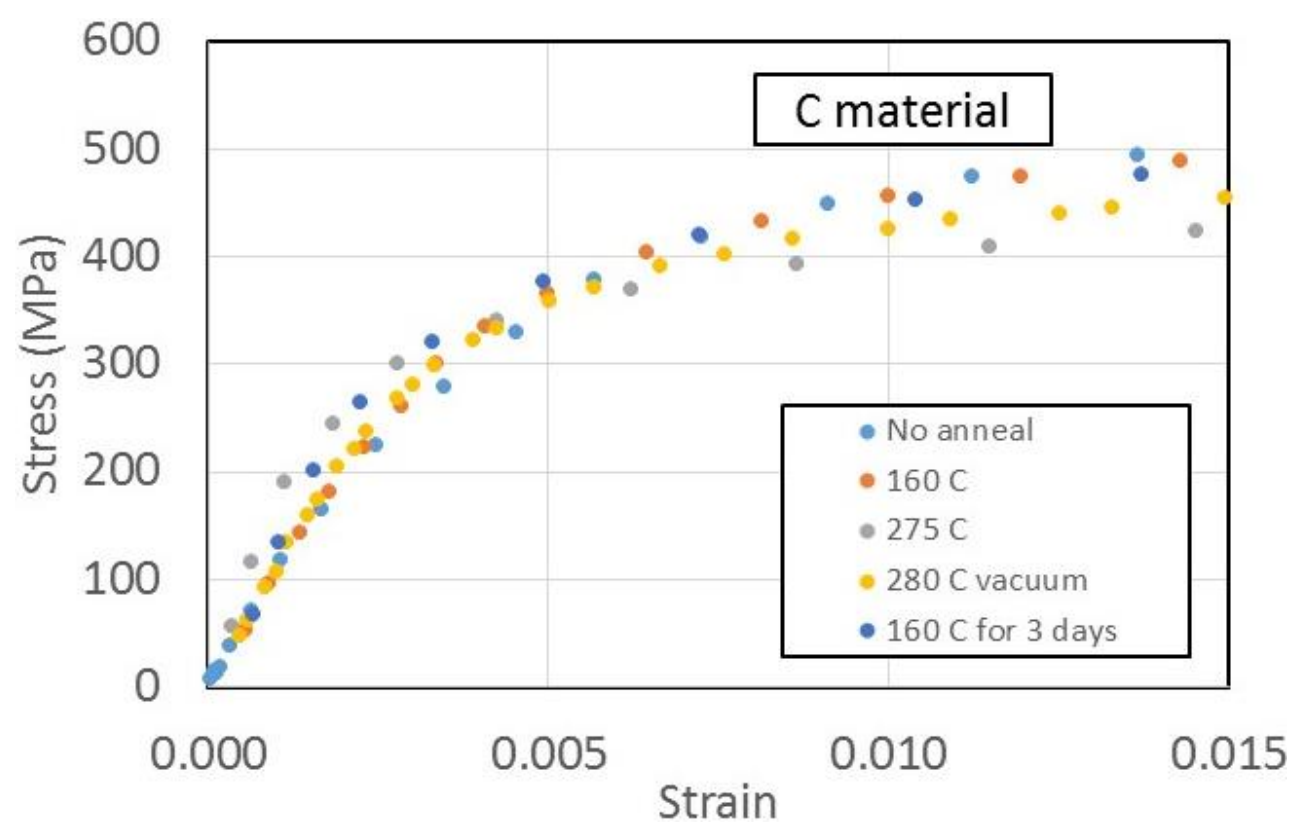

Figure 30. Initial portion of the stress-strain curves of annealed dummy $\mathrm{C}$ specimens. 


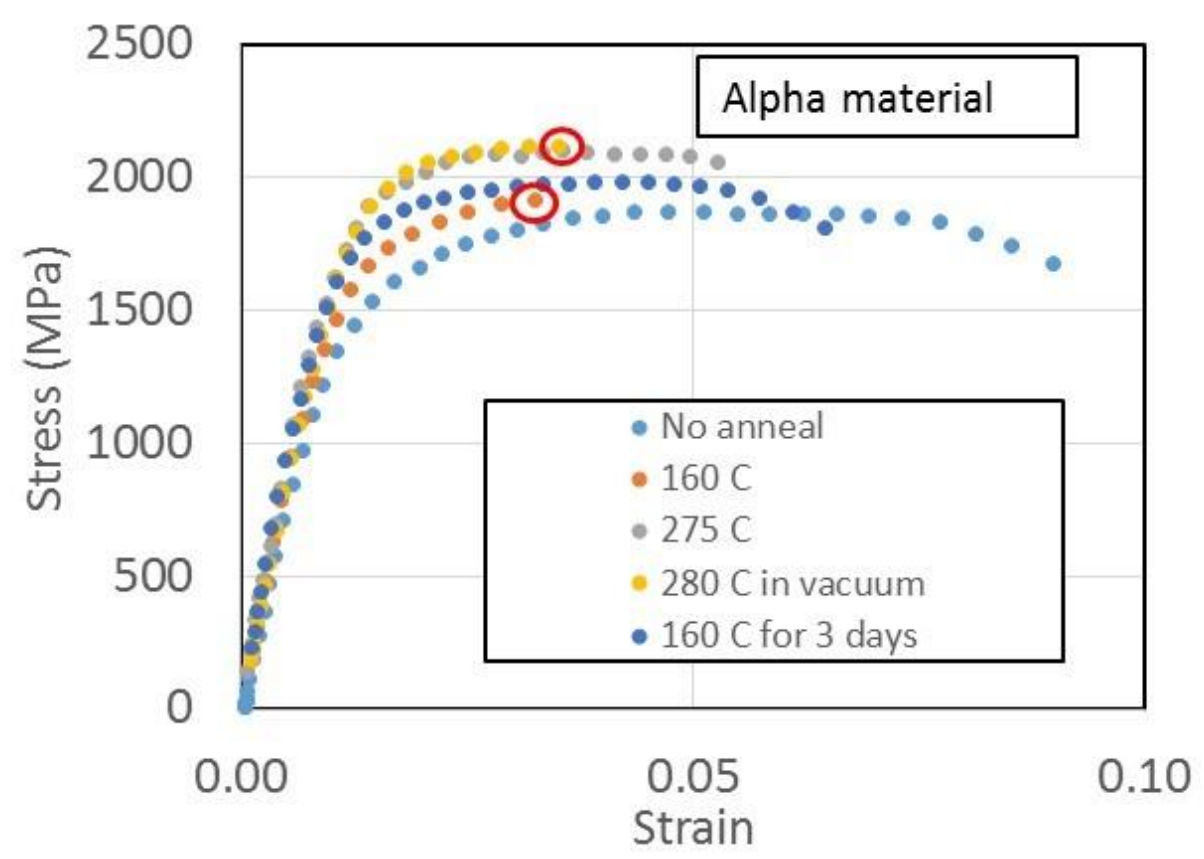

Figure 31. Engineering stress-strain curves of the annealed dummy Alpha specimens. Red circles indicate that the specimen failed near a stress concentration. Unless otherwise stated, the annealing time was 1 hour in air. (This figure is from our May 2016 progress report to ARDEC.)

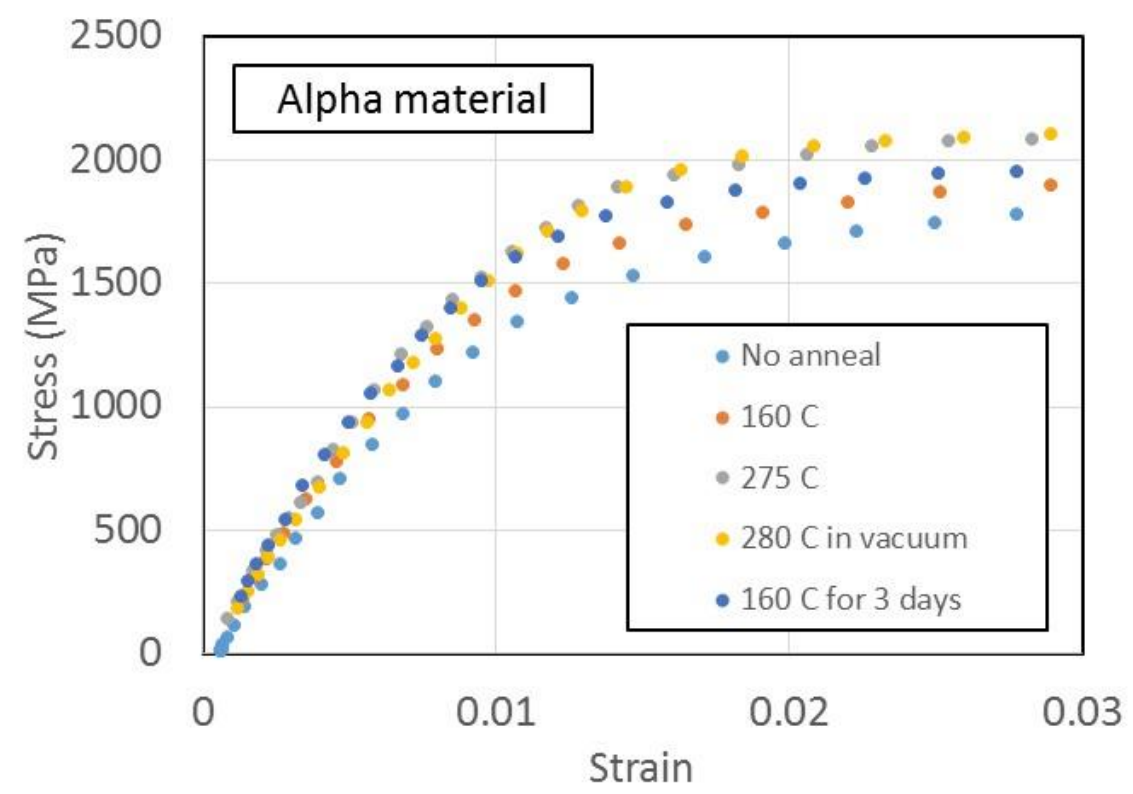

Figure 32. Initial portion of the stress-strain curves of the annealed dummy Alpha specimens. 
As shown in the above figures, for the $\mathrm{C}$ material annealing lowers the UTS and increases the ductility, this effect being more significant at temperatures above $160{ }^{\circ} \mathrm{C}$. This response is as expected for relatively pure ductile metals because annealing can lead to grain growth. Since grain boundaries impede dislocation motion and the associated plastic deformation, grain growth would lead to fewer obstacles to dislocation motion, thus lowering the strength. Note that at the anneal temperature of $160{ }^{\circ} \mathrm{C}$, increasing the time from 1 hour to 3 days did not significantly lower the strength, but it did increase the ductility.

The annealing effect on the Alpha material was more surprising to us. Annealing increased the strength and lowered the ductility, opposite to the $\mathrm{C}$ material. We speculate this could be due to precipitation hardening or due to the unusual strengthening mechanisms used in the Alpha material. The circles on Figure 31 indicate that the specimen broke at the stress concentrations. (Stress concentrations were discussed in Section 3.3 above and found to be insignificant for the as-deposited specimens.) All other specimens broke in the center of the gauge section. Only specimens of the Alpha material displayed this notch sensitivity, none of the $\mathrm{C}$ specimens did. Furthermore, for the Alpha material the anneal at $160{ }^{\circ} \mathrm{C}$ leads to significant change in the UTS and ductility. Therefore, storage at $160{ }^{\circ} \mathrm{C}$ may be an issue for the Alpha material.

Both materials appear to exhibit increased apparent Young's modulus from annealing, presumably due to stabilization of the microstructure.

In the literature, LIGA Ni specimens of sizes comparable to our S3 specimens have been found to exhibit reduction in room-temperature UTS after annealing due to grain growth $[7,8]$.

We therefore conclude from this study on annealing effects, that annealing at temperatures up to $280{ }^{\circ} \mathrm{C}$ result in lowered strength and increased ductility for the $\mathrm{C}$ material, and the opposite effect for the Alpha material. In addition, storage at $160{ }^{\circ} \mathrm{C}$ may be an issue for the Alpha material.

\section{SEM/EBSD Imaging of the Microstructure}

The microstructure of metals, which includes crystal structure, grain size and shape, and crystallographic texture and also the size and distribution of inclusions if present, has a strong influence on the mechanical properties. Correlations between "structure", meaning, microstructure, and properties are valuable to both users and producers of metals as a source of information about the properties that can be expected from particular instances of a metal and clues to how to adjust the manufacturing or fabrication process to improve the resulting product. Although detailed microstructural studies are outside the scope of the present project, we consider it desirable to investigate the microstructure of the specimen materials supplied to us by ARDEC to the extent feasible. In the course of this study, the microstructure of one material type was imaged, as follows. 
The technique we used is called electron backscatter diffraction (EBSD). This is an application of the scanning electron microscope (SEM) that has been improving in practicality over the past few decades. Use of the SEM allows investigation of finer structures than can be resolved in the optical microscope. The electron diffraction patterns that can be captured allow identification of the crystal structure and delineation of the grains. Achieving these results depends on the preparation of a microscopically flat and undeformed surface on a conductive specimen. This is a nontrivial task, especially for the small and thin specimens of the present study.

A specimen of LIGA "B" material was ground flat, mechanically polished, and electrochemically etched to prepare it for the EBSD procedure. A SEM equipped with hardware and software for EBSD was used to produce electron back scatter patterns from thousands of points located in a systematic grid pattern. These were processed to give the crystallographic structure and orientation and "pattern quality" at each point. While the crystal structure on the present specimen is constant throughout, the orientation changes from grain to grain. By a systematic false color plotting of the orientation at each point, the grain structure can be visualized. The utility of the pattern quality is similar; it is measurably reduced where the electron beam is diffracted off a region where the crystal structure is disturbed or variable, such as at a grain boundary. Mapping this quantity over the surface of the specimen can produce an image of the grain structure.

The image of the LIGA "B" material is shown in Figure 33. Generally speaking, the grain structure shown is similar to results found in the literature. The main results of this exercise for us was finding out that the present specimens can be investigated by SEM/EBSD, but that this is a non-trivial task. Previous researchers have reported EBSD studies of the grain structure of LIGA Ni alloys as well [8].

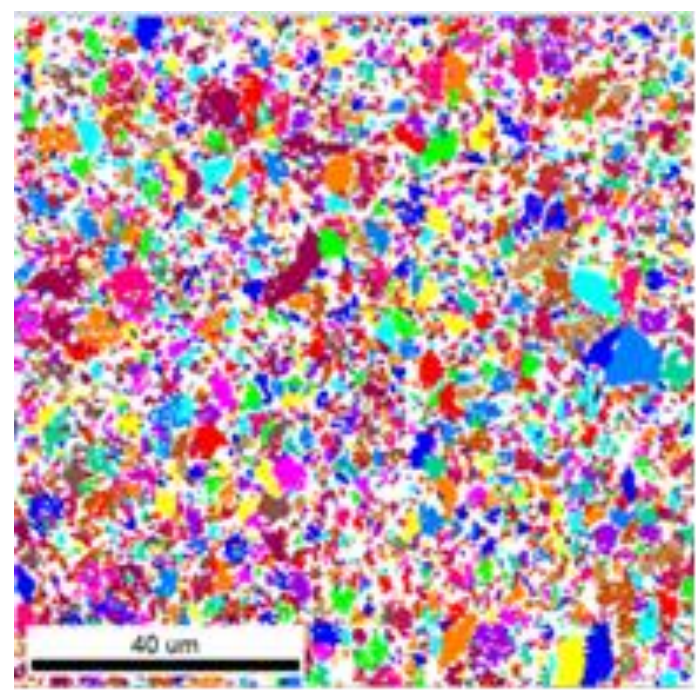

Figure 33. In-plane electron backscatter map of a first run dummy specimen of the "B" material. 


\section{Conclusion}

During the Task 2 performance period we conducted tensile tests on 2 materials, over 4 specimen sizes, and at two strain rates within the quasi-static range, $0.001 / \mathrm{s}$ and $1 / \mathrm{s}$. The specimens were fabricated by a commercial vendor. We report the full engineering stressstrain curves for each specimen as well as values for UTS, apparent Young's modulus and yield strength of each specimen and when averaged over all specimens.

The Alpha material is very strong, with UTS over $1900 \mathrm{MPa}$, and with consistent strength over several fabrication runs of the material. The $\mathrm{C}$ material has lower strength, but still comparable to many structural metal alloys, and is more ductile. The UTS of all specimen types (material/geometry/rate) was measured to within 15 percent, which includes both measurement error and statistical variations among specimens. For most of the specimen types the total uncertainty in UTS was less than 3 percent. The Alpha material shows a slight rate effect but no noticeable size effect on the UTS. The C material shows both rate and size effects on the UTS. The largest uncertainty in UTS arises from the possible measurement error for the gauge section width, but this is generally under 2 percent for Alpha specimens excluding the smallest (S4) design, and under 3 percent for all $\mathrm{C}$ specimens excluding the S4 design. With the smallest specimens included, the uncertainty is about 10 percent. Therefore, we feel confident in our measurement of the UTS.

The Young's modulus (E), however, was not reliably obtained using the present micro tensile tests. We quantified the measurement errors and statistical uncertainties in the apparent E across all combinations of material/geometry/testing-rate. The measurement error is under 10 percent for the larger Alpha specimens in the $0.001 / \mathrm{s}$ test, but is much higher for all other combinations of material/geometry/rate. Overall, our measurement error in apparent $\mathrm{E}$ ranges from 6 percent to over 100 percent for the different material/geometry/rate categories, the worst being the $C$ material in $1 / \mathrm{s}$ tests of the smallest (S4) specimens. The biggest source of error in apparent $\mathrm{E}$ is the error in the measured strain, in particular the specimen stretch measured from digital image correlation. The $1 / \mathrm{s}$ tensile tests on the $\mathrm{C}$ material also had an additional source of measurement error due to synchronization of the stresses and strains; we proposed a method to quantify this error and to reduce it during post-processing of the raw data.

However, even if the measurement errors in $\mathrm{E}$ could be reduced from improved test procedures, the LIGA materials also exhibit microplasticity which leads to considerable statistical scatter in the apparent E, and the E can and does change from the test as well due to cyclic stabilization. This has been confirmed in the literature by other researchers as well.

In the macro-testing community, it is well-documented that the tensile test is not a reliable method for measuring the Young's modulus, and the reasons apply and are exacerbated at the micro scale. It is recommended by the National Physical Laboratory in the UK [2] that dynamic measurements be used for measuring Young's modulus. This supports our 
decision to use the $\mathrm{E}$ values for the Alpha and $\mathrm{C}$ materials as obtained by the fabricator using dynamic methods.

We also conducted a study in preparation for possible future work, into the effects of lowtemperature annealing on the room-temperature tensile properties. We found that annealing at up to $280{ }^{\circ} \mathrm{C}$ lowered the strength and increased the ductility of the $\mathrm{C}$ material but had the opposite effect on the Alpha material. Finally, we also obtained an image of the "B" material's grain structure using SEM/EBSD, the results are similar to that found in the literature. 


\section{References}

[1] L.A. Liew, D. Read, N. Barbosa, "Joint Fuze Technology Program, Task 1 report from NIST: Test Method Development and Test Plan," submitted to U.S. Army ARDEC on November 1, 2015. Not publicly released.

[2] J.D. Lord and R. Morrell, Measurement Good Practice Guide No. 98: Elastic Modulus Measurement. National Physical Laboratory, UK, 2006.

[3] Tensile Testing, $2^{\text {nd }}$ Ed. ASM International, 2004.

[4] D. T. Read, "Tension-tension fatigue of copper thin films," Int. Journal of Fatigue, Volume 20, no. 3, pp. 203-209, 1998.

[5] C.A. Neugebauer, "Tensile properties of thin, evaporated gold films," J. App. Phys, Vol 31, no. 6, pp. 1096-1101, 1960.

[6] W.N. Sharpe, B. Yuan, R. Vaidyanathan, R.L. Edwards, "Measurements of Young's modulus, Poisson's ratio, and tensile strength of polysilicon," Proceedings of the $10^{\text {th }}$ International IEEE Conference on Micro Electro Mechanical Systems (MEMS '97), pp. 424-429, 1997.

[7] K. Hemker, H. Last, "Microsample tensile testing of LIGA nickel for MEMS applications," Mat. Sci. Eng. A, vol 319, pp.882-886, 2001.

[8] T.E. Buchheit, D.A. LaVan, J.R. Michael, T.R. Christenson, S.D. Leith, "Microstructural and mechanical properties investigation of electrodeposited and annealed LIGA nickel structures," Met. Mat. Trans. A., Vol. 33, pp. 539-554, 2002.

[9] R. Schwaiger, J.T. Reszat, K. Bade, J. Aktaa, O. Kraft, “A combined microtensile testing and nanoindentation study of the mechanical behavior of nanocrystalline LIGA NiFe," Int. J. Mat. Res., Vol 100, no. 1, pp. 68-75, 2009.

[10] J.G. Collins, M.C. Wright, C.L. Muhlstein, "Cyclic stabilization of electrodeposited nickel structural films," J. Microelectromechanical Systems, Vol. 20, no. 3, pp. 753-763, 2011.

[11] W.N. Sharpe, D.A. LaVan, R.L. Edwards, "Mechanical properties of LIGA-deposited nickel for MEMS transducers," Proceedings of 1997 International Conference on Solid State Sensors and Actuators (Transducers '97), pp.607-610, 1997.

[12] W.H. Robinson and A. Edgar, "the piezoelectric method of determining mechanical damping at frequencies of 30 to $200 \mathrm{kHz}$," IEEE Trans. Sonics and Ultrasonics, Vol. 21, no. 2, pp.98-105, 1974. 
[13] H. Tanimoto, S. Sakai, H. Mizubayashi, "Anelasticity of nanocrystalline metals," Mat. Sci. Eng.-A., vol 370, pp. 135-141, 2004.

[14] A. Flejszar, A. Mielczarek, G. Vidrich, W. Riehemann, "Amplitude dependent damping in electrodeposited nano-crystalline nickel after various heat treatments," Mat. Sci. Eng.-A, Vol. 521-522, pp. 299-302, 2009.

[15] American Society for Testing and Materials, ASTM E8/E8M, Standard Test Methods for Tension Testing of Metallic Materials, 2013.

[16] E. Mazza, S. Abel, J. Dual, "Experimental determination of mechanical properties of Ni and Ni-Fe microbars," Microsystem Tech., Vol, 2, pp. 197-202, 1996. 


\section{Appendix A: Improvements to Microtensile Test Set-ups}

\section{A-1. Improvements to tensile test at strain rate $0.001 / \mathrm{s}$}

From our Task 1 effort [1] we found that because of the small forces required for the S4 specimens ( $\sim 14 \mathrm{~N}$ for the dummy Alpha-S4 specimens, and $\sim 5 \mathrm{~N}$ for the dummy B- and C-S4 specimens), we needed a load cell with a smaller force range to reduce the force uncertainty so that the S4 specimens' ultimate tensile strength (UTS) can be measured within 15 percent accuracy. (See our Task 1 report for the specimen geometries.) Given the observed variations in fabrication - with higher uncertainties in widths for the S4 geometry and for the $\mathrm{C}$ material versus for the Alpha material - we calculated that the load cell would need a force uncertainty of around $0.5 \mathrm{~N}$ to accommodate the lowest-force specimen, which was the dummy C-S4 specimens. Figure A.1 shows this calculation.

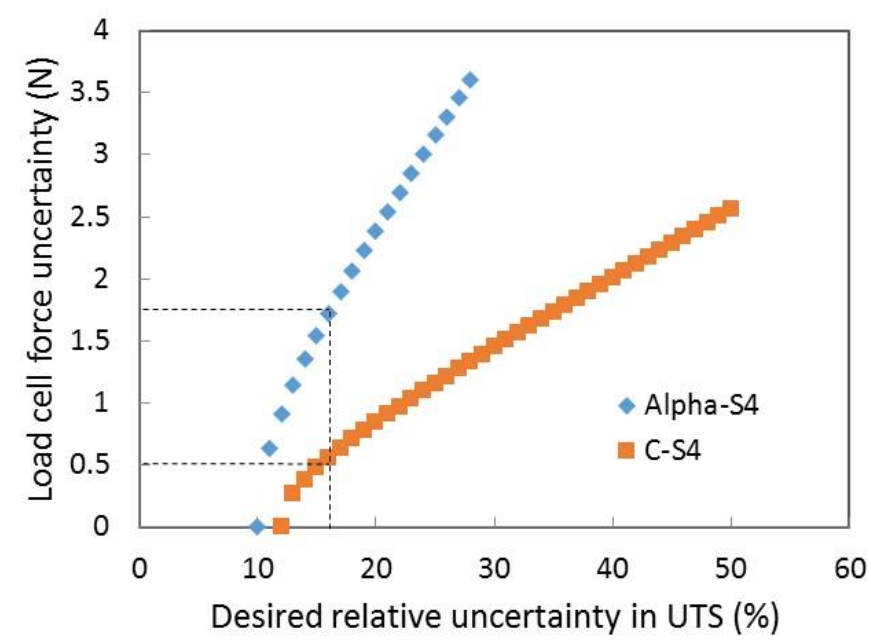

Figure A.1. Calculated required force uncertainty for the load cell, to measure the UTS of the S4 specimens with 15 percent uncertainty. (This figure is from our November 2015 progress report to ARDEC).

We improved the low-rate test set-up by replacing the previous load cell with a newly purchased lower-range load cell. This new load cell has a range of up to $334 \mathrm{~N}$ (75 lbs). We calibrated it with weights according to the same procedure used for the previous load cell (the procedure is described in the Appendix of our Task 1 report [1]).

The calibration data confirmed that it does indeed have a force uncertainty well below 0.5 $\mathrm{N}$ for the low force range appropriate to the $\mathrm{C}-\mathrm{S} 4$ specimens. Three sets of calibration runs were conducted and analyzed according to the procedures described in our Task 1 report. Figure A.2 shows a typical calibration curve. The dead weight masses hung were 200 $2000 \mathrm{~g}$ in increments of $200 \mathrm{~g}$ and a $11.34 \mathrm{~kg}$ (25-lb avoirdupois) deadweight. 


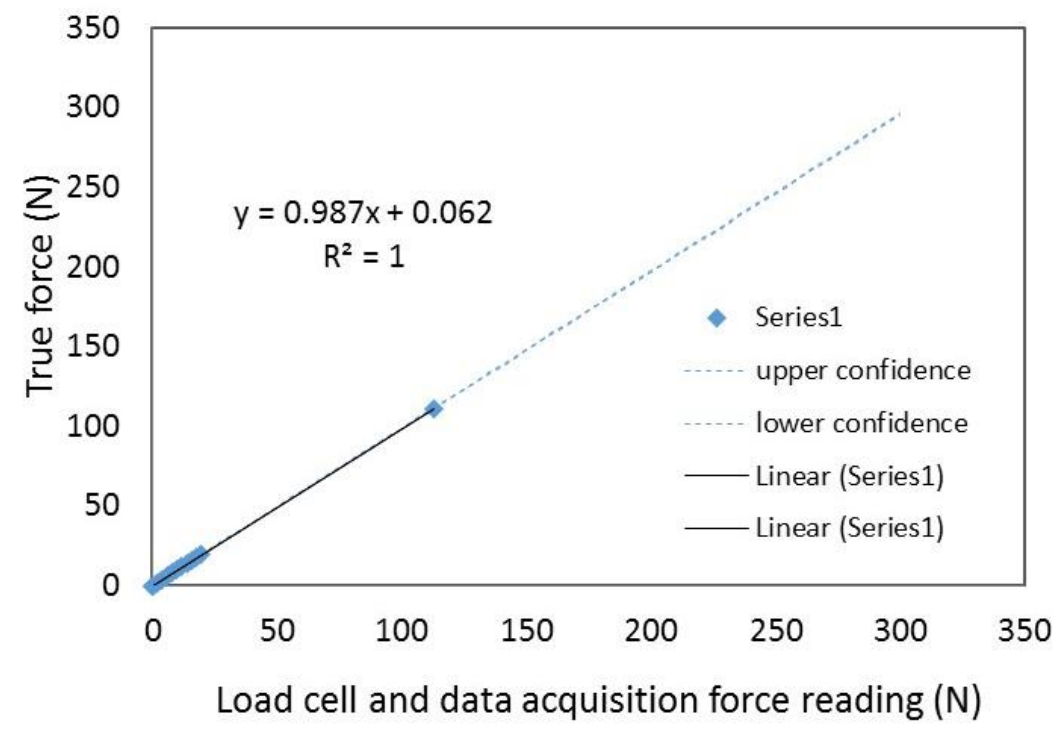

Figure A.2. Calibration run for $334 \mathrm{~N}$ (75-lb avoirdupois) load cell. The dashed lines are the calculated 95 percent confidence intervals (i.e. the force uncertainty.) The slope of the linear fit is the calibration factor, which is close to 1.0

The uncertainty in the calibration factor of 0.99 was calculated as the uncertainty in the linear least squares fit. We used the same procedure as for the previous load cell, described in the Appendix of our Task 1 report.

The force uncertainty for the higher-force ranges, corresponding to the larger specimens, is also well within that needed to measure their UTS to within 15 percent accuracy, see Table A.1. This is a significant improvement over the previous load cell which, according to our Task 1 report, had a force uncertainty of $+/-3.9 \mathrm{~N}$. We calculated a maximum force uncertainty of $0.5 \mathrm{~N}$ for the new load cell, and used this as the absolute force uncertainty for all error analyses of the UTS and apparent Young's modulus, in the $0.001 / \mathrm{s}$ test.

Table A.1. Measured force uncertainty of new $334 \mathrm{~N}$ (75-lb) load cell in the 0.001/s test set-up. The circled row corresponds to the lowest force range needed for the C-S4 specimens (the target force uncertainty for this range was $0.5 \mathrm{~N}$ ).

\begin{tabular}{|l|c|c|c|} 
& $\begin{array}{c}\text { "test 1" } \\
\text { Calibrated using } \\
1-10 \mathrm{~N}\end{array}$ & $\begin{array}{c}\text { "test 2" } \\
\text { Calibrated using } \\
1-20 \mathrm{~N}\end{array}$ & $\begin{array}{c}\text { "test 3" } \\
\text { Calibrated using } \\
1-100 \mathrm{~N}^{*}\end{array}$ \\
\hline Calibration factor & 0.994 & 0.995 & 0.987 \\
\hline Force uncertainty @ 1-10 N & $+/-0.06 \mathrm{~N}$ & $+/-0.06 \mathrm{~N}$ & $+/-0.19 \mathrm{~N}$ \\
\hline Force uncertainty @ 10-100 N & $+/-0.38 \mathrm{~N}$ & $+/-0.18 \mathrm{~N}$ & $+/-0.24 \mathrm{~N}$ \\
\hline Force uncertainty @ 100-200N & $+/-0.77 \mathrm{~N}$ & $+/-0.35 \mathrm{~N}$ & $+/-0.37 \mathrm{~N}$ \\
\hline Force uncertainty @ 200-300N & $+/-1.16 \mathrm{~N}$ & $+/-0.53 \mathrm{~N}$ & $+/-0.52 \mathrm{~N}$ \\
\hline
\end{tabular}


Figure A.3 shows tensile tests of dummy specimens, using both the previous and current load cell.

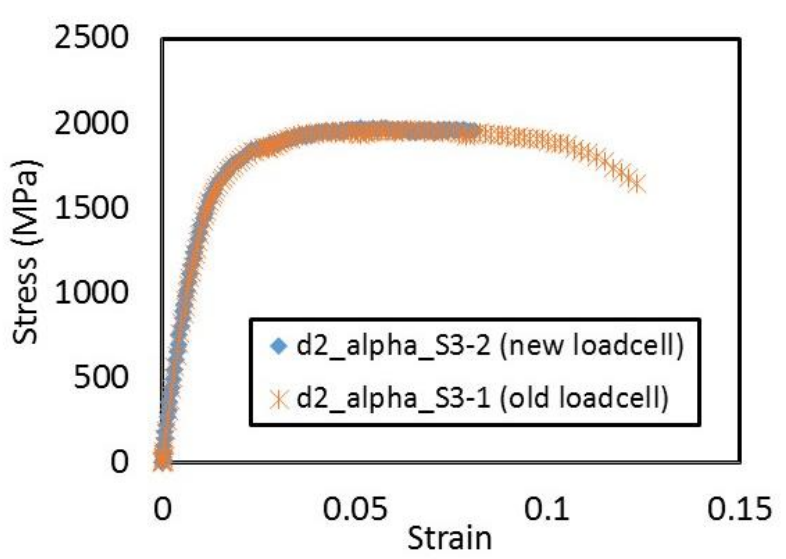

(a)

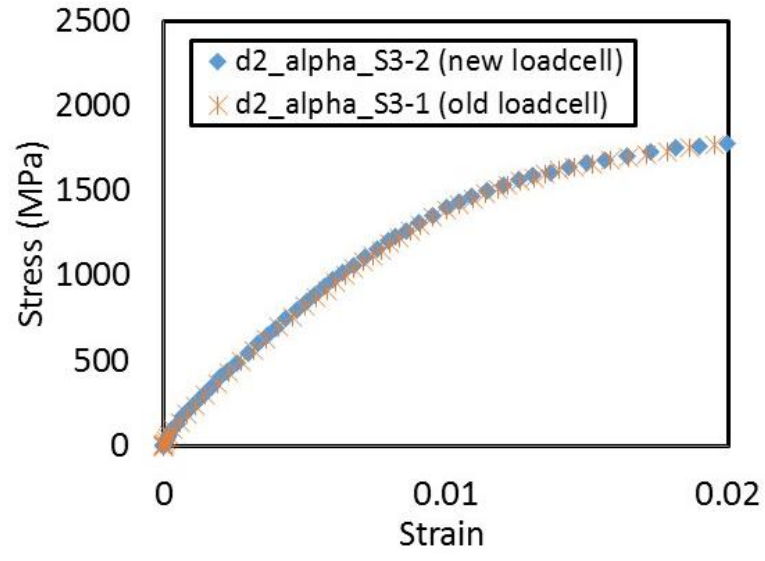

(b)

Figure A.3 (a) Engineering stress-strain curves of dummy Alpha-S1 specimens tested with the previous load cell and the current $334 \mathrm{~N}(75 \mathrm{lb})$ load cell. (b) Close up of the elastic region of the stress-strain curves. The UTS values measured are $1975 \mathrm{MPa}$ and $1964 \mathrm{MPa}$ for the old and new load cells, respectively, which is a difference of 0.5 percent. The shorter elongation of one of the specimens is due to material variability, as the individual dummy specimens have failed with different degrees of necking. (This figure is from our January 2016 progress report to ARDEC.)

\section{A-2. Improvements to tensile test at strain rate $1 / \mathrm{s}$}

We made two major improvements to the 1/s test set-up: (a) Obtaining a new objective lens with an intermediate field of view, and (b) shortening the load train to reduce force oscillations.

For our Task 1 performance period we used the original lenses on the high-speed camera but found them to have either too-big or too-small field of view. A field of view that is too small would result in part of the largest (S3) specimen's gauge section going out of the frame during the test, whereas a field of view that is too large would result in extremely poor resolution. In December 2015 we purchased an intermediate lens which we have been using ever since. The new CF-2 lens allows the entire gauge sections to be within the field of view during the test and with sufficient resolution that the microfabricated fiducial markers on the gauge sections are still clearly distinguishable for DIC. The CF-2 lens was subsequently used for all but the smallest (S4) specimens; for these we continued to use the higher-magnification $\mathrm{CF}-3$ lens.

We also re-configured the load train on the MTS Bionix ${ }^{\mathrm{TM}}$ load frame to reduce force oscillations. Figure A.4 shows the load train as we originally assembled it during the Task 1 performance period. Oscillations in forces, particularly for the smaller specimens, were 
significant. We originally used a series of 5 off-the-shelf adapters to couple the thread sizes from the load cell's metric thread to the English threads on the clevises. We have since replaced the 5 adapters with a single custom-machined adapter, and moved the load cell from above the specimen to below it so that the load cell is not accelerated during the test, as shown in Figure A.5. This way, there are fewer 'loose' parts and less inertia in the moving components.

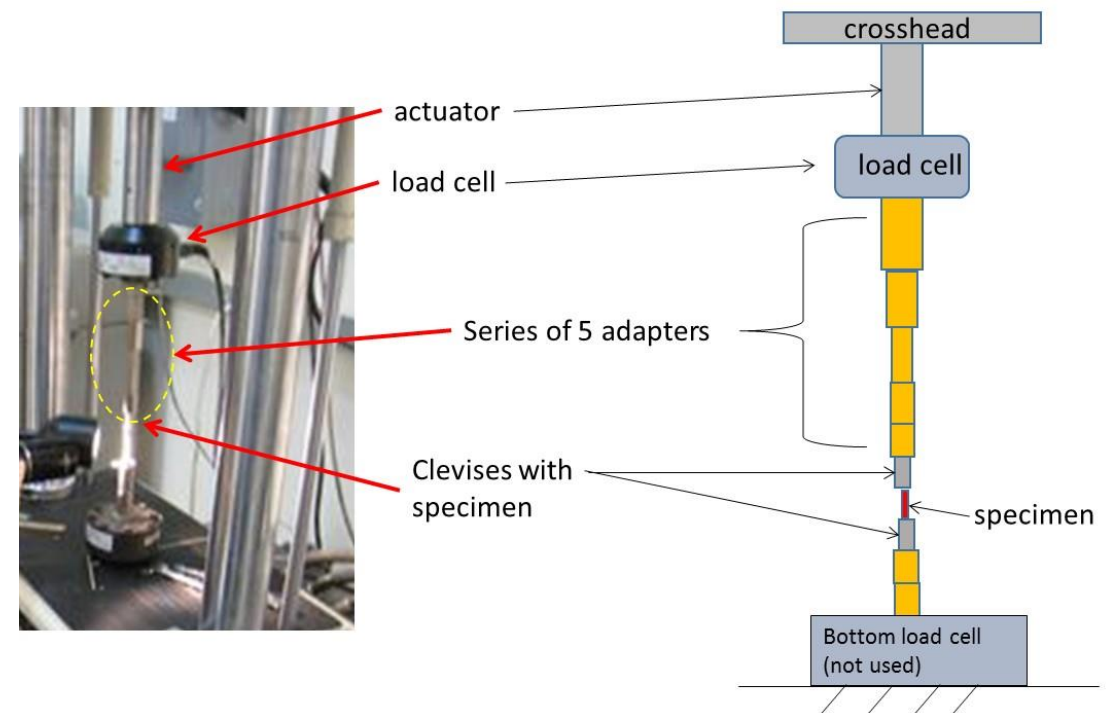

Figure A.4. Previous configuration of the load train, during Task 1 performance period [1].

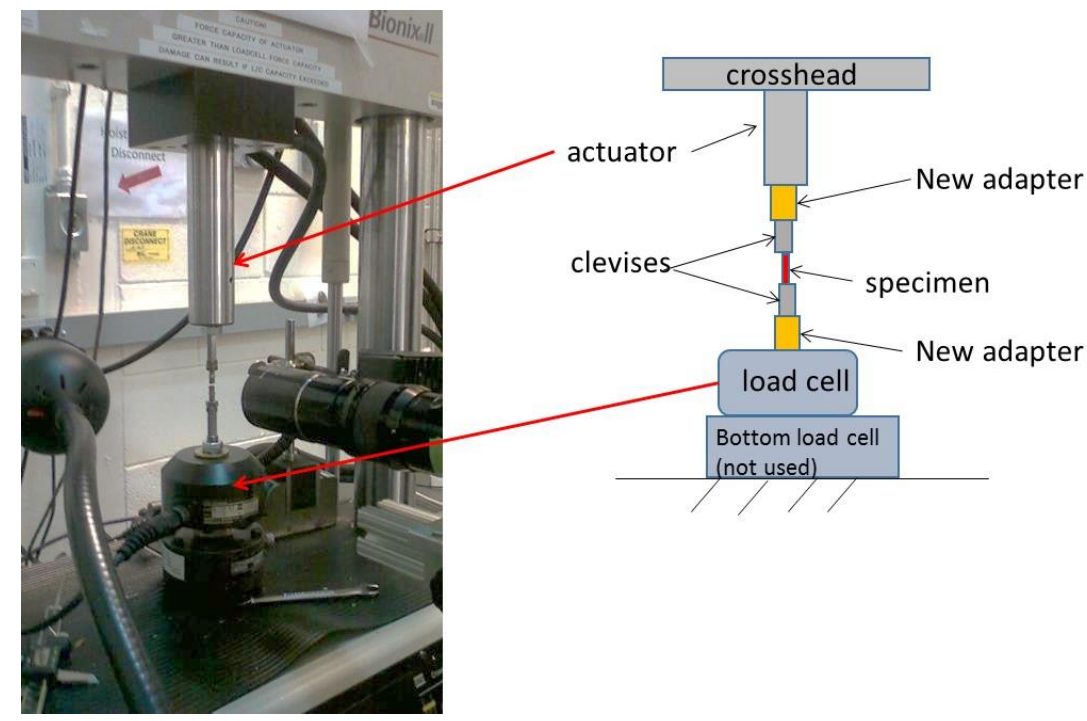

Figure A.5. Shortened load train to reduce force oscillations. (This figure is from our March 2016 progress report to ARDEC.)

Figure A.6 shows the design of the new adapters for shortening the load train on the MTS Bionix load frame for the 1/s test set-up, and Figure A.7 shows the resulting reduction in force oscillation for dummy S4 specimens. The adapters screw directly into the load cells 
on one end, and our existing clevises (see Task 1 report for drawings) screw into the other end of the adapters. This allows us to couple directly from the load cell to the clevises as shown in Figure A.5 above. The starting material is a commercially-obtained metricthreaded rod (with threads that match those on the MTS load frame's load cell) of medium strength steel (McMaster-Carr product no: 95245A172 or 95245A173).
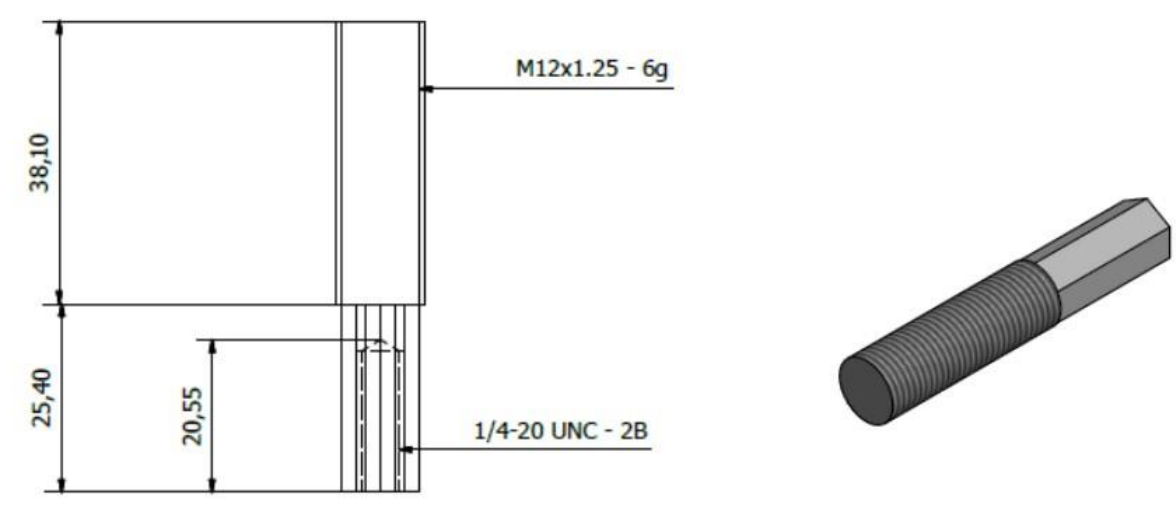

$B(3: 1)$
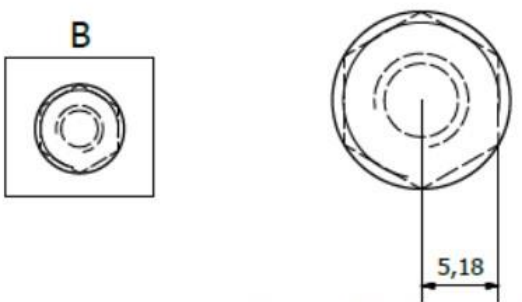

the size of the hexagonal faces

is not important, it is just to fit

in an adjustable wrench

Figure A.6. Machine drawings of new adapters for the load train, for the $1 / \mathrm{s}$ test. Dimensions in millimeters. The part is machined from commercial medium-strength stainless steel metric-threaded rod. 


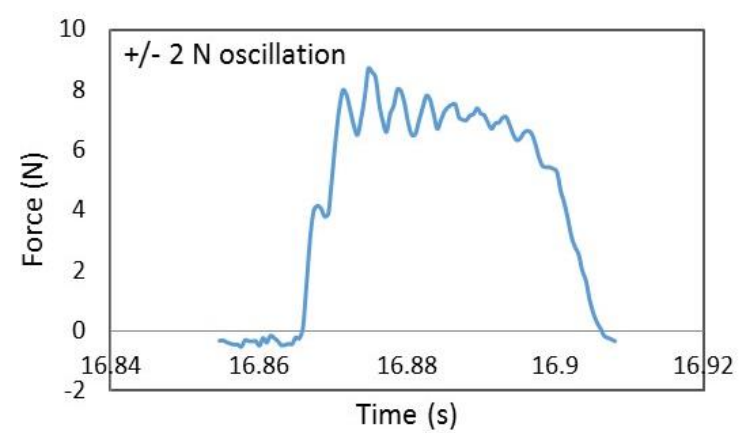

(a)
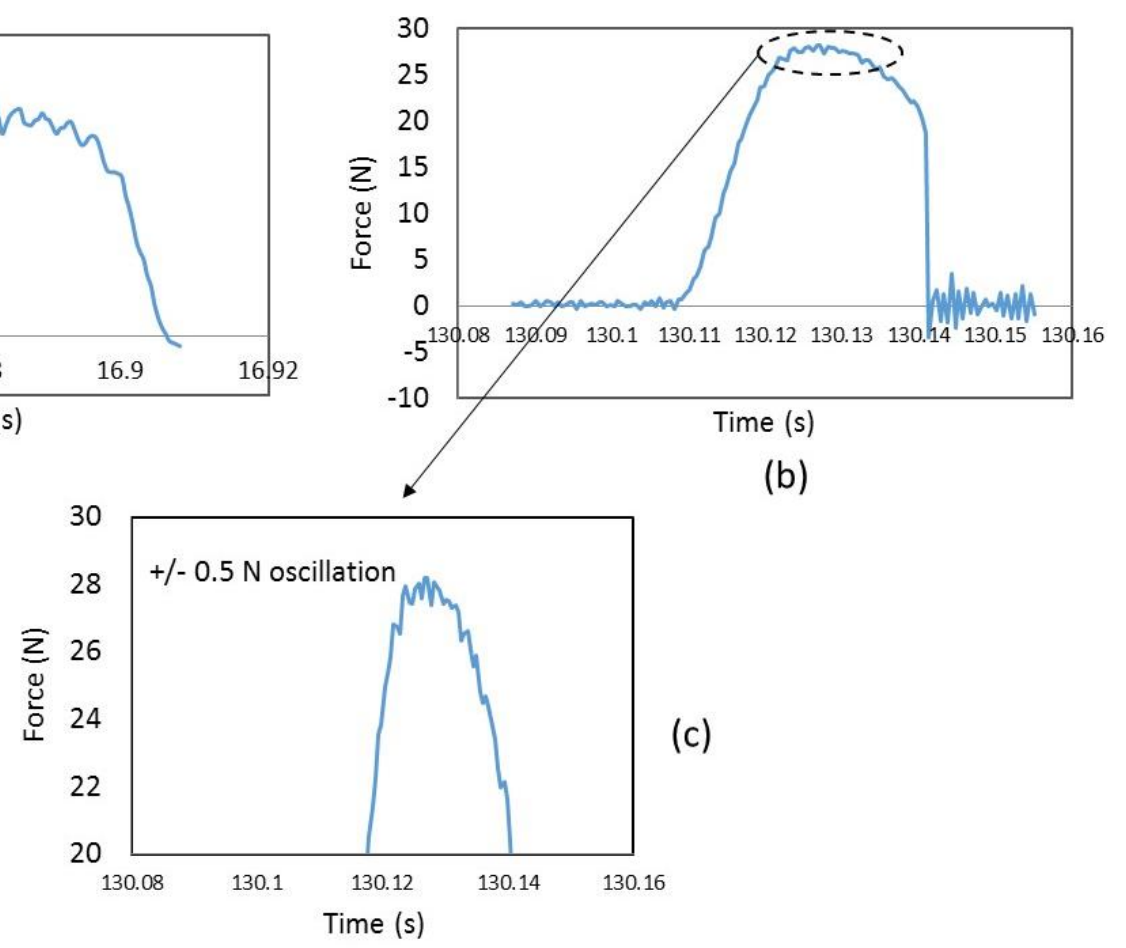

Figure A.7. Raw force vs time from the load frame during the $1 / \mathrm{s}$ tensile tests, using (a) the previous long load train on a dummy C-S4 specimen (b) new shortened load train and a dummy Alpha-S4 specimen, (c) close up of the force oscillations in (b).

\section{A-3. Specimen Carriers}

Shipping of the fragile LIGA specimens from HT Micro Analytical to NIST was an experiment unto itself. The first two runs of dummy specimens during the Task 1 performance period were shipped in standard "GelPaks". This approach, however, proved to be problematic because the specimens are free-standing, with no rigid substrate, and yet have long, thin gauge sections that are fragile and highly susceptible to bending. GelPaks come in different levels of adhesion between the shipped item and the base of the container. The first run of dummy specimens was shipped in GelPaks that were not adhesive enough and as a result many of the specimens fell out of the GelPaks during shipping and were bent. Therefore, for the second run of dummy specimens we requested that HT Micro use GelPaks with stronger adhesion. Unfortunately, the opposite problem was then encountered; the second set of GelPaks was too adherent. The larger specimens could be removed from the carrier without damage by placing some drops of isopropanol on the GelPak and letting it seep under the specimens. However, the smallest specimens - the S4 design - could not be removed from the GelPak without damaging the gauge sections, and all of the S4 dummy specimens were bent to some degree by the time they were tensile tested.

We therefore designed and 3D-printed a set of custom specimen carriers with pockets for each individual specimen. A cleanroom wipe and piece of foam placed over the filled tray 
prevent the specimens falling out of the pockets after the box's lid is taped shut. See Figure A.8 for an example of one design of carrier. We made several carriers - one for each combination of specimen material/geometry and each holding up to 18 specimens - and sent them to the fabrication vendor, who then loaded the specimens individually into each pocket and shipped them back to us. This approach has been successful for shipping the fragile micro specimens safely yet still allowing them to be easily removed without inducing damage, and we have continued to design and send custom carriers to the fabrication vendor for the shear dummy specimens for Task 3. In particular, with this approach we have not had any S4 specimens damaged during shipping or unpacking, and thus we were able to test all the S4 "real" specimens without shipping- or handling-induced damage.
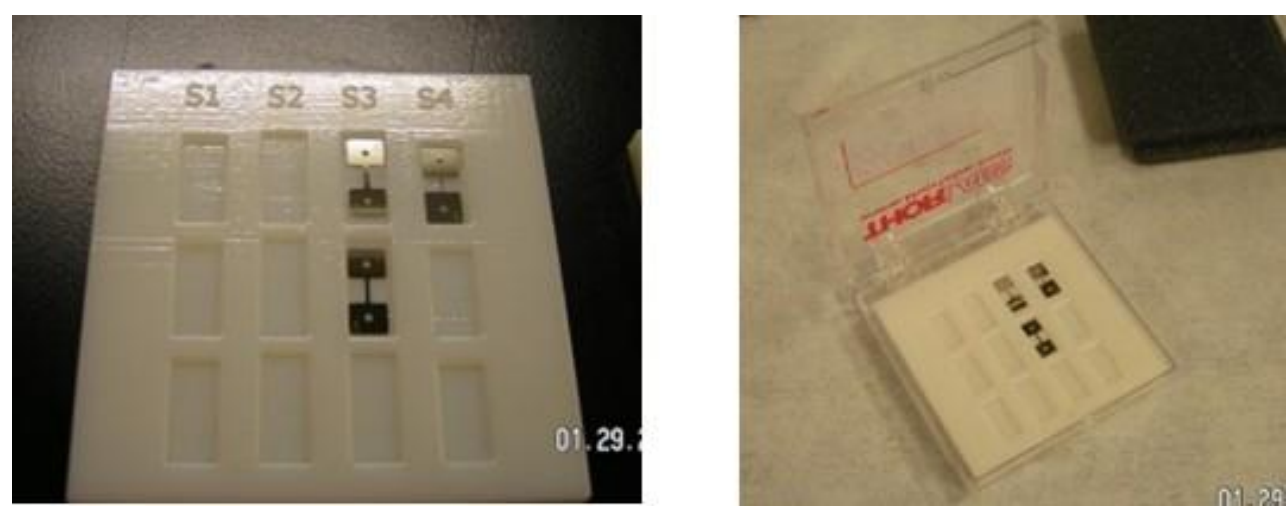

Figure A.8. Custom specimen carriers. Similar carriers with 18 pockets were made and sent to HT Micro for shipping of the majority of the micro tensile specimens. 


\section{Appendix B: Summary of Tensile Specimens Tested}

Table B.1 0.001/s tests on Alpha specimens, using "high strain analysis" to obtain the apparent E. All specimens were preloaded. (This table is from our April 2016 progress report to ARDEC).

\begin{tabular}{|c|c|c|c|c|c|c|c|}
\hline & (MPa) & (GPa) & (MPa) & & (N) & $(\mu \mathrm{m})$ & $(\mu \mathrm{m})$ \\
\hline Specimen\# & UTS & $\begin{array}{c}\text { Apparent } \\
\text { E }\end{array}$ & Yield & ext to UTS & $F_{\max }$ & thickness & max width \\
\hline Alpha_S1-1 & 1933.4 & 157 & 1350 & 0.059 & 72.5 & 190 & 197 \\
\hline Alpha_S1-2 & 1967.8 & 160 & 1330 & 0.055 & 72.7 & 189 & 194 \\
\hline Alpha_S1-3 & 1946.9 & 123 & 1453 & 0.055 & 72.4 & 188 & 197 \\
\hline Alpha_S2-1 & 1945.7 & 135 & 1423 & 0.062 & 182.5 & 188 & 499 \\
\hline Alpha_S2-2 & 1955.3 & 157 & 1350 & 0.057 & 182.6 & 188 & 496 \\
\hline Alpha_S2-3 & 1943.4 & 130 & 1513 & 0.051 & 184.1 & 190 & 498 \\
\hline Alpha_S3-1 & 1945.2 & 145 & 1472 & 0.055 & 256.6 & 189 & 697 \\
\hline Alpha_S3-2 & 1900.9 & 155 & 1389 & 0.062 & 253.6 & 192 & 694 \\
\hline Alpha_S3-3 & 1942.5 & 142 & 1434 & 0.063 & 256.9 & 189 & 699 \\
\hline Alpha_S4-1 & 1802.7 & 123 & 1246 & 0.047 & 25.4 & 189 & 74 \\
\hline Alpha_S4-2 & 1847.4 & 150 & 1360 & 0.044 & 24.5 & 192 & 69 \\
\hline Alpha_S4-3 & 1860.5 & 144 & 1321 & 0.051 & 24.9 & 190 & 70 \\
\hline
\end{tabular}

Table B.2 0.001/s tests on Alpha specimens, using "low strain analysis" to obtain the apparent E. All specimens were preloaded. (This table is from our April 2016 progress report to ARDEC).

\begin{tabular}{|c|c|c|c|c|}
\hline \multicolumn{5}{|c|}{ Low-strain analysis: } \\
\hline & Unchanged & & & \\
\hline & (M Pa) & (G Pa) & (M Pa) & \\
\hline Specimen\# & UTS & $\begin{array}{c}\text { Apparent } \\
\text { E }\end{array}$ & Yield & ext to UTS \\
\hline Alpha_S1-1 & 1933.4 & 210.8 & 1100 & 0.055 \\
\hline Alpha_S1-2 & 1967.8 & 164.4 & 1330 & 0.056 \\
\hline Alpha_S1-3 & 1946.9 & 179.5 & 1233 & 0.056 \\
\hline Alpha_S2-1 & 1945.7 & 156.2 & 1357 & 0.062 \\
\hline Alpha_S2-2 & 1955.3 & 162.2 & 1350 & 0.057 \\
\hline Alpha_S2-3 & 1943.4 & 80.9 & 1758 & 0.054 \\
\hline Alpha_S3-1 & 1945.2 & 223 & 1026 & 0.067 \\
\hline Alpha_S3-2 & 1900.9 & 178.8 & 1300 & 0.056 \\
\hline Alpha_S3-3 & 1942.5 & 179.9 & 1257 & 0.064 \\
\hline Alpha_S4-1 & 1802.7 & 70.6 & 1633 & 0.048 \\
\hline Alpha_S4-2 & 1847.4 & 130 & 1459 & 0.044 \\
\hline Alpha_S4-3 & 1860.5 & 183 & 1153 & 0.051 \\
\hline
\end{tabular}


Table B.3 1/s tests on Alpha specimens, using "low strain analysis" to obtain the apparent E. (This table is from our April 2016 progress report to ARDEC). Specimens were not preloaded unless otherwise noted.

\begin{tabular}{|c|c|c|c|c|c|c|c|c|}
\hline & (MPa) & (GPa) & (MPa) & & & (N) & $(\mu \mathrm{m})$ & $(\mu \mathrm{m})$ \\
\hline Specimen\# & UTS & Apparent E & Yield & $\begin{array}{l}\text { ext to } \\
\text { UTS }\end{array}$ & $\begin{array}{c}\text { strain } \\
\text { rate }\end{array}$ & $F_{\max }$ & thickness & $\begin{array}{c}\max \\
\text { width }\end{array}$ \\
\hline MTS_Alpha_S1-1 & 2032.3 & 117.1 & 1388 & 0.053 & 1.48 & 76.2 & 189 & 198 \\
\hline MTS_Alpha_S1-2 & 2038.21 & 136.77 & 1590 & 0.05 & 1.62 & 75.79 & 190 & 195 \\
\hline MTS_Alpha_S1-3* & 2030.7 & 116 & 1619 & 0.046 & 1.69 & 76.4 & 189 & 199 \\
\hline MTS_Alpha_S2-1 & 2038.5 & 126.2 & 1690 & 0.046 & 0.87 & 191.7 & 190 & 496 \\
\hline MTS_Alpha_S2-2 & 2032.4 & 127.9 & 1635 & 0.047 & 1 & 191.8 & 189 & 499 \\
\hline MTS_Alpha_S2-3* & 2062.7 & 175.4 & 1485 & 0.047 & 1.07 & 191.7 & 188 & 499 \\
\hline MTS_Alpha_S3-1 & 2043.6 & 133.1 & 1551 & 0.048 & 0.91 & 267.4 & 189 & 692 \\
\hline MTS_Alpha_S3-2 & 2037.4 & 141 & 1626 & 0.047 & 0.92 & 268.1 & 189 & 696 \\
\hline MTS_Alpha_S3-3* & 2040.9 & 146.6 & 1571 & 0.044 & 0.98 & 268.6 & 189 & 696 \\
\hline MTS_Alpha_S4-1 & 2065.5 & 168.4 & 1592 & 0.039 & 2.12 & 26.4 & 190 & 67 \\
\hline MTS_Alpha_S4-2 & 1973.7 & 241.6 & 1455 & 0.035 & 1.89 & 27 & 190 & 71 \\
\hline MTS_Alpha_S4-3* & 2099.9 & 166.8 & 1532 & 0.041 & 2.38 & 27.8 & 189 & 70 \\
\hline
\end{tabular}

Table B.4 0.001/s tensile tests of C specimens, using "low strain analysis" to obtain the apparent E. All specimens were preloaded. (This table is from our July 2016 progress report to ARDEC)

\begin{tabular}{|c|c|c|c|c|c|c|c|}
\hline & (MPa) & (GPa) & (MPa) & & (N) & $(\mu \mathrm{m})$ & $(\mu \mathrm{m})$ \\
\hline Specimen\# & UTS & Apparent $\mathrm{E}$ & Yield & $\begin{array}{c}\text { ext to } \\
\text { UTS }\end{array}$ & Fmax & thickness & max width \\
\hline C_S1-1 & 522.2 & 90 & 390 & 0.072 & 17.9 & 169 & 203 \\
\hline C_S1-2 & 660.5 & 149.7 & 445 & 0.06 & 23.9 & 174 & 208 \\
\hline C_S1-3 & 629.8 & 189.7 & 400 & 0.063 & 22 & 172 & 203 \\
\hline C_S2-1 & 618.2 & 156.4 & 400 & 0.053 & 52.8 & 168 & 507 \\
\hline C_S2-2 & 708.4 & 143.9 & 475 & 0.06 & 62.8 & 173 & 511 \\
\hline C_S2-3 & 729.2 & 270.4 & 410 & 0.054 & 64.2 & 174 & 506 \\
\hline C_S2-4 & 741.1 & 185.1 & 490 & 0.046 & 66 & 174 & 512 \\
\hline C_S3-1 & 634.4 & 180.6 & 400 & 0.064 & 75.3 & 168 & 706 \\
\hline C_S3-2 & 746.2 & 92.4 & 499 & 0.055 & 90.9 & 172 & 708 \\
\hline C_S3-3 & 704.6 & 193.6 & 440 & 0.059 & 83.6 & 169 & 702 \\
\hline C_S4-1 & 655.3 & 122.6 & 450 & 0.042 & 9.3 & 174 & 81 \\
\hline C_S4-2 & 505.5 & 150.9 & 376 & 0.071 & 6.9 & 167 & 82 \\
\hline C_S4-3 & 629.8 & 150 & 431 & 0.045 & 9 & 173 & 82 \\
\hline
\end{tabular}


Table B.5 1/s tensile tests of C specimens (This table is from our July 2016 progress report to ARDEC.)

\begin{tabular}{|c|c|c|c|c|c|c|c|c|}
\hline & (MPa) & (GPa) & (MPa) & & & (N) & $(\mu \mathrm{m})$ & $(\mu \mathrm{m})$ \\
\hline Specimen\# & UTS & Apparent E & Yield & $\begin{array}{c}\text { ext. to } \\
\text { UTS }\end{array}$ & strain rate & Fmax & thickness & max width \\
\hline MTS_C_S1-1 (bent) & 747.4 & 36 & 530 & 0.08 & 2 & 27.1 & 174 & 207 \\
\hline MTS_C_S1-2 & 673.8 & 70.7 & 467 & 0.082 & 1.7 & 24.5 & 172 & 210 \\
\hline MTS_C_S1-3 & 626.1 & 188.9 & 330 & 0.109 & 2.1 & 22.5 & 171 & 205 \\
\hline MTS_C_S1-4 & 582 & 42.7 & 380 & 0.093 & 2.1 & 20.7 & 169 & 207 \\
\hline MTS_C_S2-1 & 722.1 & 123.2 & 400 & 0.074 & 1.1 & 63.1 & 172 & 507 \\
\hline MTS_C_S2-2 & 747 & 183.8 & 589 & 0.065 & 1 & 65.9 & 173 & 507 \\
\hline MTS_C_S2-3 & 784 & 113.7 & 536 & 0.07 & 1.1 & 69.7 & 174 & 511 \\
\hline MTS_C_S3-1 & 819.7 & 80.4 & 554 & 0.058 & 1.2 & 101.2 & 174 & 707 \\
\hline MTS_C_S3-2 & 809.2 & 123.3 & 511 & 0.069 & 1.2 & 99.2 & 173 & 707 \\
\hline MTS_C_S3-3 & 764.9 & 119.8 & 513 & 0.072 & 1.1 & 92.6 & 717 & 707 \\
\hline MTS_C_S4-1 & 734.6 & 79.7 & 530 & 0.074 & 2.7 & 11.1 & 174 & 83 \\
\hline MTS_C_S4-2 & 660.9 & 144 & 460 & 0.066 & 2.6 & 9.5 & 170 & 84 \\
\hline MTS_C_S4-3 & 587.8 & 84.5 & 350 & 0.084 & 2.9 & 8.7 & 170 & 82 \\
\hline
\end{tabular}




\section{Appendix C: Engineering Stress-Strain Curves for Alpha Material, at Strain Rate 0.001/s}
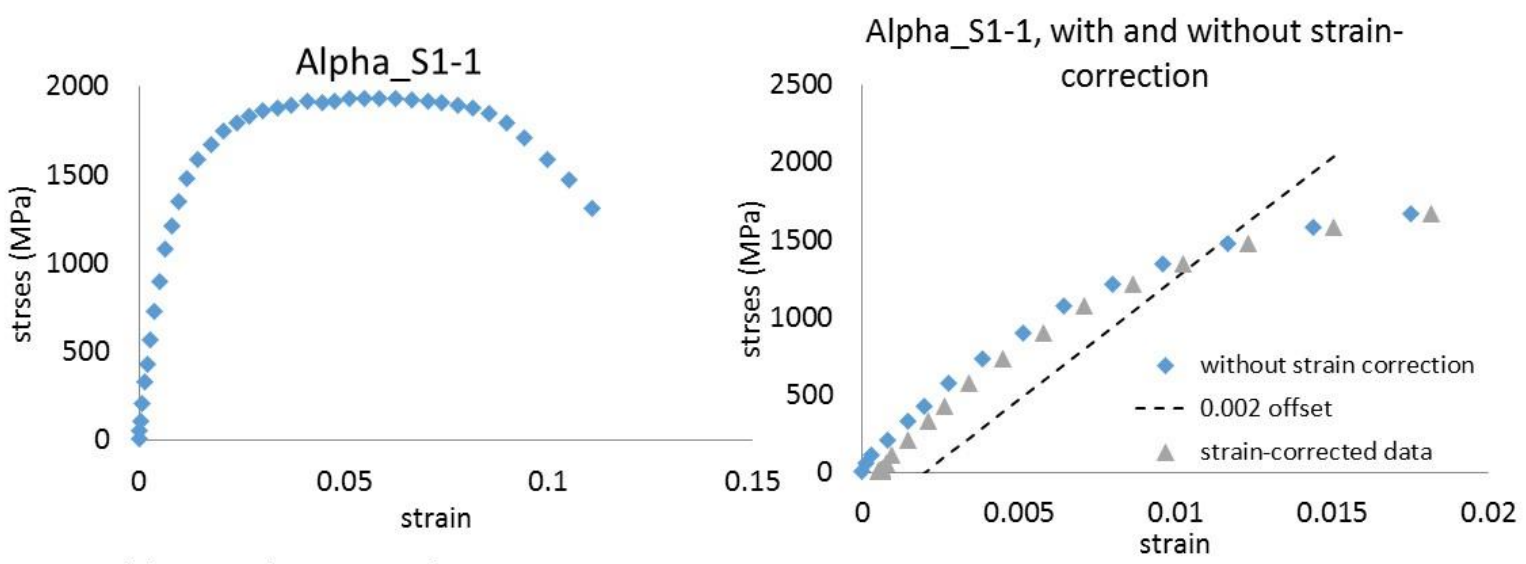

Alpha_S1-1: linear part of stress-strain curve

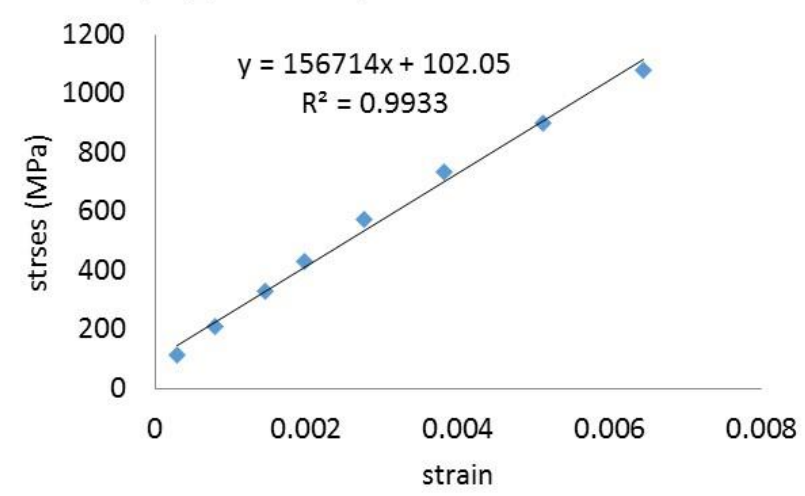

\begin{tabular}{l|c|} 
UTS $=$ & $1933.4 \mathrm{M} \mathrm{Pa}$ \\
\hline Apparent $\mathrm{E}=$ & $157.0 \mathrm{Gpa}$ \\
\hline Y.S. $=$ & $1350 \mathrm{M} \mathrm{Pa}$ \\
\hline ext to UTS $=$ & 0.059 \\
\hline Fmax $=$ & $72.5 \mathrm{~N}$
\end{tabular}

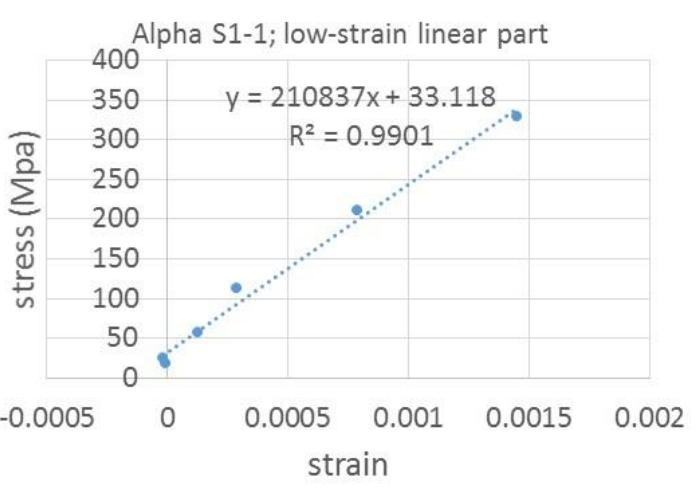

Low-strain analysis

\begin{tabular}{l|c|}
\hline UTS $=$ & $1933.4 \mathrm{M} \mathrm{Pa}$ \\
\hline Apparent $\mathrm{E}=$ & $210.8 \mathrm{G} \mathrm{Pa}$ \\
\hline Y.S. $=$ & $1100 \mathrm{M} \mathrm{Pa}$ \\
\hline ext to UTS $=$ & 0.055
\end{tabular}

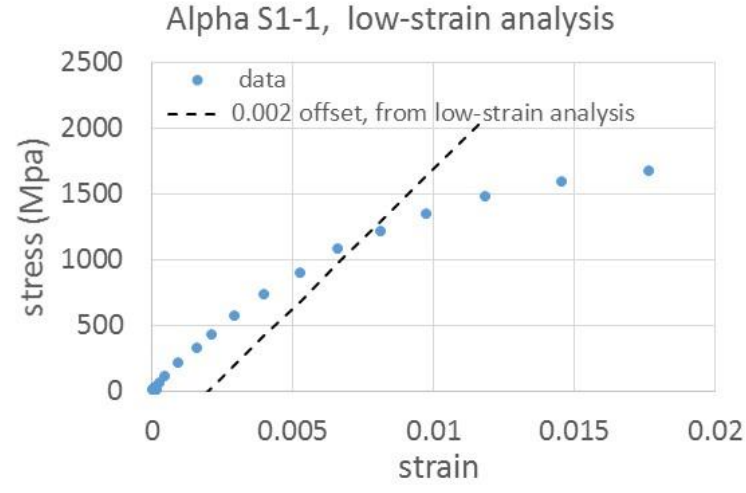

For this specimen, a low-strain analysis increases the apparent $\mathrm{E}$ by about 34\%, and lowers the Y.S. by about $19 \%$.

This value of apparent $E$ is above the expected range for LIGA Ni 

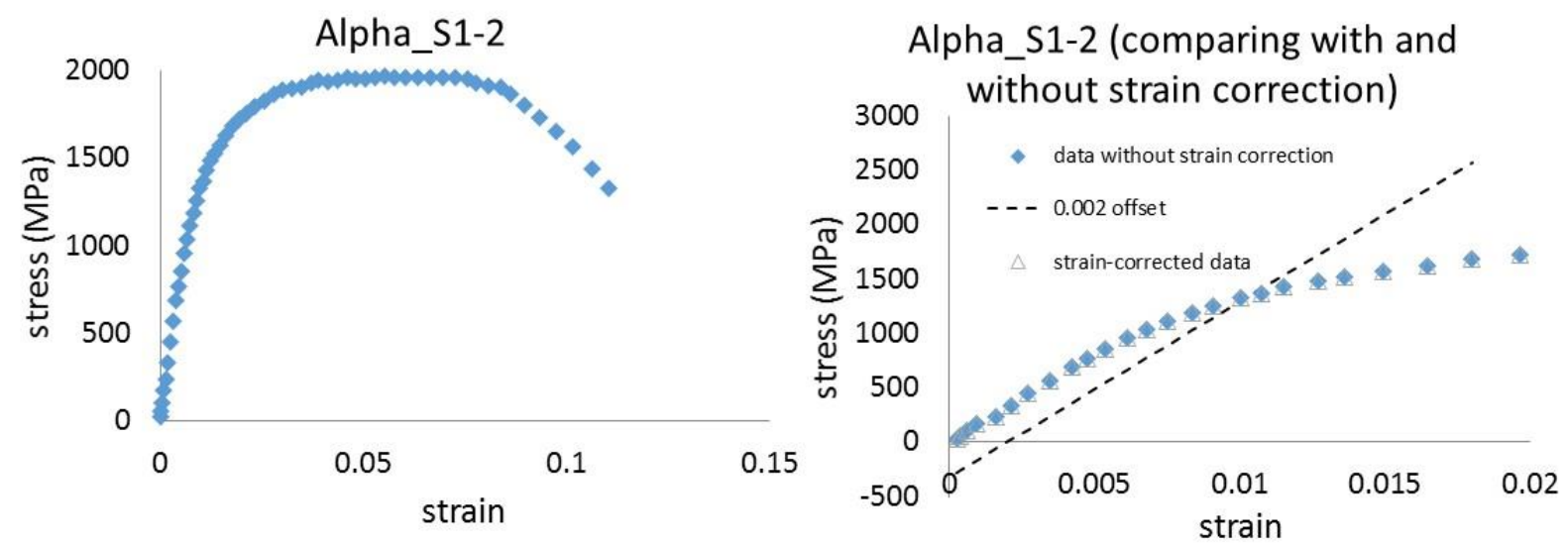

Alpha_S1-2: linear part of stress-strain curve
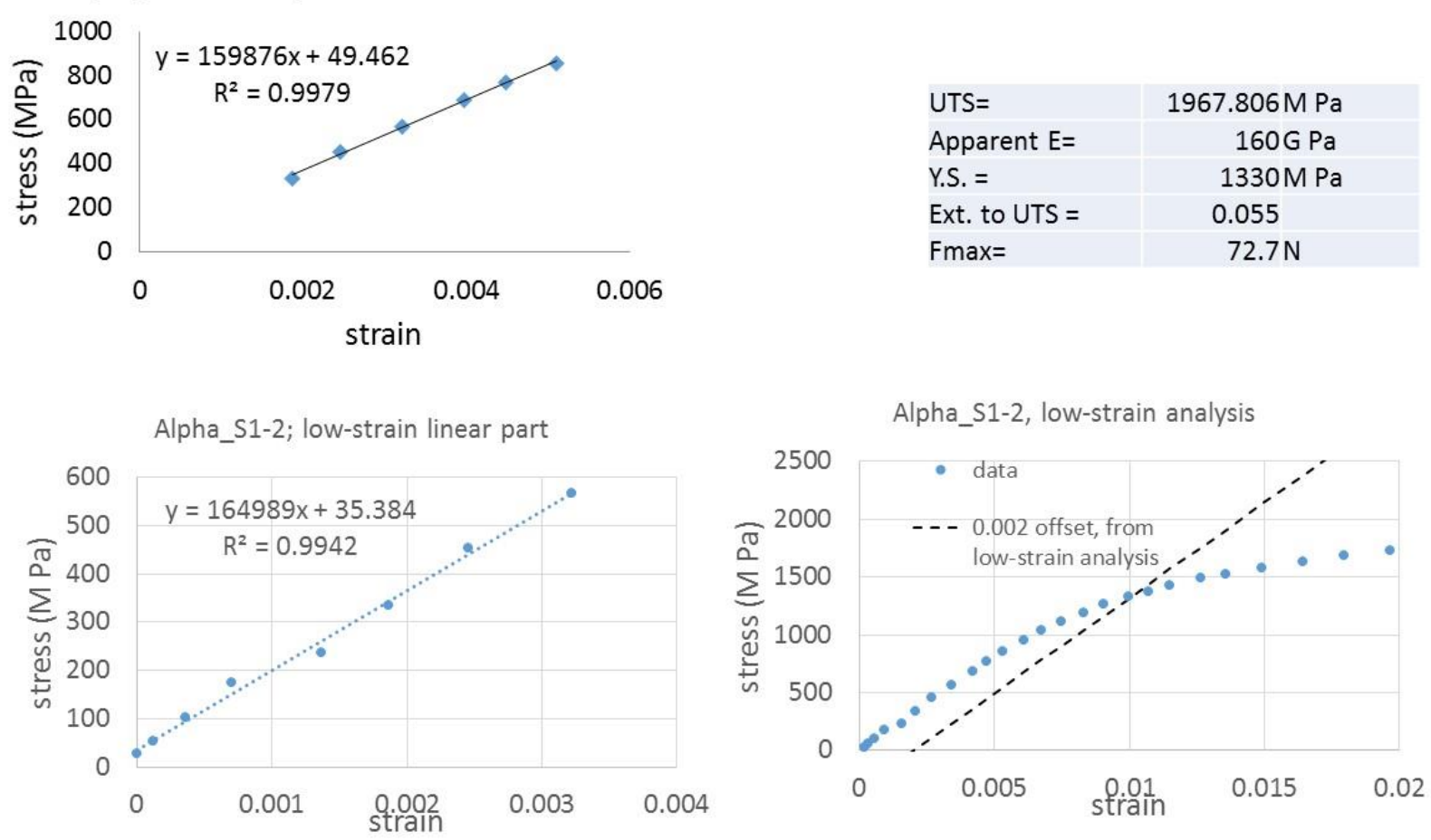

From Low-strain analysis:

\begin{tabular}{l|c|}
\hline UTS $=$ & 1967.8 \\
\hline Apparent $E=$ & $164.4 \mathrm{G} \mathrm{Pa}$ \\
\hline Y.s. $=$ & $1330.0 \mathrm{M} \mathrm{Pa}$ \\
\hline ext to UTS $=$ & 0.056
\end{tabular}

For this specimen, a low-strain analysis did not noticeably change the apparent $E$ and Y.S. 

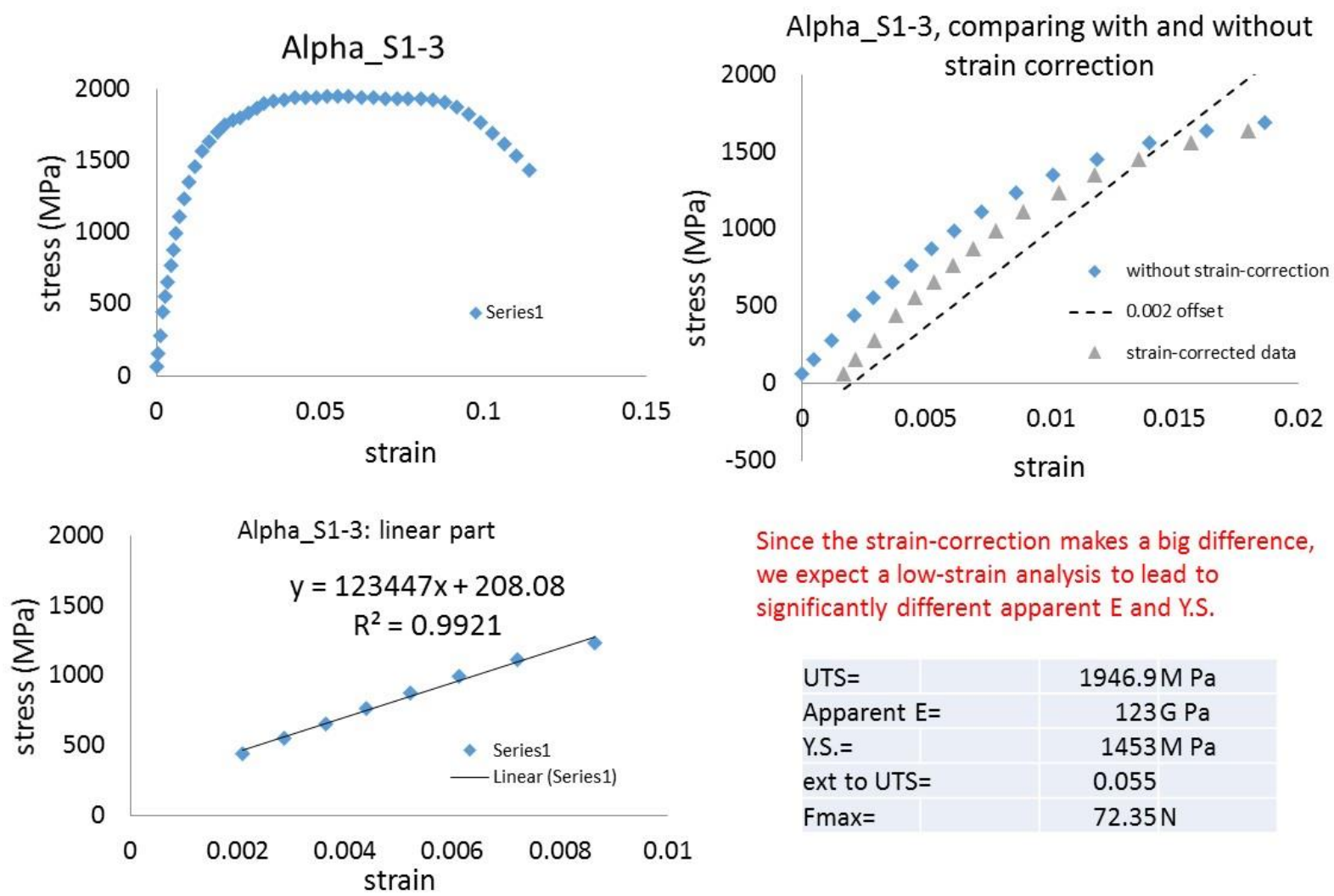

Since the strain-correction makes a big difference, we expect a low-strain analysis to lead to significantly different apparent $\mathrm{E}$ and Y.S.

\begin{tabular}{l|c|} 
UTS $=$ & $1946.9 \mathrm{M} \mathrm{Pa}$ \\
\hline Apparent $\mathrm{E}=$ & $123 \mathrm{G} \mathrm{Pa}$ \\
Y.S. $=$ & $1453 \mathrm{M} \mathrm{Pa}$ \\
ext to UTS $=$ & 0.055 \\
Fmax $=$ & $72.35 \mathrm{~N}$
\end{tabular}

Alpha_S1-3; low-strain analysis
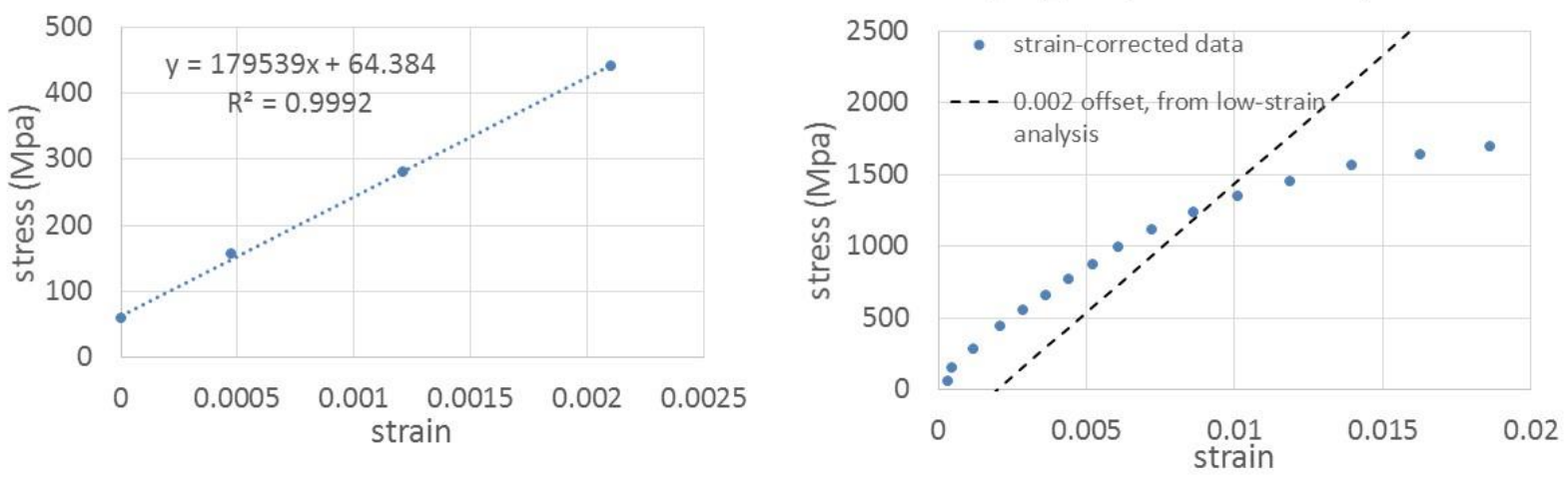

From Low-strain analysis:

\begin{tabular}{l|c|}
\hline UTS $=$ & $1946.9 \mathrm{M} \mathrm{Pa}$ \\
\hline Apparent $E=$ & $179.5 \mathrm{G} \mathrm{Pa}$ \\
\hline Y.S. $=$ & $1233 \mathrm{M} \mathrm{Pa}$ \\
\hline ext to UTS $=$ & 0.056
\end{tabular}




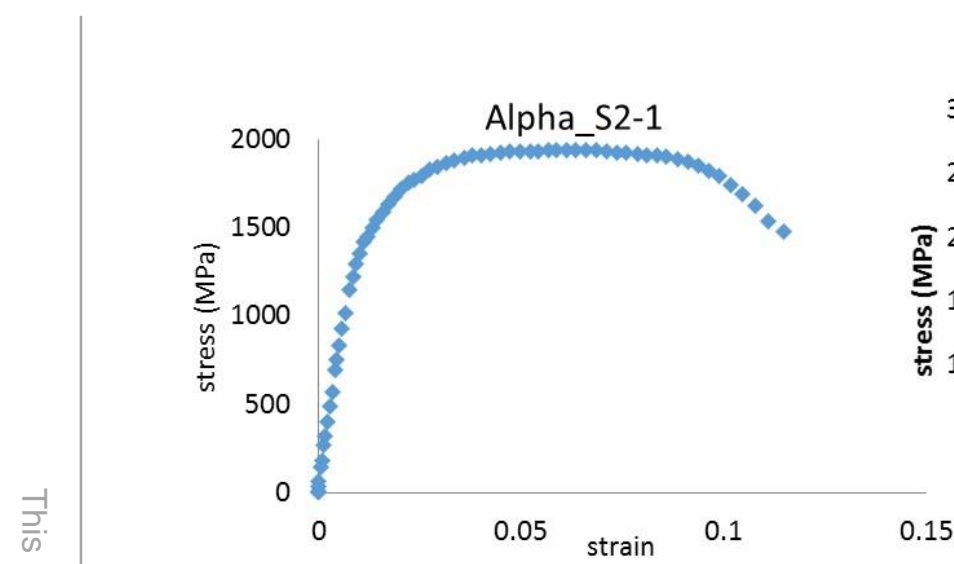

Alpha_S2-1, comparing with and without strain
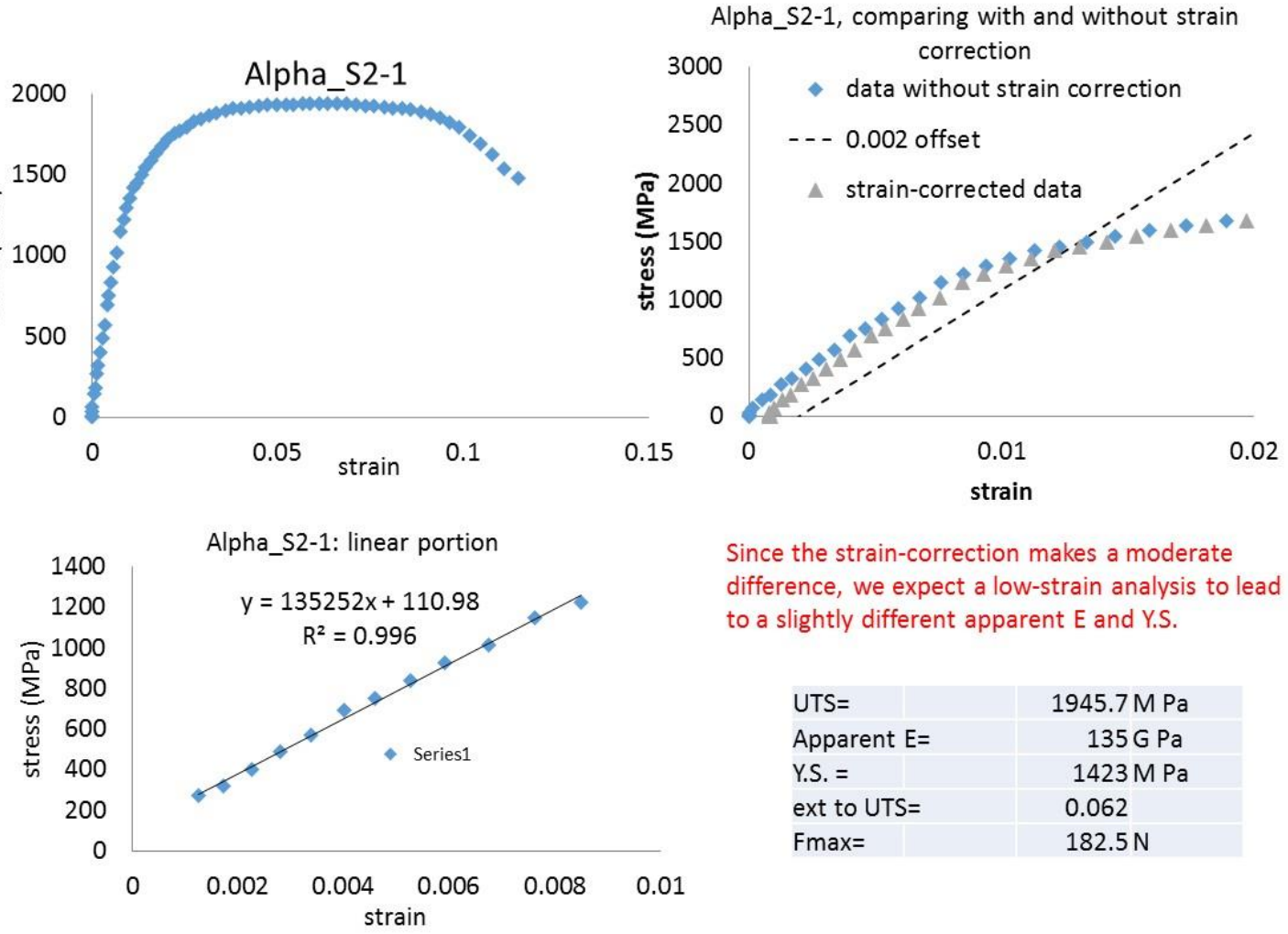

Since the strain-correction makes a moderate difference, we expect a low-strain analysis to lead to a slightly different apparent E and Y.S.

\begin{tabular}{l|c|}
\hline UTS $=$ & $1945.7 \mathrm{M} \mathrm{Pa}$ \\
\hline Apparent $\mathrm{E}=$ & $135 \mathrm{G} \mathrm{Pa}$ \\
\hline Y.S. $=$ & $1423 \mathrm{M} \mathrm{Pa}$ \\
ext to UTS $=$ & 0.062 \\
\hline Fmax $=$ & $182.5 \mathrm{~N}$
\end{tabular}

Alpha_S2-1; low-strain linear part
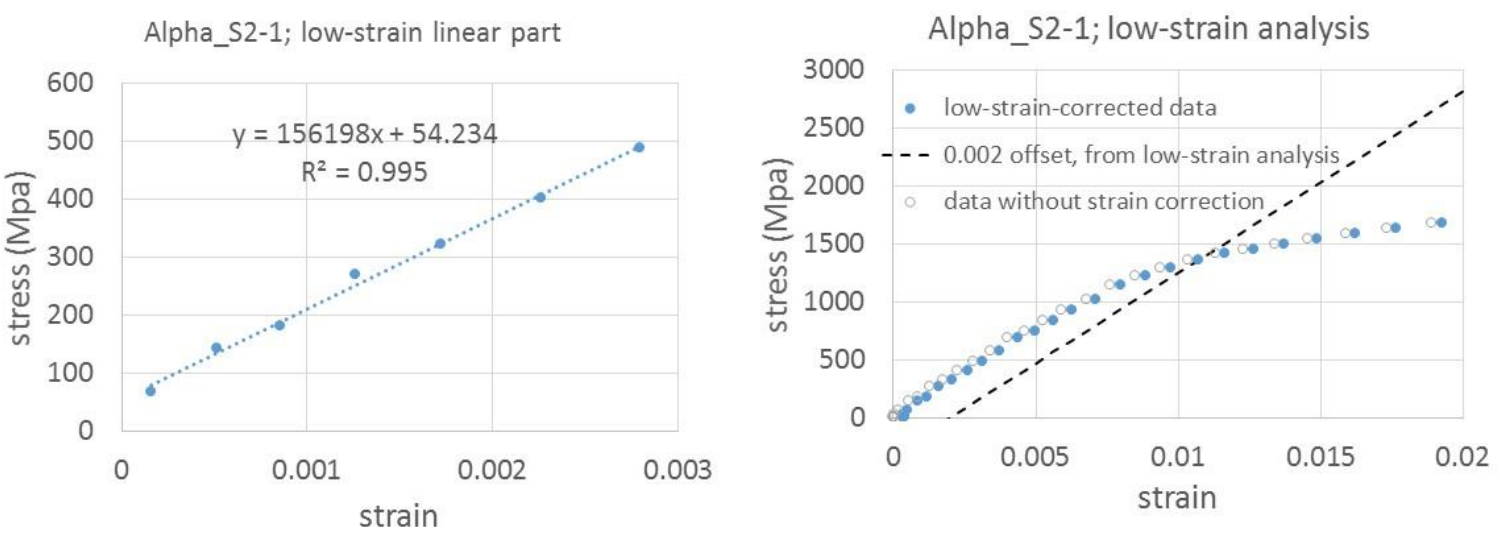

From Low-strain analysis:

UTS=

1945.7 M Pa

Apparent $\mathrm{E}=$

156.2 G Pa

Y.S. =

$1357 \mathrm{M} \mathrm{Pa}$

ext to UTS=

0.062
For this specimen, the low-strain analysis increases the apparent $\mathrm{E}$ by about $16 \%$, and decreases the Y.S. by about $5 \%$. 

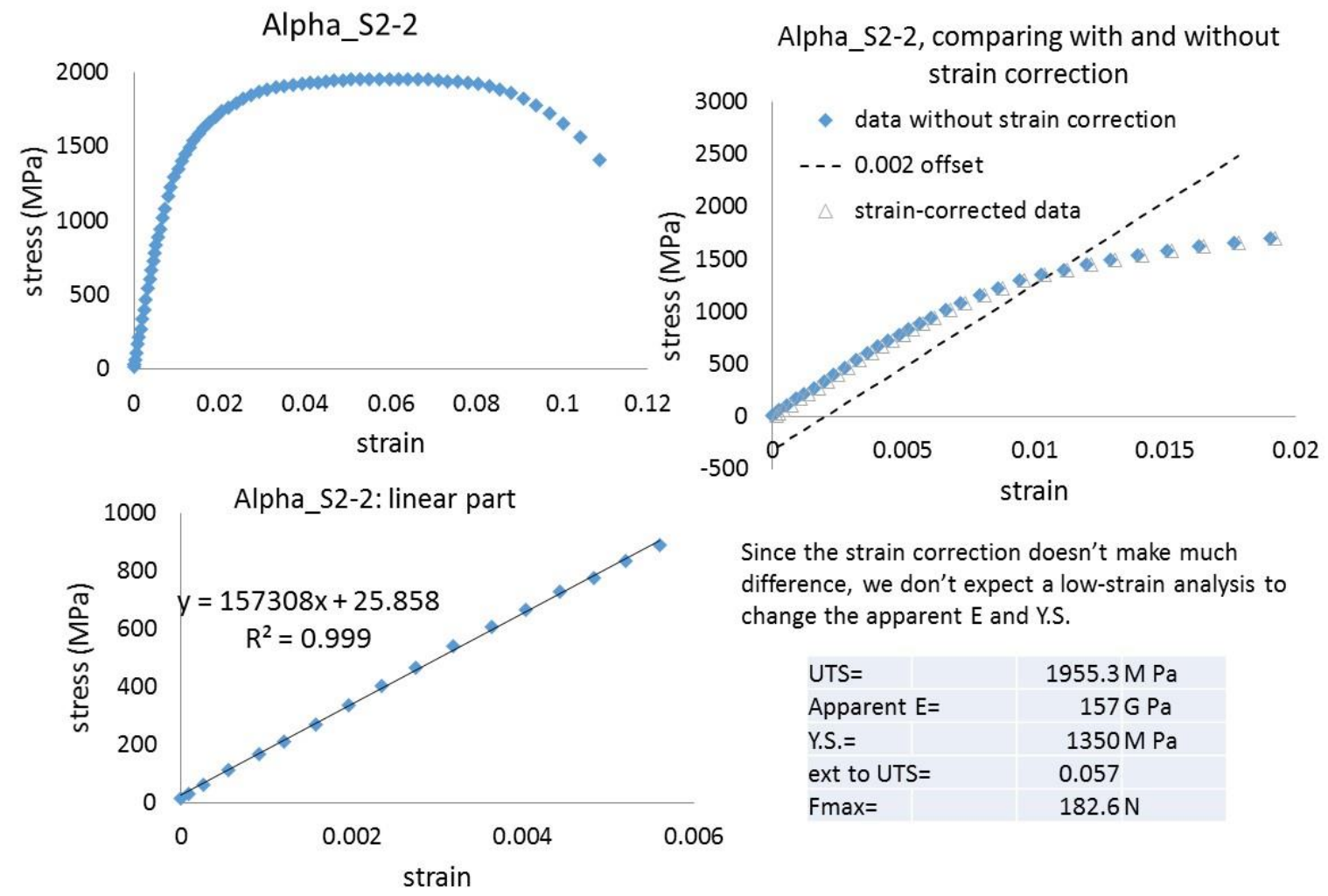

Since the strain correction doesn't make much difference, we don't expect a low-strain analysis to change the apparent $E$ and $Y . S$.

\begin{tabular}{l|c|}
\hline UTS $=$ & $1955.3 \mathrm{M} \mathrm{Pa}$ \\
\hline Apparent $\mathrm{E}=$ & $157 \mathrm{G} \mathrm{Pa}$ \\
\hline Y.S. $=$ & $1350 \mathrm{M} \mathrm{Pa}$ \\
\hline ext to UTS $=$ & 0.057 \\
Fmax $=$ & $182.6 \mathrm{~N}$
\end{tabular}

Alpha_S2-2; low-strain linear part
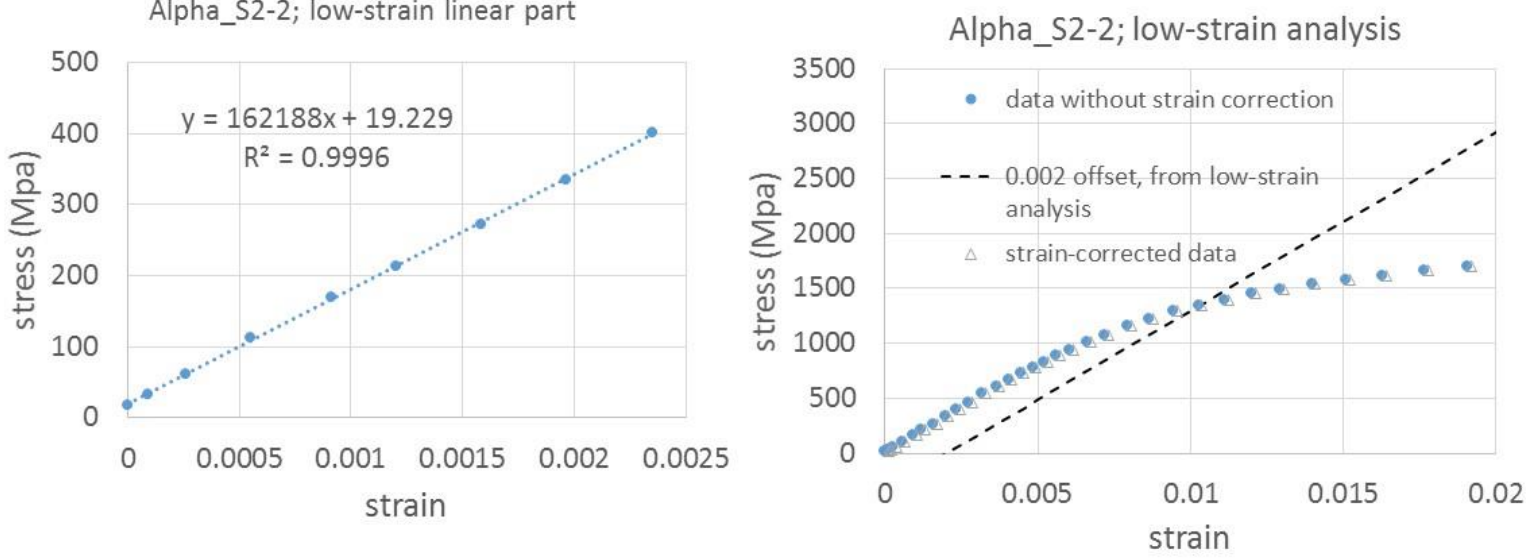

From Low-strain analysis:

\begin{tabular}{l|l|}
\hline UTS $=$ & $1955.3 \mathrm{M} \mathrm{Pa}$ \\
\hline Apparent $\mathrm{E}=$ & $162.2 \mathrm{G} \mathrm{Pa}$ \\
\hline Y.S. $=$ & $1350 \mathrm{M} \mathrm{Pa}$ \\
\hline ext to UTS $=$ & 0.057
\end{tabular}

For this specimen, as expected there is no significant change from the low strain analysis. The apparent E increased by $3 \%$ and the Y.S. is unchanged. 
Alpha_S2-3 (preloaded to $20 \mathrm{~N}$ )
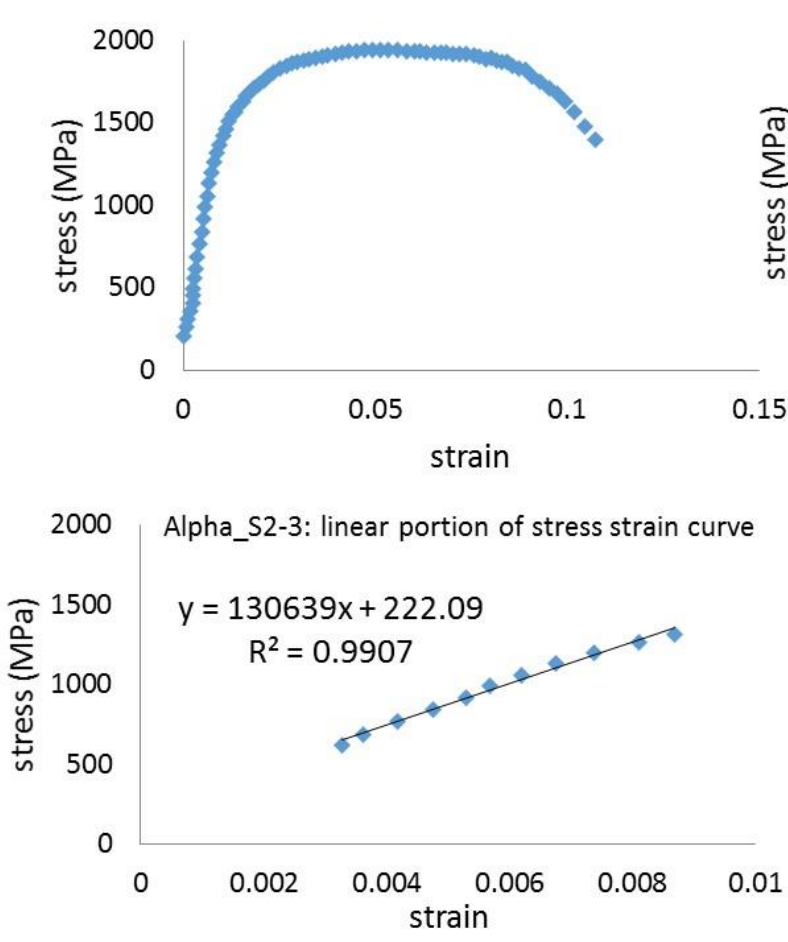

Alpha_S2-3 (preloaded to $20 \mathrm{~N}$ )

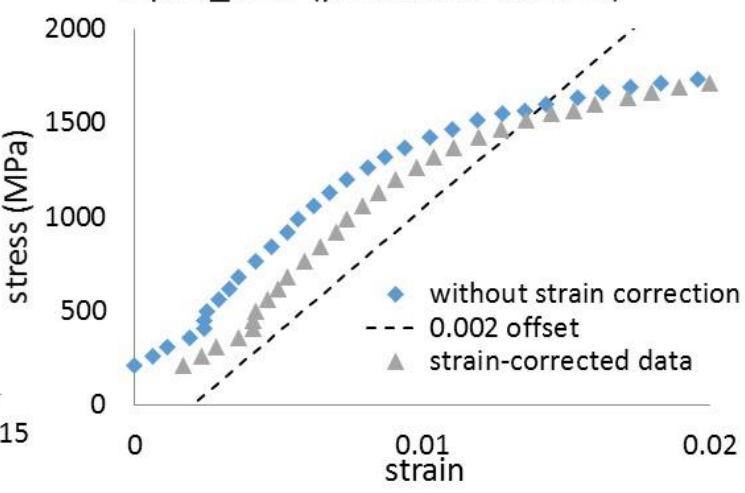

Despite the preload at $\sim 10 \%$ Fmax, the data in the low-strain region has a different slope. We therefore expect a low-strain analysis to lead to signififcantly different apparent $\mathrm{E}$ and Y.S.

\begin{tabular}{l|c|}
\hline UTS $=$ & $1943.4 \mathrm{M} \mathrm{Pa}$ \\
\hline Apparent $\mathrm{E}=$ & $130 \mathrm{G} \mathrm{Pa}$ \\
\hline Y.S. $=$ & $1513 \mathrm{M} \mathrm{Pa}$ \\
\hline ext to UTS $=$ & 0.051 \\
\hline Fmax $=$ & $184.06 \mathrm{~N}$
\end{tabular}

Alpha_S2-3; low-strain analysis

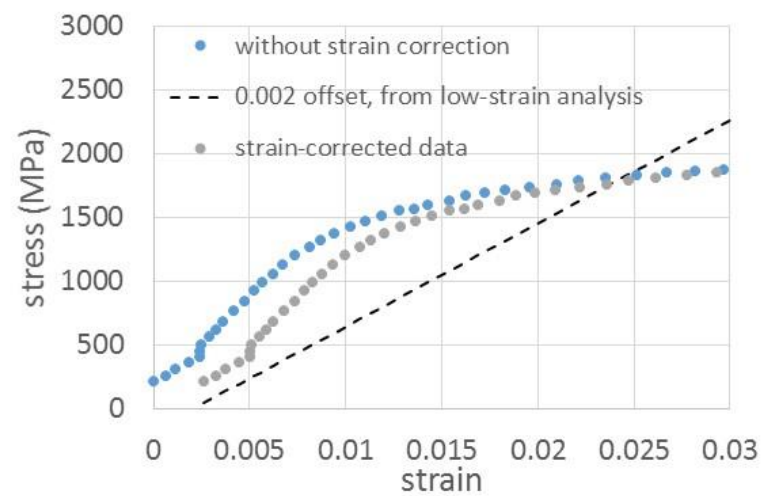

From Low-strain analysis:

UTS=

Apparent $\mathrm{E}=$

Y.S.=

1943.4 M Pa

$80.9 \mathrm{G} \mathrm{Pa}$

ext to UTS $=$
$1758 \mathrm{M} \mathrm{Pa}$

0.054
This specimen is an anomaly, because despite the preloading to $10 \%$ Fmax, the low-strain region has lower slope than the higher-strain linear part. This decreases the $\mathrm{E}$ by about $38 \%$, and increases the Y.S. by about $9 \%$. This is the only specimen with this trend. 
Alpha_S3-1
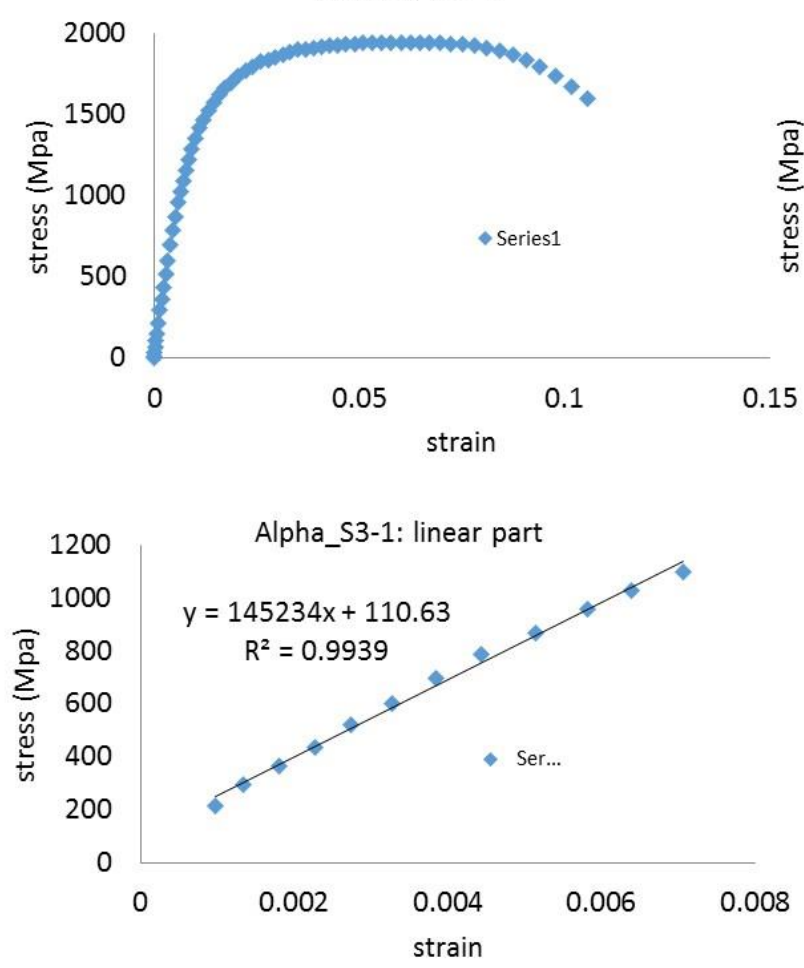

Alpha_S3-1, comparing with and without strain

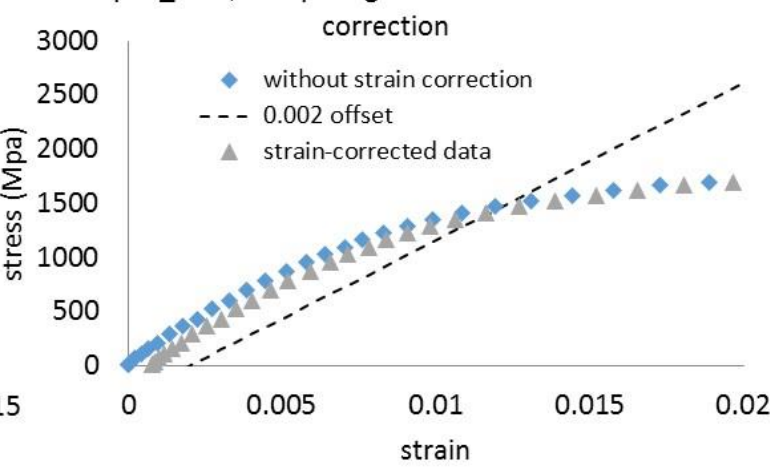

\begin{tabular}{l|c}
\hline UTS $=$ & $1945.2 \mathrm{M} \mathrm{Pa}$ \\
\hline Apparent E= & $145 \mathrm{G} \mathrm{Pa}$ \\
\hline Y.S. $=$ & $1472 \mathrm{M} \mathrm{Pa}$ \\
ext to UTS $=$ & 0.055 \\
Fmax $=$ & $256.6 \mathrm{~N}$
\end{tabular}

Since a strain correction results in the original preloaded data shifting significantly, we expect the apparent $\mathrm{E}$ to be noticeably different at the lowstrains and thus the Y.S. will decrease from the value shown on this slide

\section{Alpha_S3-1, low-strain analysis}
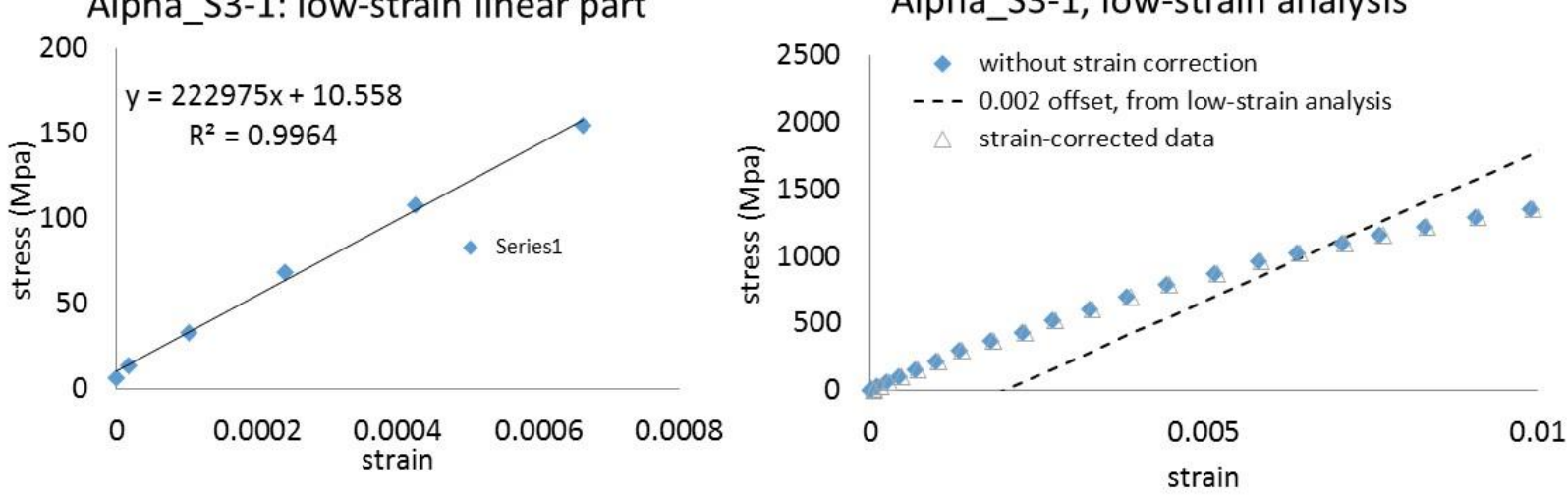

For this specimen, a low-strain analysis increases the apparent $\mathrm{E}$ by $54 \%$, and decreases the Y.S. by $30 \%$ compared to the original analysis.

Note that this value of apparent $E$ is above the range expected for LIGA Ni alloys. 

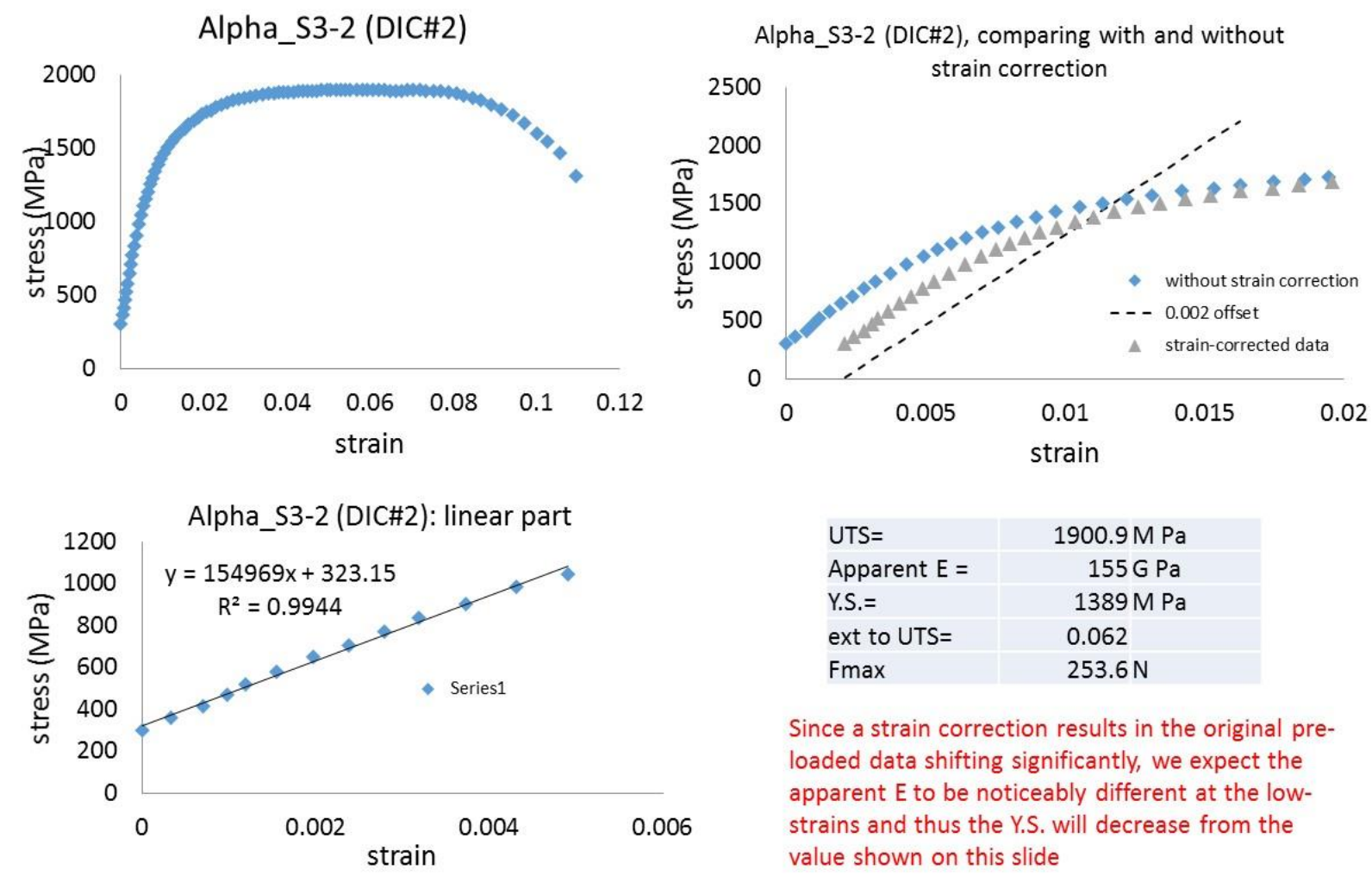

\begin{tabular}{l|l|}
\hline UTS $=$ & $1900.9 \mathrm{M} \mathrm{Pa}$ \\
\hline Apparent $\mathrm{E}=$ & $155 \mathrm{G} \mathrm{Pa}$ \\
\hline Y.S. $=$ & $1389 \mathrm{M} \mathrm{Pa}$ \\
\hline ext to UTS $=$ & 0.062 \\
\hline Fmax & $253.6 \mathrm{~N}$ \\
\hline
\end{tabular}

Since a strain correction results in the original preloaded data shifting significantly, we expect the apparent $\mathrm{E}$ to be noticeably different at the lowstrains and thus the Y.S. will decrease from the value shown on this slide
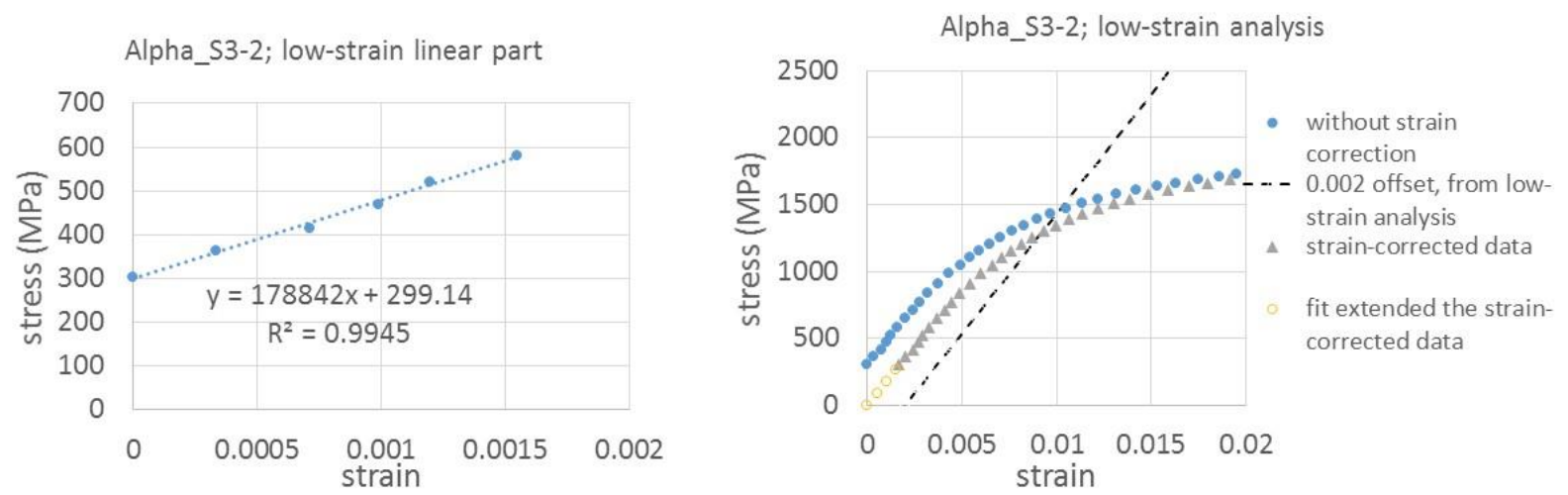

From Low-strain analysis:

\begin{tabular}{l|l|}
\hline UTS $=$ & $1900.9 \mathrm{M} \mathrm{Pa}$ \\
Apparent $\mathrm{E}=$ & $178.8 \mathrm{G} \mathrm{Pa}$ \\
Y.S. $=$ & $1300 \mathrm{M} \mathrm{Pa}$ \\
ext to UTS $=$ & 0.056
\end{tabular}

For this specimen, a low-strain analysis increases the apparent $E$ by $13 \%$, and decreases the Y.S. by $14 \%$ compared to the original analysis. 
Alpha_S3-3
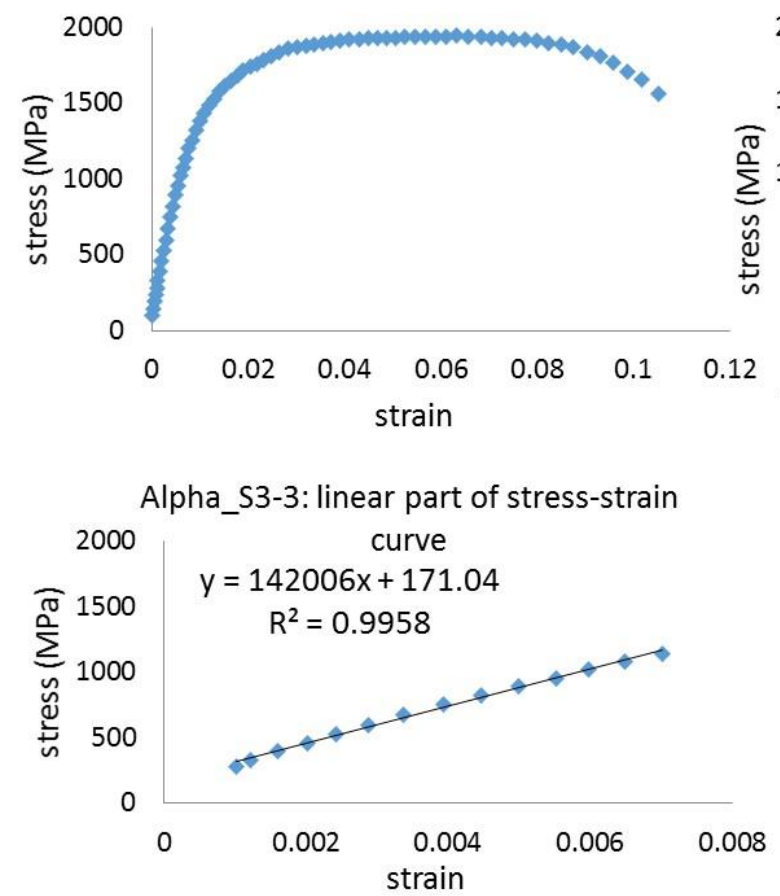

Alpha_S3-3, with and without strain correction

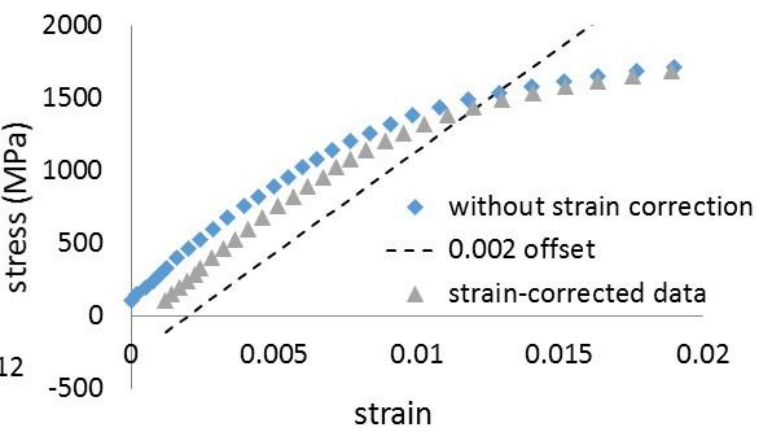

\begin{tabular}{l|c|}
\hline UTS $=$ & $1942.5 \mathrm{M} \mathrm{Pa}$ \\
\hline Apparent $\mathrm{E}=$ & $142 \mathrm{G} \mathrm{Pa}$ \\
\hline Y.S. $=$ & $1434 \mathrm{M} \mathrm{Pa}$ \\
\hline ext to UTS $=$ & 0.063 \\
\hline Fmax $=$ & $256.9 \mathrm{~N}$ \\
\hline
\end{tabular}

Since a strain correction results in the original preloaded data shifting significantly, we expect the apparent $\mathrm{E}$ to be noticeably different at the lowstrains and thus the Y.S. will decrease from the value shown on this slide
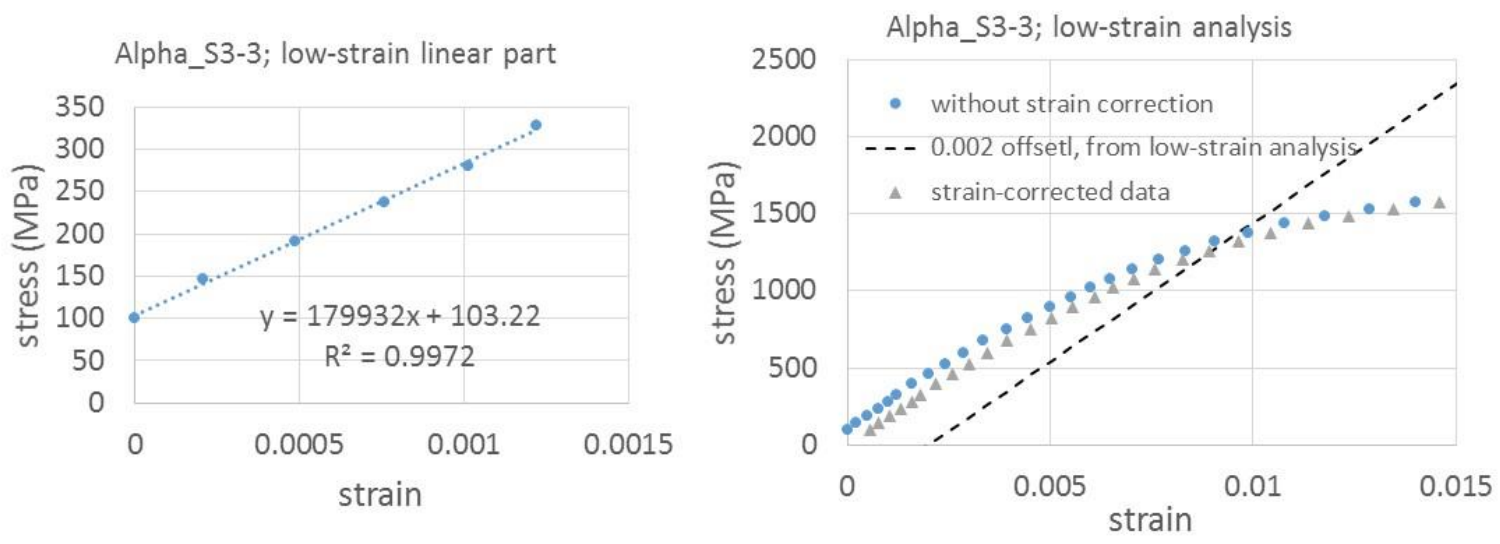

From Low-strain analysis:

\begin{tabular}{l|c|}
\hline UTS $=$ & $1942.5 \mathrm{M} \mathrm{Pa}$ \\
\hline Apparent $\mathrm{E}=$ & $179.9 \mathrm{G} \mathrm{Pa}$ \\
\hline Y.S. $=$ & $1257.0 \mathrm{M} \mathrm{Pa}$ \\
\hline ext to UTS $=$ & 0.064
\end{tabular}

For this specimen, a low-strain analysis increases the apparent $\mathrm{E}$ by $27 \%$, and decreases the Y.S. by $18 \%$ compared to the original analysis. 

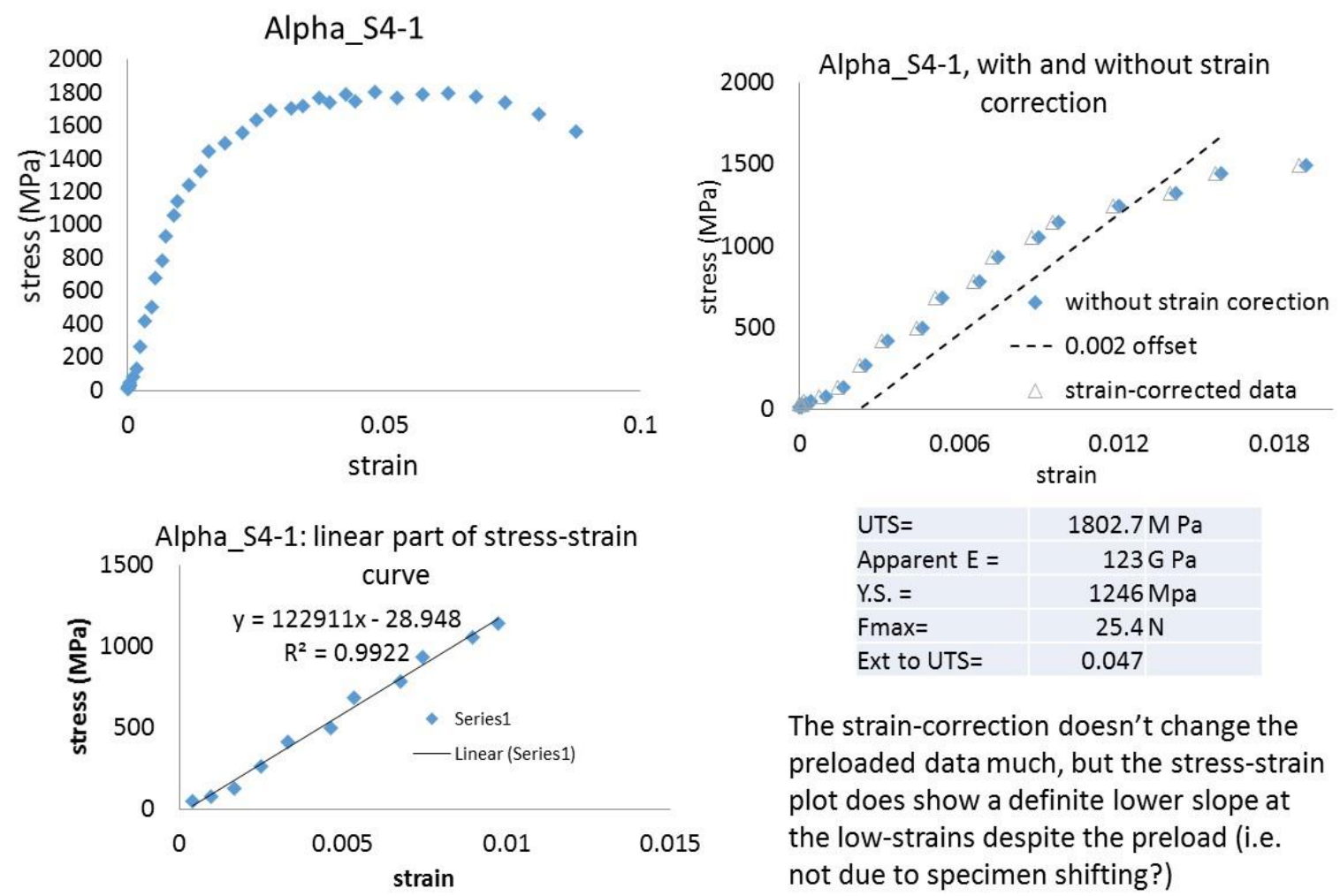

The strain-correction doesn't change the preloaded data much, but the stress-strain plot does show a definite lower slope at the low-strains despite the preload (i.e. not due to specimen shifting?)
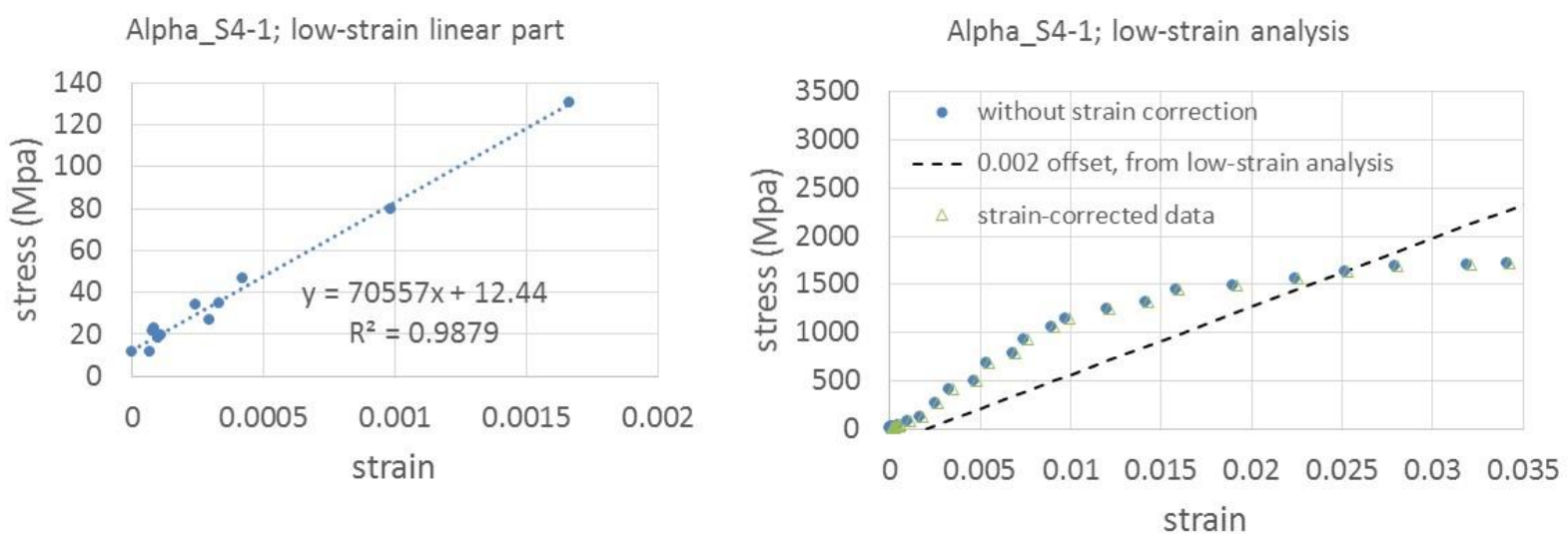

From Low-strain analysis:

UTS=

Apparent $\mathrm{E}=$

Y.S. =

ext to UTS=
1802.7 M Pa

$70.6 \mathrm{M} \mathrm{Pa}$

$1633.0 \mathrm{Mpa}$

0.048

If we assume that the lower slope of the stress-strain data in the lowstrain region is "real" and is not the specimen shifting (because the specimen was preloaded), then a low-strain analysis leads to $43 \%$ decrease in apparent $\mathrm{E}$, and $31 \%$ increase in Y.S.

It's inconclusive if this low-strain region is real data or the specimen shifting. For now, would suggest using the original analysis for this specimen. 

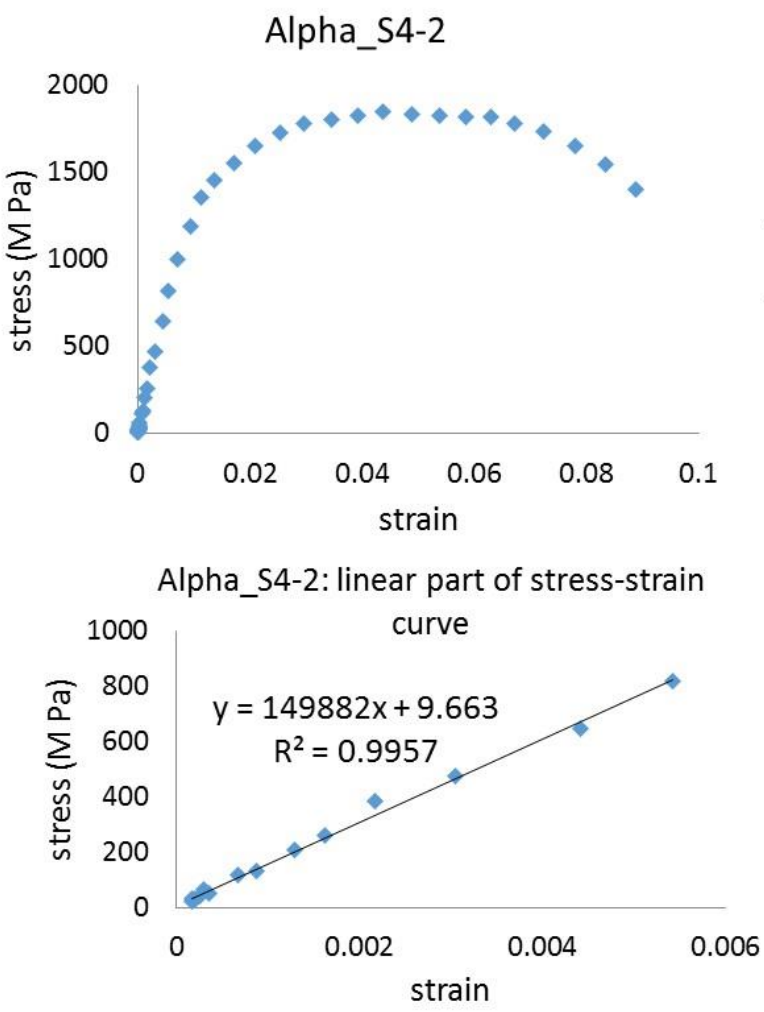

Alpha_S4-2; low-strain linear part

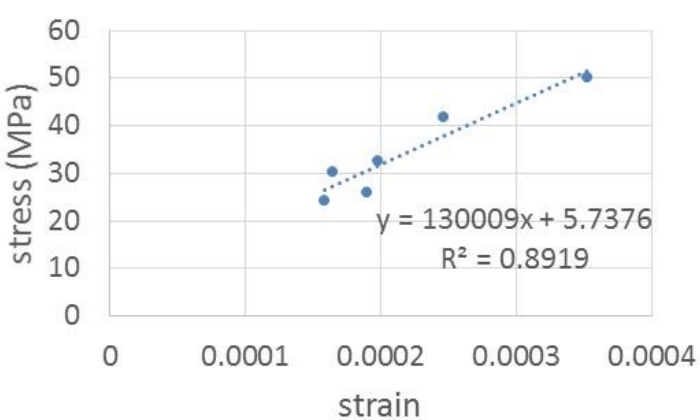

Alpha_S4-2, with and without strain correction

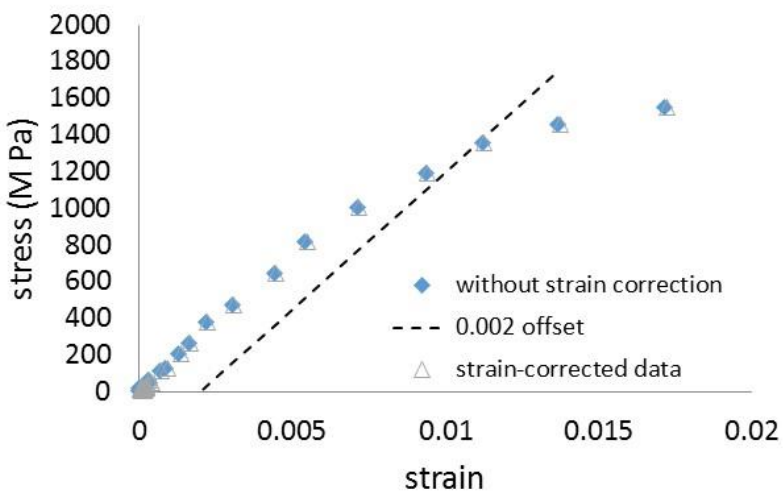

\begin{tabular}{l|c|}
\hline UTS $=$ & $1847.4 \mathrm{M} \mathrm{Pa}$ \\
\hline Apparent $E=$ & $149.9 \mathrm{G} \mathrm{Pa}$ \\
\hline Y.S. $=$ & $1360.0 \mathrm{M} \mathrm{Pa}$ \\
\hline ext to UTS $=$ & 0.044 \\
Fmax $=$ & $24.5 \mathrm{~N}$
\end{tabular}

The strain-correction doesn't change the preloaded data much, so we don't expect a low-strain analysis to significantly change the results...

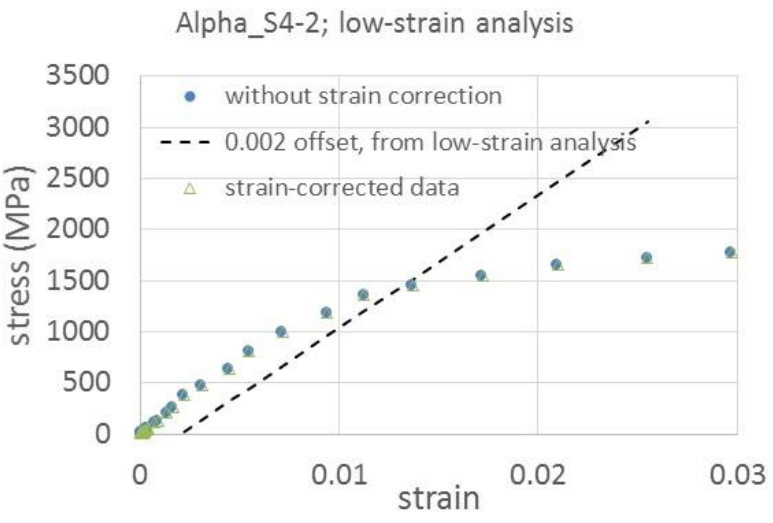

From Low-strain analysis:

\begin{tabular}{l|c|} 
UTS $=$ & $1847.4 \mathrm{M} \mathrm{Pa}$ \\
\hline Apparent $\mathrm{E}=$ & $130.0 \mathrm{G} \mathrm{Pa}$ \\
Y.S. $=$ & $1459.0 \mathrm{M} \mathrm{Pa}$ \\
ext to UTS $=$ & 0.044
\end{tabular}

As expected, a low-strain analysis does not change the apparent E or Y.S. by as much as some of the other specimens.. For this specimen, the lowstrain analysis decreased the apparent $E$ has by $13 \%$ and increased the Y.S. by $7 \%$.

Since DIC does not resolve strains below 0.0005 accurately (see our Oct 2015 progress report for a discussion on this), and the $\$ 4$ specimens are the smallest specimens, the low strains for this specimen are probably not accurate. Therefore, we recommend using the original values of apparent $E$ and $Y . S$. for this specimen. 
Alpha_S4-3

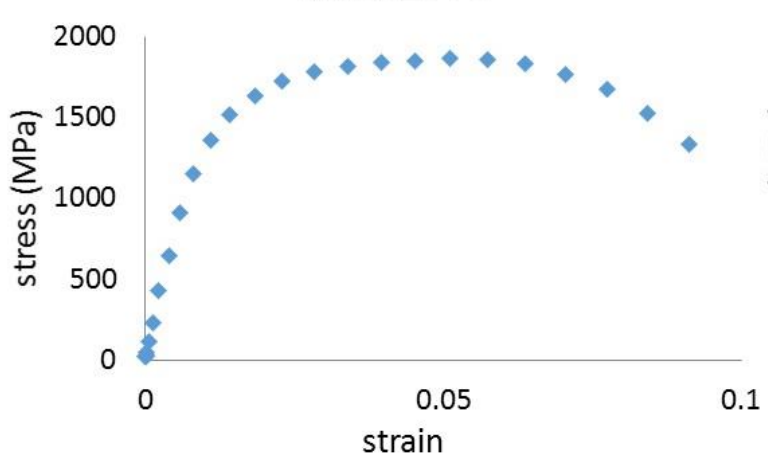

Alpha_S4-3: linear part of stress-strain curve

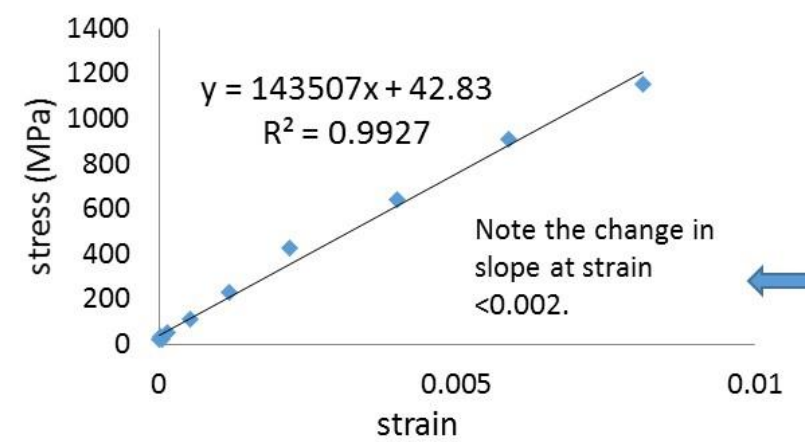

Alpha_S4-3; low-strain linear part

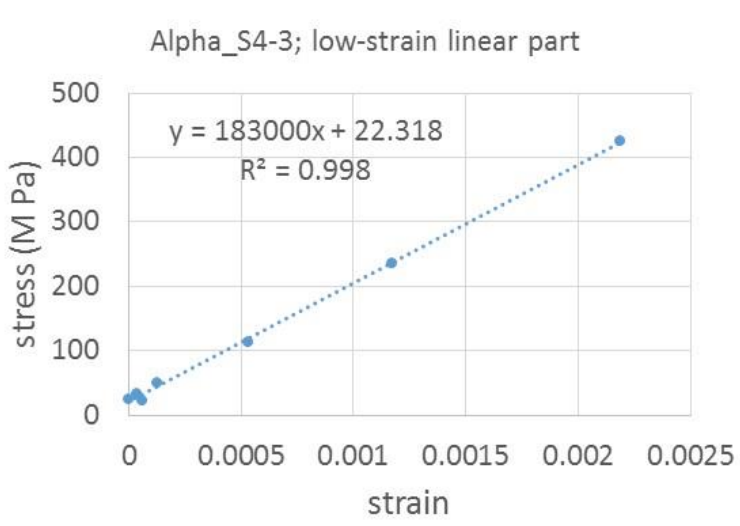

Alpha_S4-3, with and without strain correction

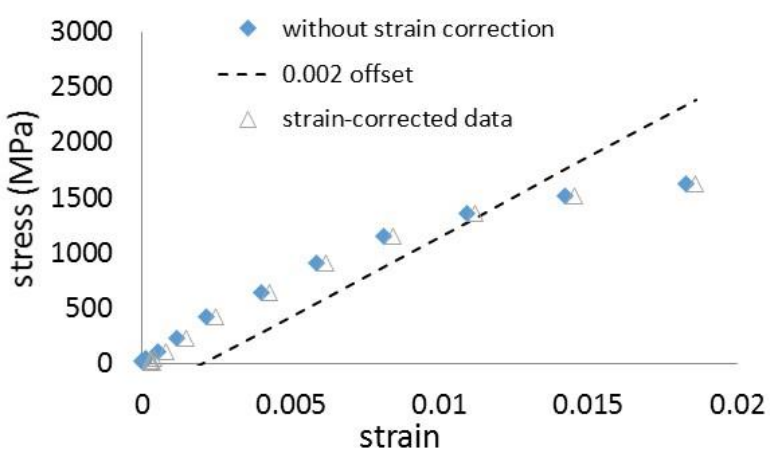

\begin{tabular}{l|c|}
\hline UTS $=$ & $1860.45 \mathrm{M} \mathrm{Pa}$ \\
\hline Apparent $E=$ & $143.5 \mathrm{G} \mathrm{Pa}$ \\
\hline Y.S. $=$ & $1321 \mathrm{M} \mathrm{Pa}$ \\
\hline ext to UTS $=$ & 0.051 \\
\hline Fmax $=$ & $24.88 \mathrm{~N}$ \\
\hline
\end{tabular}

The strain-correction appears to not change the preloaded data much but there is a change in slope at strain 0.002, therefore a low-strain analysis is expected to change the apparent $E$ and $Y . S$.

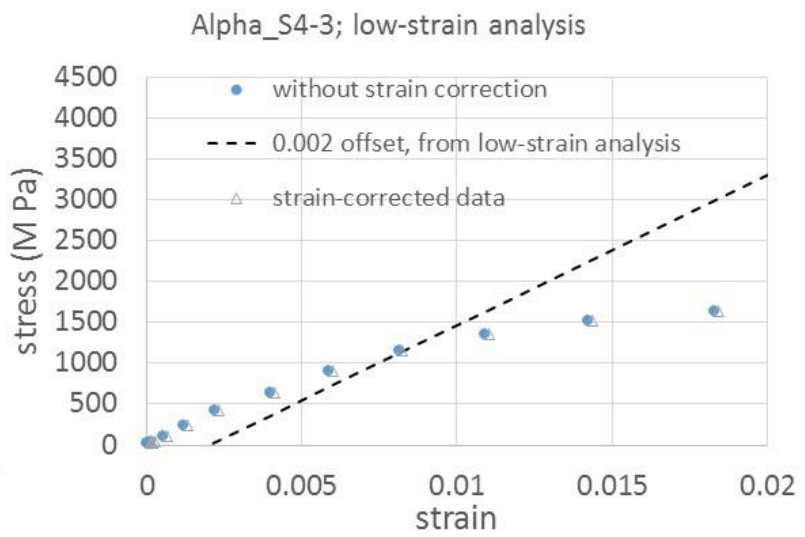

From Low-strain analysis:

\begin{tabular}{l|c|}
\hline UTS $=$ & $1860.45 \mathrm{M} \mathrm{Pa}$ \\
\hline Apparent $\mathrm{E}=$ & $183 \mathrm{G} \mathrm{Pa}$ \\
\hline Y.S $=$ & $1153 \mathrm{M} \mathrm{Pa}$ \\
\hline ext to UTS $=$ & 0.051
\end{tabular}

For this specimen, a low-strain analysis increases the apparent E by $28 \%$, and decreases the Y.S. by $13 \%$. 


\section{Appendix D: Engineering Stress-strain Curves for Alpha Material, at Strain Rate 1/s}
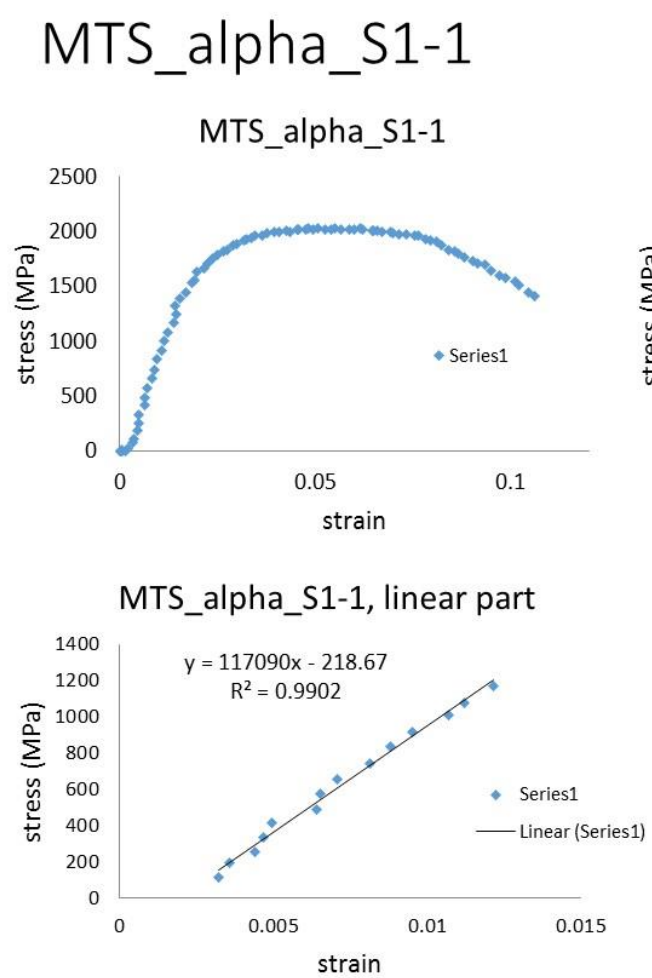
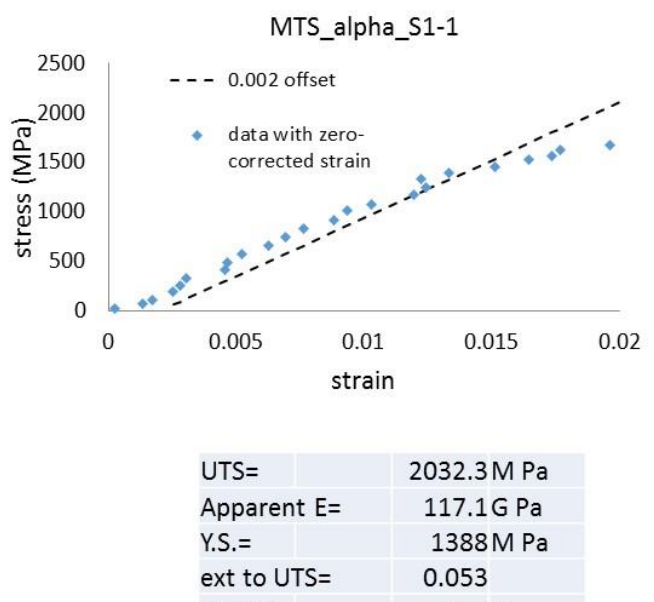

MTS_alpha_S1-1, no strain correction

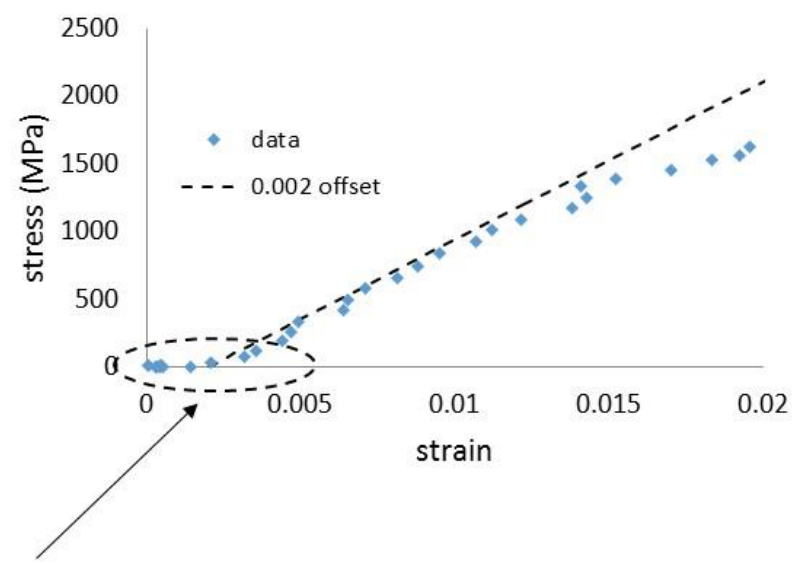

Specimen could have been shifting in this region. Specimen was not preloaded. 


\section{MTS_alpha_S1-2}
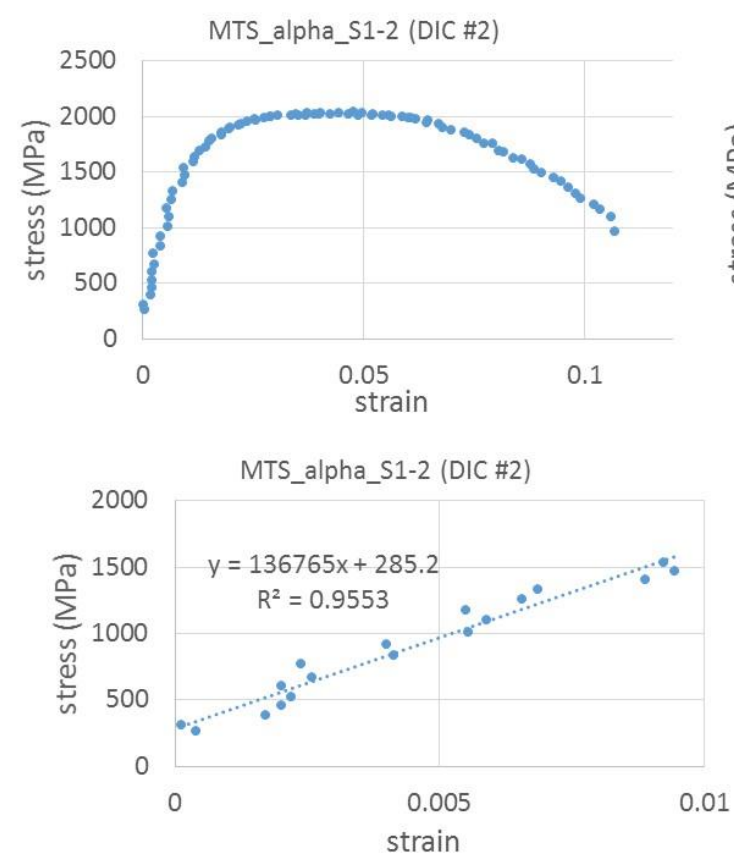

\section{MTS_alpha_S1-3}

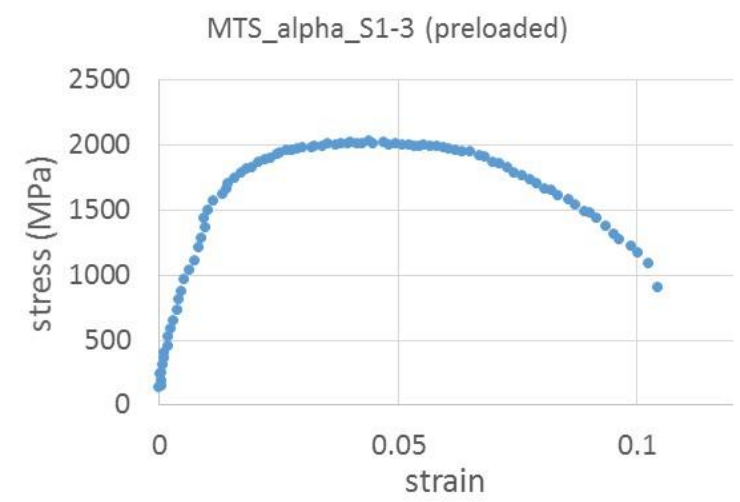

MTS_alpha_S1-3 (preloaded); linear part

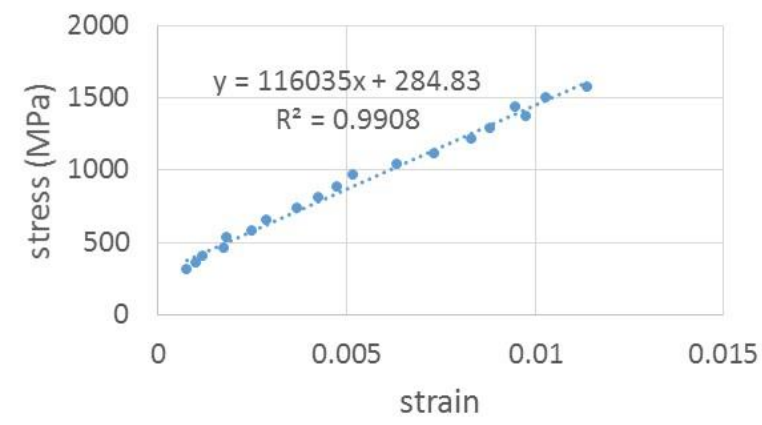

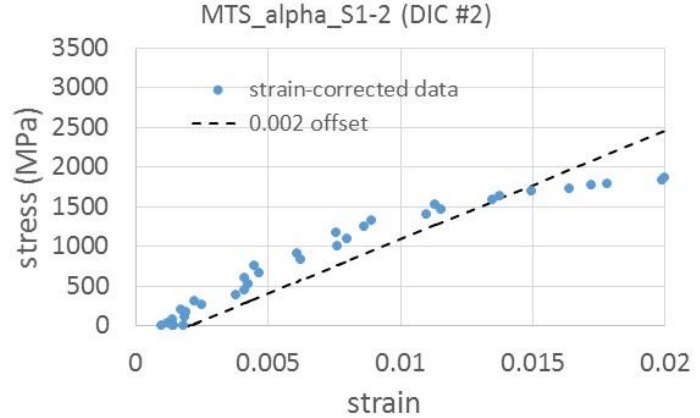

\begin{tabular}{l|c|}
\hline UTS $=$ & $2038.21 \mathrm{M} \mathrm{Pa}$ \\
\hline Apparent $\mathrm{E}=$ & $136.77 \mathrm{G} \mathrm{Pa}$ \\
\hline Y.S. $=$ & $1590.00 \mathrm{M} \mathrm{Pa}$ \\
\hline ext to UTS $=$ & 0.050 \\
\hline Fmax $=$ & $75.79 \mathrm{~N}$ \\
& \\
\hline strain rate= & 1.62 \\
\hline
\end{tabular}

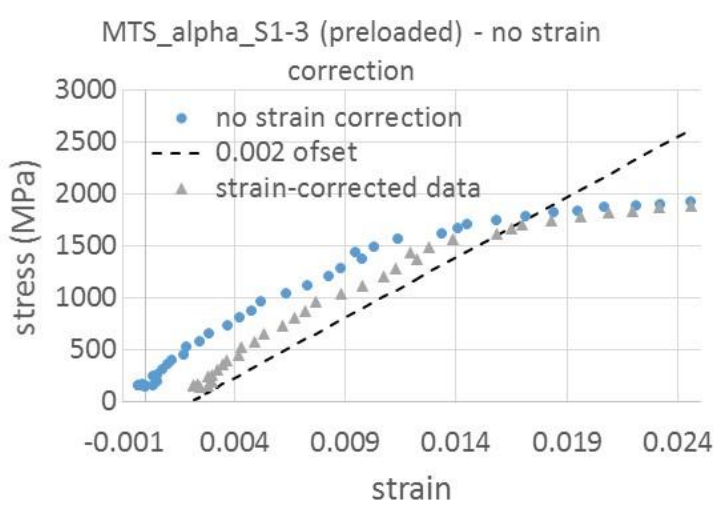

UTS=

Apparent $\mathrm{E}=$

Y.S.=

ext to UTS=

Fmax=

strain rate $=$
2030.7 M Pa

116.0 G Pa

1619.0 M Pa

0.046

$76.4 \mathrm{~N}$ 


\section{MTS_alpha_S2-1 $($ strain rate $=0.84)$}
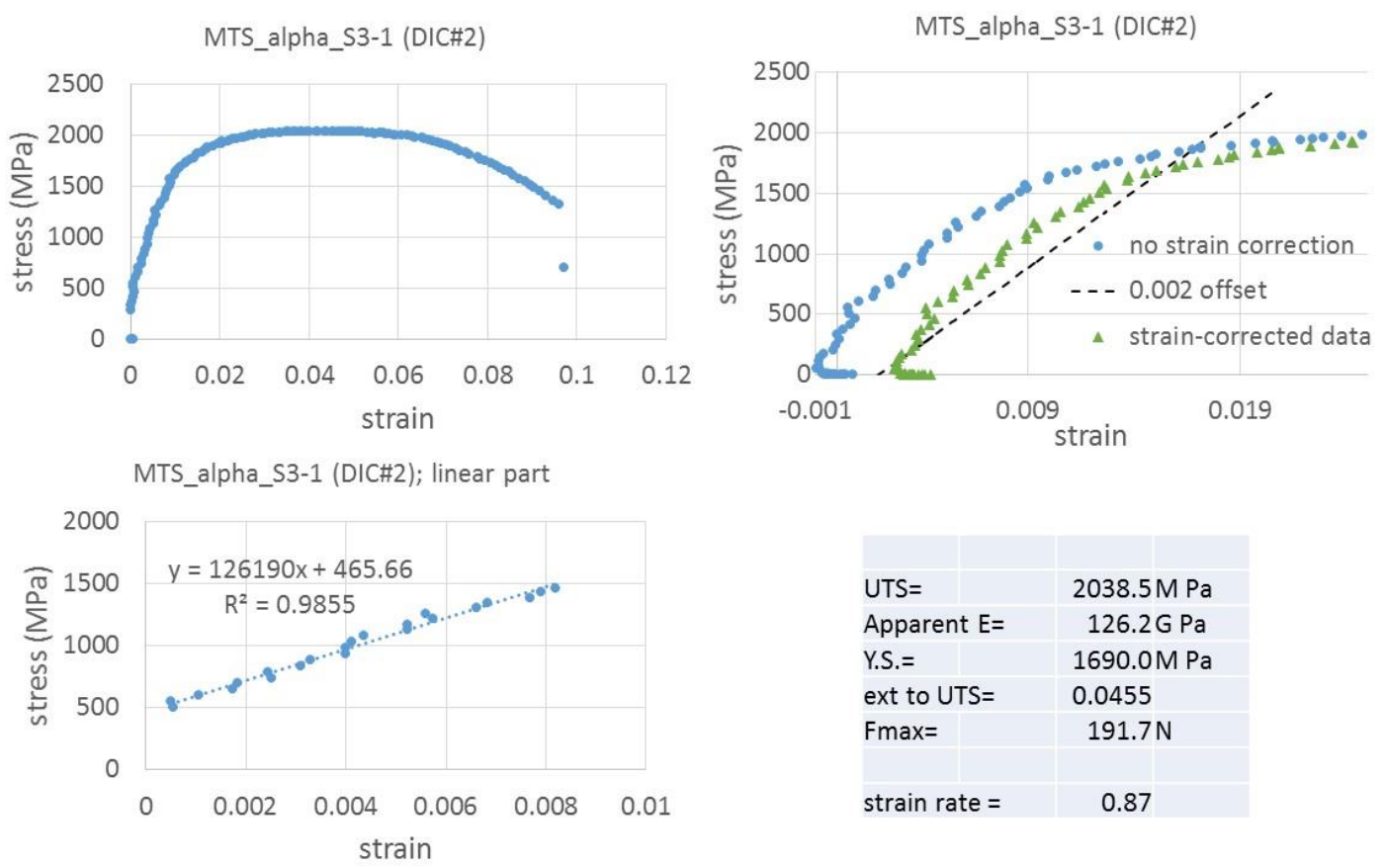

MTS_alpha_S2-2
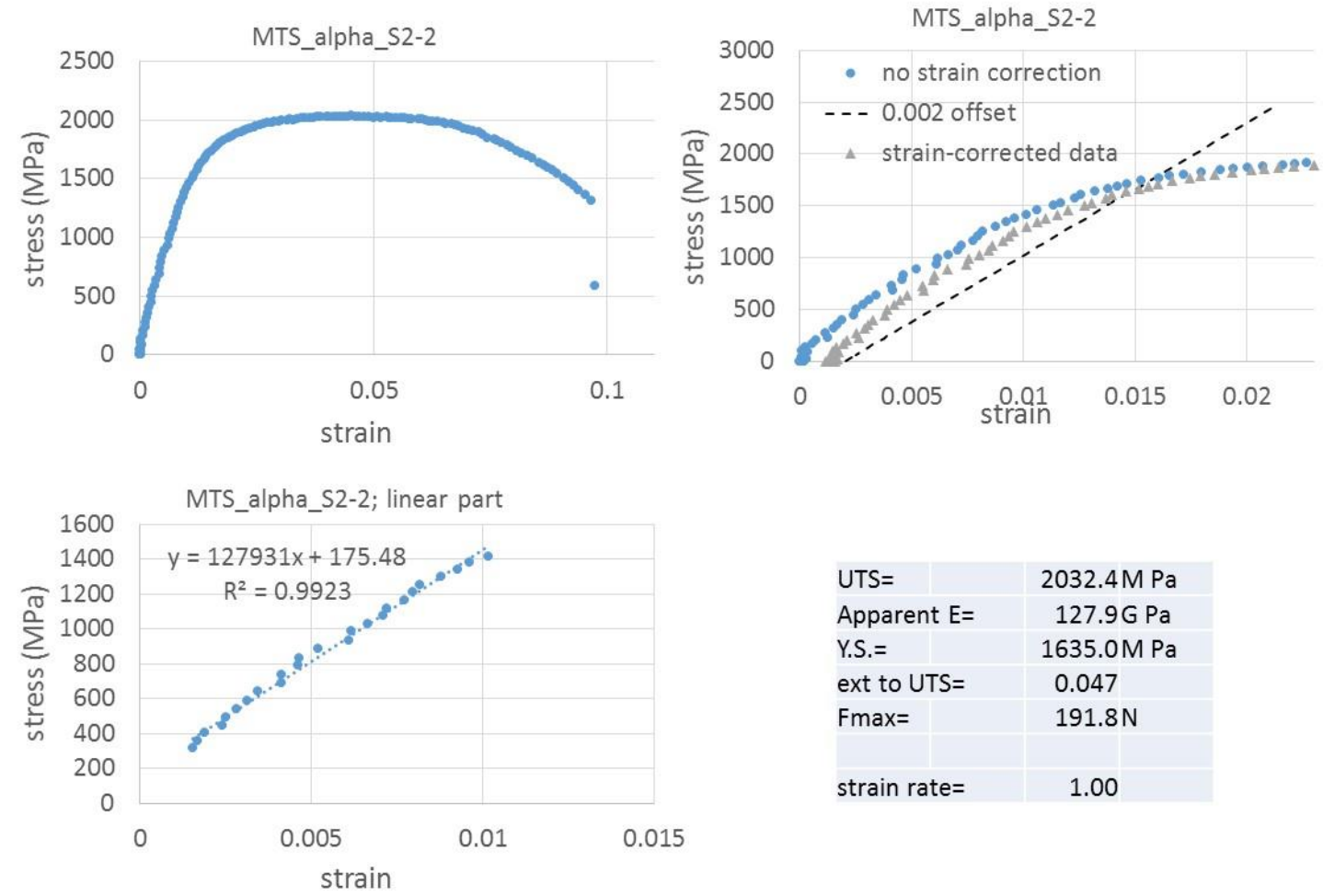

\begin{tabular}{l|c|}
\hline UTS $=$ & $2032.4 \mathrm{M} \mathrm{Pa}$ \\
\hline Apparent $\mathrm{E}=$ & $127.9 \mathrm{G} \mathrm{Pa}$ \\
\hline Y.S. $=$ & $1635.0 \mathrm{M} \mathrm{Pa}$ \\
\hline ext to UTS $=$ & 0.047 \\
\hline Fmax $=$ & $191.8 \mathrm{~N}$ \\
& \\
\hline strain rate $=$ & 1.00
\end{tabular}




\section{MTS_alpha_S2-3}
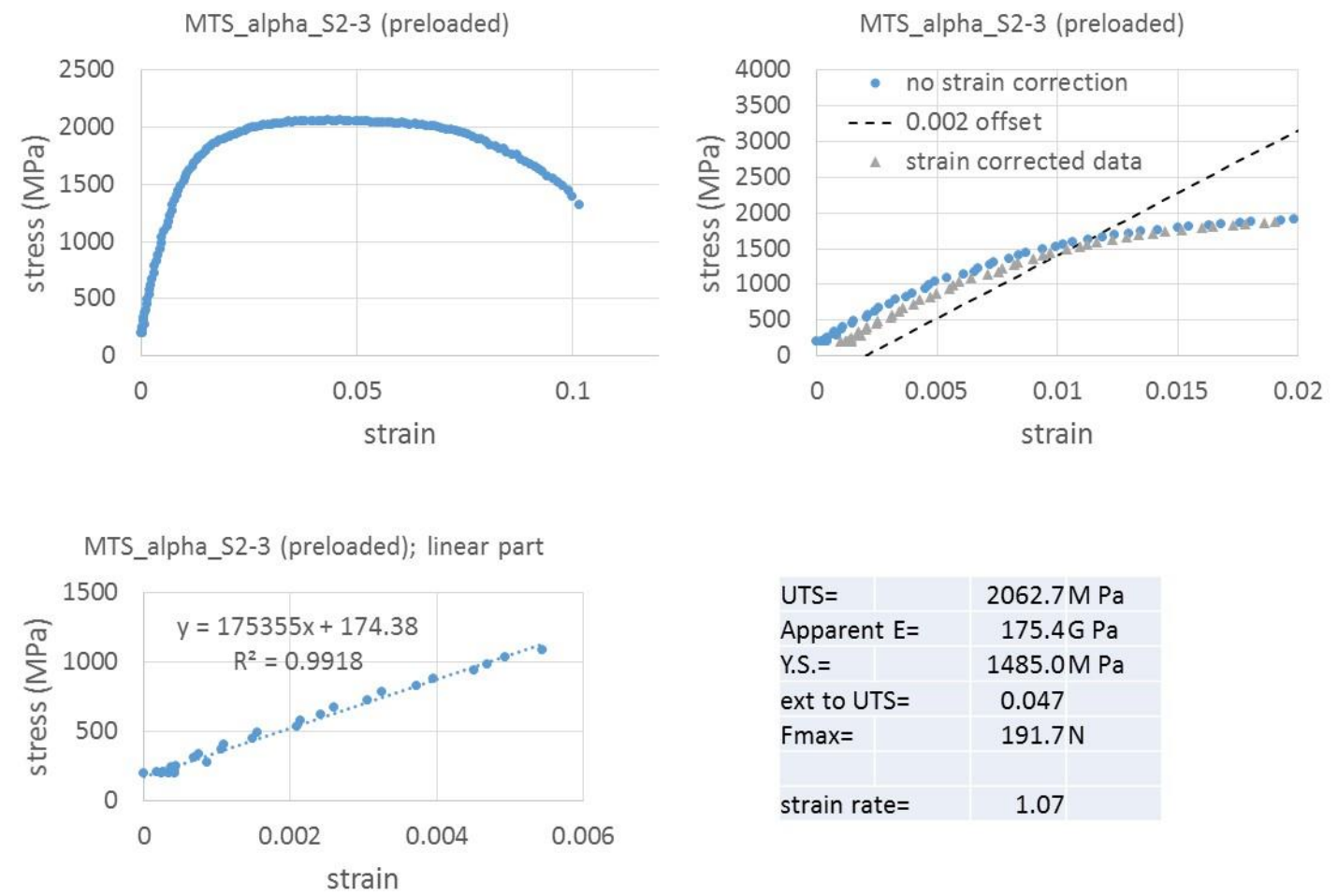

\begin{tabular}{l|c|}
\hline UTS $=$ & $2062.7 \mathrm{M} \mathrm{Pa}$ \\
\hline Apparent $\mathrm{E}=$ & $175.4 \mathrm{G} \mathrm{Pa}$ \\
\hline Y.S. $=$ & $1485.0 \mathrm{M} \mathrm{Pa}$ \\
\hline ext to UTS $=$ & 0.047 \\
\hline Fmax $=$ & $191.7 \mathrm{~N}$ \\
& \\
\hline strain rate= & 1.07
\end{tabular}

\section{MTS_alpha_S3-1 (strain rate $=0.91)$}

MTS_alpha_S3-1

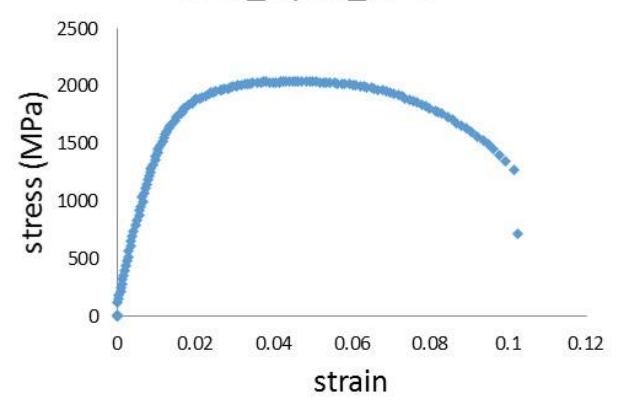

MTS_alpha_S3-1, linear part

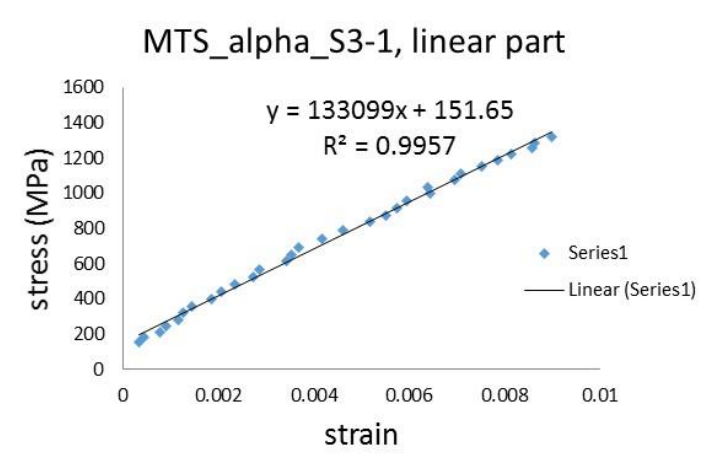

MTS_alpha_S3-1

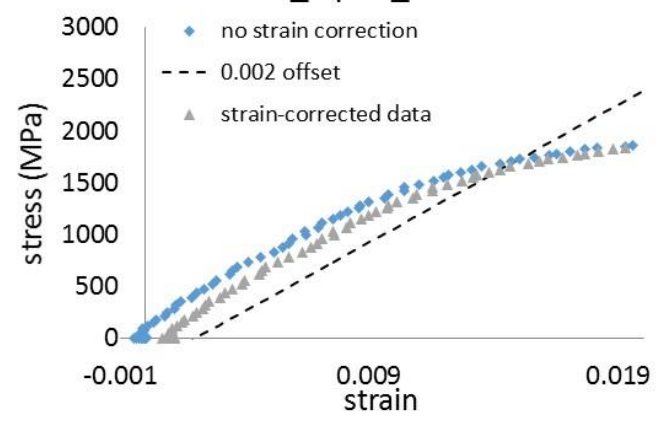

\begin{tabular}{l|c|}
\hline UTS $=$ & $2043.6 \mathrm{M} \mathrm{Pa}$ \\
\hline Apparent $\mathrm{E}=$ & $133.1 \mathrm{G} \mathrm{Pa}$ \\
\hline Y.S. $=$ & $1551 \mathrm{M} \mathrm{Pa}$ \\
\hline ext to UTS $=$ & 0.048 \\
\hline Fmax $=$ & $267.4 \mathrm{~N}$ \\
\hline & \\
\hline strain rate $=$ & 0.91 \\
\hline
\end{tabular}




\section{MTS_alpha_S3-2 $($ strain rate $=0.92)$}
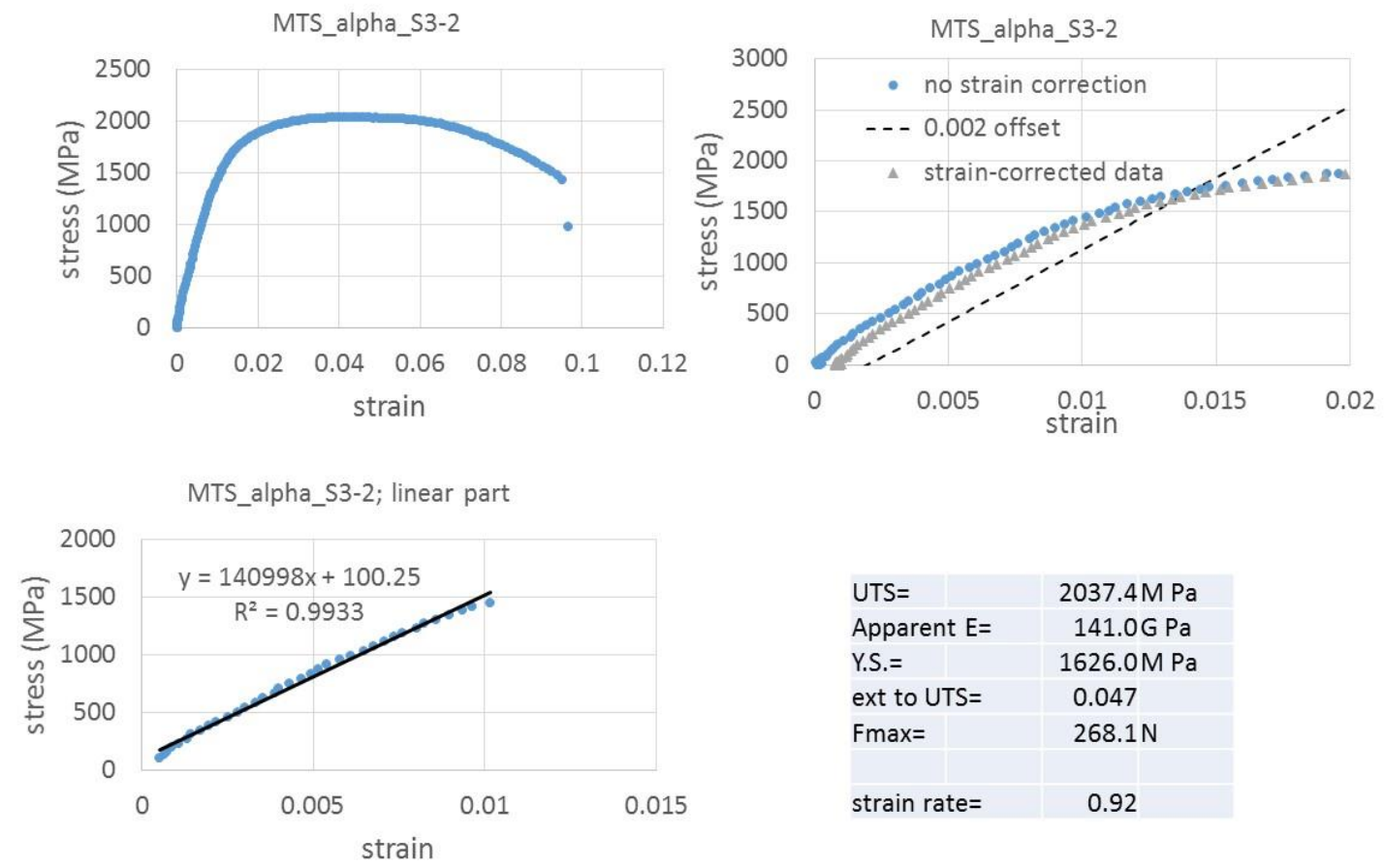

\begin{tabular}{l|c|}
\hline UTS $=$ & $2037.4 \mathrm{M} \mathrm{Pa}$ \\
\hline Apparent $\mathrm{E}=$ & $141.0 \mathrm{G} \mathrm{Pa}$ \\
\hline Y.S. $=$ & $1626.0 \mathrm{M} \mathrm{Pa}$ \\
\hline ext to UTS $=$ & 0.047 \\
\hline Fmax $=$ & $268.1 \mathrm{~N}$ \\
\hline & \\
\hline strain rate $=$ & 0.92 \\
\hline
\end{tabular}

\section{MTS_alpha_S3-3}
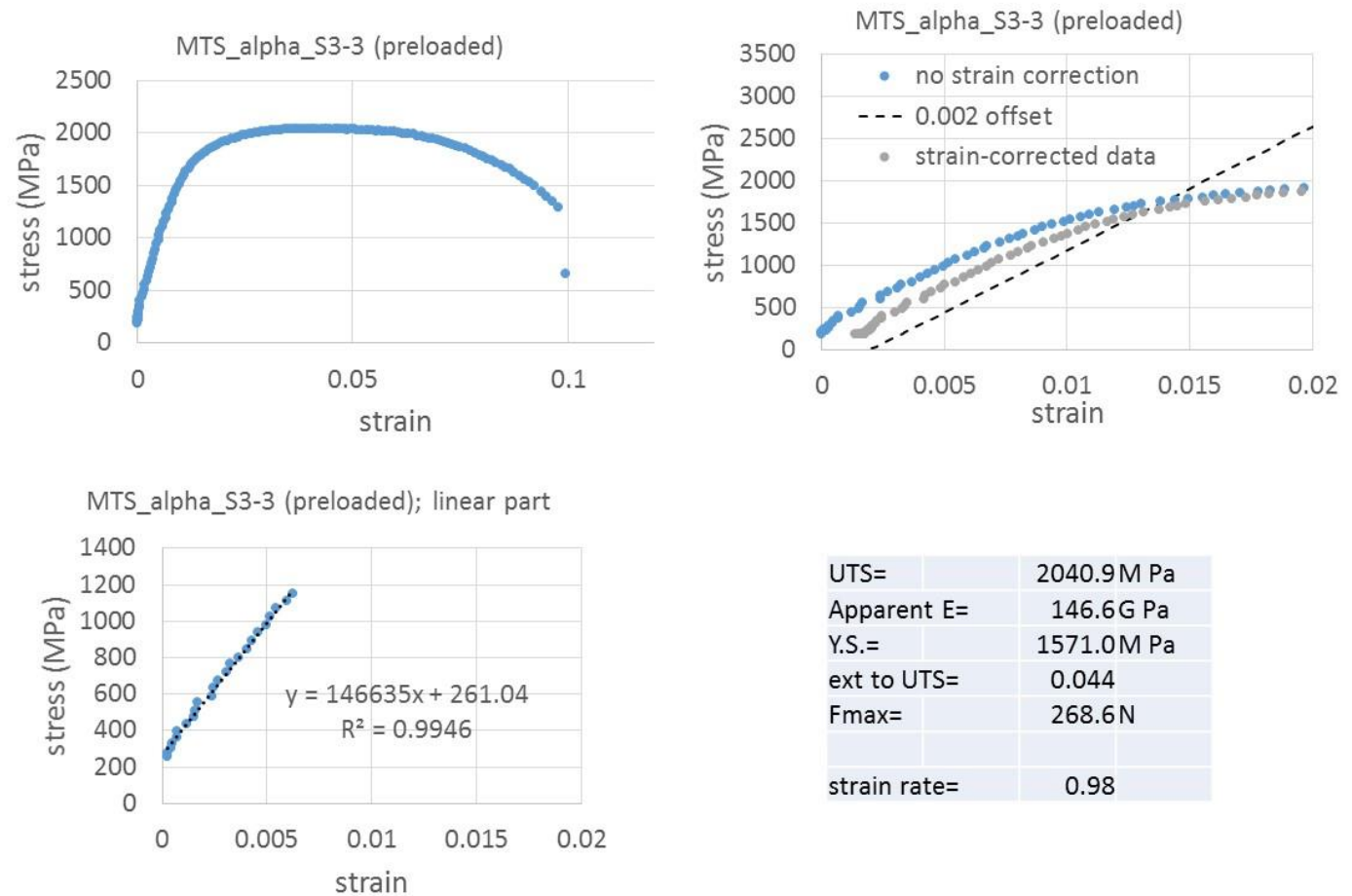

\begin{tabular}{l|c|}
\hline UTS $=$ & $2040.9 \mathrm{M} \mathrm{Pa}$ \\
\hline Apparent $\mathrm{E}=$ & $146.6 \mathrm{G} \mathrm{Pa}$ \\
\hline Y.S. $=$ & $1571.0 \mathrm{M} \mathrm{Pa}$ \\
\hline ext to UTS $=$ & 0.044 \\
\hline Fmax $=$ & $268.6 \mathrm{~N}$ \\
\hline & \\
\hline strain rate= & 0.98
\end{tabular}




\section{MTS_alpha_S4-1 $($ strain rate $=2.1)$}
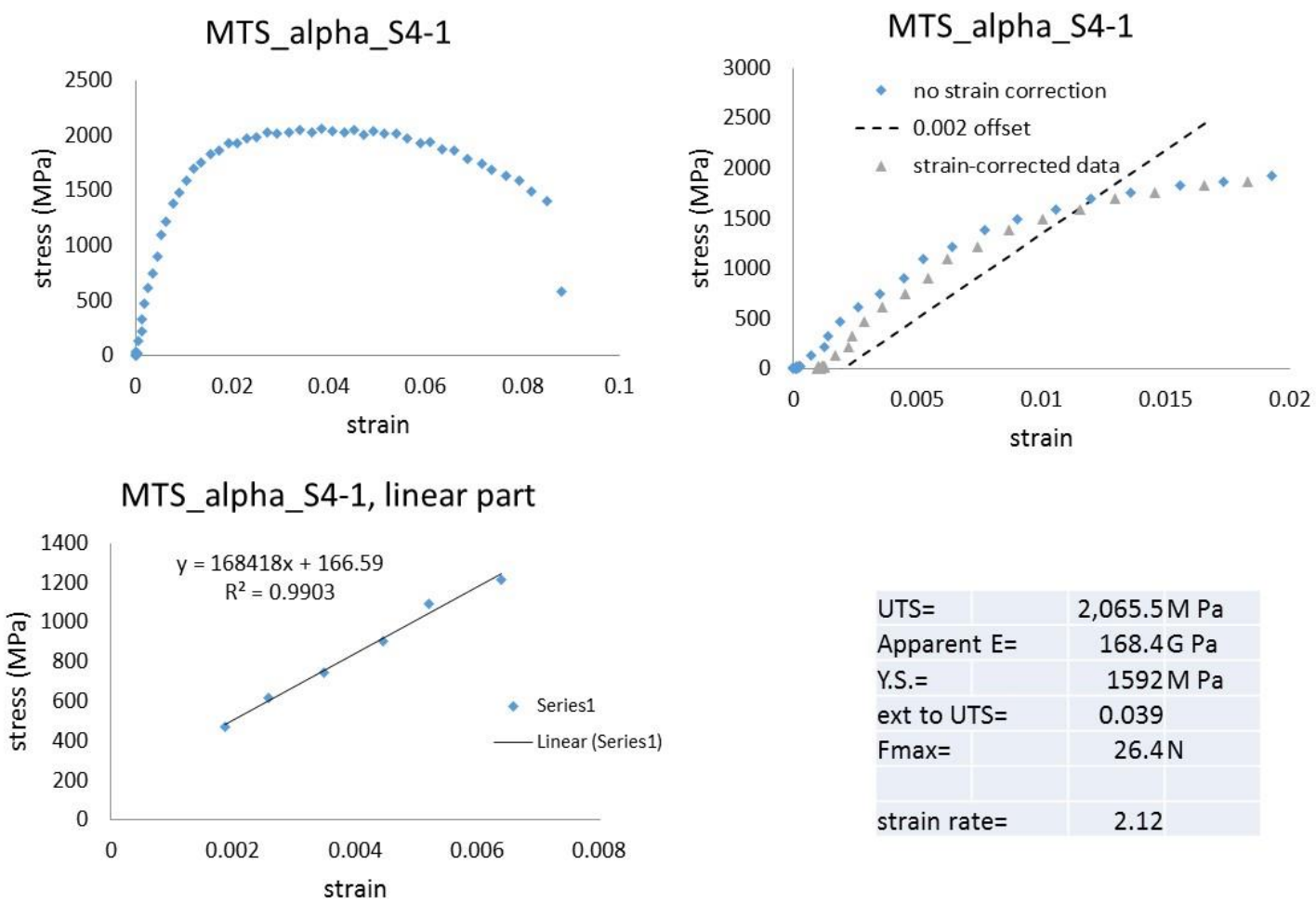

\begin{tabular}{l|c|}
\hline UTS $=$ & $2,065.5 \mathrm{M} \mathrm{Pa}$ \\
\hline Apparent $\mathrm{E}=$ & $168.4 \mathrm{G} \mathrm{Pa}$ \\
\hline Y.S. $=$ & $1592 \mathrm{M} \mathrm{Pa}$ \\
\hline ext to UTS $=$ & 0.039 \\
\hline Fmax $=$ & $26.4 \mathrm{~N}$ \\
\hline & \\
\hline strain rate $=$ & 2.12 \\
\hline
\end{tabular}

\section{MTS_alpha_S4-2 (strain rate $=1.9)$}
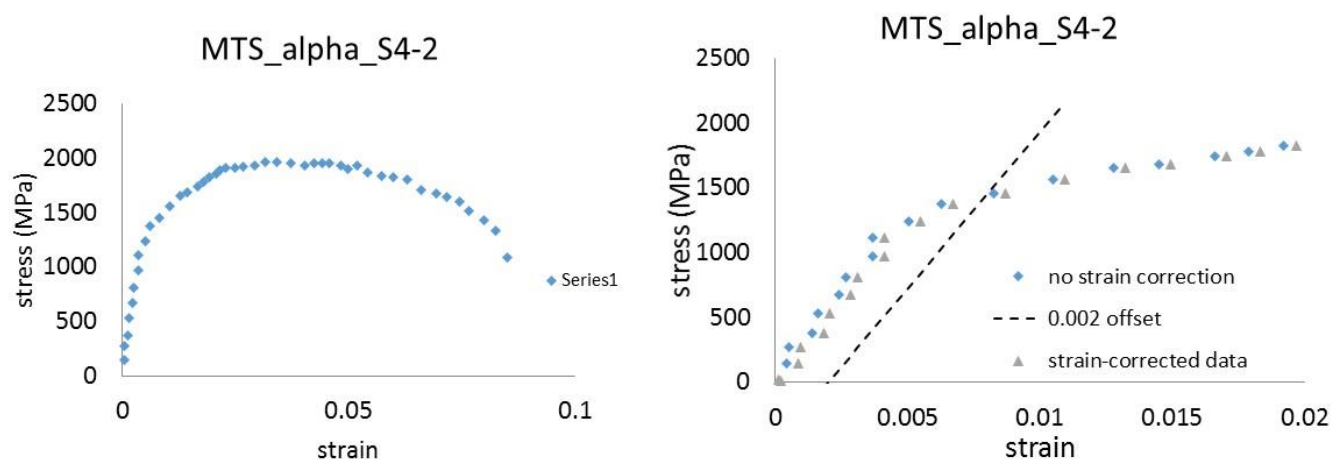

MTS_alpha_S4-2; linear part

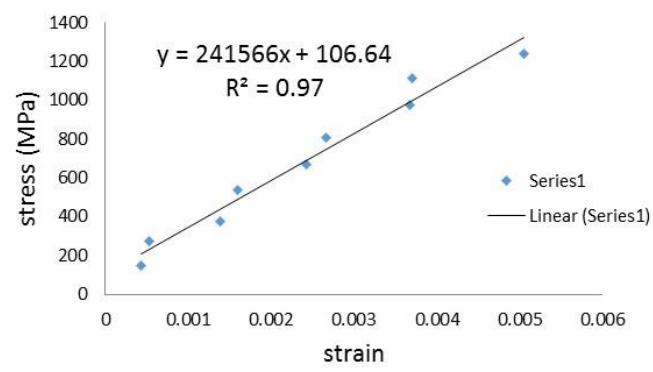

\begin{tabular}{l|c|}
\hline UTS $=$ & $1973.7 \mathrm{M} \mathrm{Pa}$ \\
\hline Apparent $\mathrm{E}=$ & $241.6 \mathrm{G} \mathrm{Pa}$ \\
\hline Y.S. $=$ & $1455.0 \mathrm{M} \mathrm{Pa}$ \\
\hline ext to UTS $=$ & 0.035 \\
\hline Fmax $=$ & $27.0 \mathrm{~N}$ \\
\hline strain rate $=$ & 1.89 \\
\hline
\end{tabular}




\section{MTS_alpha_S4-3 $($ strain rate $=2.38)$}
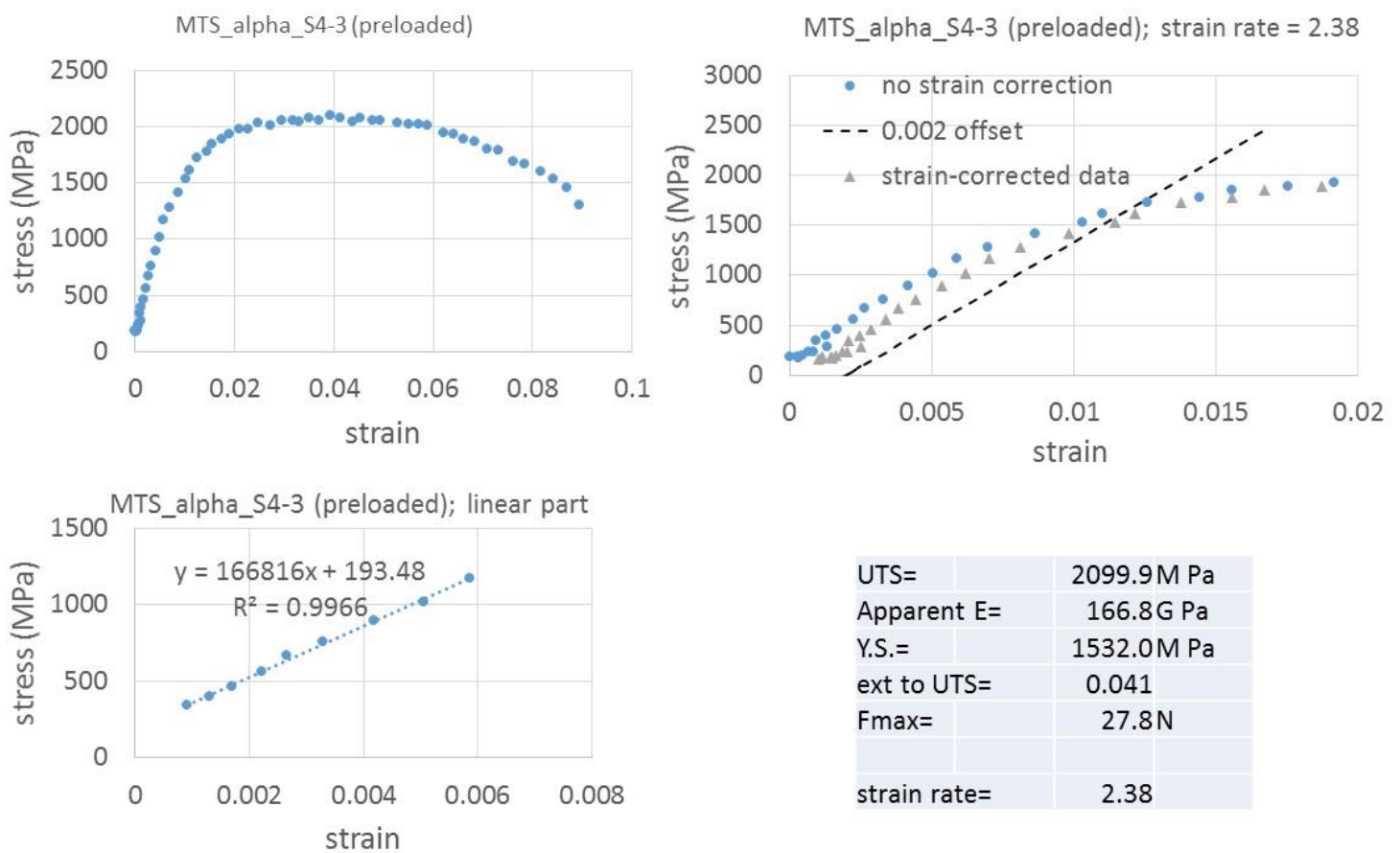

\begin{tabular}{l|c|}
\hline UTS $=$ & $2099.9 \mathrm{M} \mathrm{Pa}$ \\
\hline Apparent $\mathrm{E}=$ & $166.8 \mathrm{G} \mathrm{Pa}$ \\
\hline Y.S. & $1532.0 \mathrm{M} \mathrm{Pa}$ \\
\hline ext to UTS $=$ & 0.041 \\
\hline Fmax $=$ & $27.8 \mathrm{~N}$ \\
\hline & \\
\hline strain rate= & 2.38 \\
\hline
\end{tabular}




\section{Appendix E: Engineering Stress-Strain Curves for C Material, at Strain Rate 0.001/s}

C_S1-1

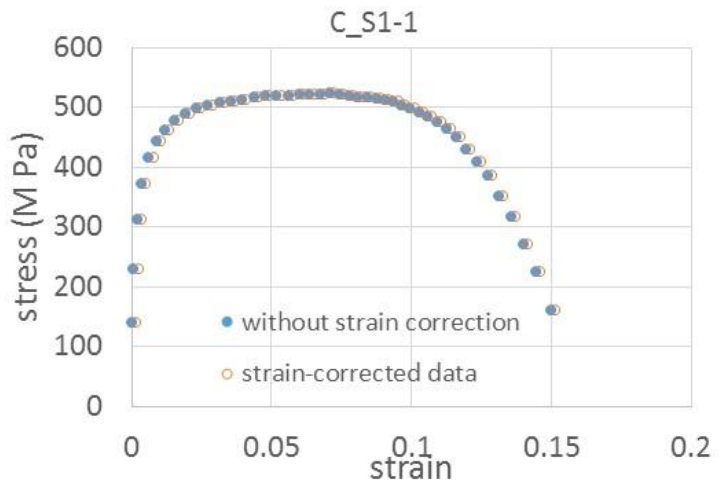

C_S1-1; linear part; low-strain analysis

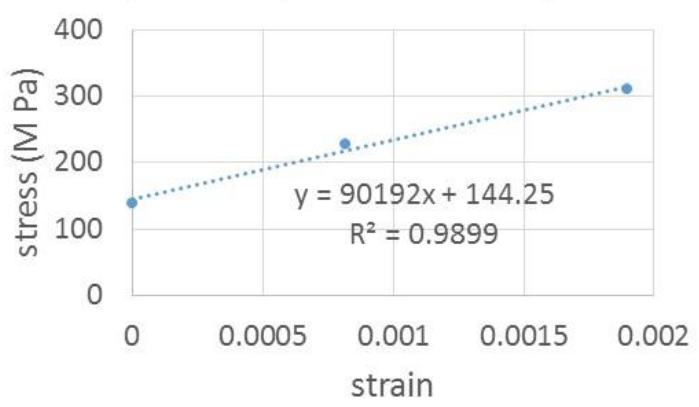

C_S1-2
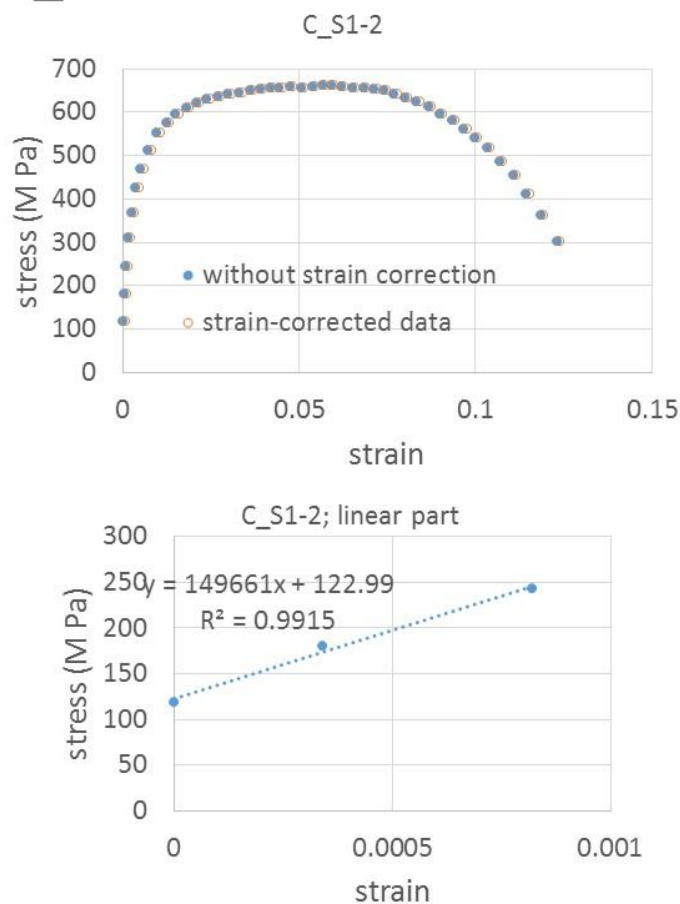

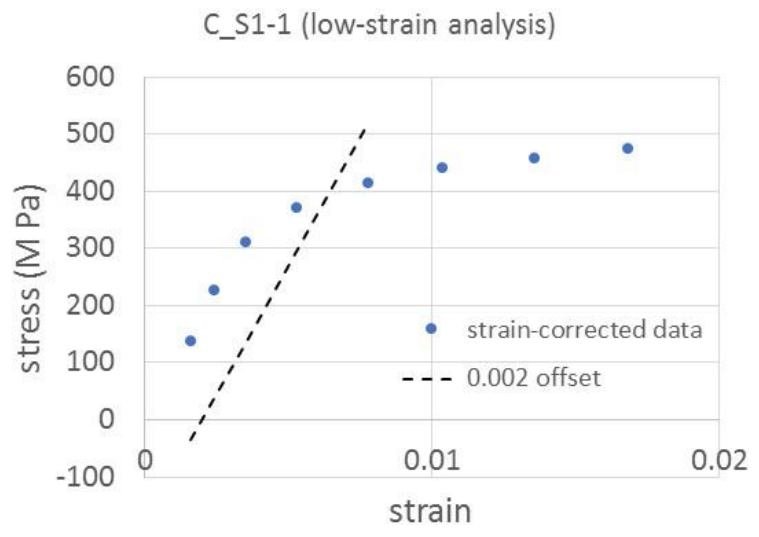

\begin{tabular}{|l|c|}
\hline UTS $=$ & $522.2 \mathrm{M} \mathrm{Pa}$ \\
\hline Apparent $E=$ & $90 \mathrm{G} \mathrm{Pa}$ \\
\hline Y.S. $=$ & $390 \mathrm{M} \mathrm{Pa}$ \\
\hline Ext. to UTS $=$ & 0.072 \\
\hline Fmax $=$ & $17.9 \mathrm{~N}$ \\
\hline
\end{tabular}

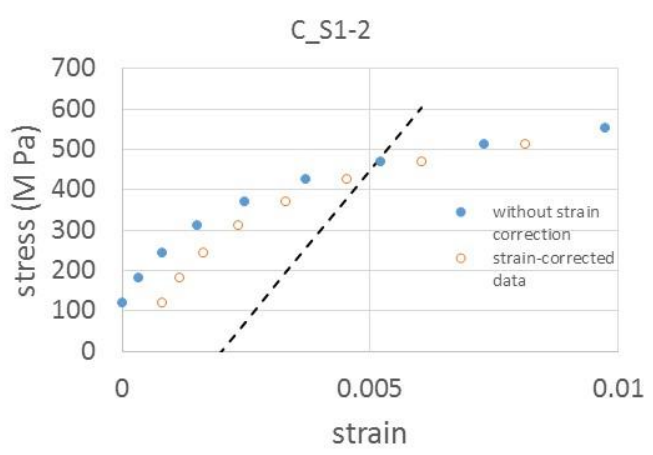

\begin{tabular}{l|l|}
\hline UTS $=$ & $660.5 \mathrm{M} \mathrm{Pa}$ \\
\hline Apparent $\mathrm{E}=$ & $149.7 \mathrm{G} \mathrm{Pa}$ \\
\hline Y.S. & $445.0 \mathrm{M} \mathrm{Pa}$ \\
\hline ext to UTS $=$ & 0.060 \\
\hline Fmax $=$ & $23.9 \mathrm{~N}$
\end{tabular}


C_S1-3

$$
\text { C_S1-3 }
$$

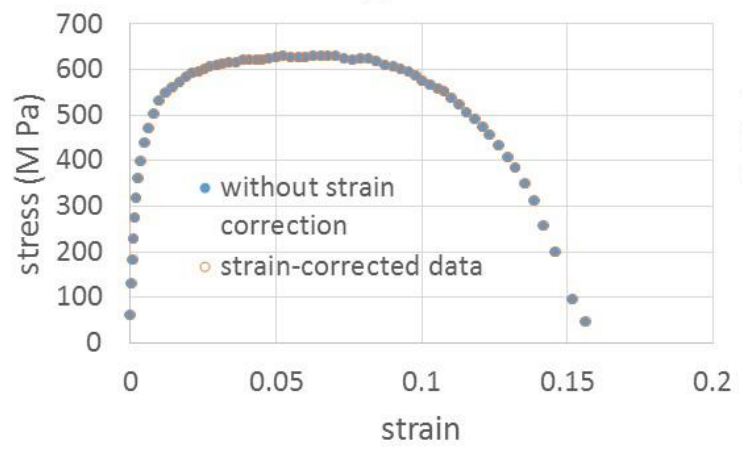

C_S1-3; linear part (low-strain analysis)

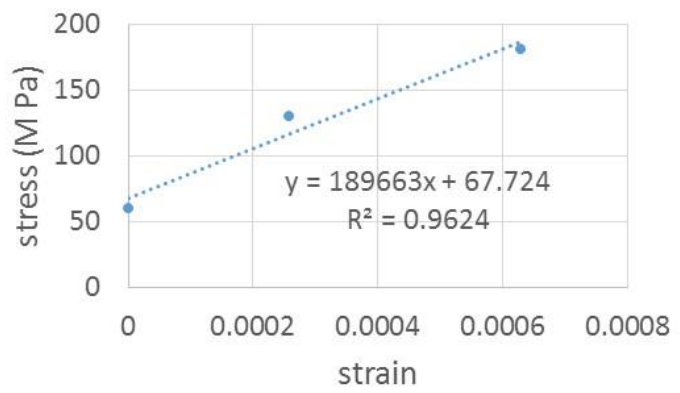

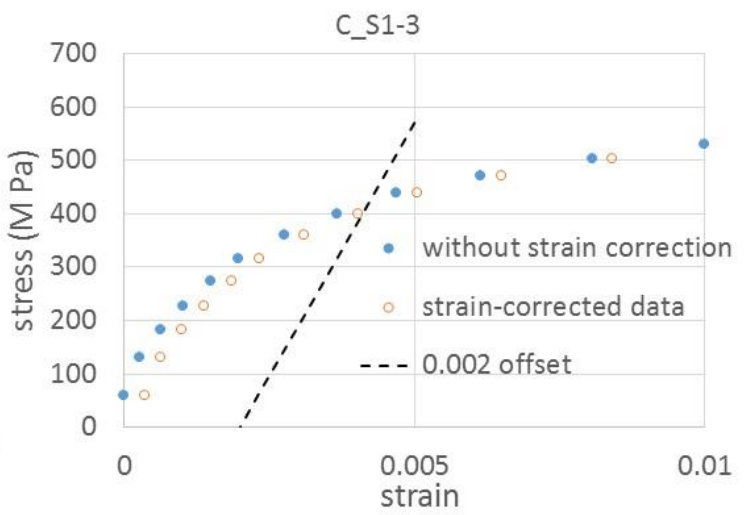

\begin{tabular}{l|l|}
\hline UTS $=$ & $629.8 \mathrm{M} \mathrm{Pa}$ \\
\hline Apparent $\mathrm{E}=$ & $189.7 \mathrm{G} \mathrm{Pa}$ \\
\hline Y.S. $=$ & $400.0 \mathrm{M} \mathrm{Pa}$ \\
\hline ext to UTS $=$ & 0.063 \\
\hline Fmax $=$ & $22.0 \mathrm{~N}$ \\
\hline
\end{tabular}

\section{C_S2-1}
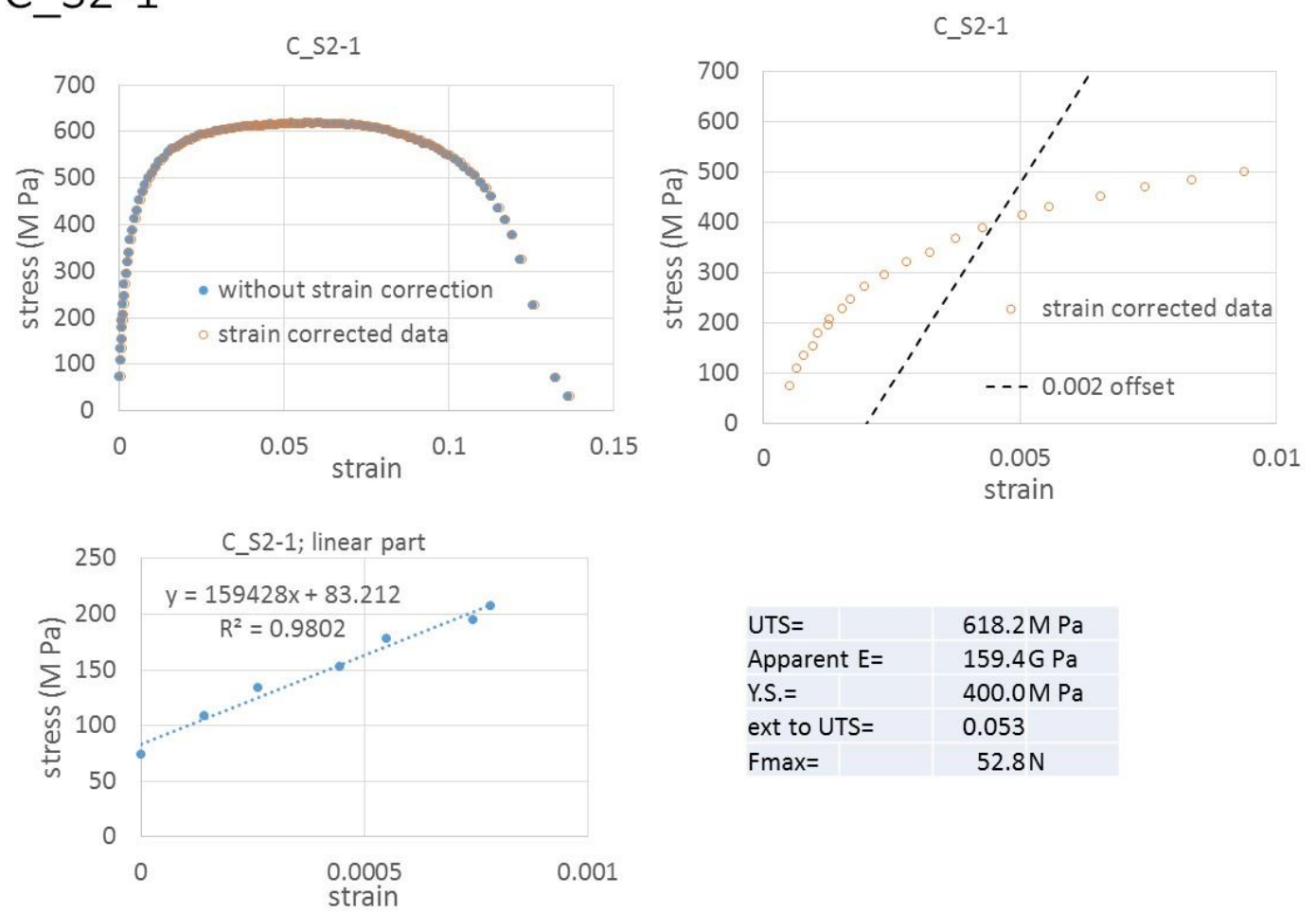

\begin{tabular}{l|l|}
\hline UTS $=$ & $618.2 \mathrm{M} \mathrm{Pa}$ \\
\hline Apparent $\mathrm{E}=$ & $159.4 \mathrm{G} \mathrm{Pa}$ \\
\hline Y.S. $=$ & $400.0 \mathrm{M} \mathrm{Pa}$ \\
\hline ext to UTS $=$ & 0.053 \\
\hline Fmax $=$ & $52.8 \mathrm{~N}$
\end{tabular}




\section{S2-2}
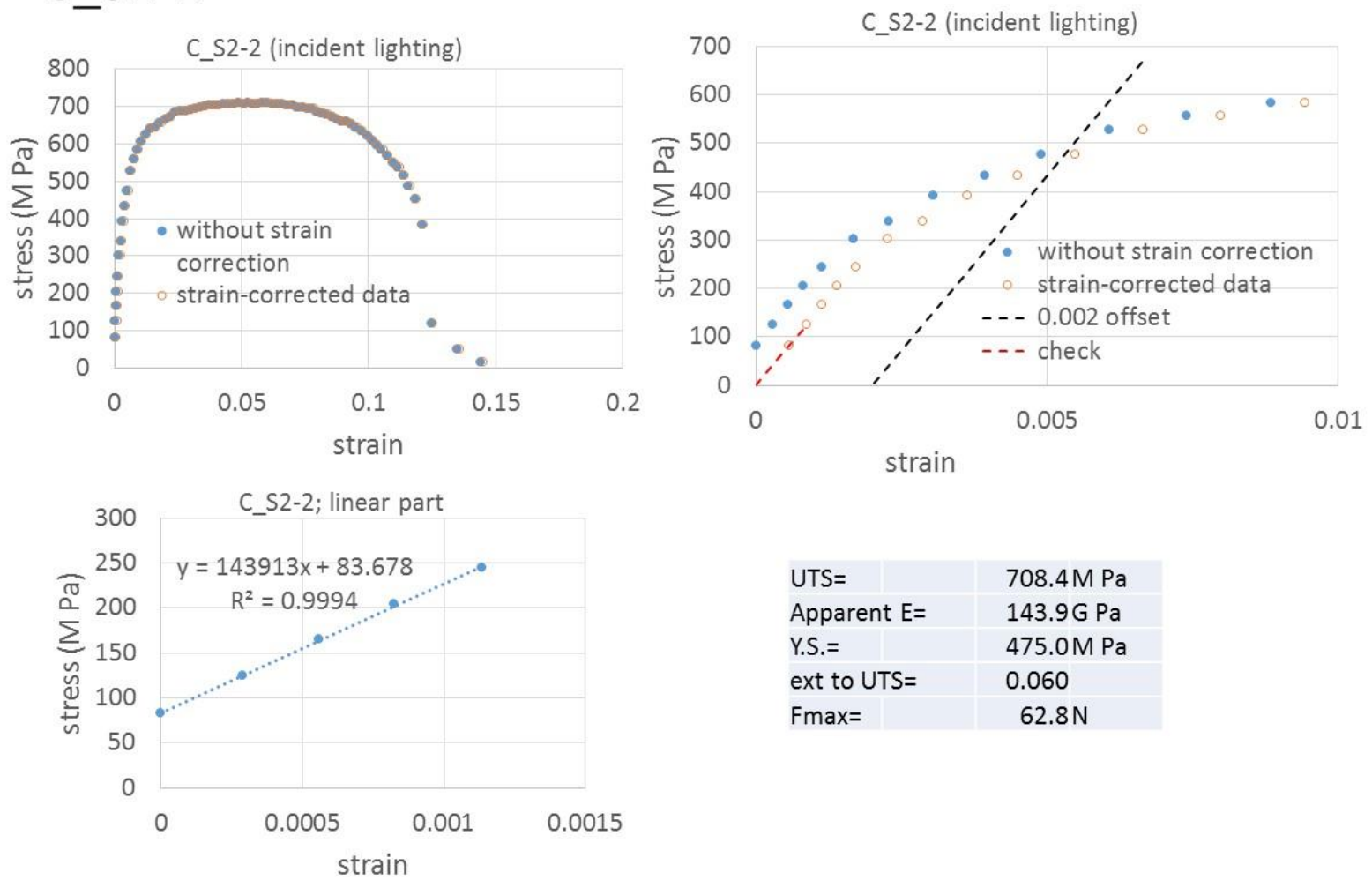

C_S2-3
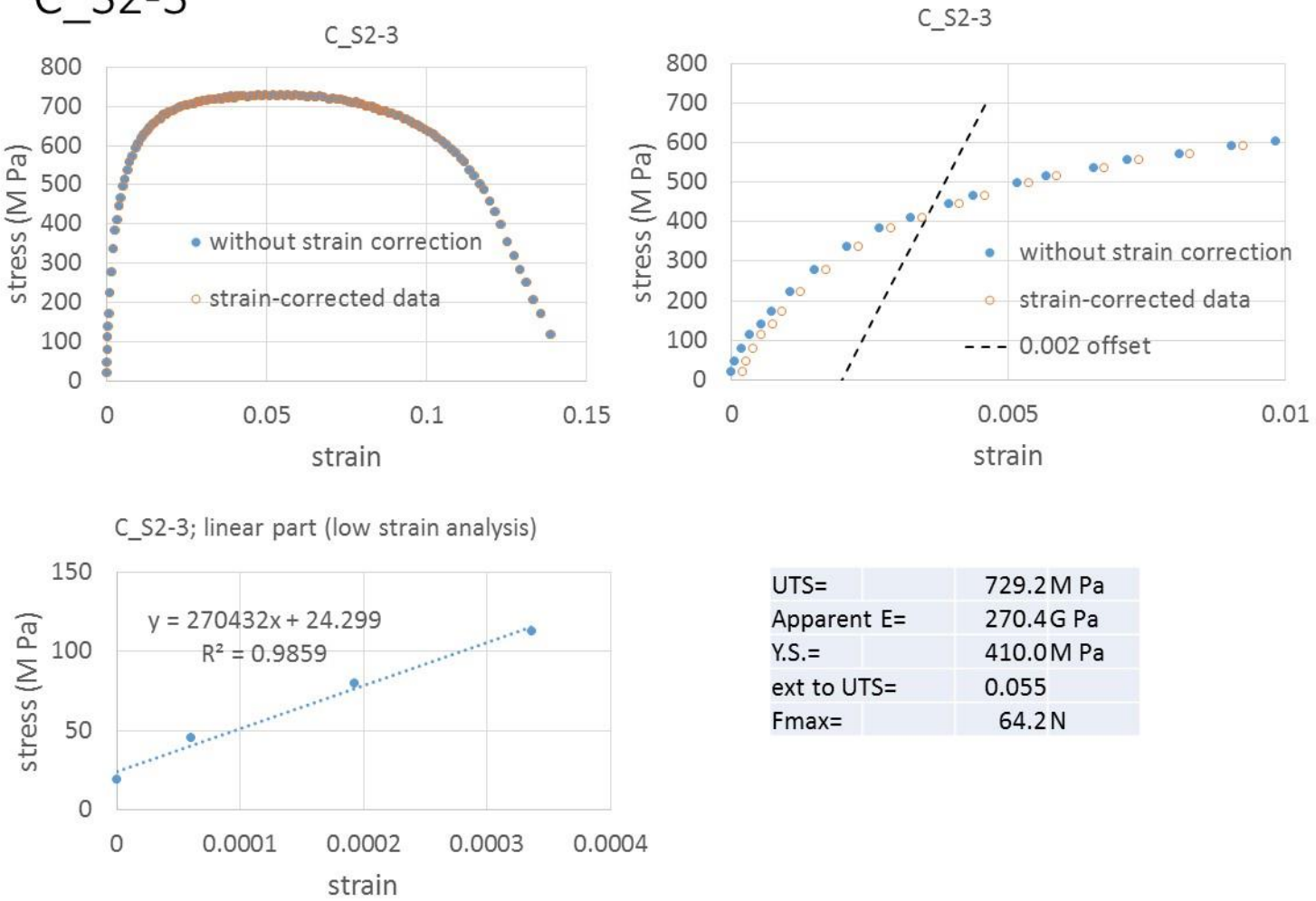


\section{C_S2-4}
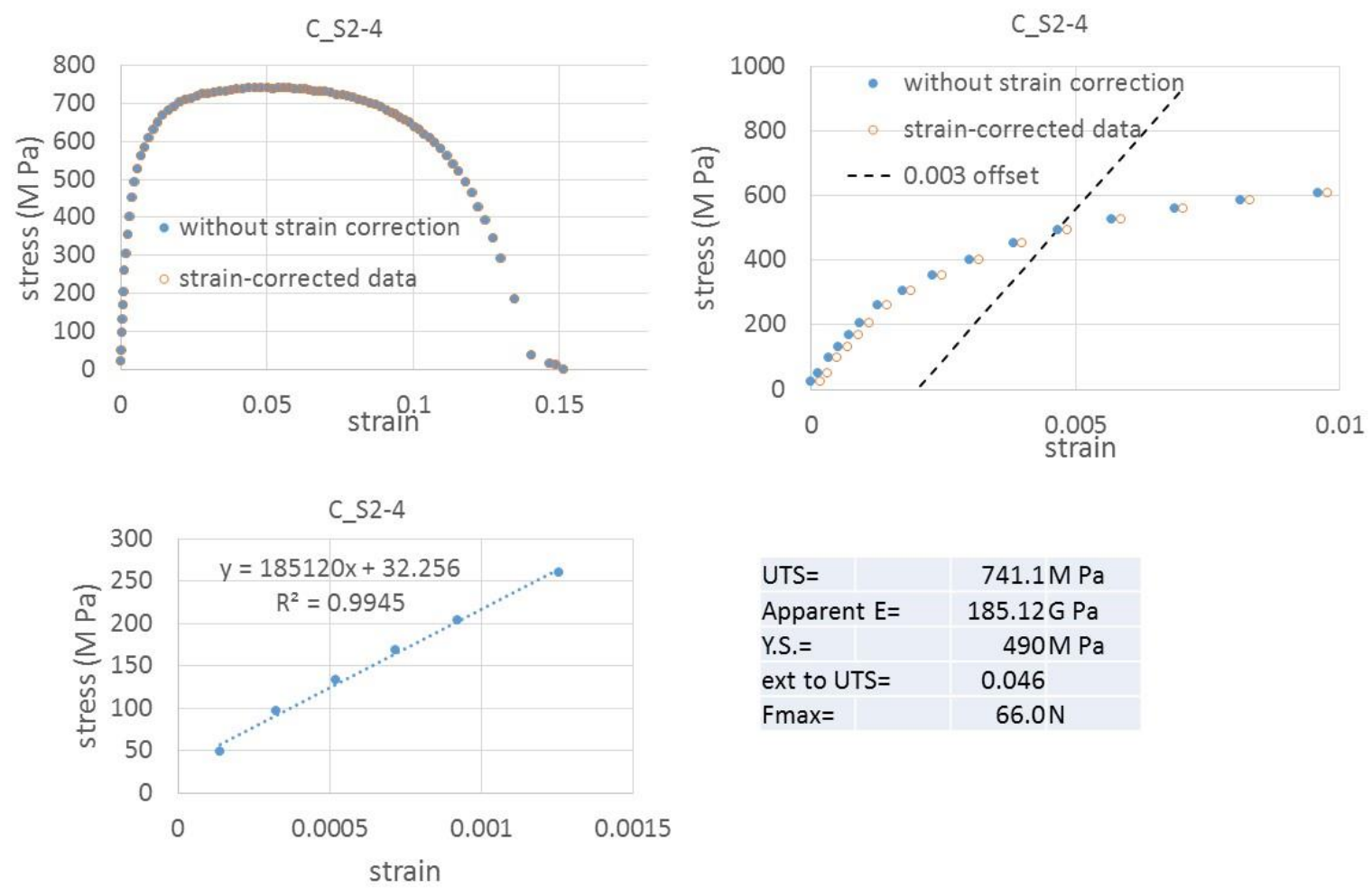

\begin{tabular}{l|c|}
\hline UTS $=$ & $741.1 \mathrm{M} \mathrm{Pa}$ \\
\hline Apparent $\mathrm{E}=$ & $185.12 \mathrm{G} \mathrm{Pa}$ \\
\hline Y.S. $=$ & $490 \mathrm{M} \mathrm{Pa}$ \\
\hline ext to UTS $=$ & 0.046 \\
\hline Fmax $=$ & $66.0 \mathrm{~N}$ \\
\hline
\end{tabular}

\section{C_S3-1}
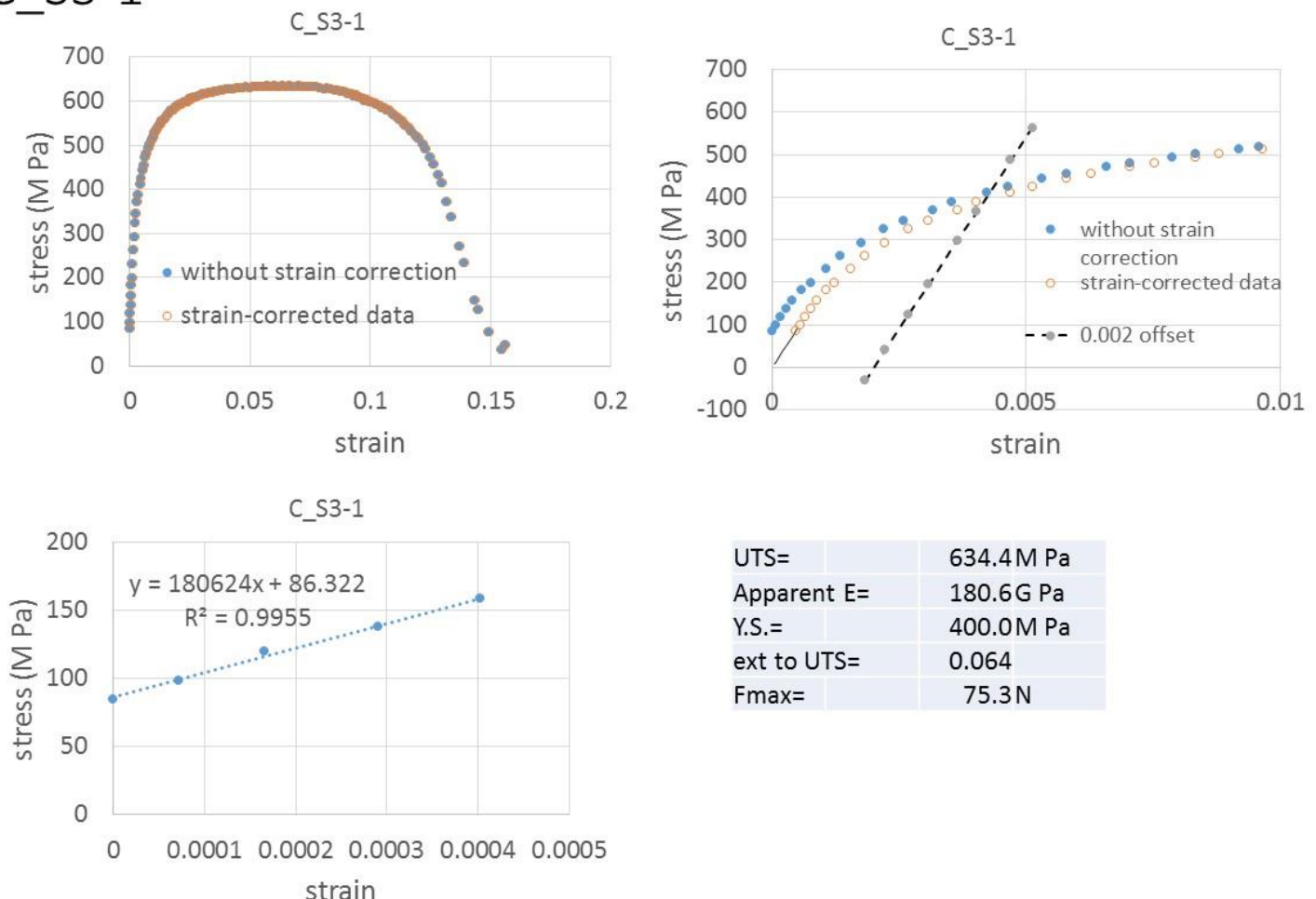

\begin{tabular}{l|l|}
\hline UTS $=$ & $634.4 \mathrm{M} \mathrm{Pa}$ \\
\hline Apparent $\mathrm{E}=$ & $180.6 \mathrm{G} \mathrm{Pa}$ \\
\hline Y.S. $=$ & $400.0 \mathrm{M} \mathrm{Pa}$ \\
\hline ext to UTS $=$ & 0.064 \\
\hline Fmax $=$ & $75.3 \mathrm{~N}$
\end{tabular}




\section{C_S3-2}
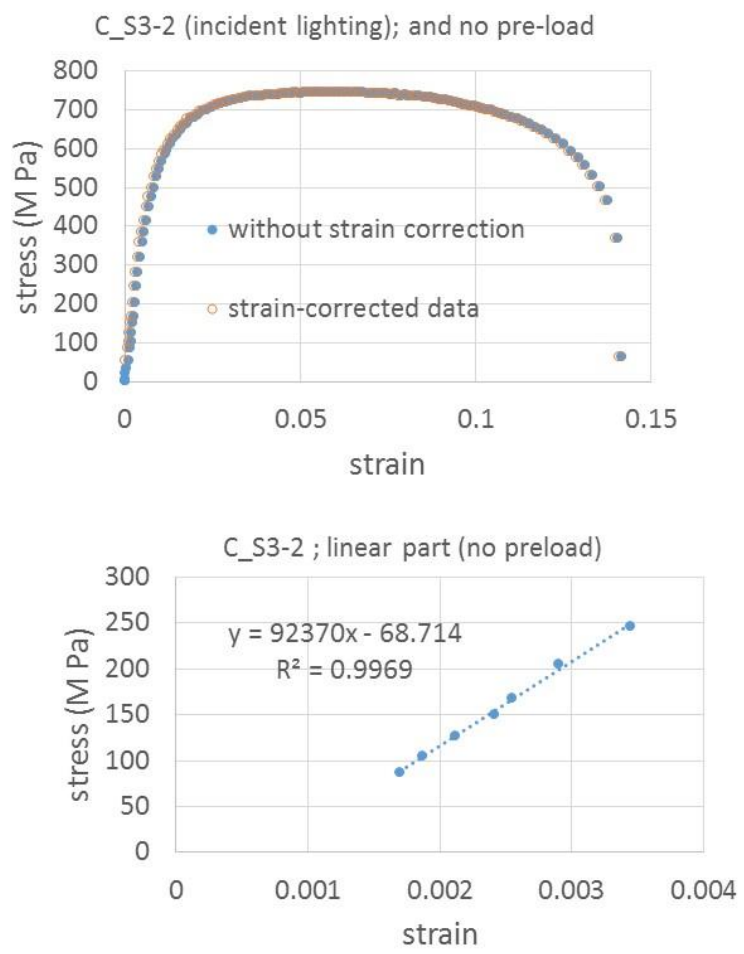

C_S3-3

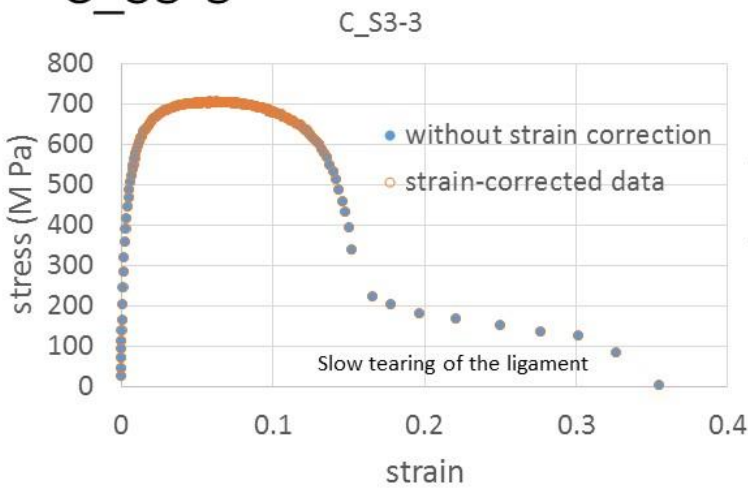

strain

C_S3-3; linear part (low strain analysis)

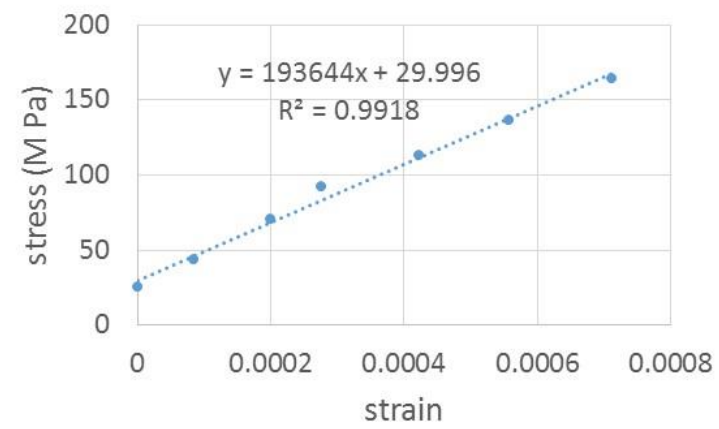

C_S3-2 (incident lighting); and no pre-load

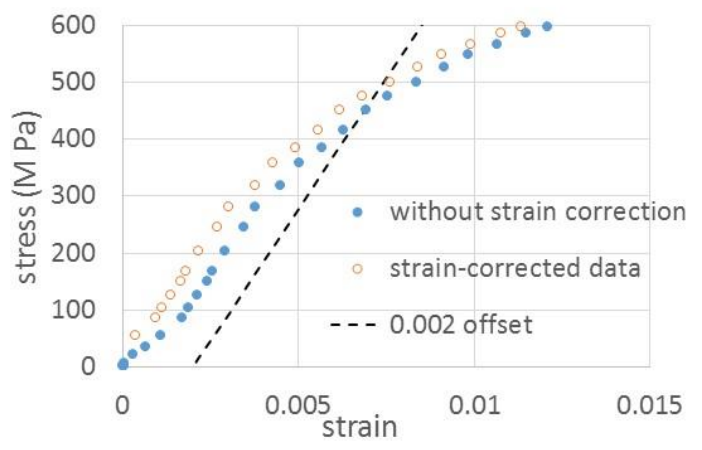

\begin{tabular}{l|c|}
\hline UTS $=$ & $746.2 \mathrm{M} \mathrm{Pa}$ \\
\hline Apparent $E=$ & $92.4 \mathrm{G} \mathrm{Pa}$ \\
\hline Y.S. $=$ & $499.0 \mathrm{M} \mathrm{Pa}$ \\
\hline ext to UTS $=$ & 0.055 \\
\hline Fmax $=$ & $90.9 \mathrm{~N}$ \\
\hline
\end{tabular}

Preload was omitted on this specimen to see if it would affect the properties. It appears that it does not.

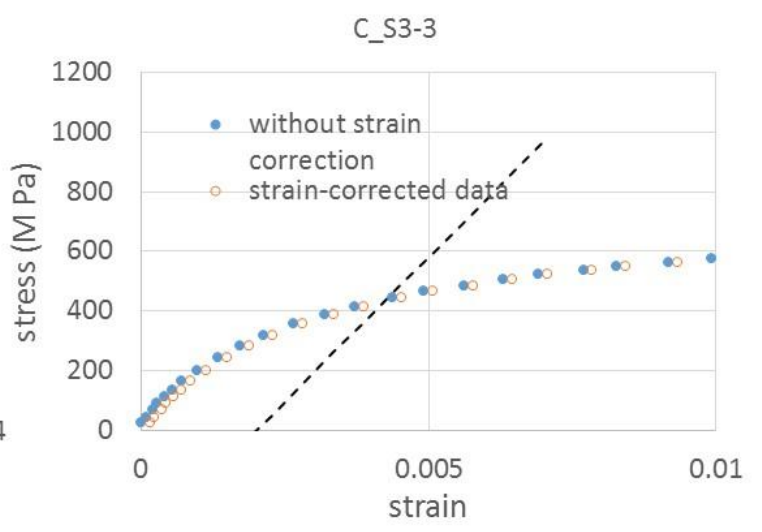

\begin{tabular}{|l|l|}
\hline UTS $=$ & $704.6 \mathrm{M} \mathrm{Pa}$ \\
\hline Apparent $\mathrm{E}=$ & $193.6 \mathrm{G} \mathrm{Pa}$ \\
\hline Y.S. $=$ & $440.0 \mathrm{M} \mathrm{Pa}$ \\
\hline ext to UTS $=$ & 0.059 \\
\hline Fmax $=$ & $83.6 \mathrm{~N}$
\end{tabular}


C_S4-1

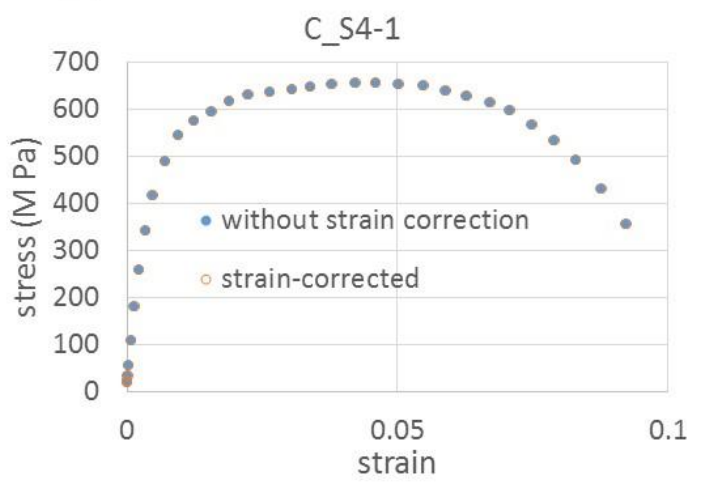

C_S4-1; linear part

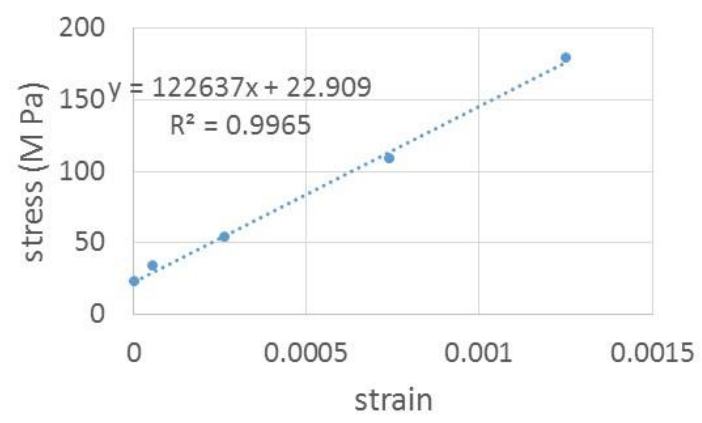

C_S4-2
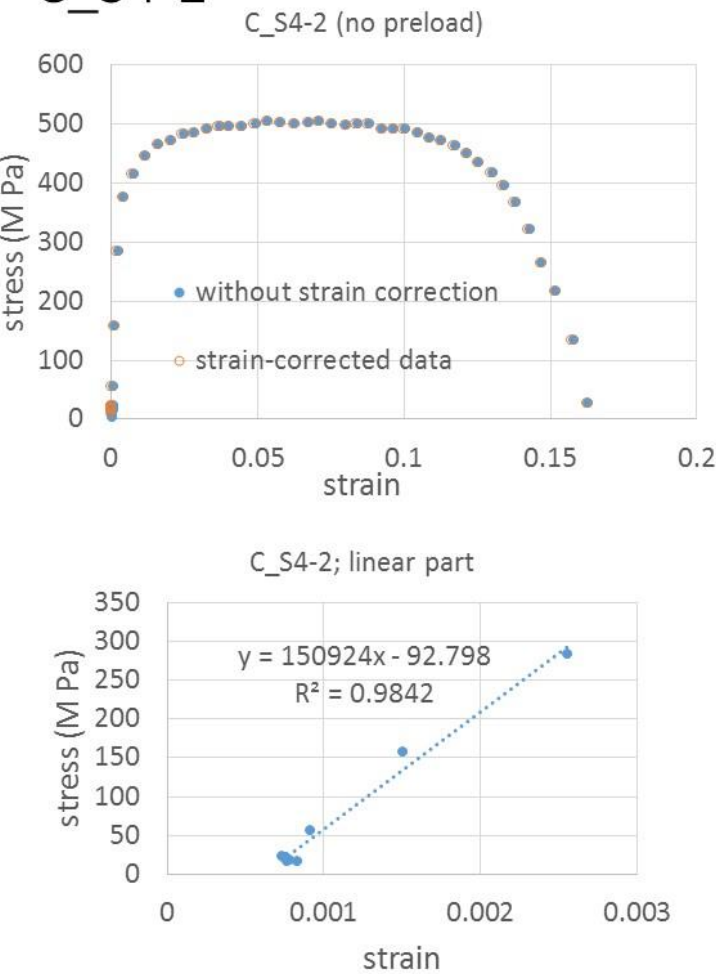

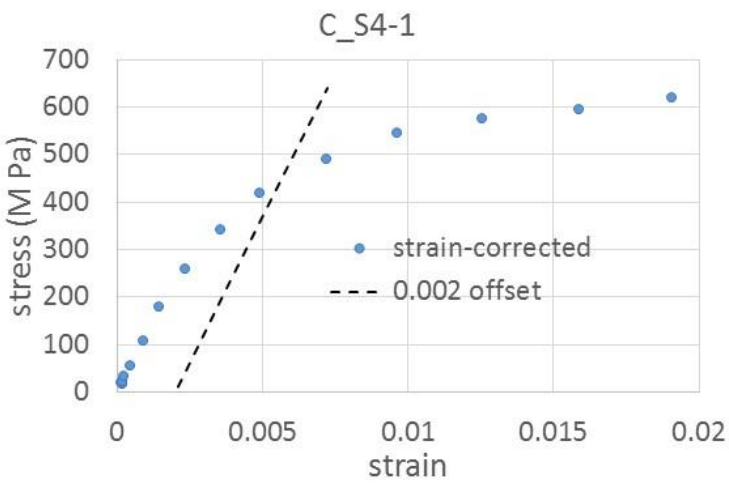

\begin{tabular}{l|l|}
\hline UTS $=$ & $655.3 \mathrm{M} \mathrm{Pa}$ \\
\hline Apparent $\mathrm{E}=$ & $122.6 \mathrm{G} \mathrm{Pa}$ \\
\hline Y.S. $=$ & $450.0 \mathrm{M} \mathrm{Pa}$ \\
ext to UTS $=$ & 0.042 \\
\hline Fmax $=$ & $9.3 \mathrm{~N}$
\end{tabular}

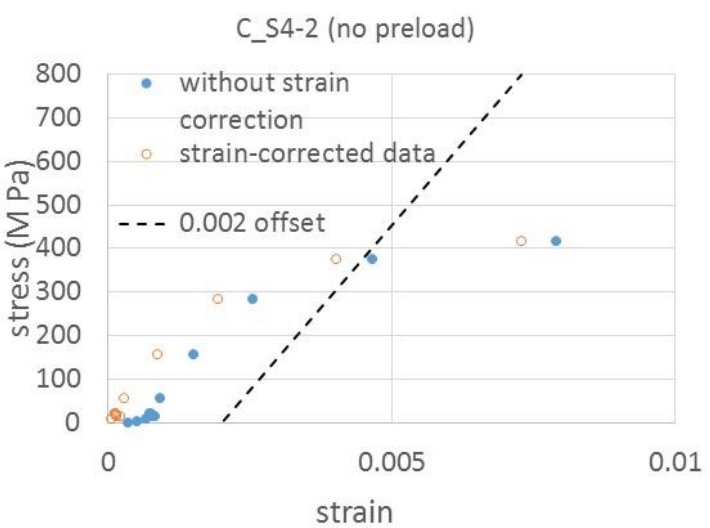

\begin{tabular}{l|l|}
\hline UTS $=$ & $505.5 \mathrm{M} \mathrm{Pa}$ \\
\hline Apparent $E=$ & $150.9 \mathrm{G} \mathrm{Pa}$ \\
\hline Y.S. $=$ & $376.0 \mathrm{M} \mathrm{Pa}$ \\
\hline ext to UTS $=$ & 0.071 \\
\hline Fmax $=$ & $6.9 \mathrm{~N}$
\end{tabular}


C_S4-3
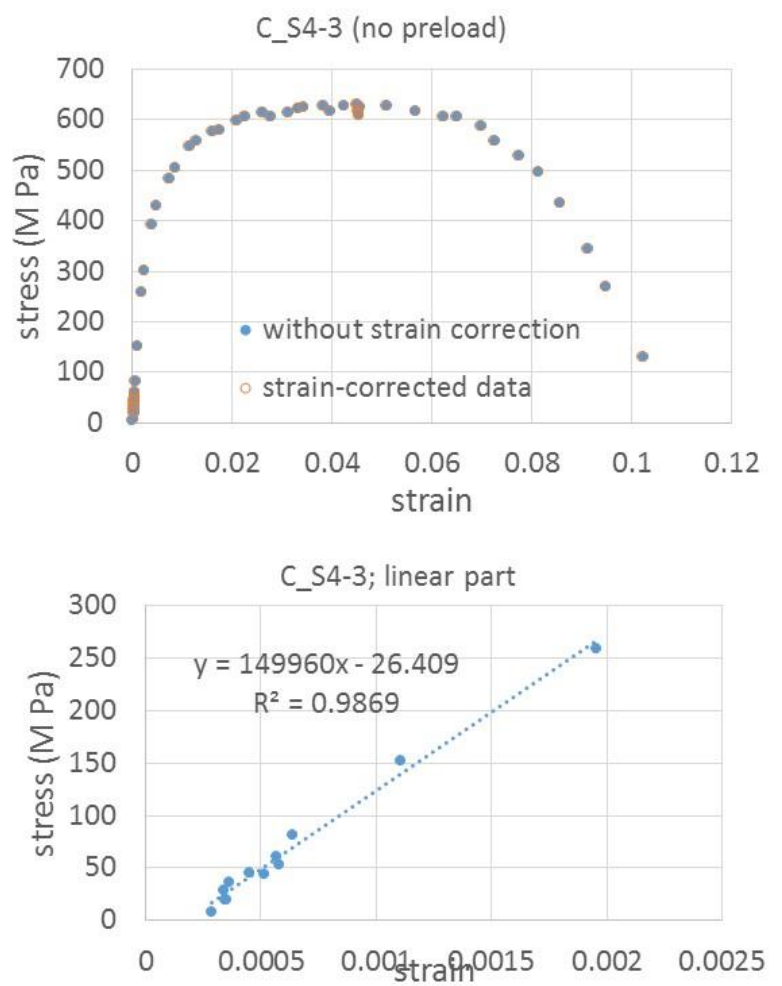

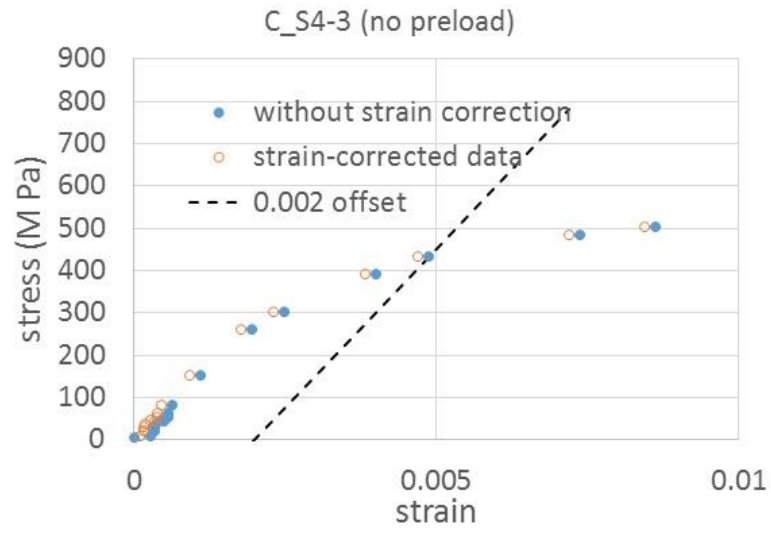

\begin{tabular}{l|l|}
\hline UTS $=$ & $629.8 \mathrm{M} \mathrm{Pa}$ \\
\hline Apparent $E=$ & $150.0 \mathrm{G} \mathrm{Pa}$ \\
\hline Y.S. $=$ & $431.0 \mathrm{M} \mathrm{Pa}$ \\
\hline ext to UTS $=$ & 0.045 \\
\hline Fmax $=$ & $9.0 \mathrm{~N}$
\end{tabular}




\section{Appendix F: Engineering Stress-Strain Curves for C Material, at Strain Rate 1/s}

MTS_C_S1-1 (bent during handling)
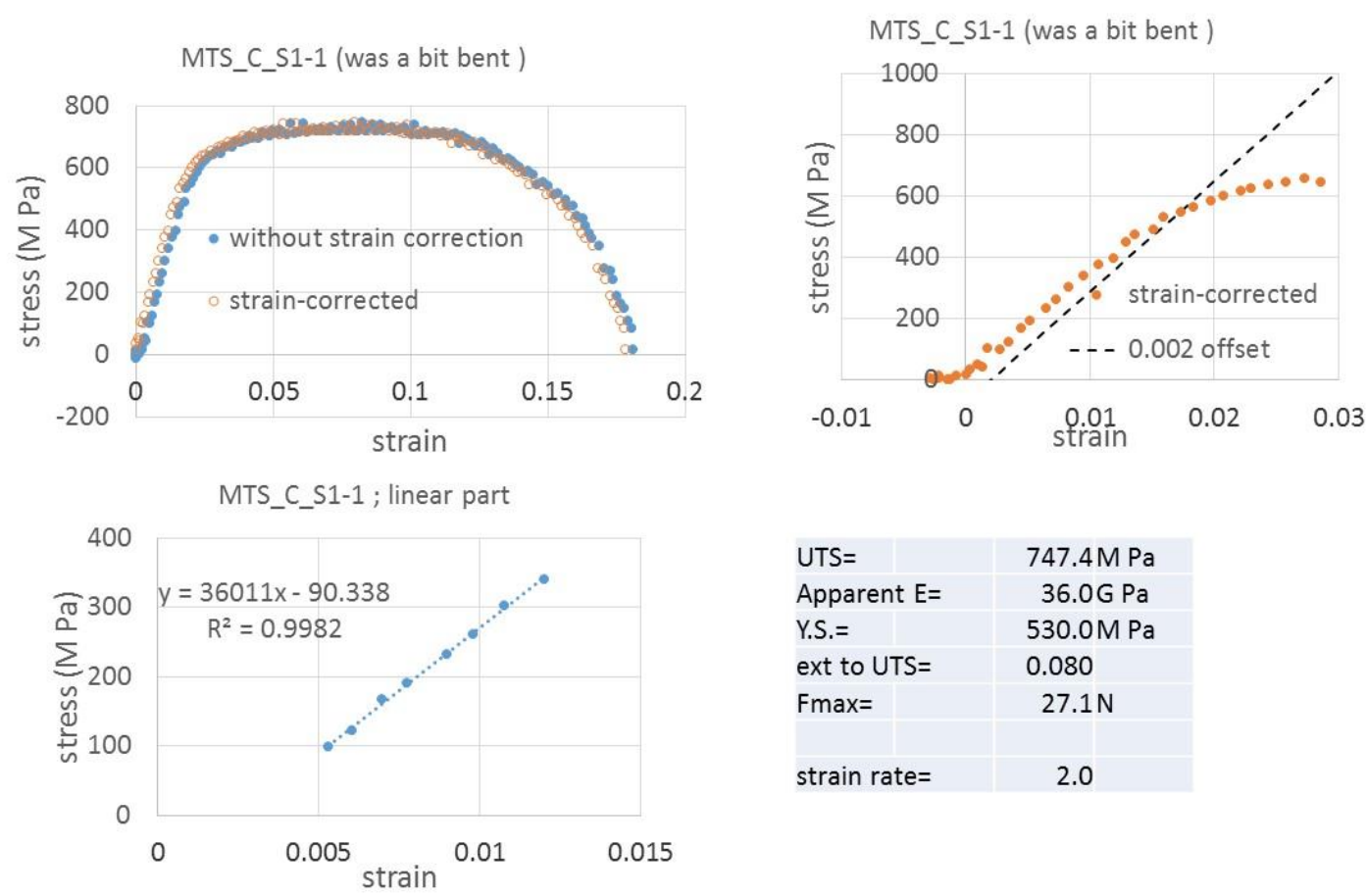

\begin{tabular}{l|c|}
\hline UTS $=$ & $747.4 \mathrm{M} \mathrm{Pa}$ \\
\hline Apparent $\mathrm{E}=$ & $36.0 \mathrm{G} \mathrm{Pa}$ \\
\hline Y.S. $=$ & $530.0 \mathrm{M} \mathrm{Pa}$ \\
\hline ext to UTS $=$ & 0.080 \\
\hline Fmax $=$ & $27.1 \mathrm{~N}$ \\
\hline strain rate $=$ & 2.0 \\
\hline
\end{tabular}

This specimen was not counted because it was bent. An extra C-S1 specimen was tested (MTS_C_S1-4). 
MTS_C_S1-2
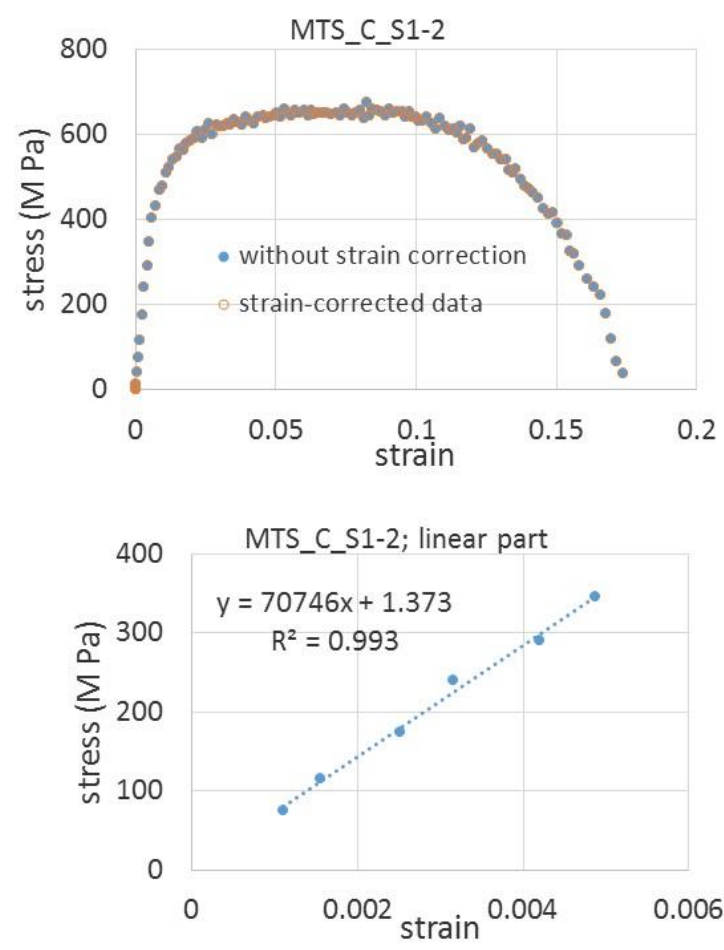

\section{MTS_C_S1-3}
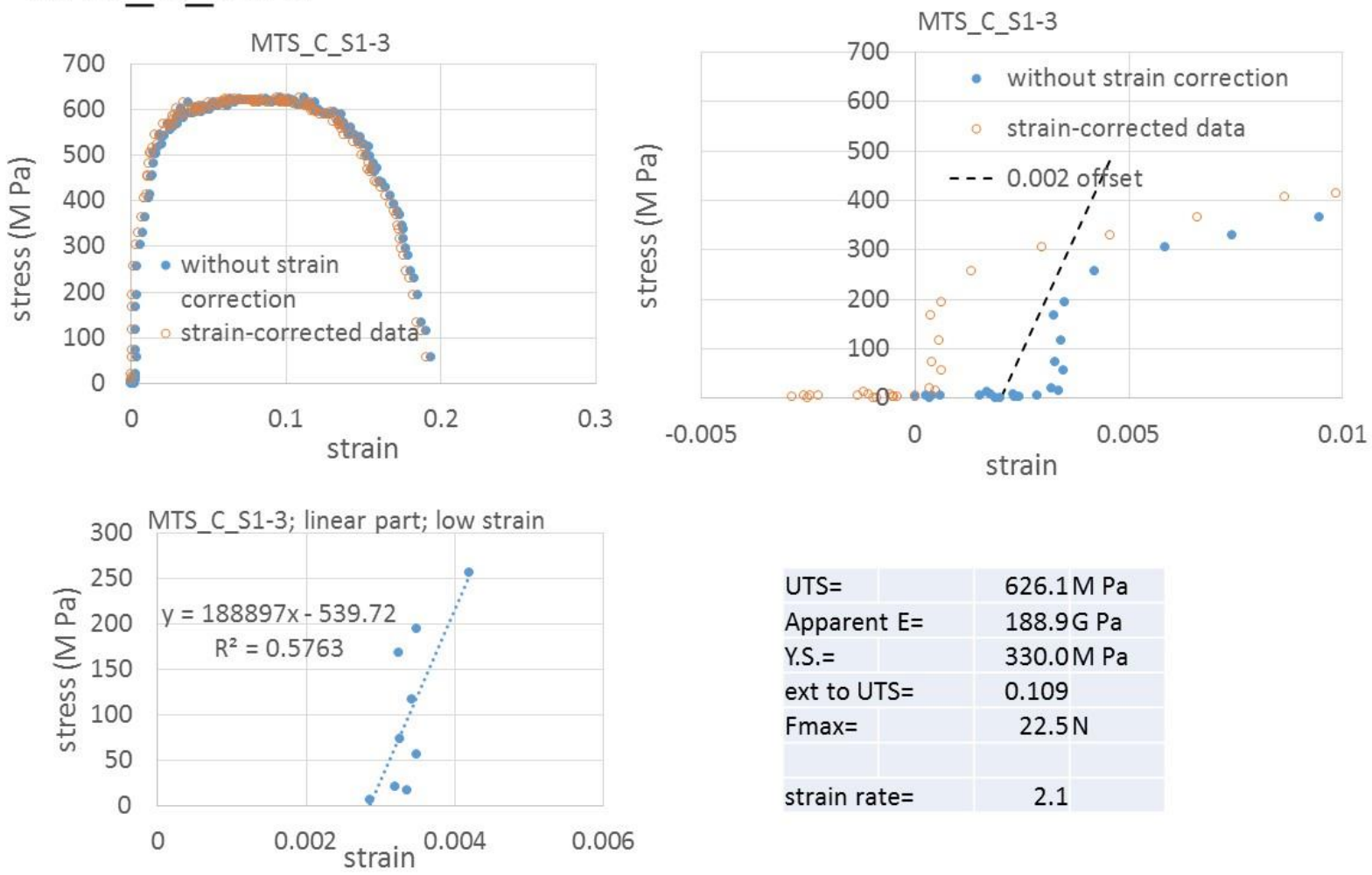

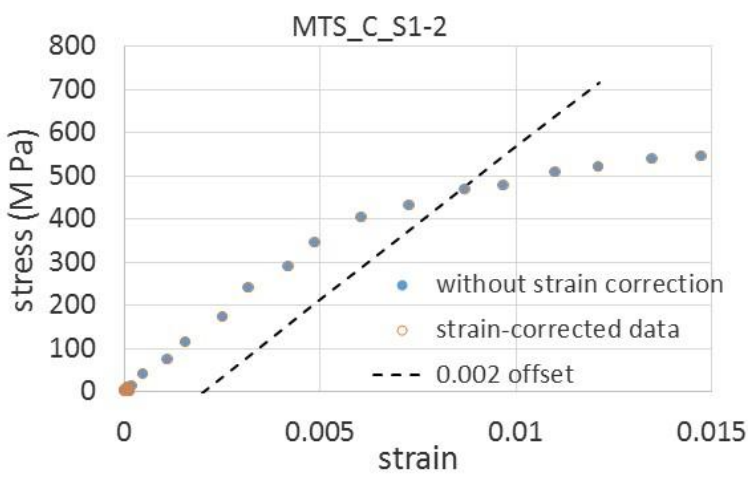

\begin{tabular}{l|c|}
\hline UTS $=$ & $673.8 \mathrm{M} \mathrm{Pa}$ \\
\hline Apparent $\mathrm{E}=$ & $70.7 \mathrm{G} \mathrm{Pa}$ \\
\hline Y.S. $=$ & $467.0 \mathrm{M} \mathrm{Pa}$ \\
\hline ext to UTS $=$ & 0.082 \\
\hline Fmax $=$ & $24.5 \mathrm{~N}$ \\
\hline & \\
\hline strain rate= & 1.7
\end{tabular}

\begin{tabular}{|l|l|}
\hline UTS $=$ & $626.1 \mathrm{M} \mathrm{Pa}$ \\
\hline Apparent $\mathrm{E}=$ & $188.9 \mathrm{G} \mathrm{Pa}$ \\
\hline Y.S. $=$ & $330.0 \mathrm{M} \mathrm{Pa}$ \\
\hline ext to UTS $=$ & 0.109 \\
\hline Fmax $=$ & $22.5 \mathrm{~N}$ \\
\hline & \\
\hline strain rate $=$ & 2.1 \\
\hline
\end{tabular}




\section{MTS_C_S1-4}
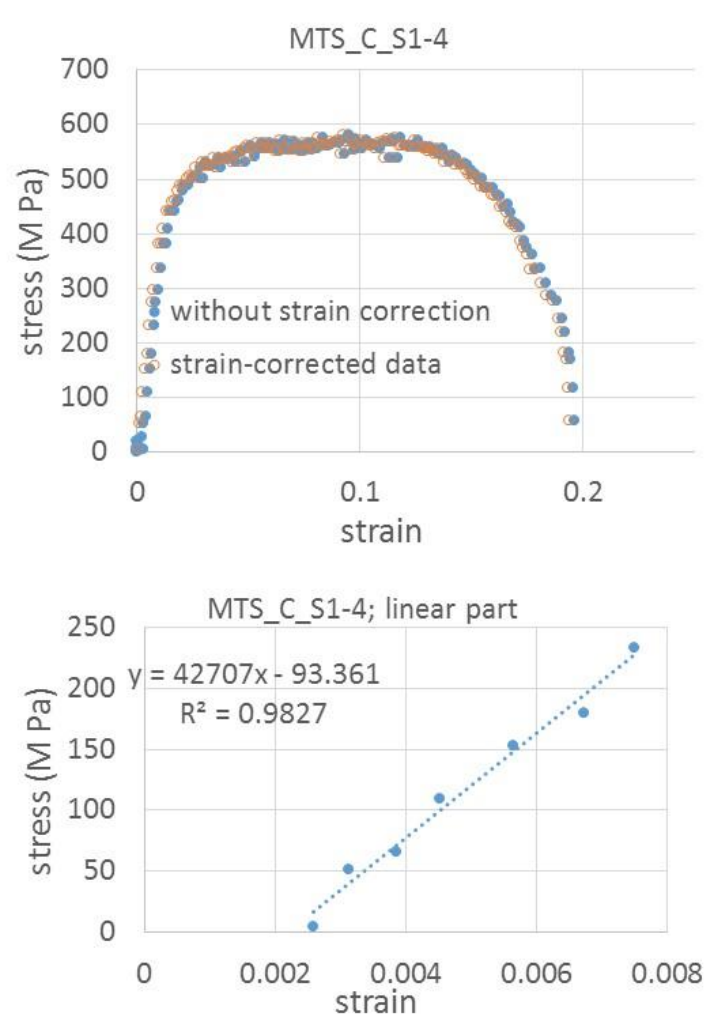

\section{MTS_C_S2-1}
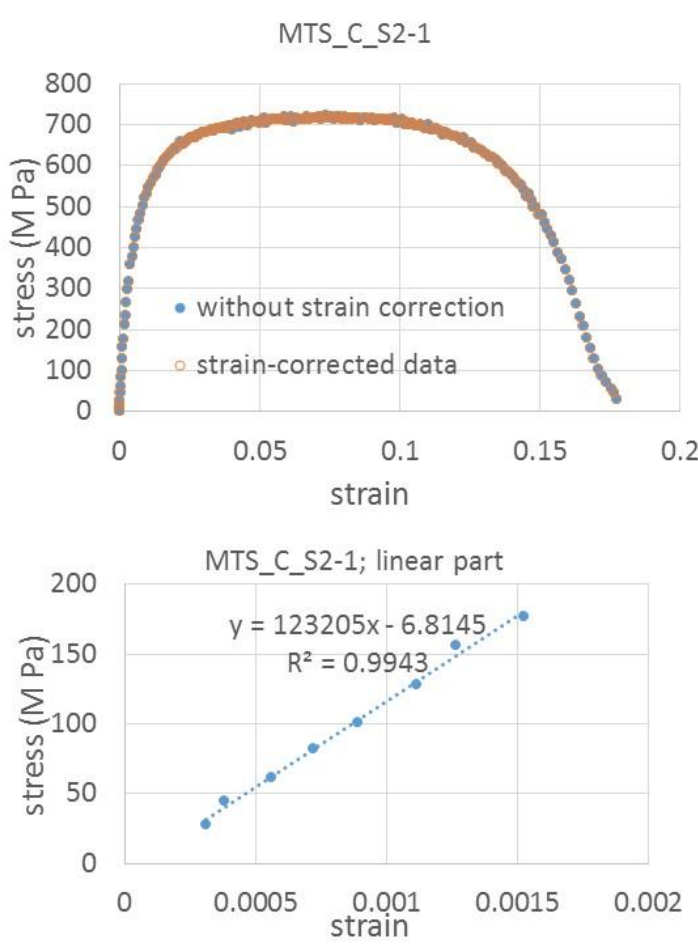

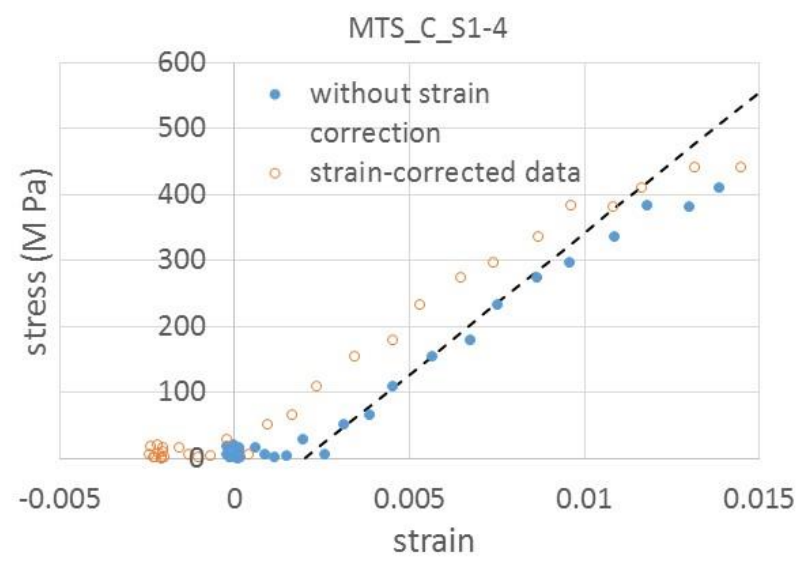

\begin{tabular}{|c|c|c|}
\hline UTS= & $582.0 \mathrm{M} \mathrm{Pa}$ & \multirow{6}{*}{$\begin{array}{l}\text { Image-shifting } \\
\text { increases apparent } \\
\text { E up to } 129 \mathrm{G} \mathrm{Pa}\end{array}$} \\
\hline Apparent $\mathrm{E}=$ & $42.7 \mathrm{G} \mathrm{Pa}$ & \\
\hline Y.S. $=$ & $380.0 \mathrm{M} \mathrm{Pa}$ & \\
\hline ext to UTS= & 0.093 & \\
\hline $\mathrm{Fmax}=$ & $20.7 \mathrm{~N}$ & \\
\hline strain rate= & 2.1 & \\
\hline
\end{tabular}

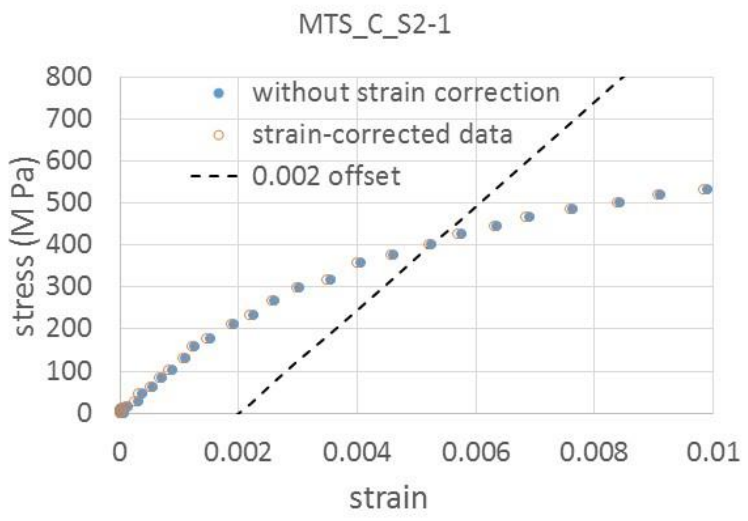

\begin{tabular}{|l|l|}
\hline UTS $=$ & $722.1 \mathrm{M} \mathrm{Pa}$ \\
\hline Apparent E= & $123.2 \mathrm{G} \mathrm{Pa}$ \\
\hline Y.S. $=$ & $400.0 \mathrm{M} \mathrm{Pa}$ \\
\hline ext to UTS $=$ & 0.074 \\
\hline Fmax $=$ & $63.1 \mathrm{~N}$ \\
\hline strain rate= & 1.1 \\
\hline
\end{tabular}




\section{MTS_C_S2-2}
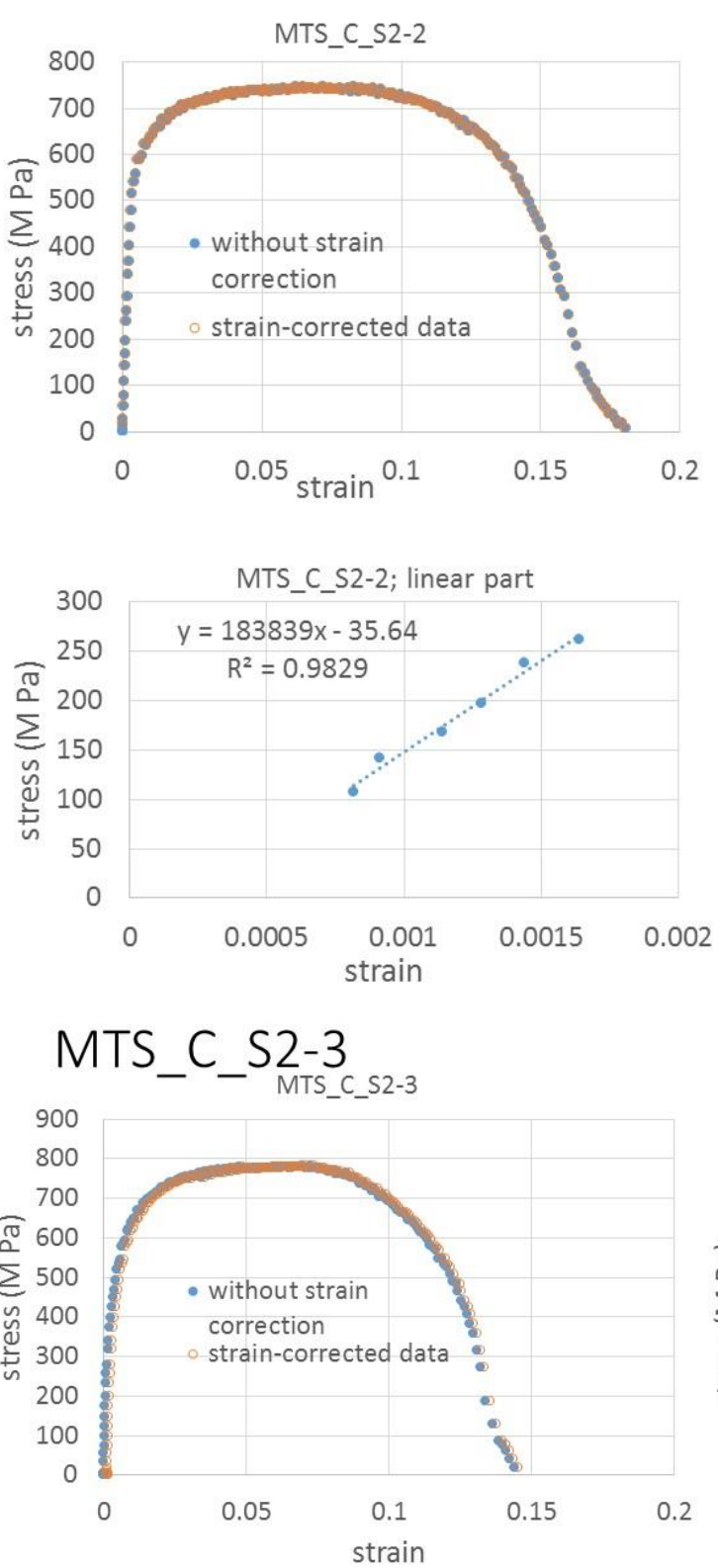

MTS_C_S2-3; linear part; high-strain region

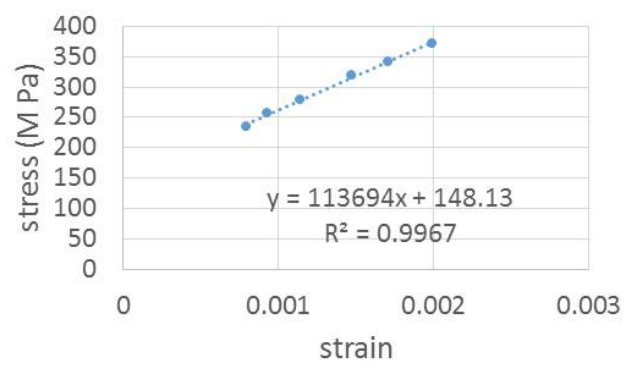

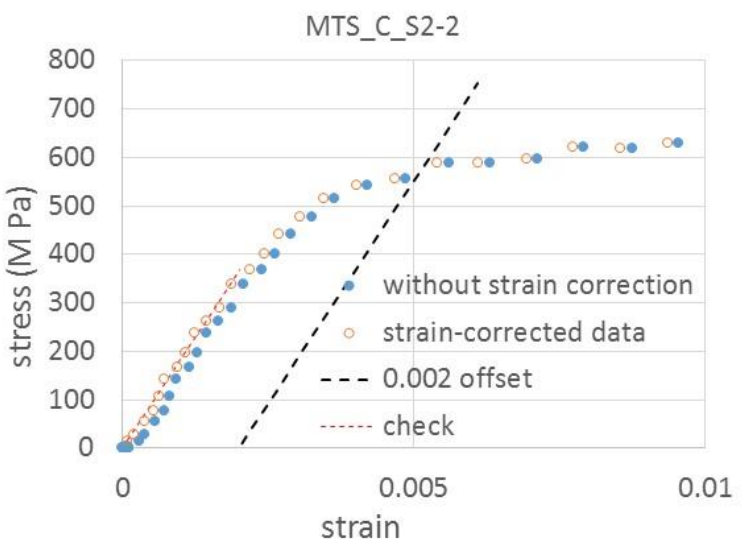

\begin{tabular}{|l|l|}
\hline UTS $=$ & $747.0 \mathrm{M} \mathrm{Pa}$ \\
\hline Apparent $\mathrm{E}=$ & $183.8 \mathrm{G} \mathrm{Pa}$ \\
\hline Y.S. $=$ & $589.0 \mathrm{M} \mathrm{Pa}$ \\
\hline ext to UTS $=$ & 0.065 \\
\hline Fmax $=$ & $65.9 \mathrm{~N}$ \\
\hline strain rate= & 1.1 \\
\hline
\end{tabular}

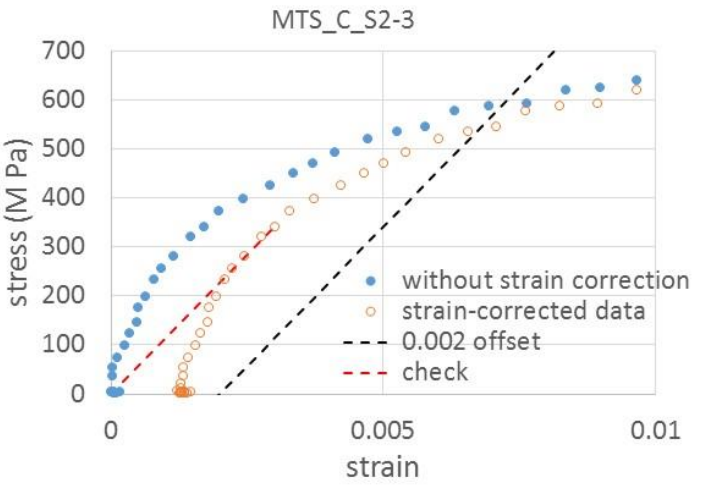

\begin{tabular}{l|c|}
\hline UTS $=$ & $784.0 \mathrm{M} \mathrm{Pa}$ \\
\hline Apparent $\mathrm{E}=$ & $113.7 \mathrm{G} \mathrm{Pa}$ \\
\hline Y.S. $=$ & $536.0 \mathrm{M} \mathrm{Pa}$ \\
\hline ext to UTS $=$ & 0.071 \\
\hline Fmax $=$ & $69.7 \mathrm{~N}$ \\
\hline & \\
\hline strain rate= & 1.1
\end{tabular}


MTS_C_S3-1
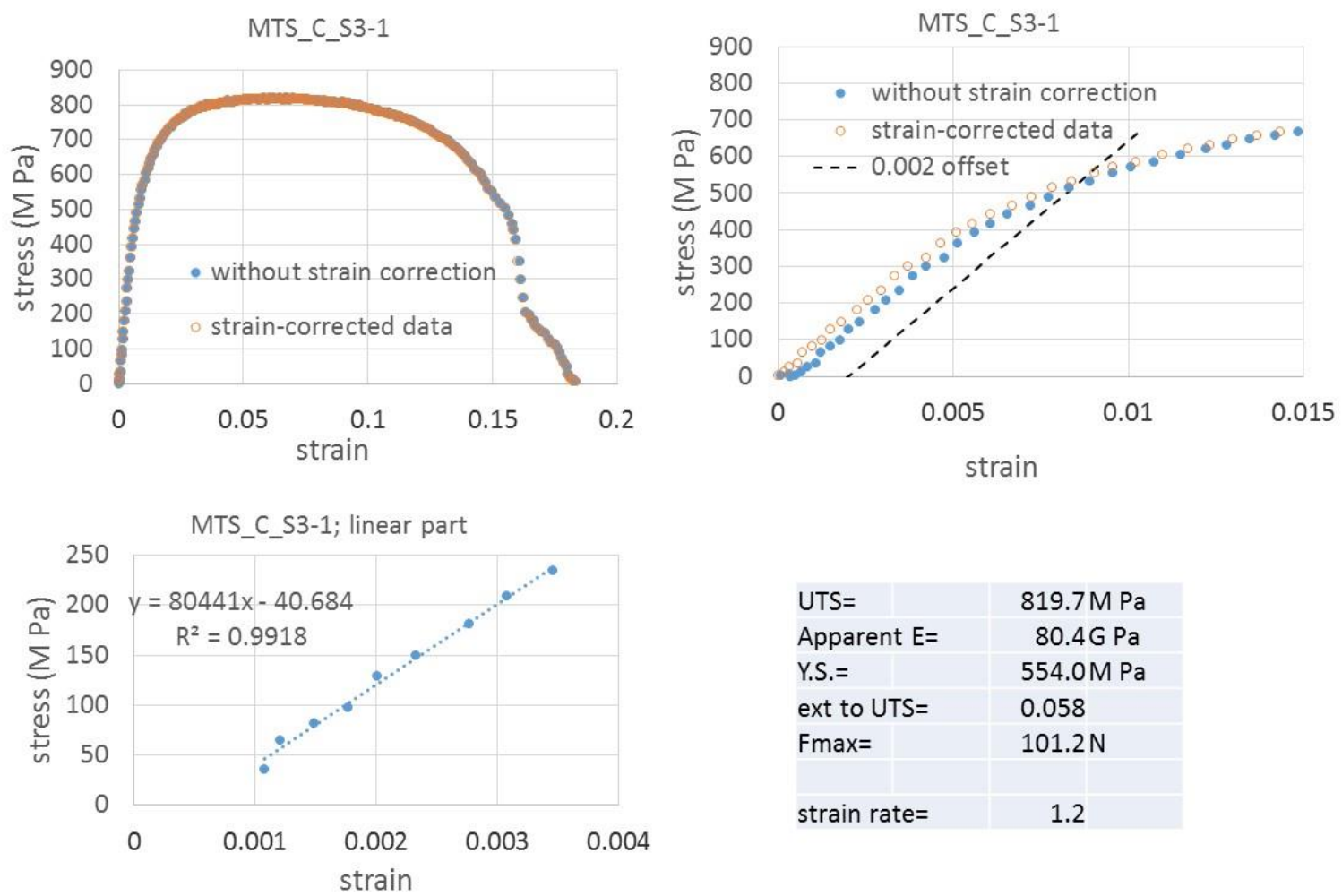

MTS_C_S3-2
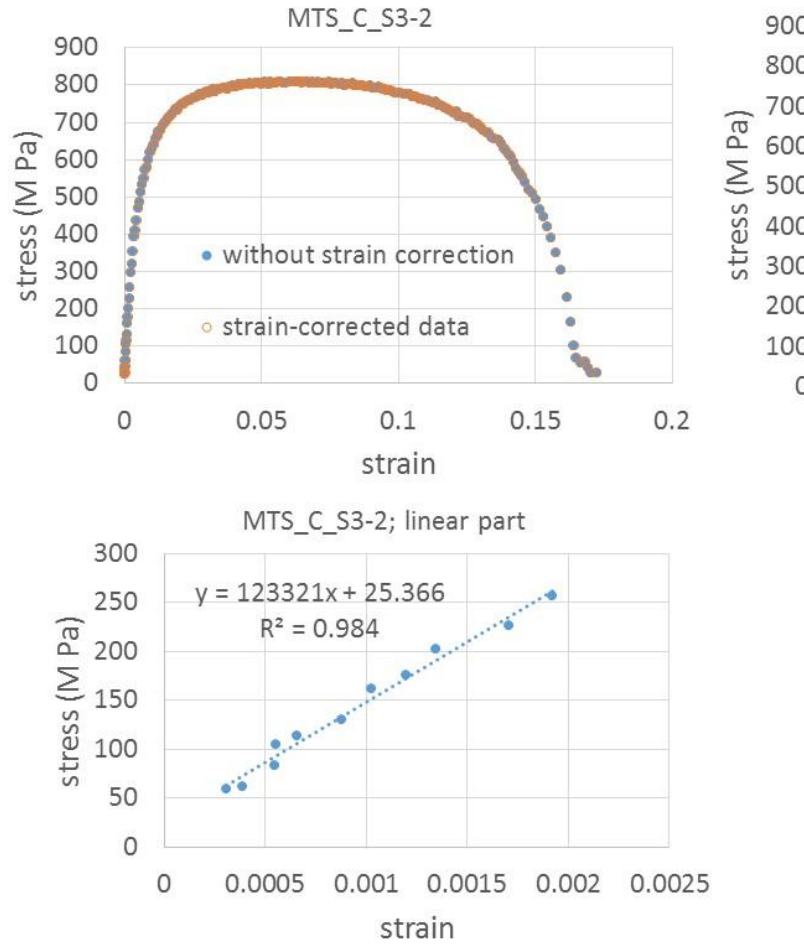

MTS_C_S3-2

\begin{tabular}{l|l|}
\hline UTS $=$ & $819.7 \mathrm{M} \mathrm{Pa}$ \\
\hline Apparent $\mathrm{E}=$ & $80.4 \mathrm{G} \mathrm{Pa}$ \\
\hline Y.S. & $554.0 \mathrm{M} \mathrm{Pa}$ \\
\hline ext to UTS $=$ & 0.058 \\
\hline Fmax $=$ & $101.2 \mathrm{~N}$ \\
\hline
\end{tabular}

strain rate=

1.2

\begin{tabular}{l|l|}
\hline UTS $=$ & $809.2 \mathrm{M} \mathrm{Pa}$ \\
\hline Apparent $\mathrm{E}=$ & $123.3 \mathrm{G} \mathrm{Pa}$ \\
\hline Y.S.= & $511.0 \mathrm{M} \mathrm{Pa}$ \\
\hline ext to UTS $=$ & 0.069 \\
\hline Fmax $=$ & $99.2 \mathrm{~N}$ \\
\hline strain rate= & 1.2 \\
\hline
\end{tabular}




\section{MTS_C_S3-3}
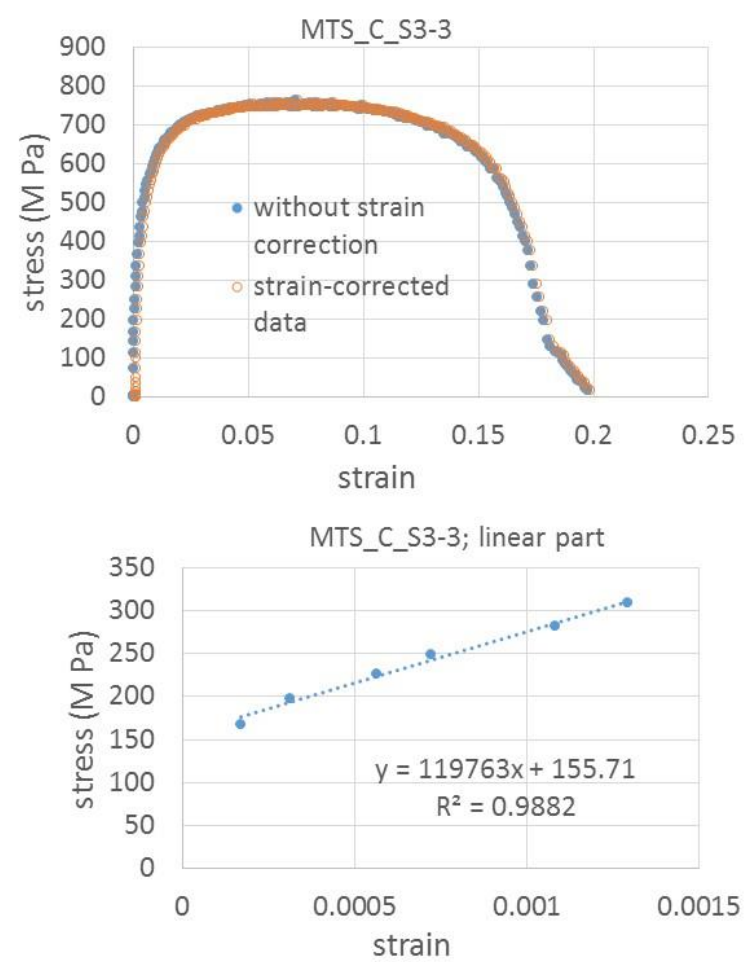

\section{MTS C S4-1}
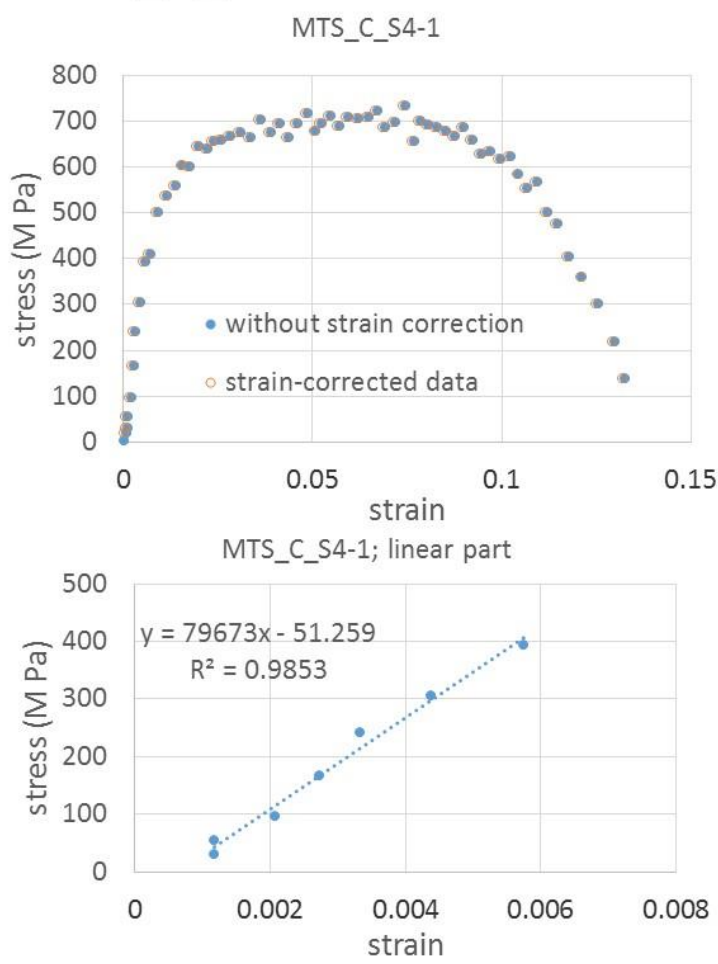

MTS_C_S3-3

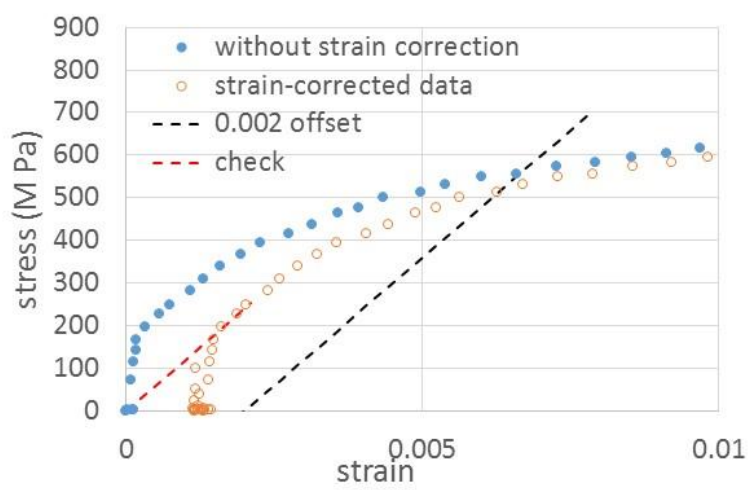

\begin{tabular}{|c|c|c|}
\hline UTS= & $764.9 \mathrm{M} \mathrm{Pa}$ & \multirow{7}{*}{$\begin{array}{l}\text { Specimen or clevis } \\
\text { could have been } \\
\text { 'stuck' at the } \\
\text { beginning of the test, } \\
\text { resulting in some } \\
\text { stress without strain }\end{array}$} \\
\hline Apparent E= & $119.8 \mathrm{G} \mathrm{Pa}$ & \\
\hline Y.S.= & 513.0M Pa & \\
\hline ext to UTS= & 0.072 & \\
\hline Fmax $=$ & $92.6 \mathrm{~N}$ & \\
\hline & & \\
\hline strain rate $=$ & 1.1 & \\
\hline
\end{tabular}

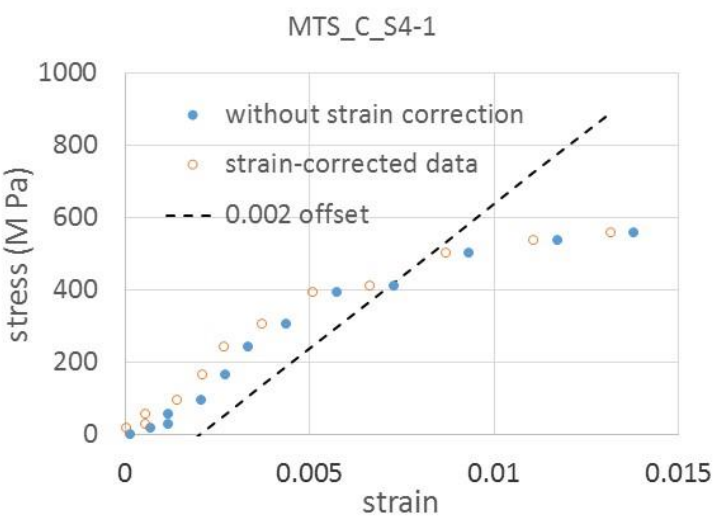

\begin{tabular}{l|c|}
\hline UTS $=$ & $734.6 \mathrm{M} \mathrm{Pa}$ \\
\hline Apparent $\mathrm{E}=$ & $79.7 \mathrm{G} \mathrm{Pa}$ \\
\hline Y.S.= & $530.0 \mathrm{M} \mathrm{Pa}$ \\
\hline ext to UTS $=$ & 0.074 \\
\hline Fmax $=$ & $11.1 \mathrm{~N}$ \\
\hline & \\
\hline strain rate $=$ & 2.7 \\
\hline
\end{tabular}




\section{MTS C S4-2}

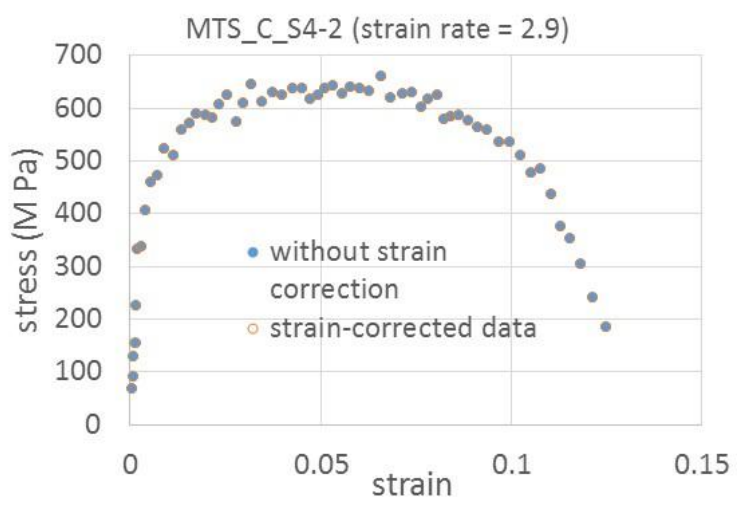

MTS_C_S4-2; linear part.

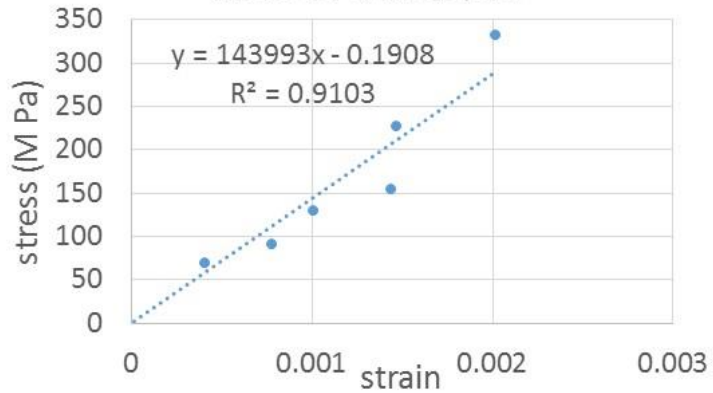

\section{MTS_C_S4-3}
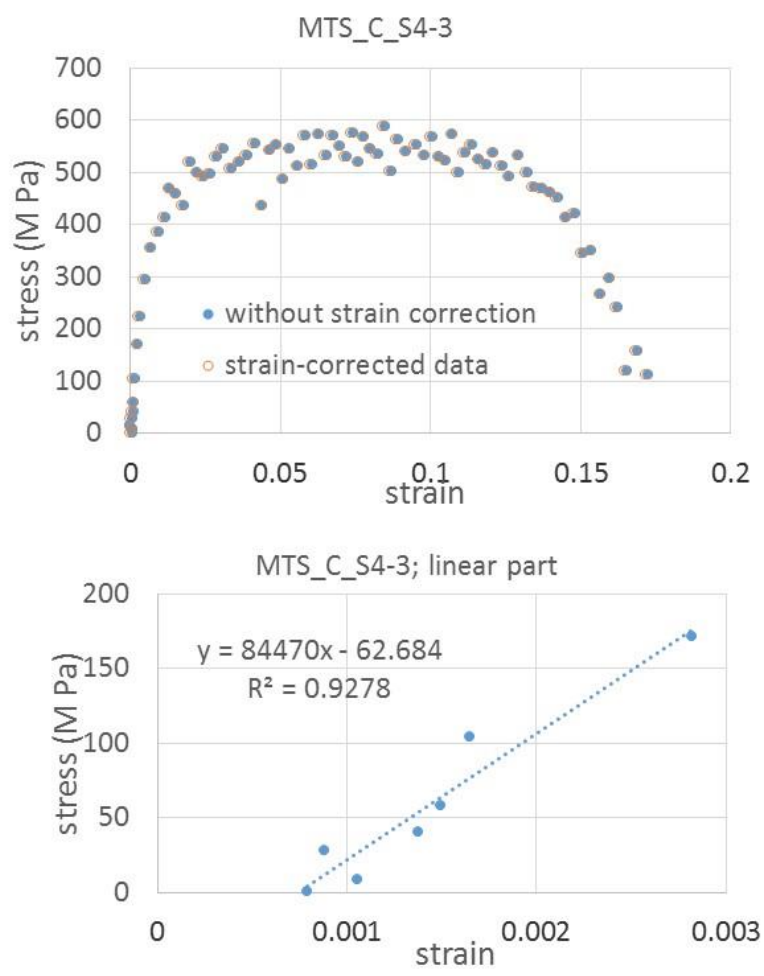

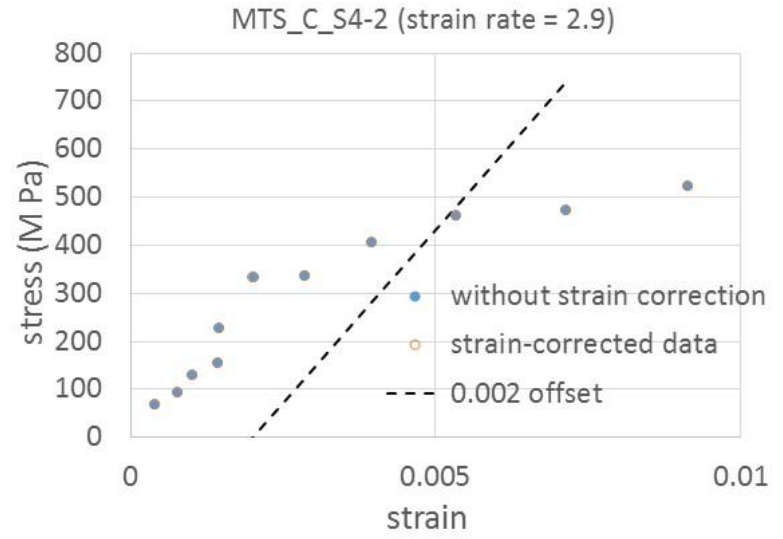

\begin{tabular}{l|l|}
\hline UTS $=$ & $660.9 \mathrm{M} \mathrm{Pa}$ \\
\hline Apparent $\mathrm{E}=$ & $144.0 \mathrm{G} \mathrm{Pa}$ \\
\hline Y.S. $=$ & $460.0 \mathrm{M} \mathrm{Pa}$ \\
\hline ext to UTS $=$ & 0.066 \\
\hline Fmax $=$ & $9.5 \mathrm{~N}$ \\
& \\
\hline strain rate= & 2.6
\end{tabular}

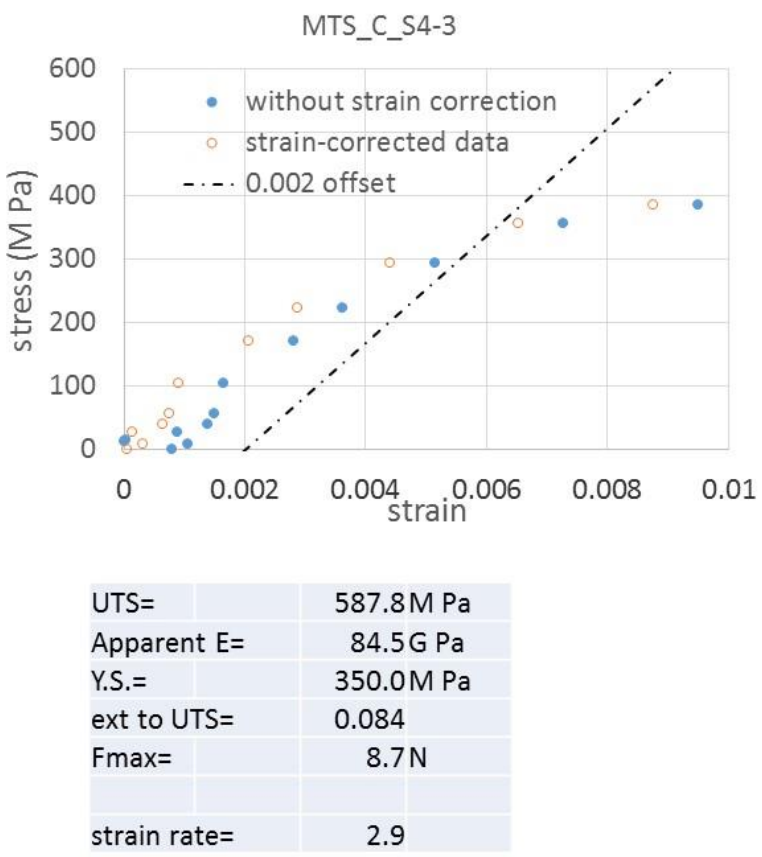




\section{Appendix G: Contributions to Measurement Error for Ultimate Tensile Strength}
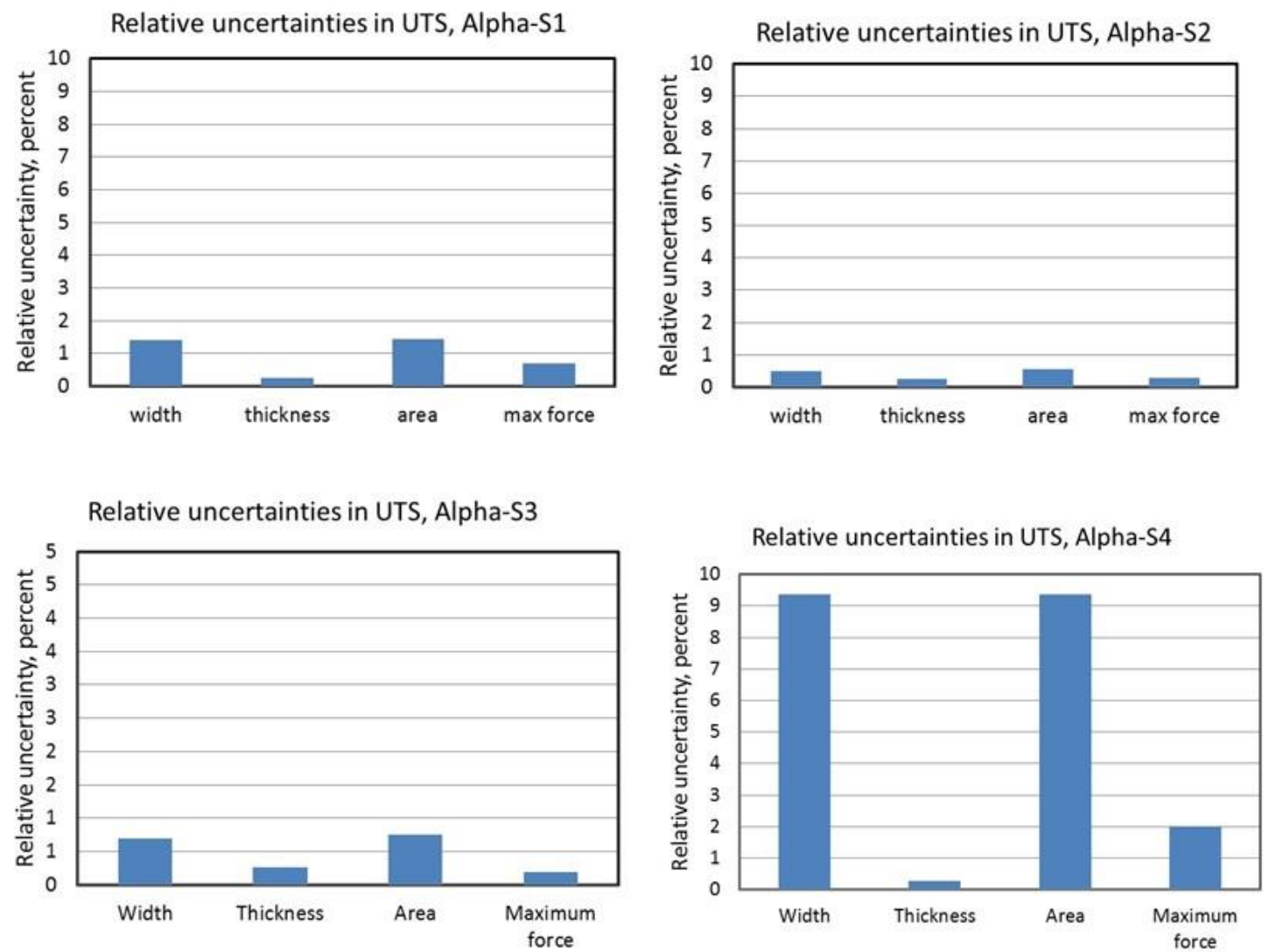

Figure G.1 Contributions to the measurement uncertainty in UTS for Alpha specimens tested at rate 0.001/s. (This figure is from our August 2016 progress report to ARDEC.) 

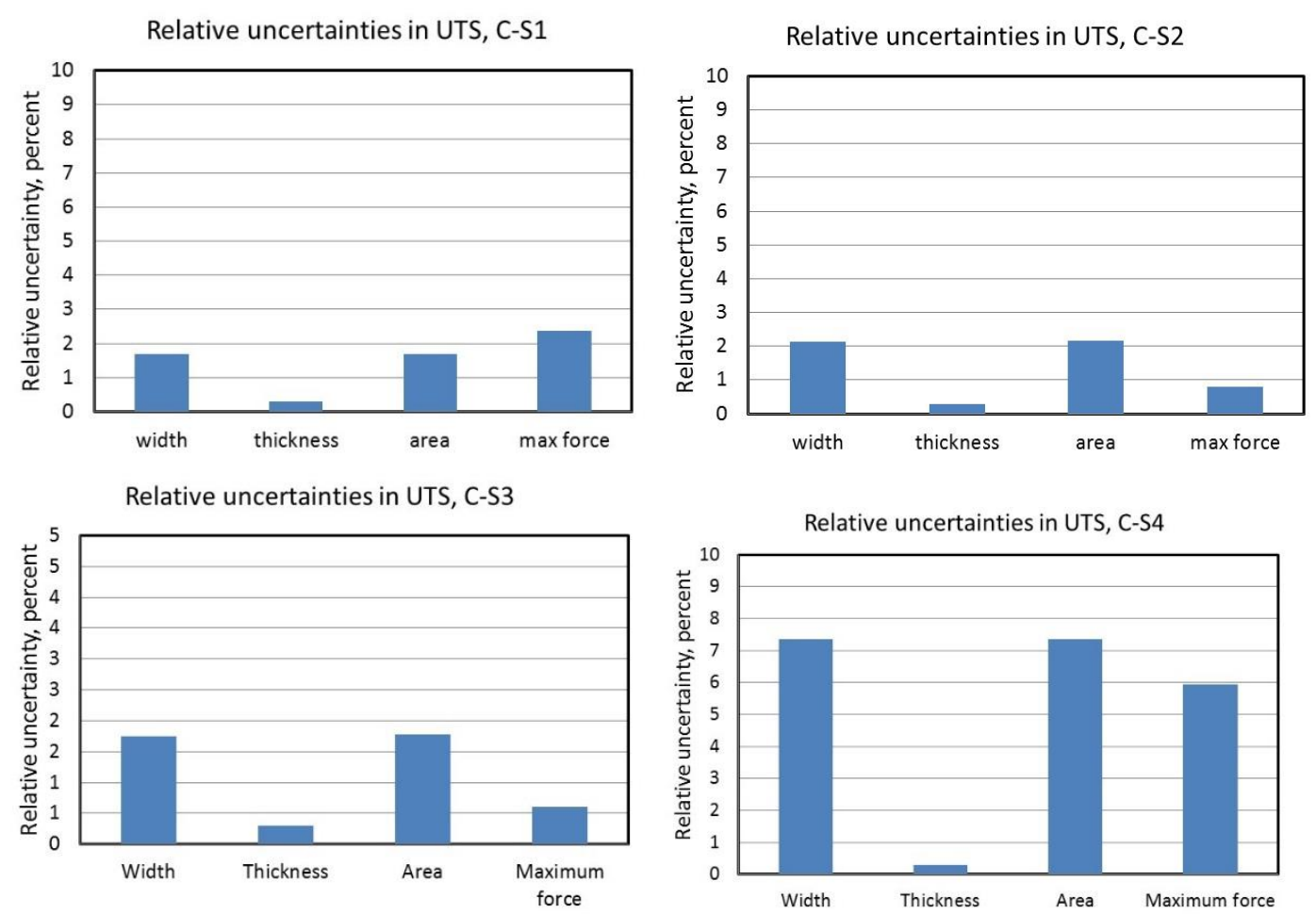

Figure G.2 Contributions to the measurement uncertainaty in UTS for C specimens tested at rate $0.001 / \mathrm{s}$. (This figure is from our August 2016 progress report to ARDEC.) 

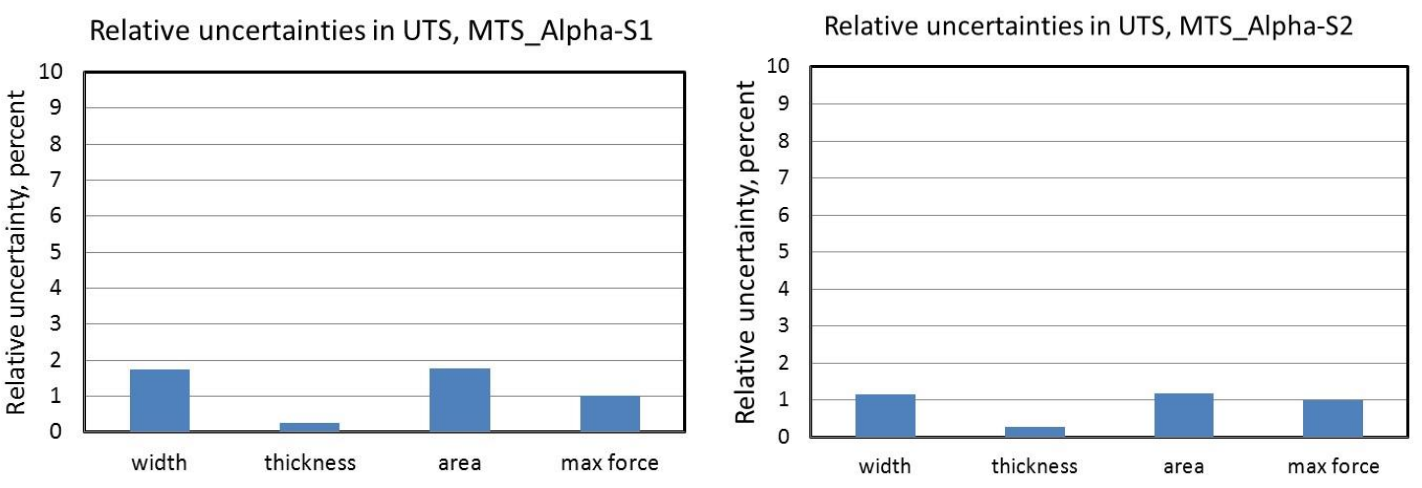

Relative uncertainties in UTS, MTS_Alpha-S3

Relative uncertainties in UTS, MTS_Alpha-S4
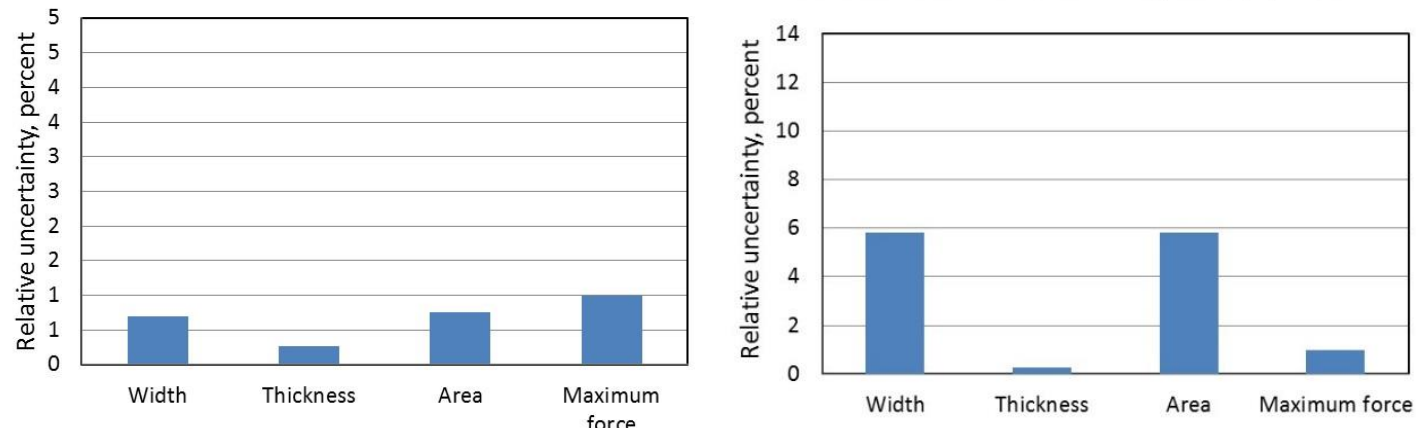

Figure G.3 Contributions to the measurement uncertainties in UTS for Alpha specimens tested at rate 1/s. (This figure is from our August 2016 progress report to ARDEC.) 
Relative uncertainties in UTS, MTS_C-S1

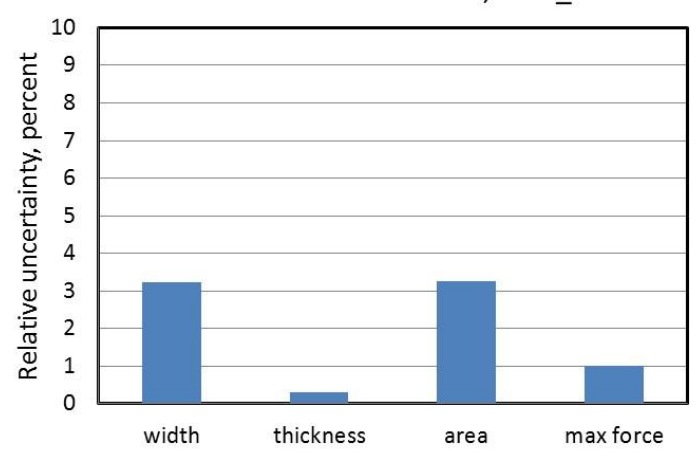

Relative uncertainties in UTS, MTS_C-S3

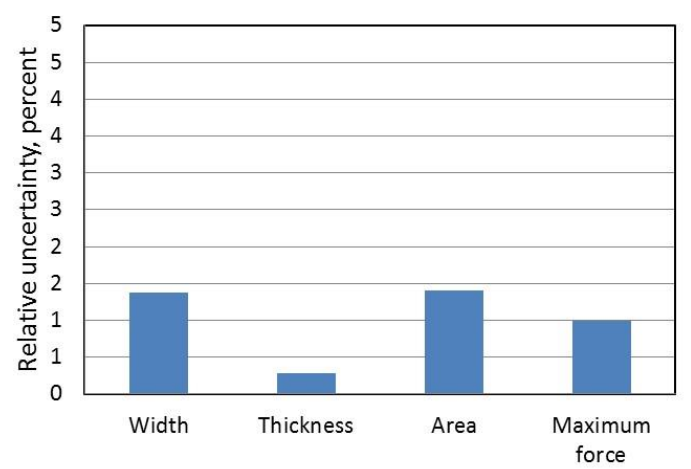

Relative uncertainties in UTS, MTS_C-S2

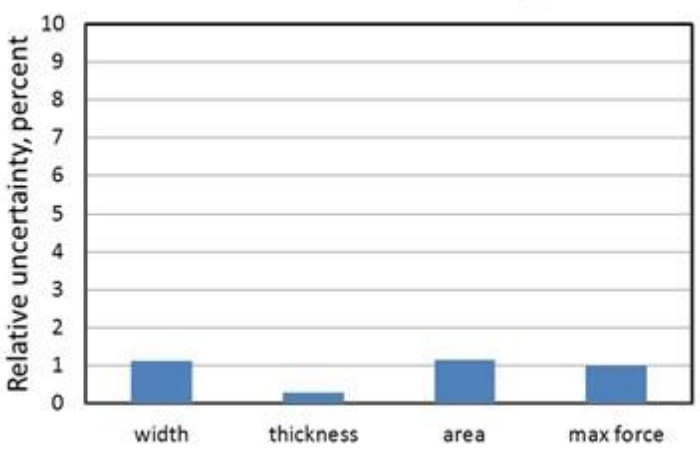

Relative uncertainties in UTS, MTS_C-S4

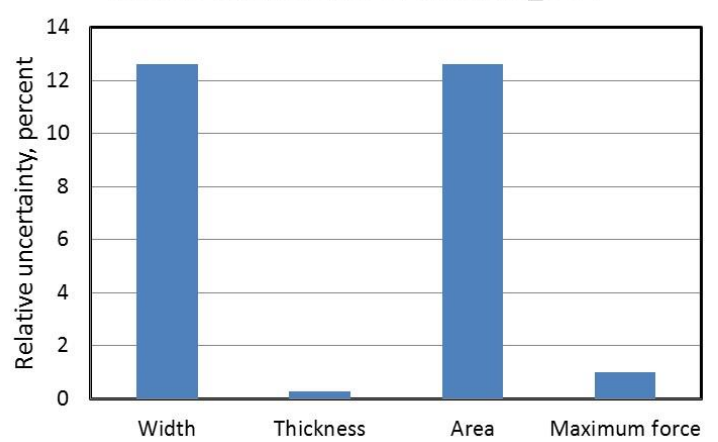

Figure G.4 Contributions to the measurement uncertainties in UTS for C specimens tested at rate 1/s. (This figure is from our August 2016 progress report to ARDEC.) 


\section{Appendix H: Contributions to Measurement Error for Apparent Young's Modulus}

Table H.1. List of the C specimens with the "best looking stress strain curves", to use for analyzing the apparent Young's modulus. (this table is from our August 2016 progress report to ARDEC.)

\begin{tabular}{|c|c|}
\hline Specimen & $\begin{array}{c}\text { Apparent E } \\
\text { (GPa) }\end{array}$ \\
\hline C_S1-1 & 90 \\
\hline C_S1-2 & 120 \\
\hline C_S1-3 & 190 \\
\hline C_S2-1 & 156 \\
\hline C_S2-2 & 144 \\
\hline C_S2-4 & 185 \\
\hline C_S3-1 & 180 \\
\hline C_S3-3 & 194 \\
\hline C_S4-1 & 123 \\
\hline MTS_C_S2-1 & 123 \\
\hline MTS_C_S3-1 & 80 \\
\hline MTS_C_S3-2 & 12 \\
\hline
\end{tabular}



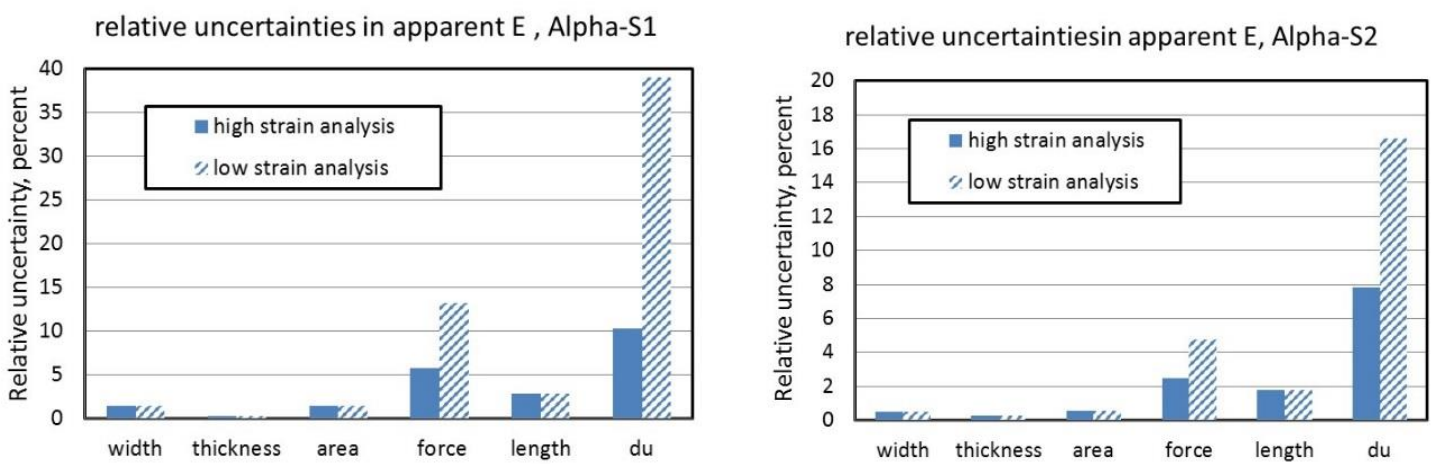

relative uncertainties in apparent $\mathrm{E}$, Alpha-S3
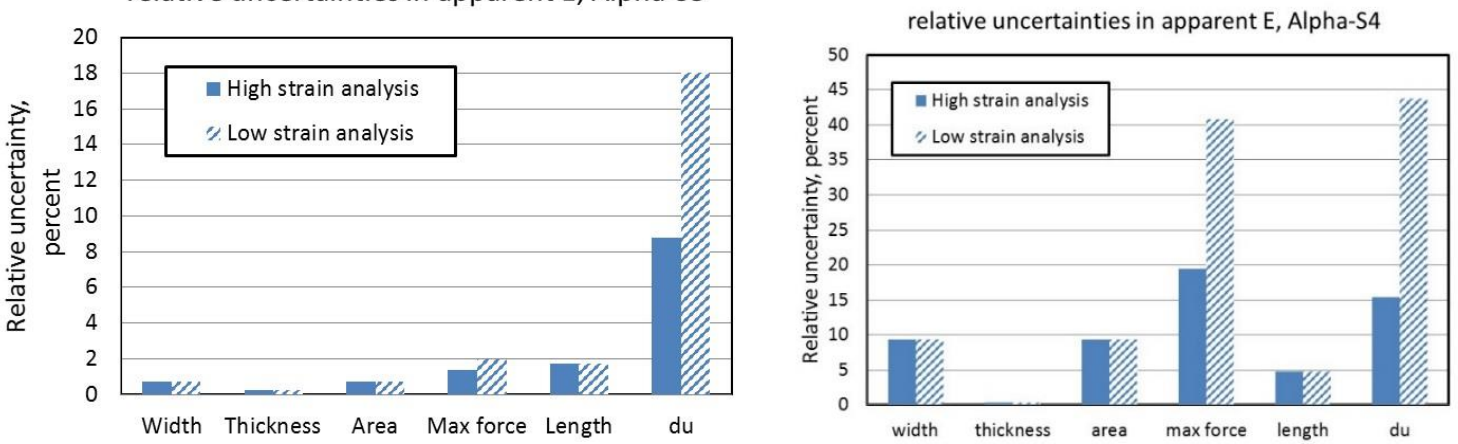

Figure H.1. Contributions to the measurement uncertainty in the apparent Young's modulus for Alpha specimens tested at rate 0.001/s. (This figure is from our August 2016 progress report to ARDEC.) 

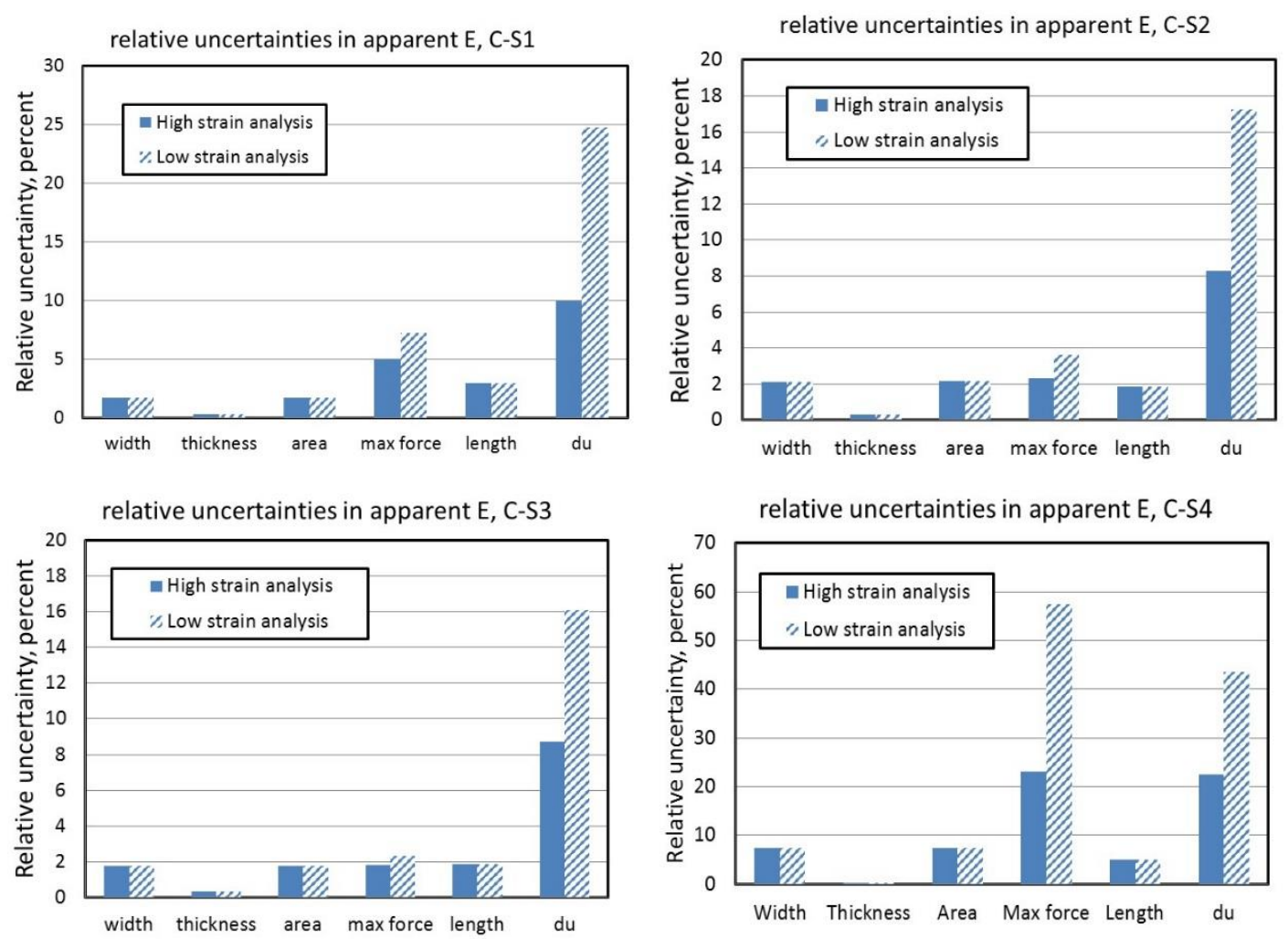

Figure H.2. Contributions to the measurement uncertainty in the apparent Young's modulus for $\mathrm{C}$ specimens tested at rate 0.001/s. (This figure is from our August 2016 progress report to ARDEC.) 

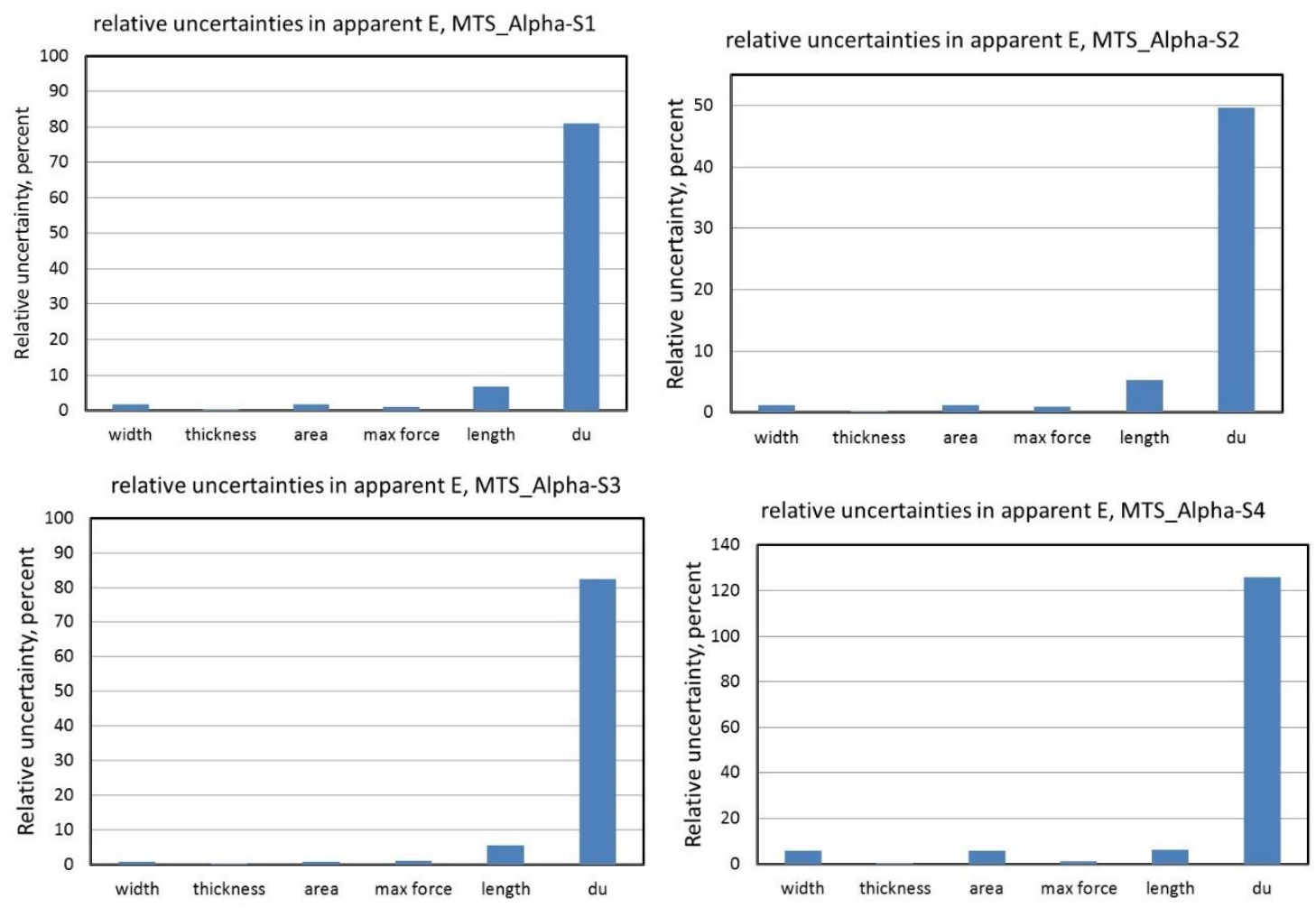

Figure H.3. Contributions to the measurement uncertainty in the apparent Young's modulus for Alpha specimens tested at rate 1/s. (This figure is from our August 2016 progress report to ARDEC.) 

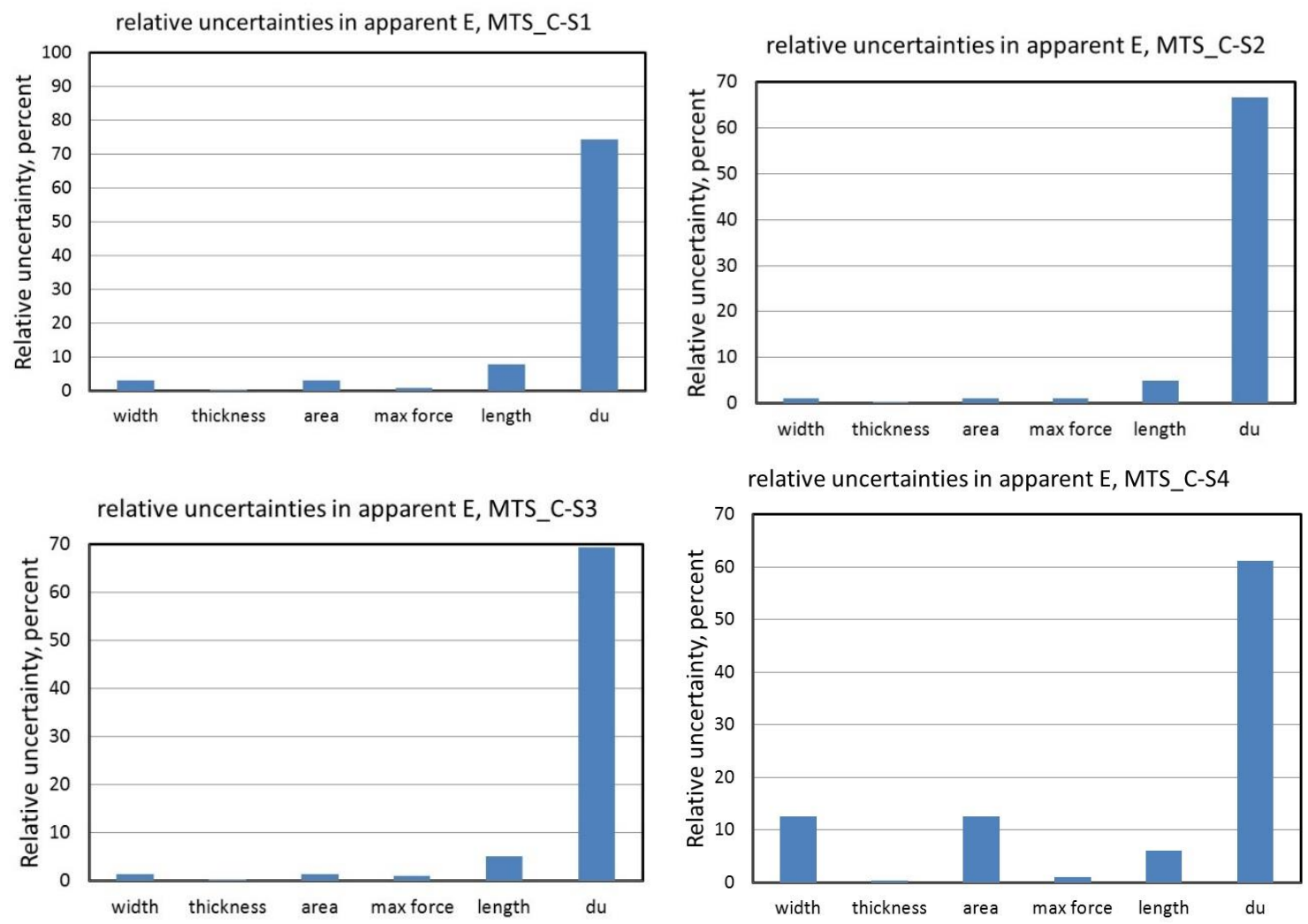

Figure H.4. Contributions to the measurement uncertainty in the apparent Young's modulus for $\mathrm{C}$ specimens tested at rate $1 / \mathrm{s}$, not including the uncertainty due to synchronization. (This figure is from our August 2016 progress report to ARDEC.) 